\title{
Source Properties of Moderate-Magnitude Earthquakes Along the Alpine Fault, New Zealand
}

\author{
By \\ Ilma del Carmen Juarez Garfias
}

A thesis submitted to Victoria University of Wellington in fulfilment of the requirements for the degree of Master of Science in Geophysics

Victoria University of Wellington 


\section{Abstract}

The Alpine Fault is a major active continental transform fault that is late in its typical cycle of large earthquakes. Extensive paleoseismic research has revealed that the central segment of the Alpine Fault ruptures in M7+ earthquakes every 291 \pm 23 years and last ruptured in $1717 \mathrm{AD}$. The paleoseismic results also reveal that some places along the fault, which coincide with pronounced along-strike changes in fault characteristics, act as conditional barriers to rupture. The geometry, seismicity rates and geology of the Alpine Fault change along three principal segments (North Westland, Central and South Westland segments) but it is unclear whether source properties (e.g. stress drop) of near-fault seismicity also vary between those fault segments, and whether these properties have some influence on conditional segmentation of the Alpine Fault during large earthquake rupture.

To examine whether source properties of earthquakes can influence or elucidate the conditional segmentation of Alpine Fault earthquakes, we have computed stress drops of moderate-magnitude earthquakes occurring on and close to the Alpine Fault. We use an empirical Green's function (EGF) approach and require each EGF earthquake to be highly correlated (cross-correlation $\geq 0.8$ ) with its respective mainshock. We use data from dense, temporary seismometer networks, including DWARFS (Dense Westland Arrays Researching Fault Segmentation), a new two-part network designed to constrain seismogenic behaviour near key transitional boundaries. Our results investigate the spatial variability of these source properties along the length of the Alpine Fault, focusing on whether earthquakes at the rupture segment boundaries behave differently to those in the middle of previously identified rupture segments.

We analyse individual P- and S-wave measurements of corner frequency and stress drop for 95 earthquakes close to (within $5 \mathrm{~km}$ ) and on the Alpine Fault. Overall, the calculated stress drops range between 1-352 MPa and show good agreement with other studies both within New Zealand and worldwide. The stress drop values obtained for the three Alpine segment are: 1-143 MPa (median values of 8 and $9 \mathrm{MPa}$ for $\mathrm{P}$ - 
and S-waves, respectively) for the South Westland/Central segment boundary zone, 2-309 $\mathrm{MPa}$ (median values of 17 and $39 \mathrm{MPa}$ for $\mathrm{P}$ - and S-waves, respectively) for the Central segment and 1-352 MPa (median values of 15 and $19 \mathrm{MPa}$ for P- and Swaves, respectively) for the North Westland/Central segment boundary zone. There are no marked differences in stress drop values along the North Westland and Central segments, but those values are slightly higher than along the South Westland segment. This may indicate a bigger difference in fault geometry, slip and seismicity rate compare with other segments, or that the South Westland segment is weaker than the other segments. We see no clear dependence of stress drop values on depth, magnitude or focal mechanism. 


\section{Acknowledgements}

First, I would like to express my entire gratitude to my supervisors Emily WarrenSmith, John Townend and Rachel Abercrombie for the incredible support given me during this amazing one-year Masters adventure. Emily, thank you for making me part of the great project you are leading and for transmitting the passion for what you do. Your helpful advice and excellent sense of humour and general all round awesomeness made this an amazing thesis. Thanks for the fantastic field trips to the Alpine Fault. John, thank you for all the opportunities you provided me over this year (field trips, the GSNZ 2020 conference, dog-house sitting and more) and for your guidance and insight to this thesis. Thank you both for making me feel very welcome in New Zealand. Rachel, thanks for your amazing advice, long Zoom calls to help me understand the EGF procedure better and for introducing me to a great group of young seismology students like me.

This project could not have happened without the financial support of the Marsden Fund of the Royal Society Te Apārangi, the Frank Evison Research Scholarship in Geophysics and the Earthquake Commission of New Zealand.

Besides my supervisors, I would like to thank Calum Chamberlain for the help to access the waveform data used in this thesis and for some fundamental Python scripts. Konstantinos Michailos, for his incredible work putting together the most complete earthquake catalogue for the central Alpine Fault. Carolyn Boulton, for her observations of the fault mechanics at the Alpine Fault that help conclude the results obtained in this thesis. I am also grateful to my thesis examiners, Finnigan Illsley-Kemp and John Ristau, for thought-provoking feedback and suggestions.

To all my office mates: Olivia, Yaasameen, Alistair, Brenton, Calvin, Emily, Josh, Sam, Theo. Thank you for the warmest welcoming to the office, you definitely make this year fun and memorable. Special thanks to my friend Oliva, who joined me from Mexico on this amazing adventure. Oli, thank you not only for our seismological night talks and your valuable comments on my work, but also for being an incredible support 
through this unreal year. You made the transition to an unknown country in a global pandemic time way easier.

I want to thank my family in my first language. Quiero agradecer a mi famila por siempre apoyar mis decisiones por mas descabelladas que sean, por estar conmigo, ser mi guia, por creer en mi y en mis capacidades. Mamá, papá, Pablo y Fatima, gracias por estar juntos y apoyarese en los momento más difíciles de este an̄o, verlos sobrepasar todas las advesidades juntos me dieron fuerza para continuar desde lejos con esta tesis. Mamá Vicky y papá Juan muchas gracias por sus consejos y por siempre ponerme los pies en la tierra. Abuelito Ruben, gracias por estar conmigo desde siempre y por sus llamadas en la madrugada con su nuevo celular. Tía Aby y Paola, gracias por poner el listón tan alto, las dos son mi principal inspiración y ejemplo. Gracias a ustedes sé que todo es posible si trabajas para lograrlo. ¡Directito a la NASA!

A todos ustedes, incluyendo a mimi, mi tía Karla y Zuleyka, gracias por el apoyo que le brindaron a mi familia durante este año. Gracias mamá Katy por insistirme en quedarme en Nueva Zelandia y terminar este trabajo que resulto ser uno de los mejores aciertos en mi carrera académica y profesional.

And lastly, special thanks to Jasper, who since the beginning was my biggest cheerleader. Thanks Jasper for your immense support, the incredible trips, the delicious food, and for making me see more than rocks. 


\section{Contents}

Abstract $\quad$ iii

Acknowledgments $\quad$ v

List of Figures $\quad$ ix

List of Tables $\quad$ xiii

1 Introduction 1

1.1 Motivation and Objectives . . . . . . . . . . . . . . 1

1.2 Thesis Structure . . . . . . . . . . . . . . . . . 3

1.3 Geological and Tectonic Setting of New Zealand . . . . . . . . . . . 5

1.4 The Alpine Fault . . . . . . . . . . . . . . . . . . . 6

1.4 .1 Geology . . . . . . . . . . . . . . . . 6

1.4.2 Structural Segments . . . . . . . . . . . . . 8

1.4 .3 Seismicity . . . . . . . . . . . . . . . 11

1.5 Earthquakes Source Properties . . . . . . . . . . . . . . . 15

2 Seismic Networks and Data $\quad 21$

2.1 Seismic Networks . . . . . . . . . . . . . . . . . . . . . . . . 21

2.1.1 DWARFS: Dense Westland Arrays Researching Fault Segmentation 25

2.2 Data and Catalogues . . . . . . . . . . . . . . . . . . 25

2.3 Selecting Earthquakes on the Alpine Fault . . . . . . . . . . . . 28

3 Empirical Green's Function Methodology 33

3.1 Empirical Green's Function (EGF) Analysis . . . . . . . . . . . . . 33

3.2 EGF Event Selection . . . . . . . . . . . . . . . . . . . . 37

3.3 Seismogram Time Window Selection and Cross-correlation . . . . . . . 38 
3.4 Spectra and Spectral Ratio Calculation . . . . . . . . . . . . . . 39

3.5 Corner Frequency Calculation . . . . . . . . . . . . . 41

3.5.1 Fitting Individual Spectral Ratios for Corner Frequency . . . . . 43

3.5.2 Fitting Stacked Spectral Ratios for Corner Frequency . . . . . . 44

3.6 Calculation of Stress Drop . . . . . . . . . . . . . . . . . . 44

4 Results $\quad 49$

4.1 EGF Analysis Results . . . . . . . . . . . . . . . . . . . 49

4.2 Seismic Moment . . . . . . . . . . . . . . . . . . 51

4.3 Corner Frequency . . . . . . . . . . . . . . . . 57

4.4 Stress Drops . . . . . . . . . . . . . . . . . . . 63

$\begin{array}{lll}5 & \text { Discussion and Conclusions } & 69\end{array}$

5.1 Key Findings . . . . . . . . . . . . . . . . . . . 69

5.1.1 Stress Drop Variability Along Strike and with Depth . . . . . . 70

5.2 Factors Affecting Stress Drop Measurements . . . . . . . . . . . . 75

5.3 Fault Mechanics Implications _. . . . . . . . . . . . . . . . . . . 78

5.4 Future Work . . . . . . . . . . . . . . . . . 80

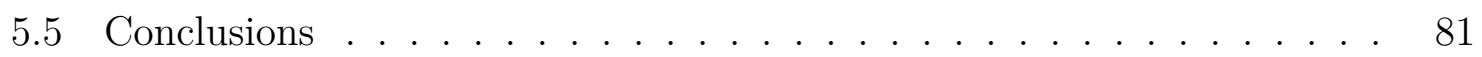

A DWARFS: Dense Westland Arrays Researching Fault Segmentation appendix

A.1 Event Detection and Phase Picking . . . . . . . . . . . . . . 99

A.2 Event Location . . . . . . . . . . . . . . . . . . 100

A.3 Magnitudes ... . . . . . . . . . . . . . . . . . 101

A.4 Focal Mechanisms . . . . . . . . . . . . . . . . . . . . . 101

B DWARFS: Ambient Noise Characteristics 103

B.1 Spectral Noise Plots . . . . . . . . . . . . . . . . . . 103

C MATLAB Scripts Workflow $\quad 123$

$\begin{array}{ll}\text { D Target Events Catalogue } & 125\end{array}$ 


\section{List of Figures}

1.1 Geologic map of New Zealand . . . . . . . . . . . . . . . . 7

1.2 Map of the South Island, New Zealand showing Alpine Fault section. 9

1.3 Theoretical source spectrum of an earthquake . . . . . . . . . . 17

1.4 Schematic figure illustrating stress drop . . . . . . . . . . . . . . 18

1.5 Global variations of stress drop. . . . . . . . . . . . . . . . . . . 19

2.1 Map of the seismic networks used in this thesis. . . . . . . . . . . . 22

2.2 Network data continuity. . . . . . . . . . . . . . . . . . 24

2.3 Dense Westland Arrays Researching Fault Segmentation (DWARFS). . 26

2.4 Site setup for DWARFS broadband stations . . . . . . . . . . . . 27

2.5 Magnitude histograms of three different Alpine Fault catalogues . . . . 27

2.6 Earthquakes from the three catalogues along the Alpine Fault. . . . . . 28

2.7 Events used for source property analysis. . . . . . . . . . . . . . . . . . 30

3.1 Schematic representation of an earthquake process. . . . . . . . . . . 34

3.2 Schematic of a Source Time Function. . . . . . . . . . . . . . . 35

3.3 Schematic of the EGF method. . . . . . . . . . . . . . 36

3.4 Schematic workflow of the EGF methodology. . . . . . . . . . . 37

3.5 Target-EGF waveform pairs . . . . . . . . . . . . . . . 40

3.6 Signal and noise spectra for four well-recorded Target events. . . . . . . 41

3.7 Source Time Functions of four Target events of different magnitudes. . 42

3.8 Stacked spectral ratios and Source Time Functions for four earthquakes 45

4.1 Magnitude histograms of final Target events from Northern and Southern DWARFS. . . . . . . . . . . . . . . . . . 51

4.2 Magnitude histograms of final Target events from the Central segment. $\quad 52$ 
4.3 Histogram of number of ratios per cross-correlation value. . . . . . . . . 53

4.4 Best $M_{L}-M_{w}$ regression fit for North Westland and South Westland segments. . . . . . . . . . . . . . . . . . 54

4.5 Box plots of stress drop values for different local magnitudes . . . . . . 56

4.6 Comparison of corner frequency measurements made on individual ratios and stacked by station ratios. . . . . . . . . . . . . . 57

4.7 Stacked spectral ratios and fits obtained with the Brune (1970) and Boatwright (1980) source models for six well-recorded Target events. . .

4.8 Comparison of corner frequency and the variance estimated with both the Brune and Boatwright source models. . . . . . . . . . . . . . . . 59

4.9 Corner frequency vs seismic moment . . . . . . . . . . . . . . . . . 61

4.10 Comparison of $\mathrm{P}$ - and S- wave corner frequencies . . . . . . . . . 62

4.11 Stress drop vs Seismic moment . . . . . . . . . . . . . . . . . . 64

4.12 Source radius plotted vs seismic moment . . . . . . . . . . . 65

4.13 Stress drop measurements from different studies. . . . . . . . . . . . 65

4.14 Box plots of final stress drop measurements. . . . . . . . . . . . . 67

5.1 Map of stress drop variations along strike. . . . . . . . . . . . . 71

5.2 Ternary diagram of focal mechanisms. . . . . . . . . . . . . . . . . 72

5.3 Cross-sections along strike of the Alpine Fault. . . . . . . . . . . . . . . 74

5.4 Schematic figure showing the stress drop variations along the three Alpine fault segments. . . . . . . . . . . . . . . . . . . 79

5.5 Complex STFs for cluster from the North Westland segment . . . . . . 82

A.1 DWARFS data continuity . . . . . . . . . . . . 100

B.1 Spectral energy plots for station BARN. . . . . . . . . . . . 105

B.2 Spectral energy plots for station CASC . . . . . . . . . . . 106

B.3 Spectral energy plots for station DATA. . . . . . . . . . . . . 107

B.4 Spectral energy plots for station DELT. . . . . . . . . . . . . . 108

B.5 Spectral energy plots for station GORG. . . . . . . . . . . . . . . 109

B.6 Spectral energy plots for station MONK. . . . . . . . . . . . . . 110

B.7 Spectral energy plots for station OLIV. . . . . . . . . . . . . . . 111

B.8 Spectral energy plots for station POMM. . . . . . . . . . . . . . . . 112

B.9 Spectral energy plots for station RICH. . . . . . . . . . . . . . 113 
B.10 Spectral energy plots for station THOM. . . . . . . . . . . . . . . . . 114

B.11 Spectral energy plots for station BELL. . . . . . . . . . . . . 115

B.12 Spectral energy plots for station GLOR. . . . . . . . . . . . . . 116

B.13 Spectral energy plots for station HURA. . . . . . . . . . . . . . . 117

B.14 Spectral energy plots for station JACK. . . . . . . . . . . . . . . . . 118

B.15 Spectral energy plots for station MORG. . . . . . . . . . . . . . . 119

B.16 Spectral energy plots for station MOSQ . . . . . . . . . . . . . 120

B.17 Spectral energy plots for station SHOT. . . . . . . . . . . . . . . 121

B.18 Spectral energy plots for station TURI. . . . . . . . . . . . . . . . 122

C.1 Extended workflow of the EGF methodology . . . . . . . . . . . . . . 124 


\section{List of Tables}

1.1 Summary of the principal tectonic characteristics of the three main segments of the Alpine Fault. . . . . . . . . . . . . . . . 10

2.1 DWARFS station locations and equipment details . . . . . . . . . . 32

$3.1 \beta$ values for the Alpine Fault segments. . . . . . . . . . . . . . . 46

4.1 Number of Target events for Alpine Fault segments . . . . . . . . . . 50

4.2 Alpine Fault segment stress drops . . . . . . . . . . . . . . . . 66

D.1 Table of Target events . . . . . . . . . . . . . . . 126 


\section{Chapter 1}

\section{Introduction}

\subsection{Motivation and Objectives}

The Institute of Geological and Nuclear Sciences (GNS Science) locates more than than 15,000 earthquakes in New Zealand and the adjacent offshore region each year and $\sim 150$ of these earthquakes are big enough to be felt by members of the public. For that reason is important to understand the physical processes that drive earthquake rupture nucleation and propagation to better prepare for the hazards they pose. New Zealand is tectonically complicated; the interaction between the Australian and Pacific plates changes markedly along the length of the country. In the North Island, the Pacific plate subducts beneath the Australian plate at the Hikurangi subduction zone. In the South Island there is a transform plate boundary (the Alpine Fault and Marlborough Fault System) and south of New Zealand there is a reversed polarity subduction zone (Puysegur subduction zone), where the Australian plate subducts beneath the Pacific plate. In this thesis we will investigate seismicity occurring along the Alpine Fault, New Zealand's largest onshore fault.

The Alpine Fault is a major active continental transform fault that accommodates up to $80 \%$ of the relative motion between the Pacific and Australian plates; however, there have been no large earthquakes along the fault since seismic records started in New Zealand (Norris and Cooper, 2001; Wallace et al., 2007; Howarth et al., 2018). According to paleoseismic research, the Central segment of the Alpine Fault ruptures in M7+ earthquakes every $291 \pm 23$ years and last ruptured in 1717 AD (Wells et al., 1999; Cochran et al., 2017; Howarth et al., 2018). These results suggest that the Alpine Fault is late in its typical seismic cycle. Large earthquakes on New Zealand's Alpine Fault have been identified as the primary seismic hazard faced in southern New Zealand 
(Stirling et al., 2012), despite the current low rate of seismicity on the Central Alpine Fault. Therefore, it is an opportune time to investigate what a future Alpine Fault earthquake might look like.

Paleoseismic results also reveal that some segments of the fault, which coincide with pronounced along-strike changes in fault characteristics, act as conditional barriers to rupture (Howarth et al., 2018). Sometimes the ruptures propagate through those barriers, increasing the overall magnitude, whereas sometimes the rupture stops at the barriers. According to paleoseismic studies there is 50:50 split between multi- and single-segment ruptures through the paleoseismic record (Howarth et al., 2018).

The geometry, seismicity rates and geology of the Alpine Fault change along three principal segments (North Westland, Central and South Westland segments) but it is unclear whether source properties (e.g. stress drop, directivity) of near-fault seismicity also vary between those fault segments, and whether these properties have some influence on, or can help us understand the controls on conditional segmentation of the Alpine Fault during large earthquake rupture. Determining what controls segmentation of plate-boundary faults remains a challenge and is crucial for our understanding of seismic hazard. Previous earthquake magnitudes, variations in stress levels along a rupture and geometric complexities are thought to be primary controls of the final rupture length (Kame et al., 2003; Lozos et al., 2012).

The main objective of this thesis is to investigate whether source properties of earthquakes can influence or elucidate the conditional segmentation of Alpine Fault earthquakes. This will be done through calculation of stress drops for Alpine Fault earthquakes along its three principal segments. To date, no substantive estimates of earthquake stress drops, or corner frequencies exist along the Alpine Fault (Abercrombie et al. (2001) estimated a very limited subset of stress drops for the 1994 Arthur's Pass earthquake).

This thesis will contribute towards a wider research project (Semi-conducting fault zones: High resolution analysis of fault segmentation and rupture) funded through a Royal Society Marsden Fast Start award, led by Dr Emily Warren-Smith (GNS Science) together with Professor John Townend (VUW), Dr Rachel Abercrombie (Boston University) and Dr Yoshihiro Kaneko (Kyoto University). The broader Marsden project seeks to identify and quantify the physical factors controlling the conditional rupture segmentation along the Alpine Fault. To do this, they deployed DWARFS (Dense Westland Arrays Researching Fault Segmentation) a two-part temporary network of 19 broadband stations at segment boundaries to record seismicity and characterise the 
seismogenic nature of these regions.

The objective of $\mathrm{my}^{1}$ work within the broader Marsden project is to quantify spatial heterogeneity in earthquake source properties along the Alpine Fault, including those recorded by the DWARFS networks. The estimation of directivity will help us to infer the orientation of the fault plane, the rupture velocity and azimuths of peak ground shaking. In addition, the calculation of stress drop is fundamental to understanding the strength of the fault in each segment. Directivity and stress drop calculations will together help to understand the rupture process and conditional segmentation of earthquakes and thereby improve seismic hazard models for the South Island of New Zealand. In addition, these parameters will be incorporated by other members of the Marsden research team in computational models of earthquake rupture scenarios in order to determine which physical parameters are most influential in con-trolling the conditional segmentation of the Alpine Fault.

This thesis's primary objectives can be summarised as below:

1. Identify moderate-magnitude earthquakes occurring on and close to the Alpine Fault.

2. Calculate source properties for identified earthquakes on and close to the Alpine Fault.

3. Identify possible spatial variability in source properties along the Alpine Fault.

\subsection{Thesis Structure}

This thesis consists of five chapters and four appendices. Its contents are summarised below:

\section{- Chapter 1: Introduction}

This chapter is divided into three parts. The first section (Section 1.1) outlined the motivation and objectives that led us to carry out this thesis. The second part (Sections 1.3 and 1.4) describes the broader scale tectonic setting of New

\footnotetext{
${ }^{1}$ This thesis documents original research conducted by me, Ilma del Carmen Juarez Garfias, under the supervision of Dr Emily Warren-Smith, Prof. John Townend and Dr Rachel Abercrombie. To reflect standard scientific practice and my supervisor's input throughout the project, and in anticipation of publishing these findings as a peer-reviewed manuscript, for now on this thesis is written in the first person plural ("we").
} 
Zealand and then focuses on the regional context of the study area by outlining the regional geological, structural and seismological characteristics. The last part (Section 1.5) presents background on earthquake source properties to introduce stress drop and observations of it from different studies.

\section{- Chapter 2: Seismic Networks and Data}

This chapter provides a summary of the seismic networks used in this study (Section 2.1) along with a detailed description of DWARFS (Section 2.1.1) and then addresses the data and catalogues used in this thesis. At the end of this chapter (section 2.3), we present the procedure followed to select earthquakes occurring on and close to the fault plane.

\section{- Chapter 3: Empirical Green's Function Methodology}

Chapter 3 describes the Empirical Green's Function (EGF) methodology used to calculate corner frequency (Sections 3.2 to 3.5) and the last part explains how to estimate stress drop (Section 3.6).

\section{- Chapter 4: Results}

The results chapter is divided into three key sections. The first (Section 4.2) explains how we calculate seismic moment from the available magnitudes. The second (Section 4.3), presents the preferred corner frequency results. Last section (Section 4.4) shows the preferred stress drop estimation for the three principal Alpine Fault segments and comparison of our result with stress drop estimates in other tectonic settings.

\section{- Chapter 5: Discussion and Conclusions}

This chapter presents five sections. A key findings section (Section 5.1) where we analyse the stress drop values obtained with along strike changes and depth. The second (Section 5.2) addresses the uncertainties resulting from the stress drop calculation. The third section (Section 5.3) presents an interpretation of fault mechanics based on the stress drop results. The fourth (Section 5.4) addresses future research with the corner frequency and stress drop estimations for the Alpine Fault earthquakes. The final section (Section 5.5) contains the key conclusions of this thesis.

- Appendix A

A detailed description of event detection, picking, location, magnitude and focal mechanism calculations using DWARFS.

- Appendix B

Presents the spectral energy figures for DWARFS. 
- Appendix C

A summary of the codes used for each part of the EGF methodology to calculate corner frequency and stress drop.

- Appendix D

A table presenting summarised information on the 245 earthquakes for which source properties are calculated.

\subsection{Geological and Tectonic Setting of New Zealand}

New Zealand's basement geology consists of a series of volcano-sedimentary terranes, intruded by batholiths and overprinted by metamorphism, that were accreted onto the Pacific margin of Gondwana during the Paleozoic and Mesozoic (Cox and Sutherland (2007); Figure 1.1). The continental landmass, referred to as Zealandia (Mortimer and Campbell, 2014), underwent multiple phases of tectonic deformation as part of the Gondwana supercontinent (Landis and Coombs, 1967; Carter and Norris, 1976; Mortimer, 2004; Cox and Sutherland, 2007). Zealandia rifted away from the AustraliaAntarctica landmass between 80 and $60 \mathrm{Ma}$ (late Cretaceous to Paleocene), forming the north Tasman Sea. Prior to $45 \mathrm{Ma}$ (Eocene), no active plate boundary existed in Zealandia (Sutherland et al., 2000).

Present day New Zealand is situated on the boundary between the Pacific and Australian plates (Figure 1.1). South of New Zealand, the Australian plate subducts eastwards beneath the Pacific plate along the Puysegur subduction zone (Berryman et al., 1992). On land, the plate boundary takes the form of the Alpine Fault, an oblique dextral reverse fault that splits northwards by slip-partitioning into the Marlborough Fault Zone (Sutherland et al., 2000). The Marlborough Fault Zone includes four major faults (Wairau, Awatere, Clarence and Hope Faults; Little and Jones (1998)). On the east coast of New Zealand's North Island, the subduction polarity reverses and is characterised by westwards subduction of the Pacific plate underneath the Australian plate. Together, the Alpine Fault and the Marlborough Fault zone link these subduction zones of opposite polarity (Berryman et al., 2012).

The New Zealand land mass encompasses different geological terranes of varying age (Mortimer (2004); Figure 1.1). The Eastern Province, known as the Torlesse province, can be found from Otago to East Cape and was formed by the deposition of sediments (sandstone, mudstone and volcanic rocks) in turbidity currents along the eastern coastline of Godwana. The Western Province basement rocks extends from Fiordland along 
the West Coast to Nelson, formed from sediments deposited along the margin of Gondwana (Figure 1.1). In the South Island, Eastern Province rocks are now being rapidly uplifted by the Alpine Fault, their metamorphic grade increase from east to west (Norris and Toy, 2014).

\subsection{The Alpine Fault}

\subsubsection{Geology}

The Alpine Fault is a major dextral, transpressional fault that represents the principal tectonic structure of the Australian-Pacific plate boundary in the South Island (Norris and Toy, 2014) and poses the greatest seismic hazard in southern New Zealand (Stirling et al., 2012). Geologist Harold Wellman first identified the Alpine Fault in 1941 (Wellman and Willet, 1942); he described a major fault that extends along the west of the Southern Alps and extended to the Marlborough Fault Zone. The Southern Alps are the result of oblique continental collision between two largely submerged continental fragments (Cox and Sutherland, 2007) and are a young transpressive orogen that exhibits high exhumation rates, high erosion rates and high heat flow (Cox and Sutherland, 2007; Norris and Toy, 2014; Sutherland et al., 2013, 2017). The central Southern Alps present exhumation at rates of up to $8 \mathrm{~mm} / \mathrm{yr}$, that are associated with extreme climatic conditions, such as high precipitation and erosion rates (Herman et al., 2007; Koons, 1990; Cox et al., 2012; Beavan et al., 2010). The extreme erosional conditions erode the upper part of the crust, making it weaker, steepening the isotherms and facilitating the flow of hotter material from the bottom of the crust (Koons et al., 2003). The interaction between high exhumation and erosion rates increases the heat flow and makes the crust weaker (Zeitler et al., 2001; Koons et al., 2003).

The Alpine Fault separates the Western and Eastern Provinces (Figure 1.1). The Western Province includes the Buller Terrane, which is dominated by late Cambrian to late Ordovician quartzose sediments that have been regionally metamorphosed (Nathan (1976); Figure 1.1), and the Takaka Terrane, that is volumetrically smaller and contains a diverse assemblage of deformed and metamorphosed Paleozoic sedimentary and volcanic rocks (Cooper, 1989). During the earliest Devonian, the two terranes were amalgamated (Cox and Sutherland, 2007). The Eastern Province on the South Island encompasses the Torlesse Composite Terrane, which includes the Pahau and Rakaia terranes. This composite Terrane is dominated by lithic and feldspathic metagreywackes, but includes volcanic and intrusive assemblages that were accreted during Gondwana 


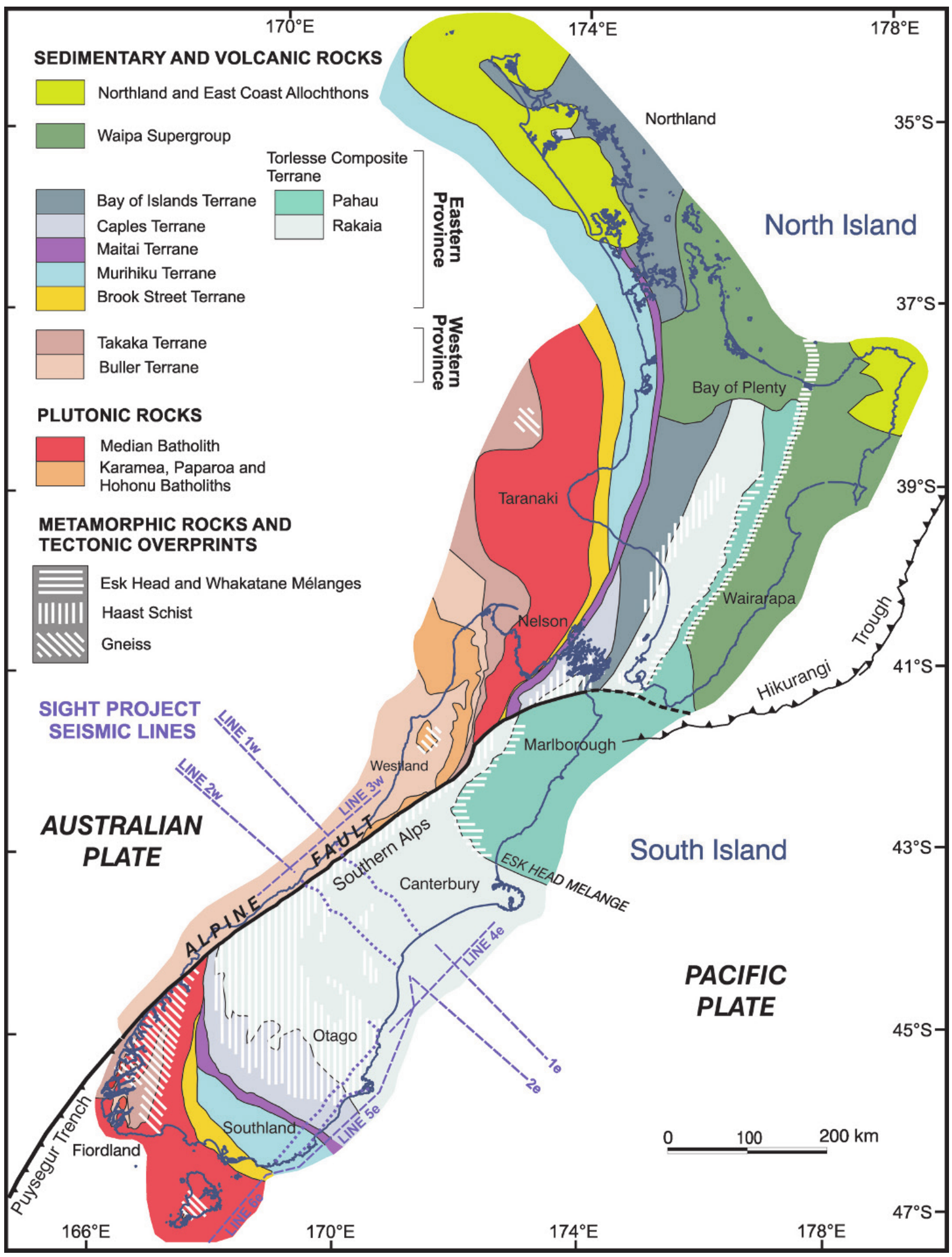

Figure 1.1: Basements terranes of New Zealand. The Alpine Fault (black line) is a significant tectonic feature in the South Island and separates the Buller Terrane (Western Province) from the Rakaia Terrane (Eastern Province). From Cox and Sutherland (2007). 
(Mortimer, 1994; Cox and Sutherland, 2007). The Rakaia terrane depositional ages mostly range from the Permian to the Jurasic and the Pahau Terrane is formed by late Jurassic to early Cretaceous sedimentary rocks that are partly recycled from the Rakaia Terrane (Mortimer, 2004; Mackinnon, 1983). The closest section of the Rakaia terrain to the Alpine Fault is formed by semischist and mylonite (Cox and Sutherland, 2007).

Bell and Fraser (1906) first recognized fault rocks associated with the Alpine Fault between Ross and Hokitika. Reed (1964) recognized three groups of fault rocks occurring in the Fraser Complex immediately west of the Alpine Fault trace. The gouge and breccia which he inferred were related to Quaternary movements, the cataclasite series and mylonite series, both prominent in granite, related to late Tertiary movement and the Jurassic and Cretaceous metamorphism, respectively.

\subsubsection{Structural Segments}

Berryman et al. (1992) recognized and named five different structural segments on the Alpine Fault: From northeast to southwest, Wairau, North Westland, Central, South Westland and Fiordland segments (Figure 1.2). At the north and south ends of the Alpine Fault are the Wairau and Fiordland segments. The Wairau segment (Figure 1.2) consists of the Wairau Fault that has a length of $200 \mathrm{~km}$, an average strike of $067^{\circ}$, a strike-slip rate of 3-5 mm/yr, an almost vertical dip and close to zero dip-slip rates (Zachariasen et al., 2006). The Fiordland segment consists of two right-stepping fault sections named the Nancy and Resolution sections (Figure 1.2). Overall, the Fiordland segment has a length of $130 \mathrm{~km}$, an average strike of $040^{\circ}$, a strike-slip rate of 27.2 $\mathrm{mm} / \mathrm{yr}$ which increases to $31.4 \mathrm{~mm} / \mathrm{yr}$ towards the southern extent of this segment (Barnes et al., 2005; Barnes, 2009). The dip and dip-slip rate are largely unknown for this segment (Barth et al., 2013). The percentage of plate boundary motion in this segment is the highest (87\%) along the Alpine Fault (Barth et al., 2013).

In this study we focus on the North Westland, Central and South Westland segments. The North Westland segment from Matakitaki River to Toaroha River (Figure 1.2), accommodates oblique dextral-reverse slip with northward decreasing strike-slip rates of $14 \mathrm{~mm} / \mathrm{yr}$ at Inchbonnie to $10 \mathrm{~mm} / \mathrm{yr}$ at Maruia river (Langridge et al., 2010, 2017). The dip-slip rate along this segment has values from $1.3 \mathrm{~mm} / \mathrm{yr}$ at Maruia River to 6 $\mathrm{mm} / \mathrm{yr}$ at Inchbonnie (Norris and Cooper, 2001). The average strike and dip are $055^{\circ}$ and $55^{\circ} \mathrm{SE}$, respectively. 


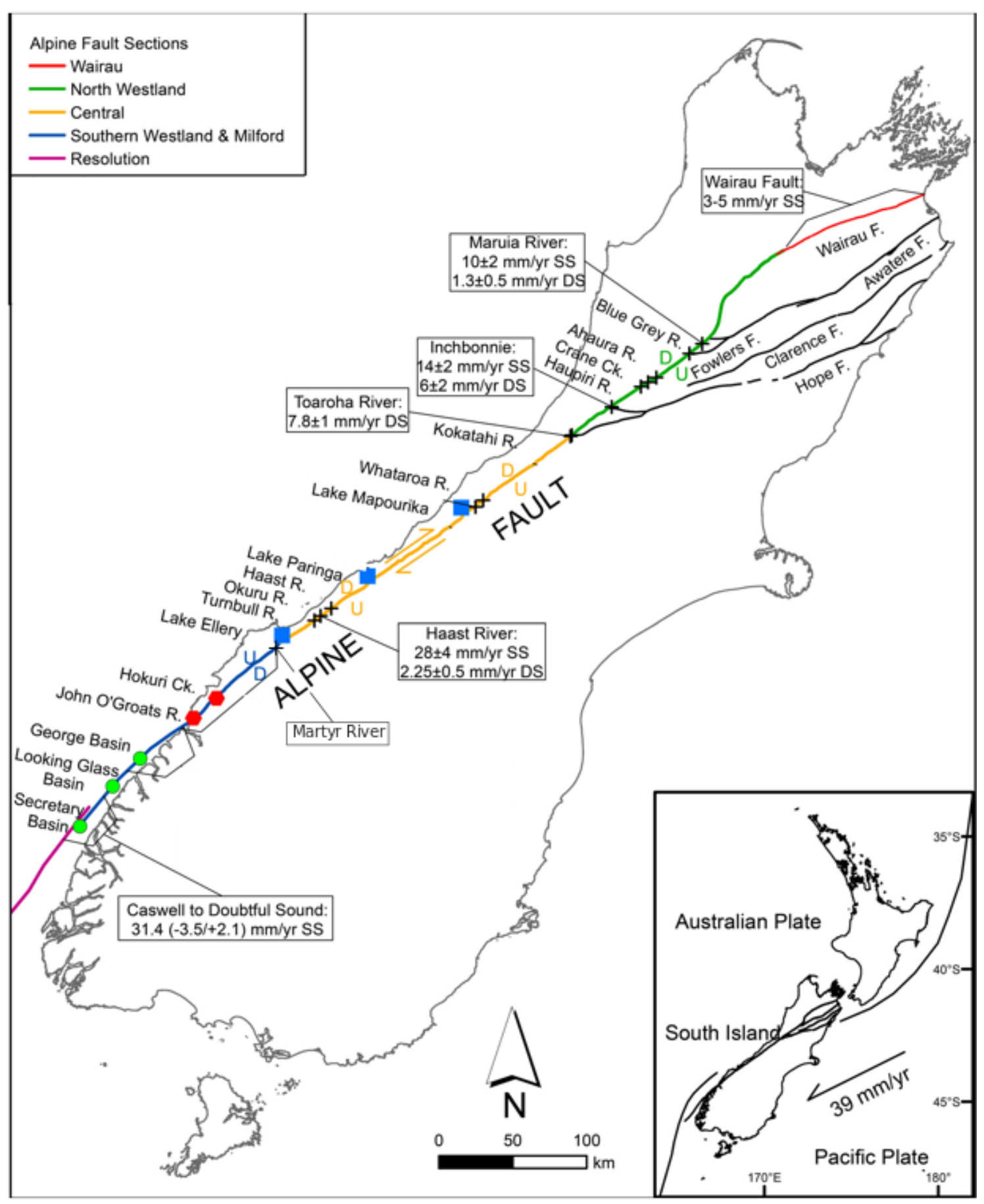

Figure 1.2: Map of the South Island, New Zealand showing the sectioning of the Alpine Fault. Subdivision of the Alpine Fault according to Barth et al. (2013). The Wairau fault in red, the North Westland segment of the Alpine Fault in green, the Central segment in yellow, the South Westland segment in blue and the Fiordland segment in dark pink. Figure from Howarth et al. (2018). 
Table 1.1: Summary of the principal tectonic characteristics of the three main segments of the Alpine Fault. Table adapted from Barth et al. (2013).

\begin{tabular}{||l||l|l|l||}
\hline \hline Information & $\begin{array}{l}\text { North Westland } \\
\text { segment }\end{array}$ & Central segment & $\begin{array}{l}\text { South Westland } \\
\text { segment }\end{array}$ \\
\hline \hline Length $[\mathrm{km}]$ & 150 & 250 & 160 \\
\hline Northeastern extent & Matakitaki River & Toaroha River & Martyr River \\
\hline $\begin{array}{l}\text { Southeastern extent } \\
\text { Strike-slip rate }[\mathrm{mm} / \mathrm{yr}]\end{array}$ & Toaroha River & Martyr River & Caswell Sound \\
\hline Dip-slip rate $[\mathrm{mm} / \mathrm{yr}]$ & $3.4-6(-6 /+2)$ & $2.25-8(-0.5 /+1)$ & $0.6(-0.2 /+0.3)$ \\
\hline $\begin{array}{l}\text { Current \% of plate boundary } \\
\text { motion }\end{array}$ & $26-35 \%$ & $72-77 \%$ & $63-74 \%$ \\
\hline $\begin{array}{l}\text { Regional fault strike }(>10 \mathrm{~km} \\
\text { lengths })\end{array}$ & $006^{\circ}-055^{\circ}$ & $052^{\circ}-060^{\circ}$ & $040^{\circ}-059^{\circ}$ \\
\hline Section average fault strike & $055^{\circ}$ & $055^{\circ}$ & $052^{\circ}$ \\
\hline Section average fault dip & $55^{\circ} \mathrm{SE}$ & $045^{\circ} \mathrm{SE}$ & $082^{\circ} \mathrm{SE}$ \\
\hline \hline
\end{tabular}

The Central segment extends from Toaroha river to Martyr River (Figure 1.2) and has a dextral strike-slip rate of $27-29 \mathrm{~mm} / \mathrm{yr}$, which is considerably higher than the two northern segments (Norris and Cooper, 2001; Sutherland et al., 2007). Rates of dip-slip vary along strike and are the highest along the Alpine Fault, ranging from 7.8 $\mathrm{mm} / \mathrm{yr}$ in Toaroha River to $2.25 \mathrm{~mm} / \mathrm{yr}$ at Haast River, near the boundary with the South Westland segment. The average strike of the fault is $055^{\circ}$, but the dip angles in this segment range from $40^{\circ}$ to $60^{\circ}$ according to surface structural (Norris and Cooper, 1997), seismicity (Guo et al., 2017) and geodetic data (Beavan et al., 1999).

The South Westland segment, from Martyr River to Caswell sound (Figure 1.2), also accommodates oblique dextral motion, but unlike the North Westland and Central segments, the net uplifted side is the Australian plate to the northwest (Howarth et al., 2018). The strike-slip rates vary from 23-29.6 mm/yr (Barth et al., 2014), while the dip-slip rate decreases to $0.6 \mathrm{~mm} / \mathrm{yr}$ (Barnes et al., 2005). The average strike here is $052^{\circ}$, a small anti-clockwise rotation from the Central segment, and the dip angle changes abruptly to become $82^{\circ} \mathrm{SE}$ in surface exposures at Martyr River, although the deeper dip angle is largely unknown (Barth et al., 2013).

Table 1.1 outlines summarised information of the three main segments of the Alpine Fault considered in this study: the North Westland, Central and South Westland segments. 


\subsubsection{Seismicity}

The Alpine Fault accommodates up to $80 \%$ of the relative motion between the Pacific and Australian plates, but there have been no large earthquakes along the fault since seismic records started in New Zealand (Norris and Cooper, 2001; Wallace et al., 2007; Howarth et al., 2018). Evison (1971) was the first to provide an overview of the Alpine Fault seismicity. He noted low levels of seismic activity on the Central Alpine Fault and suggest a seismic gap along this section. He linked that observation with the idea that seismic gaps observed on the San Andreas Fault in California can produce larger earthquakes and suggested that the Alpine Fault was capable of producing large earthquakes as well.

In order to better understand the seismic cycle characteristics over millenial time-scales, a wide range of paleoseismic studies have been conducted along the Alpine Fault since 1980, including studies of regional forest disturbance, landscape features and trenches across the fault (Wells et al., 1998, 1999, 2001; Cullen et al., 2003; Langridge et al., 2012; Hull and Berryman, 1986; Yetton and Wells, 2010; Berryman et al., 2012), supplemented with sedimentary evidence from fault-proximal lakes and wetlands (Cooper and Norris, 1990; Howarth et al., 2016).

Howarth et al. (2018) reviewed existing paleoseismic data and created a continuous record of past Alpine Fault earthquakes. The records indicates that large earthquakes have occurred every $291 \pm 23$ for at least the past $8000 \mathrm{yr}$ and the fault last ruptured in $1717 \mathrm{AD}$ (Howarth et al., 2018). At the time of writing, more than 300 years have elapsed since the 1717 AD earthquake, meaning that the Alpine Fault is late in its seismic cycle.

The paleoseismic results also reveal that past ruptures have exhibited both multi- and single-segment ruptures, the terminations of which coincide with the major pronounced along-strike Alpine Fault segments outlined in Figure 1.2. Howarth et al. (2021) tested the hypothesis that minor geometric complexities act as conditional barriers to rupture at the intersection between the Central and South Westland segments. They also estimated that there is a $75 \%$ probability of a single-segment or multi-segment rupture of the Alpine, and a $82 \%$ probability that the next event will be a multi-segment rupture of $M_{W} \geq 8$.

At the time of writing, more than 300 years have elapsed since the 1717 AD earthquake, meaning that the Alpine Fault is late in its seismic cycle.

Despite no large earthquakes occurring on the Alpine Fault during the last 300 years, 
microseismicity (Scholz et al., 1973; Caldwell and Frohlich, 1975; O'Keefe, 2008; Boese et al., 2012; Warren-Smith et al., 2017b; Michailos et al., 2019), swarms (Boese et al., 2014), seismic tremors (Wech et al., 2012, 2013) and low-frequency earthquakes (Baratin et al., 2018; Chamberlain et al., 2014) have been observed occurring on and near the Alpine Fault.

Since seismicity studies began along the Alpine Fault, localised networks have typically been used to detect and locate seismicity. Evison (1971) and Scholz et al. (1973) were the first to perform microearthquake studies across the central and southern South Island. Scholz et al. (1973) observed that the microseismicity along the Central Alpine Fault segment occurred between depths of 2-20 km. Caldwell and Frohlich (1975) observed that on the South Westland segment, south of Haast, the depth distribution of the microearthquakes were $4-14 \mathrm{~km}$ and the seismicity rates were higher than along the Central segment. The seismicity they documented was not clearly associated with major faults. Rynn and Scholz (1978) investigated the spatial distribution of the seismicity of the Arthur's Pass region in South Island (near the North Westland segment). They found that earthquakes occur within the crust in definite subparallel zones and composite focal mechanism solutions indicated a west-northwest compressive axis orientation with an average slip direction of $\mathrm{N} 72^{\circ} \mathrm{E}$.

Between 1975 and 1983, a nine-seismometer network recording seismicity near Lake Pukaki (Reyners, 1988) recorded 2825 earthquakes of magnitude $M_{L} \geq 0.8,98 \%$ of which were shallower than $15 \mathrm{~km}$.

In 1990, the New Zealand National Seismic Network was deployed in the South Island with approximately $100 \mathrm{~km}$ spacing. Eberhart-Phillips (1995) located 122 events using the new national seismic network for the Central Alpine Fault, she found the seismicity cut-off depth varied between 10-20 km.

The Southern Alps Passive Seismic Experiment (SAPSE) was deployed for six months in 1995-1996 to monitor seismicity across the Southern Alps. Leitner et al. (2001) located 5491 earthquakes of $M_{L} 2.0-4.2$ using the SAPSE network and 15 permanent national seismic stations: 195 of those events were located close to the Alpine Fault. The seismogenic zone adjacent to the Central Alpine Fault extended down to $12 \mathrm{~km}$. Leitner et al. (2001) also found that the focal mechanisms of earthquakes were dominated by oblique strike-slip and thrust mechanisms. Leitner et al. (2001) further observed a low-seismicity zone near the Alpine Fault between Franz Josef and the Wanganui River. They attributed this apparent seismicity gap to the transition between deformation on the Alpine Fault and deformation across multiple fault structures in 
the Marlborough Fault Zone.

Recent microseismic studies using dense networks have further improved depth constraints on the Central Alpine Fault. O'Keefe (2008) deployed a temporary network of eight seismometers between Harihari and Fox Glacier during September 2006 and March 2007. This study recorded 411 events with a magnitude of completeness of 1.6 and maximum depth of $15 \mathrm{~km}$. O'Keefe (2008) also reported the low-seismicity zone between Franz Josef and the Wanganui River.

Boese (2012) deployed the Southern Alps Microearthquake Borehole Array (SAMBA), a now semi-permanent network of ten short-period seismometers in November 2008 to June 2009 between the Copland Valley and Whataroa Valley. This network continues operating and is described in more detail in Chapter 2.1. Using SAMBA and GeoNet stations, Boese et al. (2012) constructed a detailed earthquake catalogue of 1791 earthquakes of $M_{L} 0.3-4.2$ and found a seismogenic thickness of $10 \pm 2 \mathrm{~km}$ beneath the surface trace of the Alpine Fault, shallowing to $8 \pm 2 \mathrm{~km}$ within $20 \mathrm{~km}$ of the fault trace, before deepening to $15 \pm 2 \mathrm{~km}$ farther afield. Boese et al. (2012) also observed a seismicity gap between the Whataroa and Wanganui river valleys, and attributed that feature to a strong unfractured block surrounded by more highly attenuating fractures zones. Boese et al. (2012) computed 211 focal mechanisms for the Central Alpine Fault and found a maximum horizontal compressive stress azimuth, $S_{H \max }$, of $115 \pm 10^{\circ}$.

Bourguignon et al. (2015) relocated more than 1300 earthquakes with a magnitude of completeness of 1.5 to the north of the Wanganui River and south of Ross (i.e. north of Boese et al. (2012)'s study). Bourguignon et al. (2015) observed high seismicity rates $10 \mathrm{~km}$ southeast of the Central Alpine Fault with depths up to $7 \mathrm{~km}$ and low seismicity rates within $9 \mathrm{~km}$ with seismicity depths between $4-11 \mathrm{~km}$.

Warren-Smith et al. (2017b) presented a microseismicity catalogue for the Southern Lakes region and northern Fiordland regions southeast of the Alpine Fault from July 2012 to October 2013, using the Central Otago Seismic Array (COSA). This array continues operating and is described in more detail in Chapter 2.1. The microseismicity observed by Warren-Smith et al. (2017b) in the continental lithosphere is predominantly shallower than $\sim 20 \mathrm{~km}$. Warren-Smith et al. (2017a) calculate 155 focal mechanisms to examine the local stress field and they obtained an average $S_{H \max }$ azimuth of $114 \pm 10^{\circ}$.

Michailos et al. (2019) determined 9111 high-precision locations from continuous data recorded by five temporary seismic networks and five GeoNet sites, deployed for various lengths of time between late 2008 and early 2017 along the Central Alpine Fault. This is the most complete, continual catalogue generated to date for the Central Alpine 
Fault and enables the distribution and characteristics of the seismicity to be analysed in unprecedented detail. Michailos et al. (2019) derived a new local magnitude scale calibrated against GeoNet $M_{w}$ values; their magnitudes range between $M_{L} 1.2-4.6$. Michailos et al. (2019) observed that seismicity mainly occurs southeast of the Alpine Fault and exhibits low magnitudes. They also observed a seismic gap in Whataroa, consistent with Boese et al. (2012), O'Keefe (2008) and Leitner et al. (2001). The seismogenic depth varies along strike of the Alpine Fault from $8 \mathrm{~km}$, beneath the highest topography, to $20 \mathrm{~km}$ in the adjacent areas. Michailos et al. (2020) constructed a new data set of 845 focal mechanisms to investigate the stress on the Central Alpine Fault segment, they obtained an average maximum horizontal compressive stress azimuth, $S_{H \max }$, of $121 \pm 11^{\circ}$.

Earthquake swarms have been observed on the Central Alpine Fault segment by Boese et al. (2014). Both background and triggered swarms (sequences with no apparent mainshock) consisting of low-magnitude $\left(M_{L} \geq 2.8\right)$ earthquakes have been observed. Boese et al. (2014) suggested that some of the swarms were triggered by regional earthquakes. Tectonic tremor signals have also been observed on the Alpine Fault. Wech et al. (2012) and Wech et al. (2013) detected tremors occurring south of Mount Cook and attributed the phenomenon to deep slow slip on the Alpine Fault. Chamberlain et al. (2014) were the first to identify low-frequency earthquakes (LFEs) associated with the deep extension of the transpressional Alpine Fault. The LFEs ocurred within known tremor periods. Later work by Baratin et al. (2018) computed focal mechanisms for these LFE families to show they exhibited slip on fault planes consistent with the deep structure of the Alpine Fault.

In addition to shallow seismicity, intermediate depth earthquakes, occurring beneath the shallowest seismogenic cut-off depth, have been observed adjacent to the Alpine Fault. Haines et al. (1979) and Reyners (1988) recorded 15 events between 1975 and 1983 at depths $>33 \mathrm{~km}$. Kohler (2003) detected 16 events between 1990 and 200 at depths $>30 \mathrm{~km}$. Boese et al. (2013) identified 20 subcrustal earthquakes recorded between December 2008 and February 2012 at depths of 45-74 km. These studies led Boese et al. (2014) to identify three distinct seismic zones along the Alpine Fault. (1) The subduction zones at north and south ends of the Alpine Fault present intermediate-depth and deep earthquakes, (2) the mid/south Central and South Westland Alpine Fault segments present few intermediate-depth earthquakes and (3) the mid-north Central and North Westland Alpine Fault present tremors and intermediate depth earthquakes.

To summarise the seismicity of the Alpine Fault segments: 
1. Wairau segment: Background seismicity has not been studied much and has been found to be low with seismic cut-off depths of 20-35 km (Arabasz and Robinson, 1976). No dense recording instruments exist close to this segment.

2. North Westland segment: Background seismicity rates are slightly increased relative to the Wairau segment but still generally low in comparison to seismicity rates in other Alpine Fault segments. The seismicity cut-off depths ranges from 15-20 km (Bourguignon et al., 2015; Boese et al., 2012). There are few dense instruments, so catalogues are restricted.

3. Central segment: The most studied seismicity on the Alpine Fault, with overall low seismicity rates, but shallow microearthquake activity is recorded. Swarms, tremors and LFEs are present. The average seismic cut-off depth ranges between $8 \mathrm{~km}$ and $20 \mathrm{~km}$, defined by high density instrumentation along this segment.

4. South Westland segment: Background microseismicity is high along this segment. Seismicity is found shallower than $\sim 15 \mathrm{~km}$ and is distributed on both sides of the Fault (Warren-Smith et al., 2017b).

5. Fiordland segment: Seismicity in this segment defines a steep Wadati-Benioff zone dipping at around $70^{\circ}$ to the southeast extending to depths of at least 150 km (Reyners et al., 2017).

While many Alpine Fault seismicity studies have catalogued the locations of earthquakes, there are very limited studies focusing on their physical source properties, including stress drops. In the next section we outline earthquake source properties and the relevance of stress drop estimations for better understanding Alpine Fault seismicity.

\subsection{Earthquakes Source Properties}

Earthquakes are characterised by several parameters, including (in approximate order of computational complexity) hypocentral location, seismic moments, fault plane solutions, corner frequency, stress drop and directivity. Many of these parameters, such as hypocentral location, are routinely determined for most moderate to large events $M>3$ in New Zealand by GeoNet, although dense, temporary deployments are required to extend this consistently to smaller, microseismic events. Similarly, earthquake magnitudes, including Local $\left(M_{L}\right)$ and summary $(M)$ magnitudes are routinely 
calculated by GeoNet, whereas moment magnitudes $\left(M_{w}\right)$ and seismic moment $\left(M_{o}\right)$ are only calculated for a subset of larger earthquakes by Ristau et al. (2016) through moment tensor inversion (e.g. Dreger, 2003; Herrmann, 2013). Earthquake moments can also be calculated from the long-period asymptote on displacement spectra (Aki and Richards, 2002). Moment tensor solutions can also provide constraints on the orientations of the nodal and auxilliary planes of an earthquake's fault plane solution. This "beach ball" can additionally be constrained using polarities of first-arriving Pwaves which vary across the focal sphere, an approach which is not currently routinely undertaken in New Zealand, but which has been studied by numerous local network studies (Boese et al., 2012; Warren-Smith et al., 2017a; Michailos et al., 2020).

In addition to these more routine source properties, constraints on source physics from earthquake frequency spectra are less frequently studied in New Zealand. The corner frequency of an earthquake can be defined as the frequency at the intersection of the low- and high-frequency asymptotes in the signal spectrum (for a finite fault model by Haskell (1964, 1966); Figure 1.3) and provides information pertaining to the physics of the earthquake source (see Section 3.5 for further details). The spectrum is characterized by three parameters. First, the low-frequency level, a flat spectrum which is proportional to the seismic moment. Secondly, a spectrum with a slope $\omega^{-1}$ that represents the corner frequency. Thirdly, the spectrum slope decays $\omega^{-2}$ for the highfrequencies (Stein and Wysession (2003); Figure 1.3). Corner frequency measurements are difficult to make because of data limitations (e.g. noise levels and bandwidth) and because of the need to correct for attenuation and path effects, specially for smaller earthquakes in which high frequency noise, attenuation and path effects hide the real corner frequency. 


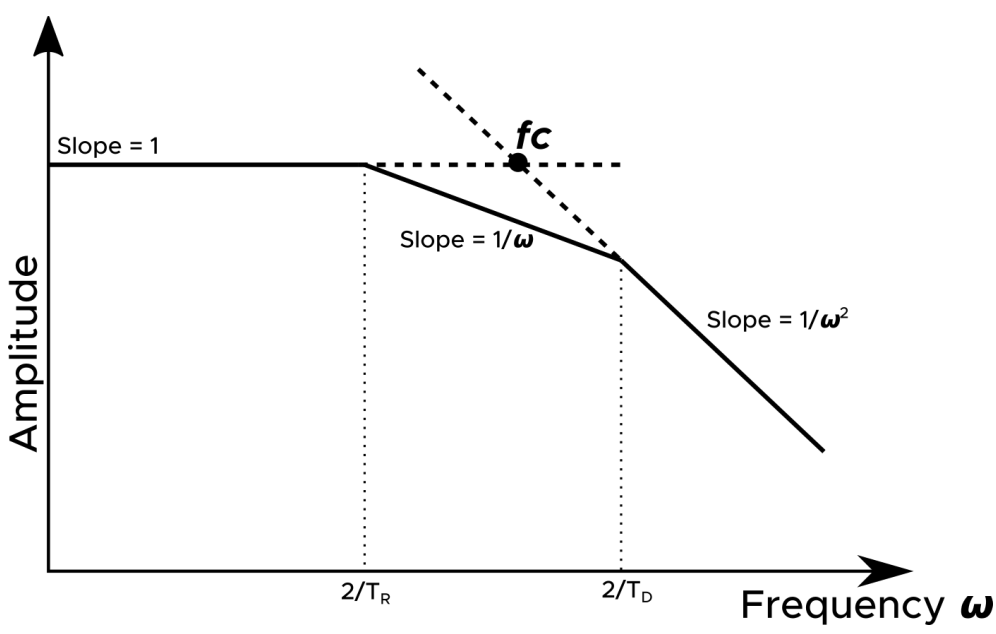

Figure 1.3: Theoretical source spectrum of an earthquake. The spectrum is modeled as three regions with slopes of $1, \omega^{-1}$ and $\omega^{-2}$ divided by angular frequencies corresponding to the rupture $\left(T_{R}\right)$ and rise $\left(T_{D}\right)$ times (the rupture and rise time are explained in Chapter 3). Schematic figure taken from Stein and Wysession (2003).

Earthquake stress drop $(\Delta \sigma)$ is the change in shear stress on a fault during an earthquake (i.e. the difference between its pre-loaded shear stress, and its post-seismic stress state; Figure 1.4). Measurements of stress drop are essential for understanding the physics of the rupture process (Kanamori and Brodsky, 2001), calculating seismic hazard (Cotton et al., 2013; Fry and Gerstenberger, 2011) and in monitoring seismology. Estimating stress drop is relatively easy, but very hard to measure reliably and accurately; this is illustrated by the high variability $(\sim 0.1-100 \mathrm{MPa})$ in global stress drop measurements presented in different studies (Figure 1.5).

Despite large observed variation, some studies have proposed identifiable patterns in stress drops, which may partly explain their scatter. For example, global studies of earthquake sources have found that reverse earthquakes at subduction zones appear to have lower stress drop values than normal and strike-slip earthquakes (Allmann and Shearer, 2009; Shearer et al., 2006). Viegas et al. (2010) and Oth and Kaiser (2014) estimate high stress drop for intraplate earthquakes in eastern North America and Canterbury, New Zealand, respectively. The values reported by Oth and Kaiser (2014) were higher than earthquakes in regions at Japan with higher seismic rate. Oth and Kaiser (2014), Shearer et al. (2006) and Oth et al. (2011) reported spatial and temporal variation in stress drop for New Zealand (Canterbury region), southern California and Japan, respectively. Calderoni et al. (2013) found increasing stress drop with increasing seismic moment for the 2009 l'Aquila earthquake sequence in Italy, while Shearer et al. (2006) and Oth and Kaiser (2014) found no dependence of stress drop on the seismic 


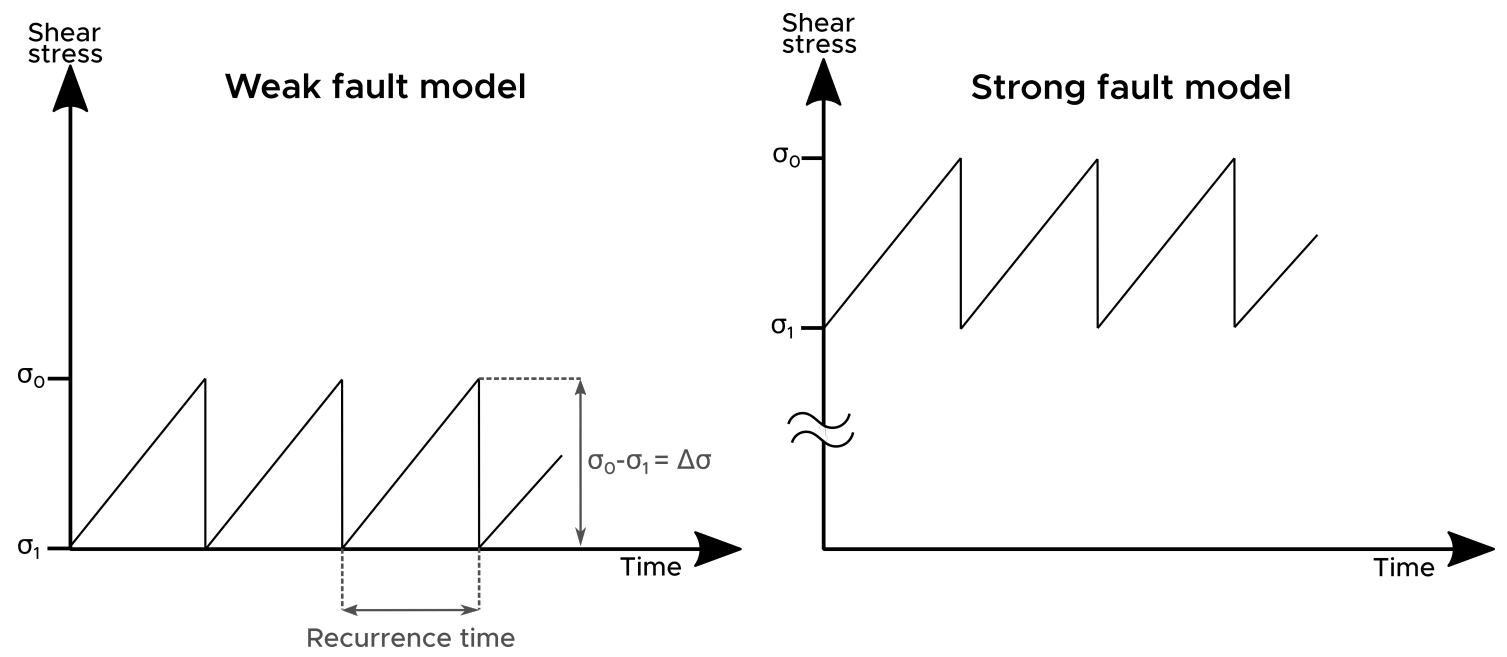

Figure 1.4: Schematic figure showing the stress drop variations on weak and strong fault models. $\sigma_{0}$ and $\sigma_{1}$ are the shear stress on the fault before and after an earthquake, respectively. The difference between $\sigma_{0}$ and $\sigma_{1}$ is the stress drop of the earthquake. Modified from Kanamori (1994).

moment for earthquakes in southern California and New Zealand (Canterbury region), respectively. Hardebeck and Aron (2009) and Trugman and Shearer (2017) both found that stress drops are dependent on depth and faulting mechanism in California. Boyd et al. (2017) and Huang et al. (2017) found that stress drop are influenced by tectonic setting. Meanwhile, Huang et al. (2016) and Shearer et al. (2019) conclude that some of those trends may be artefacts and result from the large uncertainties.

Only a limited number of studies have investigated stress drop in New Zealand. Oth and Kaiser (2014) estimated stress drops for the Canterbury 2010-2011 sequence (the sequence beginning with the $2010 M_{w} 7.2$ Darfield earthquake (one of the most wellrecorded earthquakes in New Zealand). The Darfield earthquake produced the largest ground motions ever measured in New Zealand (Fry and Gerstenberger, 2011). Oth and Kaiser (2014) presented a source parameter study using more than 200 earthquakes from the Canterbury sequence, covering magnitudes from $M_{w} 3.0$ to $M_{w} 7.2$. They used a source spectra approach and the non-parametric generalized inversion technique from Oth et al. (2011) to isolate the earthquake source spectra from the observed S wave amplitude spectra. They estimated that stress drops ranged between 1-20 MPa.

Abercrombie et al. (2017a) calculated stress drops for four sequences of earthquakes in New Zealand. Two sequences involved normal faulting within the subducting slab of the Pacific Plate (the 2005 Upper Hutt and the 2014 Eketāhuna sequences). The third sequence (2013 Cook Strait) involved strike-slip faulting in the upper Australian plate close to Blenheim. The last sequence (2015 Pongaroa), involved a thrust faulting 


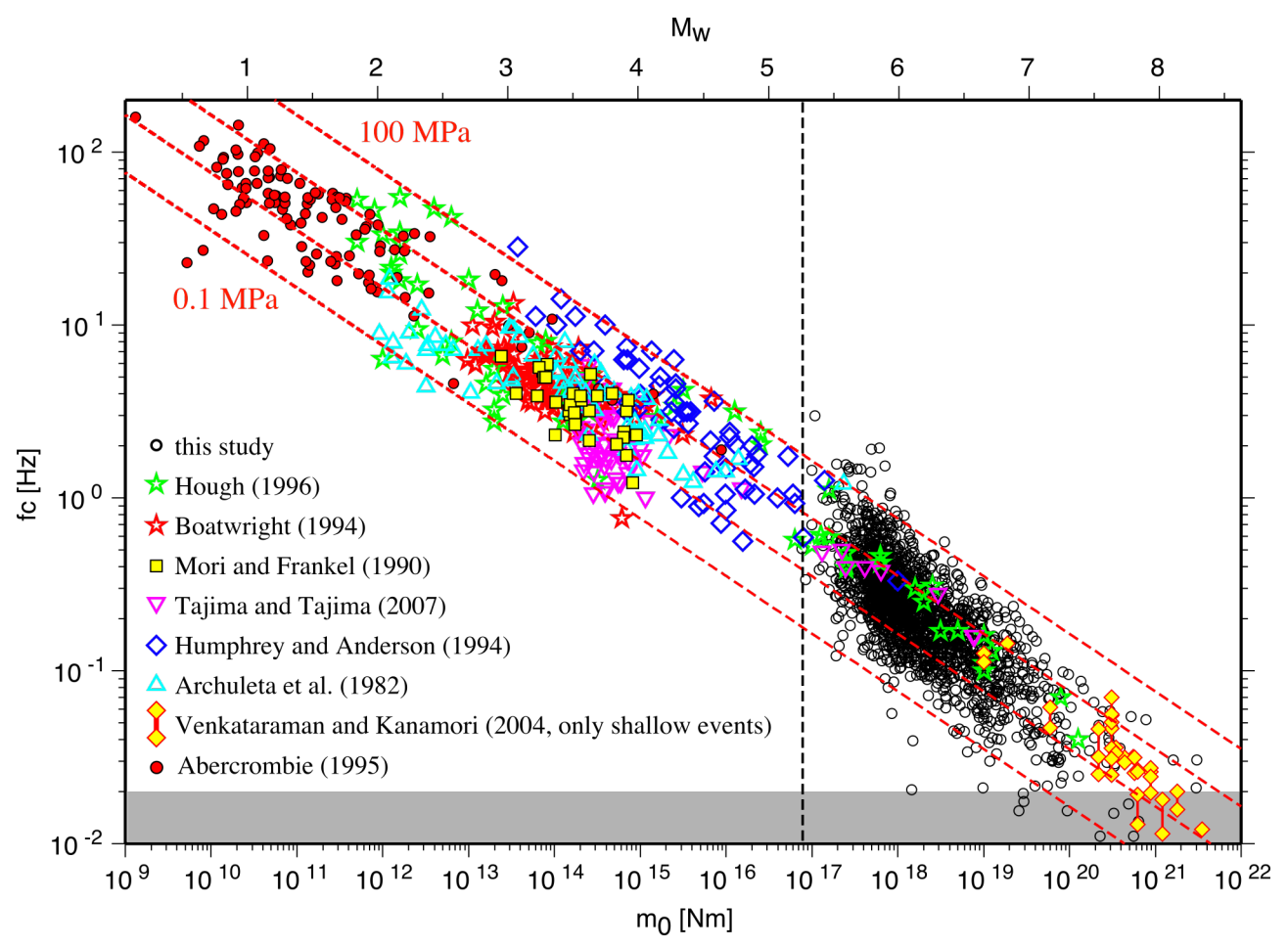

Figure 1.5: Corner frequency versus seismic moment. Global variations of stress drop from different studies, figure adapted from Allmann and Shearer (2009). Points labelled as "This study" are from Allmann and Shearer (2009).

sequence on the Pacific plate interface, including a magnitude range between M2.6 to M6.6. In total they calculated stress drops for 176 earthquakes using an Empirical Green's Function approach and stress drop values range between 1-100 MPa.

Along the Alpine Fault, estimates of stress drops for earthquakes are poorly resolved and limited to a handful of observations. Abercrombie et al. (2001) computed twodimensional slip inversions for four earthquakes in the $M_{w} 6.71994$ Arthur's Pass earthquake aftershock sequence and constrained their stress drops to be between 1-10MPa.

All this high variability in stress drop suggests that it is fundamentally difficult to identify whether stress drop values depends on their tectonic setting, magnitude, depth and time. However, stress drop is a fundamental source parameter and understanding any dependence, specially on tectonic setting, is important to determinate the factors that control dynamic rupture, and for predicting future ground motion and seismic hazard (Abercrombie et al., 2017a). 


\section{Chapter 2}

\section{Seismic Networks and Data}

This chapter consists of three main sections. Section 2.1 presents details of previously deployed temporary and permanent seismic networks used in this thesis, in addition to DWARFS (Dense Westland Arrays Researching Fault Segmentation), a new two-part network designed to constrain seismogenic behaviour near key transitional boundaries on the Alpine Fault. Section 2.2 includes a detailed description of the data and catalogues used for this thesis. Section 2.3 outlines the procedure to select earthquakes occurring on and near the Alpine Fault from pre-existing catalogues.

\subsection{Seismic Networks}

To facilitate source spectra frequency analysis and subsequent stress drop calculation, recordings of earthquakes on seismographs are required from along the Alpine Fault. In this section, the instrumentation and frequency band information for the seismic networks used for these recordings are outlined.

The GeoNet network operated by GNS Science is part of the national geophysical monitoring system that includes broadband and strong motion instruments (blue and violet inverse triangles in Figure 2.1, respectively) and which has been operating continuously since 1990. Broadband stations (considered in this study) are equipped with Guralp CMG 3ESP sensors, with a sample rate of $100 \mathrm{~Hz}$ (Nyquist frequency $50 \mathrm{~Hz}$ ). Generally, the spatial and azimuthal coverage along the Alpine Fault is poor. For this reason, we rely heavily on dense and temporary networks (e.g. SAMBA, WIZARD, ALFA-08, DFDP-10, DFDP-13, COSA and DWARFS) deployed along the Alpine Fault to increase the coverage needed for this study. Specific location and sensor information can 


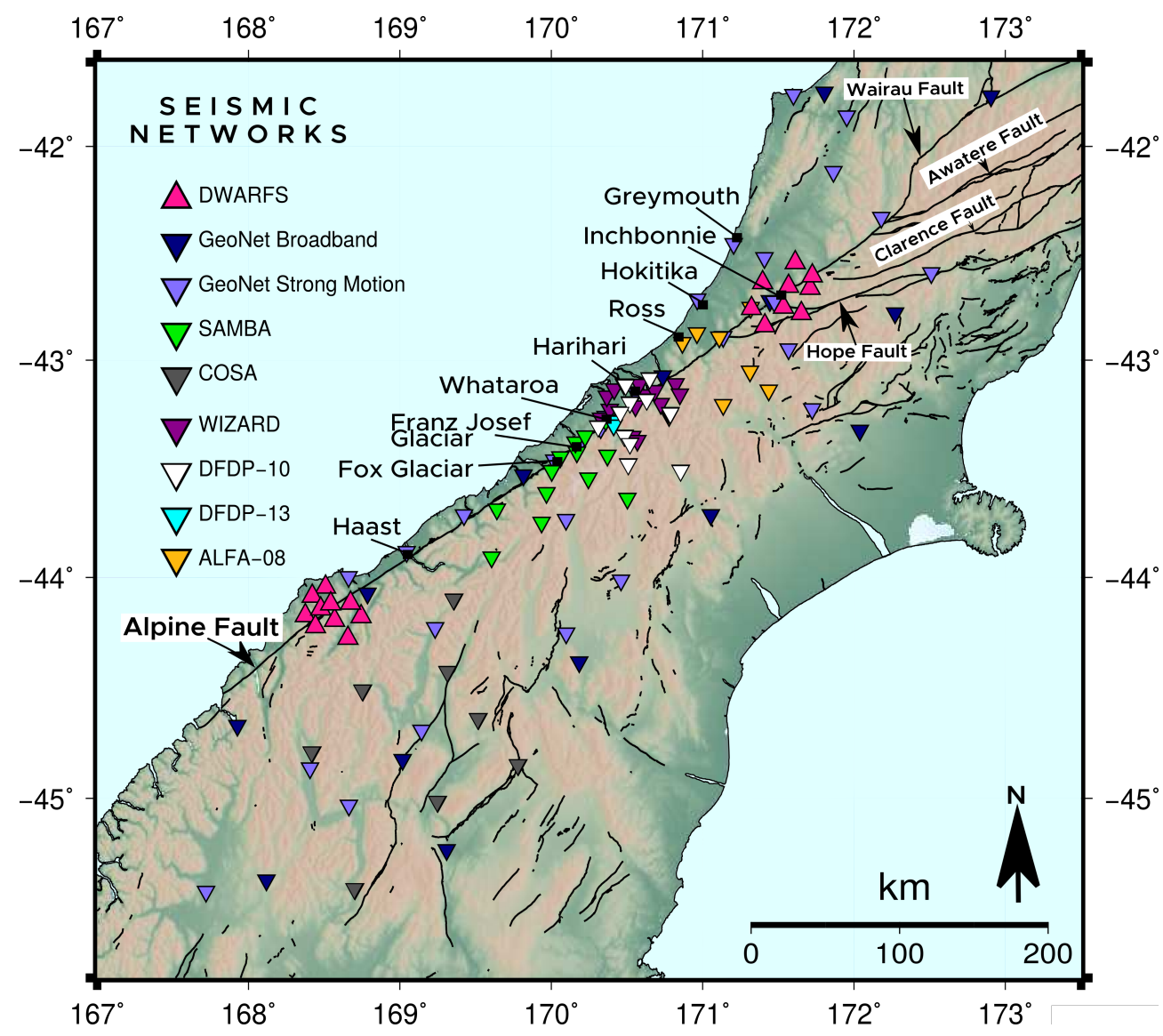

Figure 2.1: Map of the seismic networks used in this thesis along the Alpine Fault. Inverse triangles in green, yellow, orange, cyan, purple and red represent the temporary networks, SAMBA, ALFA-08, DFDP-10, DFDP-13, WIZARD and COSA, respectively. The permanent broadband and strongmotion GeoNet network stations are marked by blue and violet inverse triangles. The new two-part network, DWARFS, is shown by pink triangles. Black thick lines represent the active faults.

be found in Michailos (2019).

The Southern Alps Micro-earthquake Borehole Array, SAMBA (Boese et al., 2012; Chamberlain et al., 2014; Chamberlain, 2016), is a 10-borehole short-period (GeoSpace Tech HS-1-LT and Mark products L-4C3D, recording at $200 \mathrm{~Hz}$ ) network deployed along the Central segment of the Alpine Fault in late 2008. Three additional surface short-period sensors were deployed in 2013 forming a southern extension of the network (green inverse triangles in Figure 2.1). Originally, SAMBA was designed for microearthquake detection as part of a Marsden project entitled "Putting a stethoscope on the Alpine Fault" but it has since been used for low-frequency earthquake (Chamberlain et al., 2014) and tremor (Wech et al., 2013) detection. This network is still in operation and data are collected approximately every six months. 
The Alpine Fault Array, ALFA-08, used by Bourguignon et al. (2015) to conduct a microseismicity and seismic tomography study, operated from October 2008 to October 2009 and consisted of eight broadband (CMG-40T and LE-3Dlite) seismometers deployed near the northeastern portion of the Central segment between Harihari and Hokitika (yellow inverse triangles in Figure 2.1).

Seismological monitoring in conjunction with the Deep Fault Drilling Project, DFDP (Townend et al., 2009; Sutherland et al., 2013; Chamberlain et al., 2017; Sutherland et al., 2017), existed in two phases and involved geometrically overlapping, but non contemporaneous seismic networks deployed in the Whataroa Valley and surrounding areas. The goal of the DFDP was to drill into the Alpine fault and determine the temperature, fluid pressure and chemistry, rock properties, and prevailing stress state through direct observations of the fault zone at depth (Townend et al., 2009). For the first phase, the DFDP-10 network operated in 2010 and included 12 short-period (Mark Products L-22D3D) sensors (orange inverse triangles in Figure 2.1). Since the second phase, the DFDP-13 network has been operating semi-continuously and includes four shallow borehole (IESE HS-1-LT) sensors (cyan inverse triangles in Figure 2.1).

The Wisconsin New Zealand Array Regional Deployment, WIZARD, network included 10 short-period (Mark Products L22) and 10 broadband (Guralp CMG3-ESP) sensors (Feenstra et al., 2016), was deployed along the Central segment northeast of SAMBA network in January 2012 and operated until January 2014 (purple inverse triangles in Figure 2.1).

Farther from the central Alpine Fault, the Central Otago Seismic Array, COSA, is composed of eight broadband (Guralp CMG 40T and ESP3C, recording at $100 \mathrm{~Hz}$ ) sensors deployed around the Southern Lakes and Central Otago (Warren-Smith et al., 2017b) and has been in operation since 2012 (red inverse triangles in Figure 2.1) One site (KING) at the southern end of the network was disestablished in early 2019. The network was originally installed to monitor local microseismicity in Central Otago and quantify its relationship to crustal thickening processes in the region.

The data continuity of the networks used in this thesis is shown in Figure 2.2 


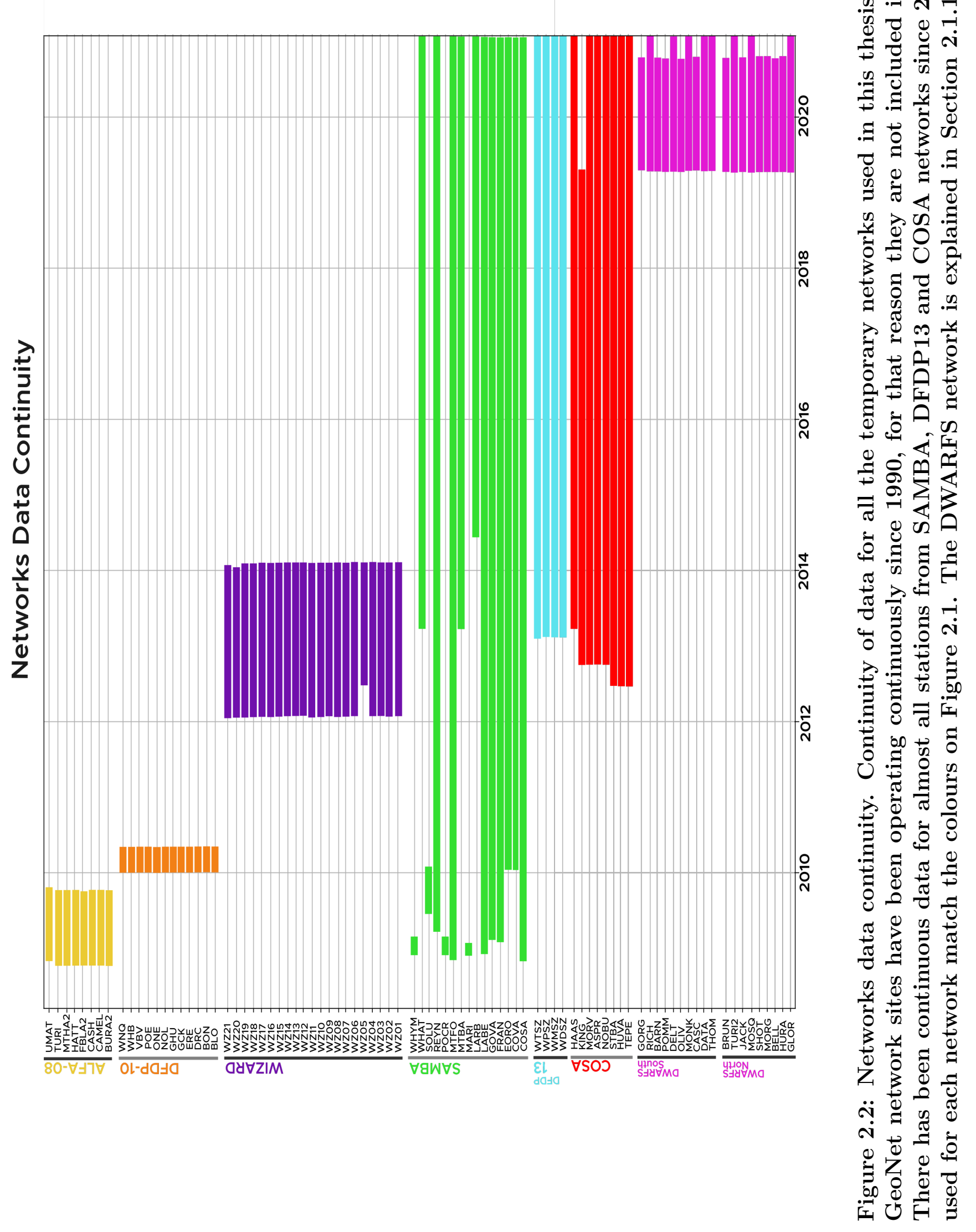




\subsubsection{DWARFS: Dense Westland Arrays Researching Fault Segmentation}

While previous temporary networks have focused primarily on the Central segment of the Alpine Fault, few have been deployed near the key transitional segment boundaries (Warren-Smith et al., 2017b). To analyse the seismicity near these transitional zones in more detail, the Dense Westland Arrays Researching Fault Segmentation (DWARFS) stations were installed in April 2019 as a two-part temporary network composed of 19 broadband stations (Figure 2.3). The stations are distributed on either side of the Alpine Fault with a station spacing of $\sim 10 \mathrm{~km}$ to have good depth constraints for seismicity as shallow as $\sim 5 \mathrm{~km}$. The network geometry was designed to complement existing permanent and temporary stations and provide optimal focal sphere coverage for focal mechanisms anticipated on the major faults within each network. Specific station locations were chosen based on fundamental requirements, such as: good sunlight, north facing aspect, good access to bedrock and away from noise sources like major rivers, trees and power lines. Ideally sites were located with $\sim 30 \mathrm{~cm}$ of topsoil over consolidated bedrock. Analysis of the noise spectra for DWARFS sites is included in Appendix B.

DWARFS was designed to investigate the boundary between the principal segments of the Alpine Fault. Therefore, nine stations in northern DWARFS (Figure 2.3) were deployed between Haupiri and the Taipo River and 10 stations in southern DWARFS (Figure 2.3) were deployed between Jackson Bay and the Gorge River.

Each DWARFS station consists of a three-component broadband seismometer recording at $200 \mathrm{~Hz}$ (Guralp CMG 40T (60 or 30 second), with the exception of TURI2, which has a Nanometrics Trillium Compact 120; Table 2.1), a digitizer (Nanometrics Taurus or a Reftek RT-130), a GPS clock and a power supply (a solar panel, charger controller and two $12 \mathrm{~V}$ car batteries). Each sensor is encased in a plastic bucket and rests directly on a level concrete paving slab atop compacted sand. The sensors are oriented with their North horizontal channel aligned with true (geographic) North. See diagram of the site setup in Figure 2.4.

\subsection{Data and Catalogues}

We use three micro-earthquake catalogues for this study, one for each Alpine Fault segment. For the Central segment we use the catalogue from Michailos et al. (2019) 


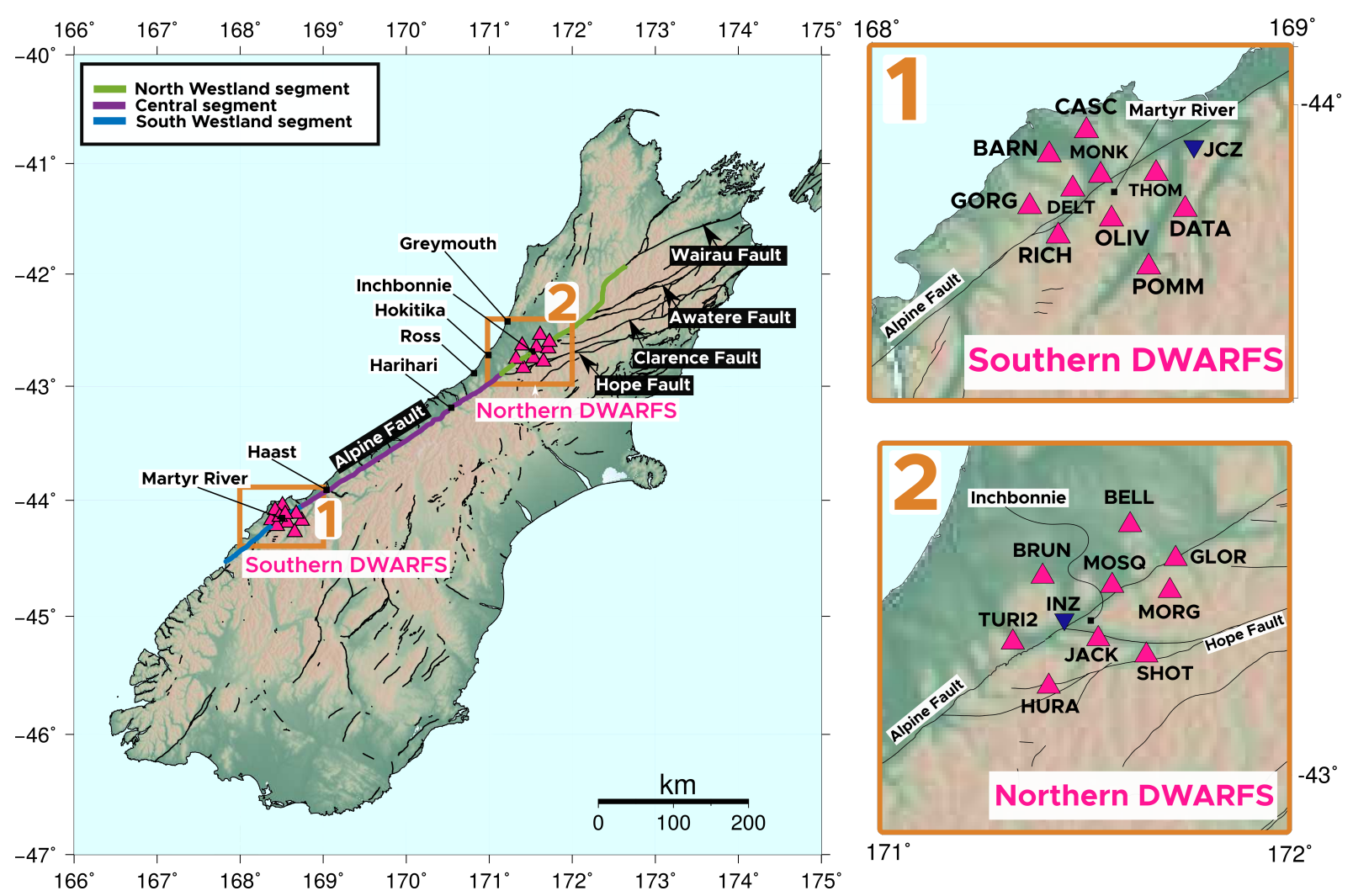

Figure 2.3: Dense Westland Arrays Researching Fault Segmentation (DWARFS). Map of the South Island, New Zealand showing the two-part temporary DWARFS network (pink triangles). Square 1 shows southern DWARFS distribution along the South Westland Alpine Fault segment. Square 2 shows spatial distribution of north DWARFS along the North Westland Alpine Fault segment.

which contains over ten years of seismicity for the region recorded on all available seismic networks including SAMBA, WIZARD, ALFA-08, DFDP-10, DFDP-13 and five permanent GeoNet seismic sites where available. This catalog contains accurate relative earthquake relocations for 9111 events obtained using the latest 3-D P- and S-wave velocity models (Guo et al., 2017). Michailos et al. (2019) later constrained earthquake locations with high-quality automatic and manual picks and then performed relocations using waveform cross-correlation to better constrain hypocenters. They also derived a new local magnitude scale calibrated against GeoNet $M_{w}$ values. The magnitudes range between $M_{L^{-}} 1.2$ and $M_{L} 4.6$ and the catalogue is complete above $M_{L} 1.1$. Michailos et al. (2020) constructed a new data set of 845 focal mechanisms derived from the Michailos et al. (2019) microearthquake catalogue. They use a manually picked P wave polarities for all earthquakes larger than $M_{L} 1.5$.

Away from the Central segment, there are few published catalogues available near the segment boundaries for the analysis. For these regions, we use 11-months of an un- 


\section{Site Setup for DWARFS}

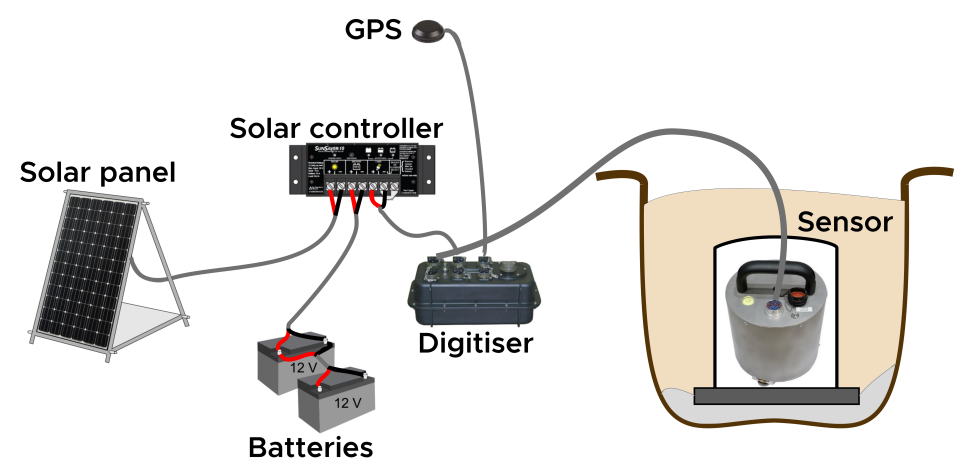

Figure 2.4: Site setup for DWARFS broadband stations. Typical site setup and equipment used. For equipment information consult Table 2.1. Figure modified from Warren-Smith (2016).
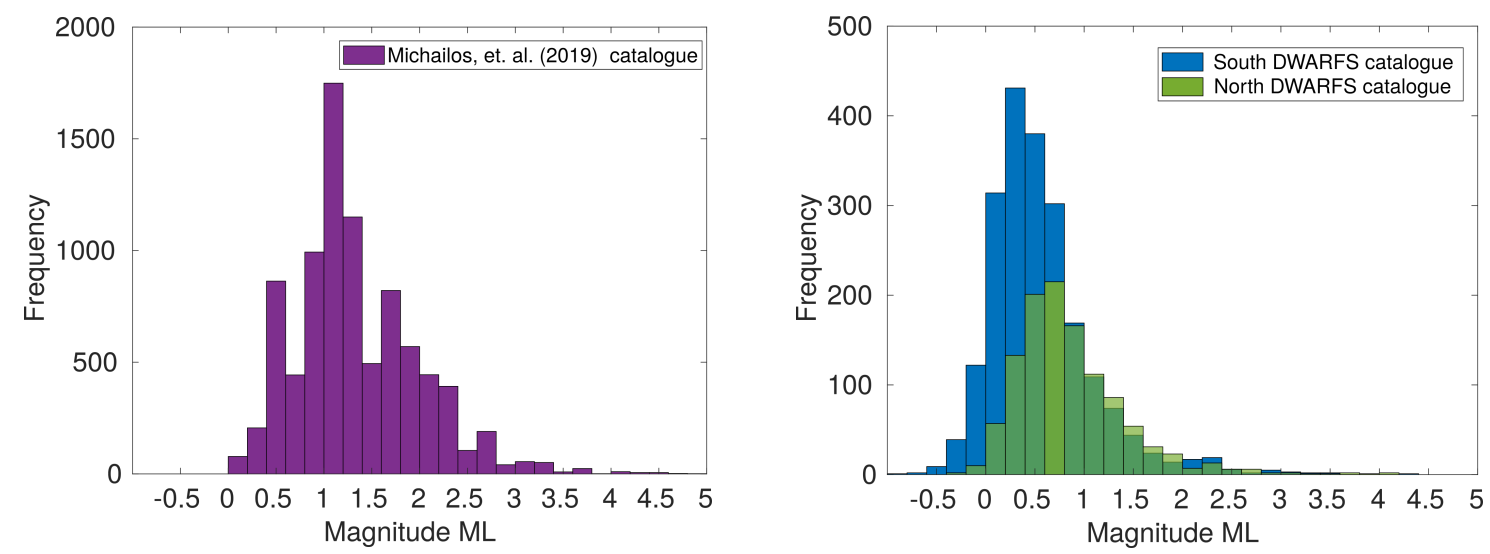

Figure 2.5: Magnitude histograms of three different Alpine Fault catalogues. Left: Michailos et al. (2019) catalogue for the Central Alpine Fault. Right: catalogues from the North (green) and South Westland (blue) Alpine Fault (Warren-Smith, pers. comm. 2020).

published microearthquake catalogue constructed as part of the larger project for the DWARFS networks. Dr. Emily Warren-Smith located 1134 and 2093 earthquakes for Northern and Southern DWARFS, respectively, using seismic data from DWARFS and other temporary seismic networks collected between April 2019 and March 2020. Events were located using the NonLinLoc algorithm (Lomax et al., 2009) and then relocated using a double-difference relative relocation algorithm (HYPODD) (Waldhauser, 2001) using a 3D velocity model from Eberhart-Phillips et al. (2010). Local magnitudes were calculated and calibrated against GeoNet $M_{L}$ and range from $M_{L^{-}}$to $M_{L}$ 4.3. Dr. Emily Warren-Smith obtained focal mechanisms by picking direct P-phase arrival polarities and using the Bayesian approach of Walsh et al. (2009). Northern and southern DWARFS catalogues are constructed using the same consistent methodologies for both Northern and Southern Alpine Fault regions, and the details of the event 


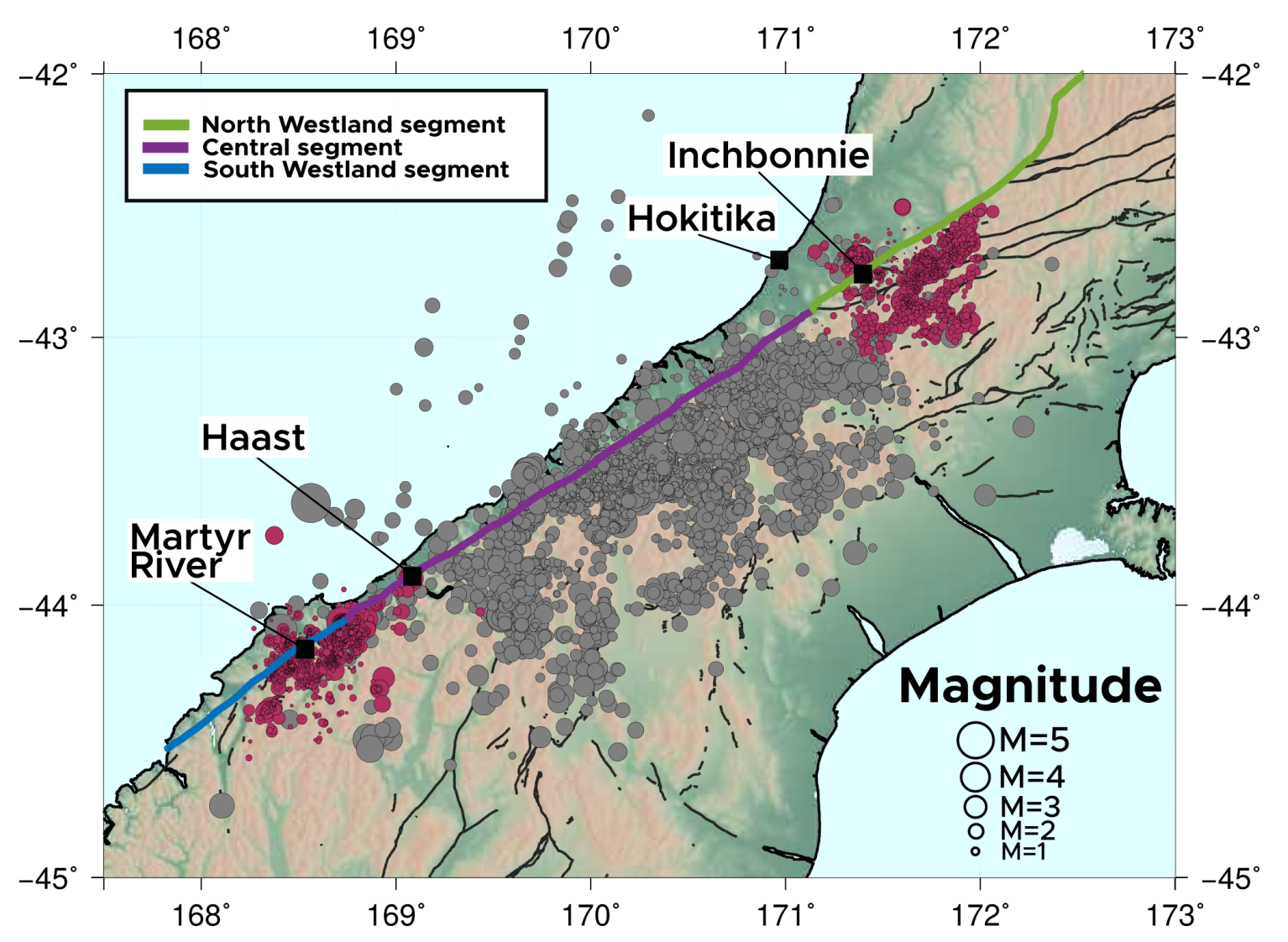

Figure 2.6: Earthquakes from the three catalogues along the Alpine Fault. Gray circles are events from the Michailos et al. (2019) catalogue and purple circles are events from E. Warren-Smith's catalogues (pers. comm. 2020)

detection, picking, location, magnitude and focal mechanism calculations undertaken outside of this thesis are found in Appendix A.

In total, we consider 10,946 candidate earthquakes (see Figure 2.6) from the three microearthquake catalogues for our source property analysis. Magnitudes vary from $M_{L}-1$ to $M_{L} 4.6$ (see magnitude distribution in histograms in Figure 2.5). Absolute earthquake hypocenters have a mean horizontal error of $503 \mathrm{~m}$ and depth error of 801 m.

\subsection{Selecting Earthquakes on the Alpine Fault}

We select earthquakes occurring on and near the Alpine Fault from the three microearthquake catalogues. We considered each Alpine Fault segment individually for this process. We begin by defining a plane that matches the geometry of the fault plane (see Table 1.1) and select those earthquakes located within $5 \mathrm{~km}$ of the plane. 
For the North Westland segment between the Matakitaki and Toaroha rivers, we adopt a representative fault plane with a strike of $055^{\circ}$ (Barth et al., 2013) and two dip values of $50^{\circ}$ and $60^{\circ} \mathrm{SE}$. We located 542 and 311 earthquakes for each dip value, respectively, with magnitudes between $M_{L^{-}} 0.2$ and $M_{L} 2.8$ from the Northern DWARFS catalogue (see cross-section D on Figure 2.7).

The Central segment of the Alpine Fault lies between the Toaroha River and Haast. For this segment we adopt a fault plane with a strike of $055^{\circ}$ (Barth et al., 2013) and consider three dip values, $45^{\circ}, 50^{\circ}$ and $60^{\circ}$ SE (Norris and Cooper, 1997; Guo et al., 2017; Beavan et al., 1999). We find 1091, 848 and 555 earthquakes, respectively, with magnitude values of between $M_{L^{-}} 1.2$ and $M_{L}$ 4.3. from the catalogue of Michailos et al. (2019). Based on the seismic velocity structure and seismicity (Feenstra et al., 2016), the Central segment of the Alpine Fault is dipping steeply $\left(50^{\circ}-60^{\circ}\right)$ in the upper part of the crust, before becoming listric $\left(25^{\circ}-30^{\circ}\right)$ at greater depths $(15-20 \mathrm{~km})$, hence why we chose a range of dip options. Nevertheless, we're only looking at shallow seismicity, so the dip shouldn't change overly within the shallowest $10 \mathrm{~km}$. Only considering earthquakes bigger than $>M_{L} 2.5$ (anticipated to provide sufficient signal to noise for source spectra analysis) found on and close to (within $5 \mathrm{~km}$ of) the Central segment, and combining the results of the different dips, we select 145 earthquakes to take forward to the source properties analysis.

For the South Westland segment, we made a subdivision after Barth et al. (2013) as the dip angle changes abruptly at Martyr River. For the first section, between Haast and Martyr River, we use a fault plane with a strike of $058^{\circ}$ and two dip values of $50^{\circ}$ and $60^{\circ}$ SE. 567 and 511 earthquakes were found with magnitude ranges of $M_{L}-0.7$ and $M_{L} 3.3$. For the second section, between Martyr Creek and Mount Pembroke, we use a strike of $060^{\circ}$ and two dip values of $75^{\circ}$ and $85^{\circ}$ SE. We locate 412 and 414 earthquakes for two dip dip values, respectively, with magnitude values of between $M_{L}-0.5$ and $M_{L} 3.4$, using the Southern DWARFS catalogue.

Despite finding many earthquakes ( $\sim 500$ for each segment) located in the fault plane for the North and South Westland segments, most are $M<2.0$. As we decide to work with earthquakes larger than $M 2.5$, only $\sim 5$ earthquakes per segment remained. For that reason, we decide to work with all earthquakes $(M>2.5)$ from the north and south DWARFS catalogues to calculate source properties. Using this magnitude limit increases the earthquake quantity to $\sim 15$ per each segment. Following frequency spectra analysis (see Section 3.4), it became apparent that smaller earthquakes between $M 2.0$ and M2.5 recorded by DWARFS also contained sufficient signal above the noise level. Thus, we decide to lower the magnitude limit to $M>2.0$ and select 43 and 57 


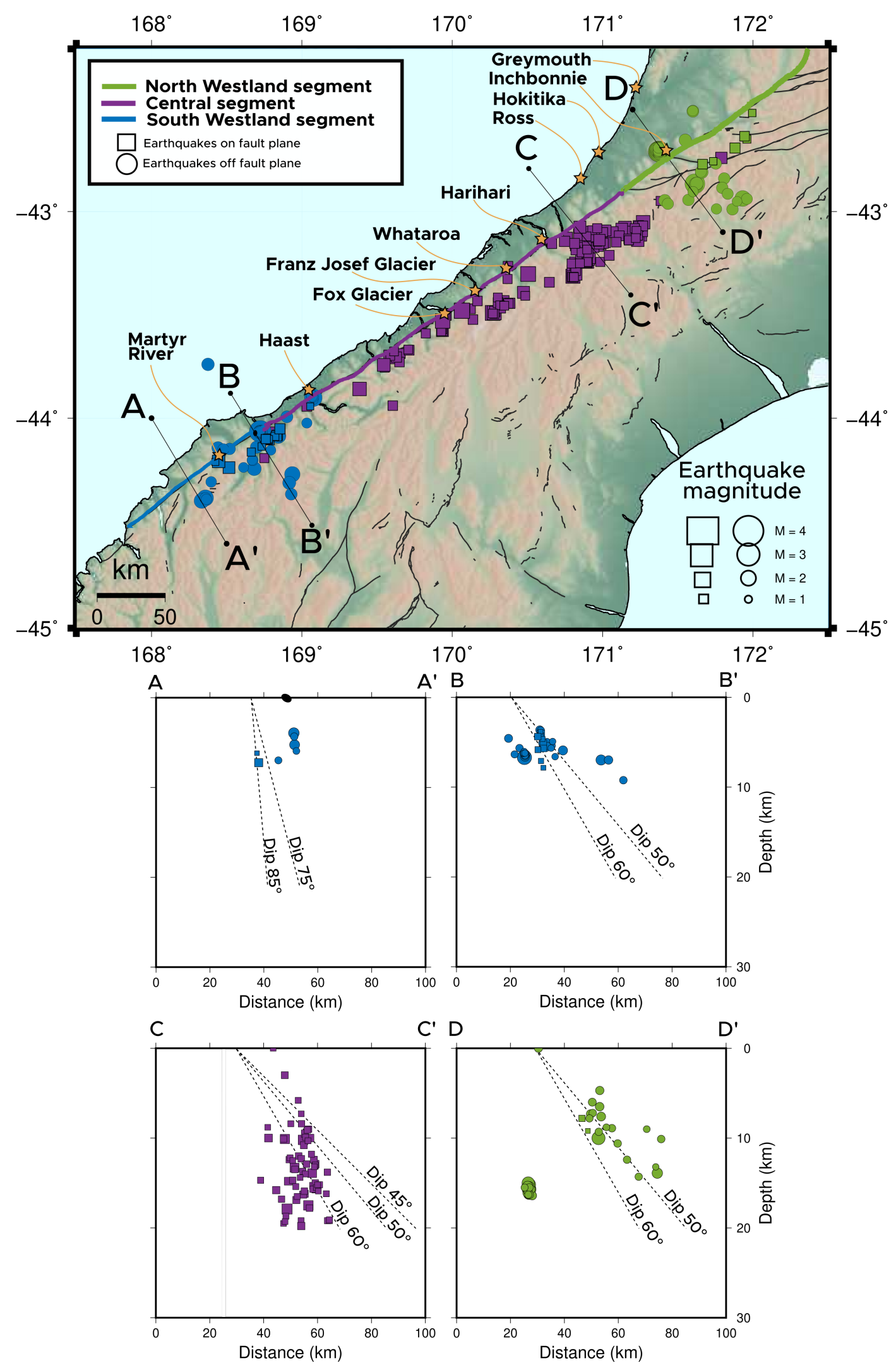

Figure 2.7: Events used for source properties analysis. Top Figure, circles and squares represent all the events used for source property analysis. Squares represent events found on or within $5 \mathrm{~km}$ of the Alpine Fault. Circles are the events $M>2.0$ from the north and south DWARFS catalogue that are not in the fault plane. Bottom figure, four cross-section along strike. 
earthquakes for the North and South Westland segments, respectively.

Overall, we construct a new catalogue ("Target events catalogue") of 245 earthquakes (Table D.1) that is processed using the methods explained in the next chapter (Chapter 3$)$. 


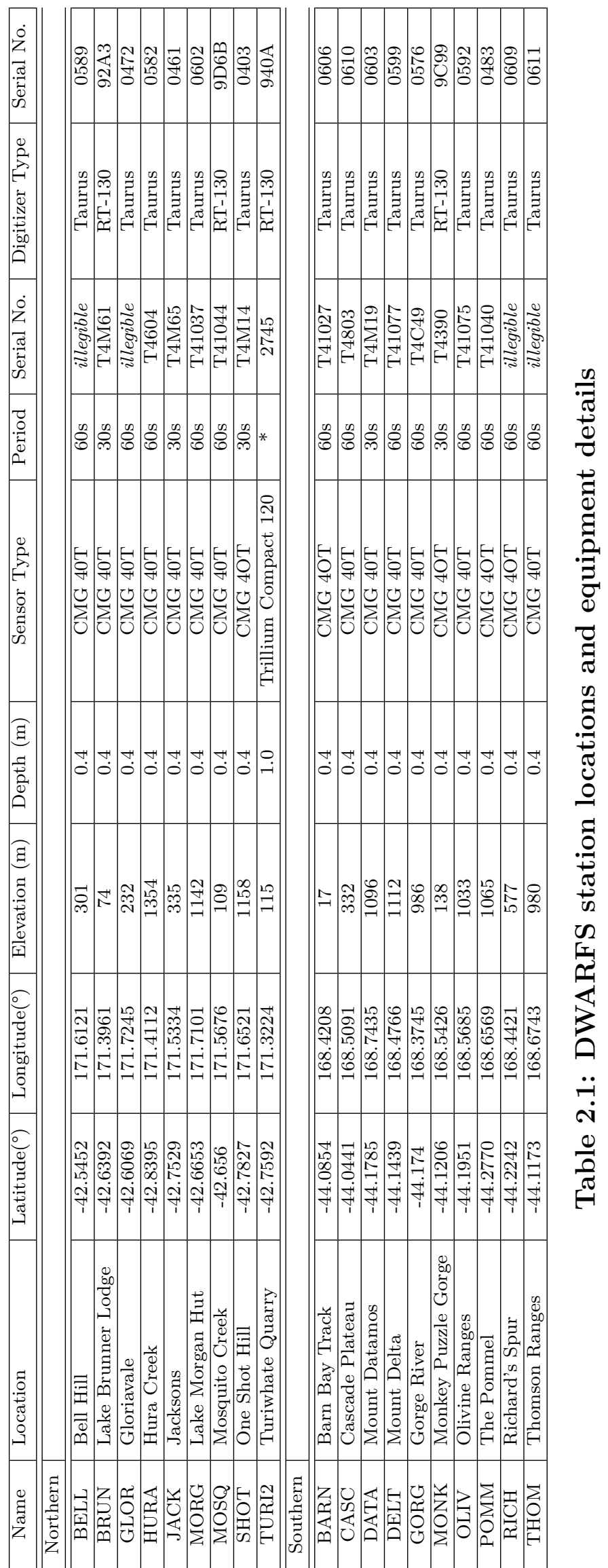




\section{Chapter 3}

\section{Empirical Green's Function Methodology}

\subsection{Empirical Green's Function (EGF) Analysis}

An earthquake is a sudden rupture process caused by tectonic stress. The energy released by the earthquake transforms into seismic waves that propagate through a medium and are recorded at a receiver (Figure 3.1). The resulting record is called a seismogram and contains information about both the source and the medium through which the waves have passed.

More specifically, an earthquake seismogram, $S(t)$, is the convolution of the radiation from the earthquake source, $e(t)$, with the combined propagation effects or Green's function, $G(t)$, along the path, including both near-source and site effects, and finally the instrument response, $I(t)$ (Abercrombie, 2015, 2014). This can be expressed as follows:

$$
S(t)=e(t) * G(t) * I(t)
$$

The instrument response $(I(t))$ is usually known and straightforward to remove from recordings, but the same is not true for the other terms.

The Source Time Function (STF; panel d in Figure 3.2) represents the moment rate release and rupture propagation of an earthquake and is the convolution of the rupture time $\left(T_{R}\right)$ and the rise time $\left(T_{D}\right)$ (panel $\mathrm{c}$ in Figure 3.2 ). The rupture time is the 


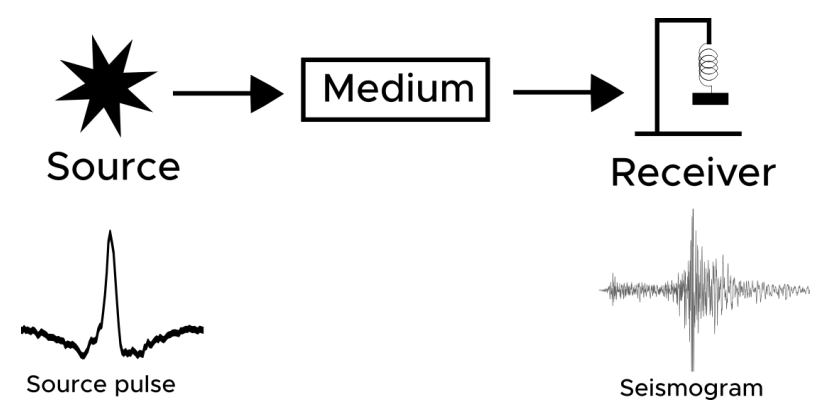

Figure 3.1: Schematic of an earthquake travelling from the source to the receiver. Black arrows represent the seismic waves being emitted from an earthquake source, travelling through a medium and being recorded by a receiver. Modified from Stein and Wysession (2003).

time that the rupture takes in a single event and depends on the fault length (L), the rupture velocity $\left(V_{R}\right)$ and the azimuth $\theta$ from the initial point of rupture (panel a in Figure 3.2). The rise time is the time taken for slip on a particular part of the fault to reach its final offset value (panel b in Figure 3.2).

The propagation effects, $G(t)$, which represent the impulse response of the medium is commonly separated into a path attenuation effect, often described using a constant value for the attenuation quality factor, Q, and a site effect (Ko et al., 2012; Oth et al., 2011; Oth and Kaiser, 2014; Anderson and Hough, 1984). However, this approach rarely accounts for realistic attenuation heterogeneity found in earthquake source regions which leads to large trade-offs between parameters (Ko et al., 2012). Another commonly used approach is to use a small, co-located earthquake as an Empirical Green's Function (EGF). This can be assumed to correspond to the impulse response of the medium and thus can be used to correct for all propagation effects (including instrumentation response if both earthquakes are recorded on the same instrument) (Mori and Frankel, 1990) (Figure 3.3). Ide et al. (2003) found that using EGFs to correct for the path removed attenuation and resulted in higher stress drop estimates than using simple attenuation models. However, as discussed by Abercrombie et al. (2017a), using an imperfect EGF may still introduce significant uncertainty and care should be taken to choose appropriate EGFs for deconvolution.

Many previous studies have used an EGF approach to estimate source properties (e.g. stress drop, directivity, source radius). Imanishi and Ellsworth (2006) and Uchida et al. (2012) calculated source properties (stress drops, source radius and slip amount) of microseismicity in the San Andreas fault and earthquakes rupturing an interplate asperity off Kamaishi, NE Japan, respectively. Ko et al. (2012) used the EGF methodology and the attenuation modeling to investigate the variation of both $\mathrm{Q}$ and stress drop with 


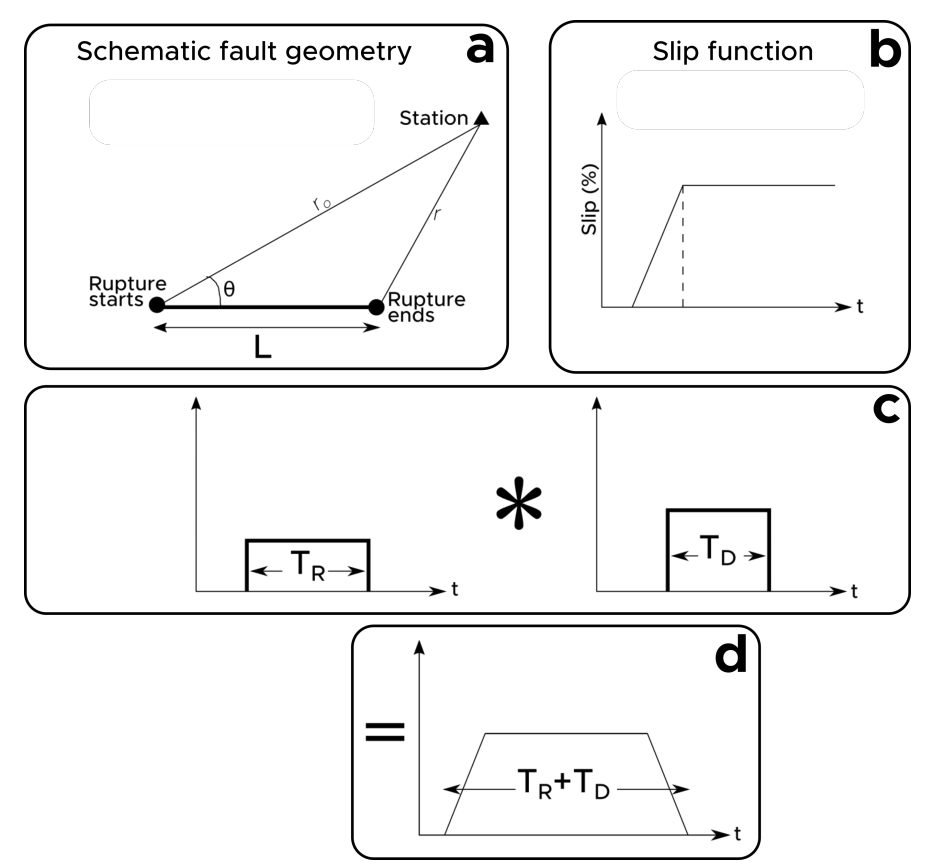

Figure 3.2: Schematic of a Source Time Function. Schematic representation of the convolution of the rupture time $\left(T_{R}\right)$ and the rise time $\left(T_{D}\right)$. a) represents a fault geometry of length $L$, and the STF varying as a function of azimuth, $\theta$, and rupture velocity. b) shows the slip percentage as function of time. c) a schematic representation of the convolution of the rupture time $\left(T_{R}\right)$ and the rise time $\left(T_{D}\right)$. d) schematic representation of the STF Modified from Stein and Wysession (2003).

depth and location beneath Japan. In New Zealand, Abercrombie et al. (2017a) applied the EGF method to estimate stress drop for four sequences of earthquakes in the North Island. Abercrombie et al. (2001) also applied the EGF method to estimate directivity and stress drops for aftershocks of the 1994 Arthur's Pass earthquake. Oth et al. (2011); Oth and Kaiser (2014); Pacor et al. (2016) used a nonparameterized approach to resolve spatial variability in stress drop in the Canterbury earthquake sequence in New Zealand as well as in Japan and Italy while using a large area of fixed Q.

In this study, we use an Empirical Green's Function (EGF) method to isolate the source and correct the recorded data for the instrument, path and site effects. Applying the EGF method to a given earthquake (hereafter referred to as the "Target" event), the path and site (including instrument response) effect contributions to the seismic signal are approximated by the ground motion of a smaller earthquake sharing a similar source location and focal mechanism (Figure 3.3). This assumes that the smaller earthquake (hereafter referred to as the "EGF" event) approximates a point source relative to the Target earthquake and that the waveform of the smaller earthquake mainly represents the propagation path and site effect. Therefore, the Target event source can be obtained by deconvolving the EGF event signal from the Target event signal (Figure 3.3). 


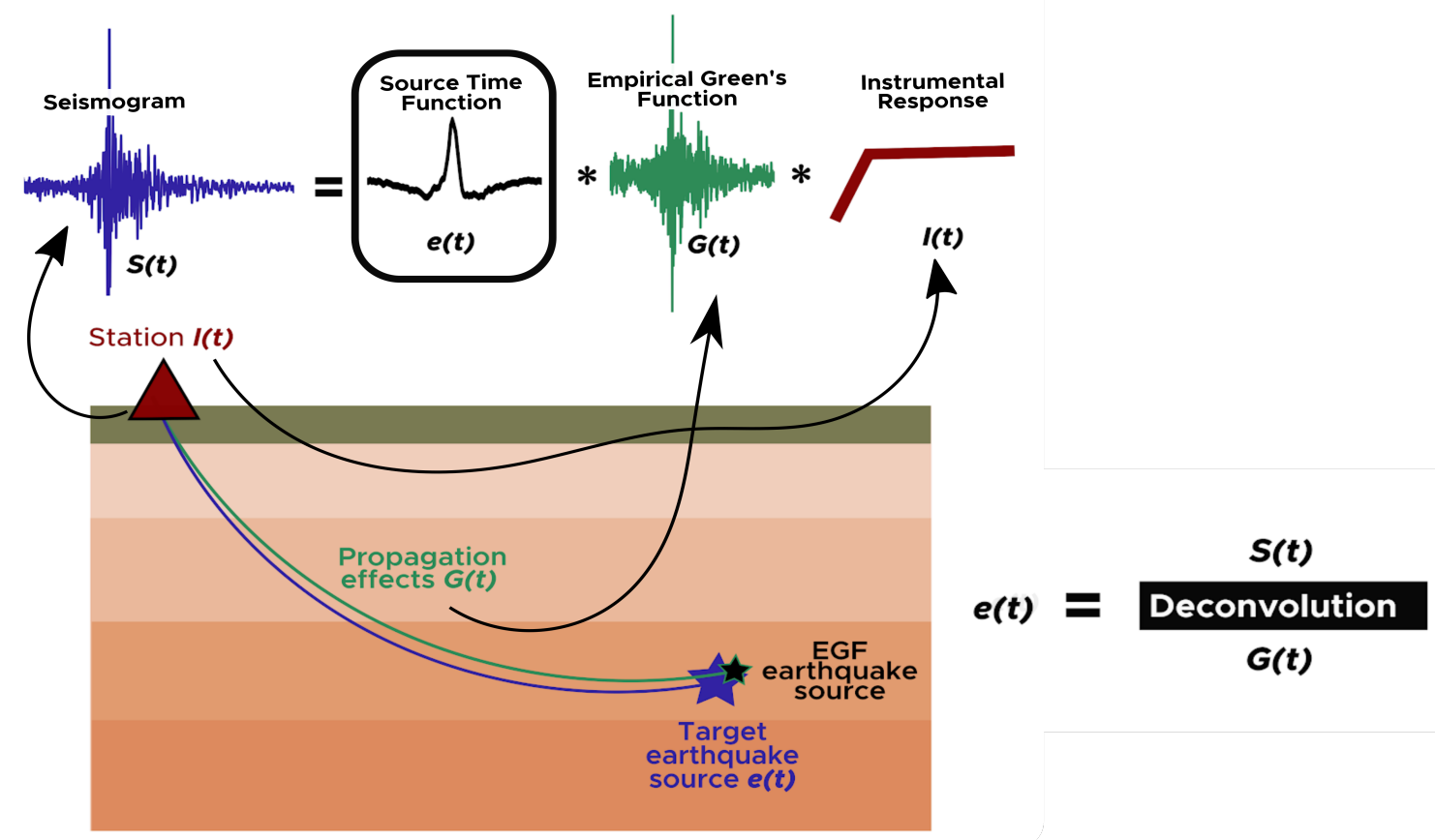

Figure 3.3: Schematic of the EGF method. If both earthquakes, a Target, bigger magnitude earthquake and an EGF, smaller magnitude earthquake, have similar hypocenter locations and are recorded by the same station, the recorded seismogram of the EGF earthquake can represent the propagation effects $(G(t))$ for the Target earthquake. The instrumental response cancels out, as both events are recorded by the same station. To calculate the Source Time Function $(e(t))$ of the Target event a deconvolution between the recorded seismogram of the Target event $(S(t))$ and the recorded seismogram of the EGF event $(G(t))$ is performed.

The EGF analysis method we employ is based on that described by Abercrombie et al. (2017a), Abercrombie (2014), Abercrombie (2015) and Viegas et al. (2010) and is implemented in a sequence of codes written in MATLAB (2019) by R. Abercrombie (pers. comm.). Additional pre-processing steps to extract waveforms and convert pick information from QuakeML to SAC formats are undertaken using Python and the Obspy package (Beyreuther et al., 2010). Each step of the methodology is summarised in Figure 3.4. A more detailed description of each step and the corresponding script names is presented in Appendix C. The process starts by selecting potential EGF events for each Target event and then choosing a time window for the seismograms. We extract the waveforms for all Target and EGF events from continuous data and calculate the cross-correlation between the EGF and Target event seismograms to identify the best EGF events for spectral analysis. Next, we calculate the corner frequencies using both P- and S- waves on all three components, before computing stress drop estimates. This workflow is outlined in more detail the following Sections 3.2-3.6. 


\section{Empirical Green's Function Methodology}

STEPS

1. Identify potential EGF events

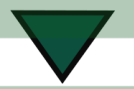

2. Time window selection for waveforms

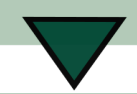

3. Cross-correlation between Target and EGF waveforms

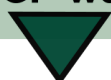

\section{Deconvolution}

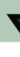

\section{Calculate Spectra and Spectral ratio}

\section{Corner Frequency calculation}

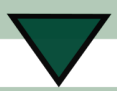

\section{Stress Drop calculation}

\section{CHAPTER 3 \\ SECTIONS}

\section{Section 3.2}

Section $\mathbf{3 . 3}$

Section 3.4

\section{Section 3.5}

\section{Section 3.6}

Figure 3.4: Schematic workflow of the EGF methodology. The section number where we describe each of the steps can be found in the right column.

\subsection{EGF Event Selection}

Using the Target event catalogue of 245 events constructed using methods and criteria outlined in Section 2.3, the first step is to identify EGF events for each Target earthquake. Three main criteria are considered for selecting EGF events (Kane et al., 2013):

1. The EGF event has to be sufficiently small to approximate a point-source to the Target event.

2. The EGF event must be close enough to the Target event that the propagation 
paths between the two events and a given station is very similar.

3. The EGF event must have the same focal mechanism as the Target event such that the two events have similar radiation patterns.

In many cases, it is not practical to impose all of these criteria (for example where focal mechanisms are not available for very small magnitude events) and a degree of flexibility is employed. For this work, we identify potential EGF events based on epicentral distance, depth difference and magnitude relative to the Target event and use two criteria based on other studies (Abercrombie et al., 2017a; Ruhl et al., 2017; Hatch et al., 2018):

1. Sufficiently close: epicentral distance of $<3 \mathrm{~km}$ and absolute depth difference of $<5 \mathrm{~km}$.

2. Sufficiently small: $3 \geq M_{\text {Target event }}-M_{\mathrm{EGF}} \geq 1$.

Given the earthquake-station path lengths of $>200 \mathrm{~km}$ in some cases, these small variations in hypocentral location translate to very small differences in path between the Target and EGF events. Furthermore, this degree of flexibility encompasses location uncertainties in event hypocenters, meaning earthquakes which are truly co-located, but are catalogued with different depths, for example owing to location uncertainties, are considered. Using these criteria we identify an average of 100 EGF events for each Target event, with a minimum of 2 EGF events and a maximum of 338 EGF events (see Appendix D). At this analysis stage, it is preferable to include as many EGF events as possible; any events which do not represent good point source estimates will be removed at later cross-correlation thresholding stages.

\subsection{Seismogram Time Window Selection and Cross- correlation}

For each Target event and corresponding EGFs' waveforms, we use an empirical magnitudedependent expression from Abercrombie et al. (2017a) to calculate a time window for both P- and S-waves:

$$
t_{\text {window }}=\operatorname{round}\left(10 \times \text { Magnitude }^{3} / 15\right) / 10
$$


where Magnitude is the moment magnitude $\left(M_{w}\right)$ of the Target event. Larger events typically have longer source durations, and hence require a longer window to capture the source time function. If the window length is smaller than $1.28 \mathrm{~s}$, then it is set to $1.28 \mathrm{~s}$, and if the window length is greater than $5 \mathrm{~s}$, then it is set to $5 \mathrm{~s}$. This maximum window length is in excess of the minimum anticipated rupture duration for even our largest events. If the $\mathrm{S}-\mathrm{P}$ time is smaller than the $t_{\text {window }}$, that $\mathrm{P}$-wave is not used further in the analysis.

In order to achieve high cross-correlation between the two earthquakes (Hatch et al., 2018), we apply a low-pass filter (Equation 3.3) to both the Target and EGF events at a frequency just below the expected corner frequency of the Target event. We also use a default high-pass filter corner $\left(f_{\text {highpass }}\right)$ of $1 \mathrm{~Hz}$ to remove the strong microseism noise prevalent on broadband stations in New Zealand, particularly in coastal locations.

$$
f_{\text {lowpass }}=\left(10 / t_{\text {window }}+f_{\text {highpass }}\right)
$$

We then calculate the cross-correlation coefficient between the unfiltered and filtered time-windowed P- and S-waveforms for the Target and EGF events and only preserve the filtered Target-EGF waveform pairs with cross-correlation coefficients of $\geq 0.7$. The time is shifted for the correlation to account for uncertainties and inconsistencies in picking arrivals (especially when emergent) and improve the correlations accounting for small differences in location (see Figure 3.5). Abercrombie (2015) found that using an EGF with a low cross-correlation can bias the source parameter results markedly. To illustrate this filtering and cross-correlation stage, four representative Target events of different magnitudes are presented in Figure 3.5. Overall, the four examples are well cross-correlated; the magnitude-dependent time window and low-pass filter appear to work for a range of different magnitudes and for the other Target events considered.

\subsection{Spectra and Spectral Ratio Calculation}

For each Target-EGF seismogram pair, we calculate the frequency spectra of the unfiltered seismograms for both $\mathrm{P}$ - and S-waves and then the spectral ratios using the multitaper method of Prieto et al. (2009). The spectra of pre-arrival noise is also calculated for $\mathrm{P}$ - and S-waves using the same $t_{\text {window }}$ length for each Target event and used to determine the signal-to-noise ratio. The noise signal for the S-waves includes the $\mathrm{P}$-waves coda in order to ensure there is no contamination of the $\mathrm{S}$ spectra with P-waves energy at higher frequencies (Abercrombie et al., 2017a). In Figure 3.6, signal 

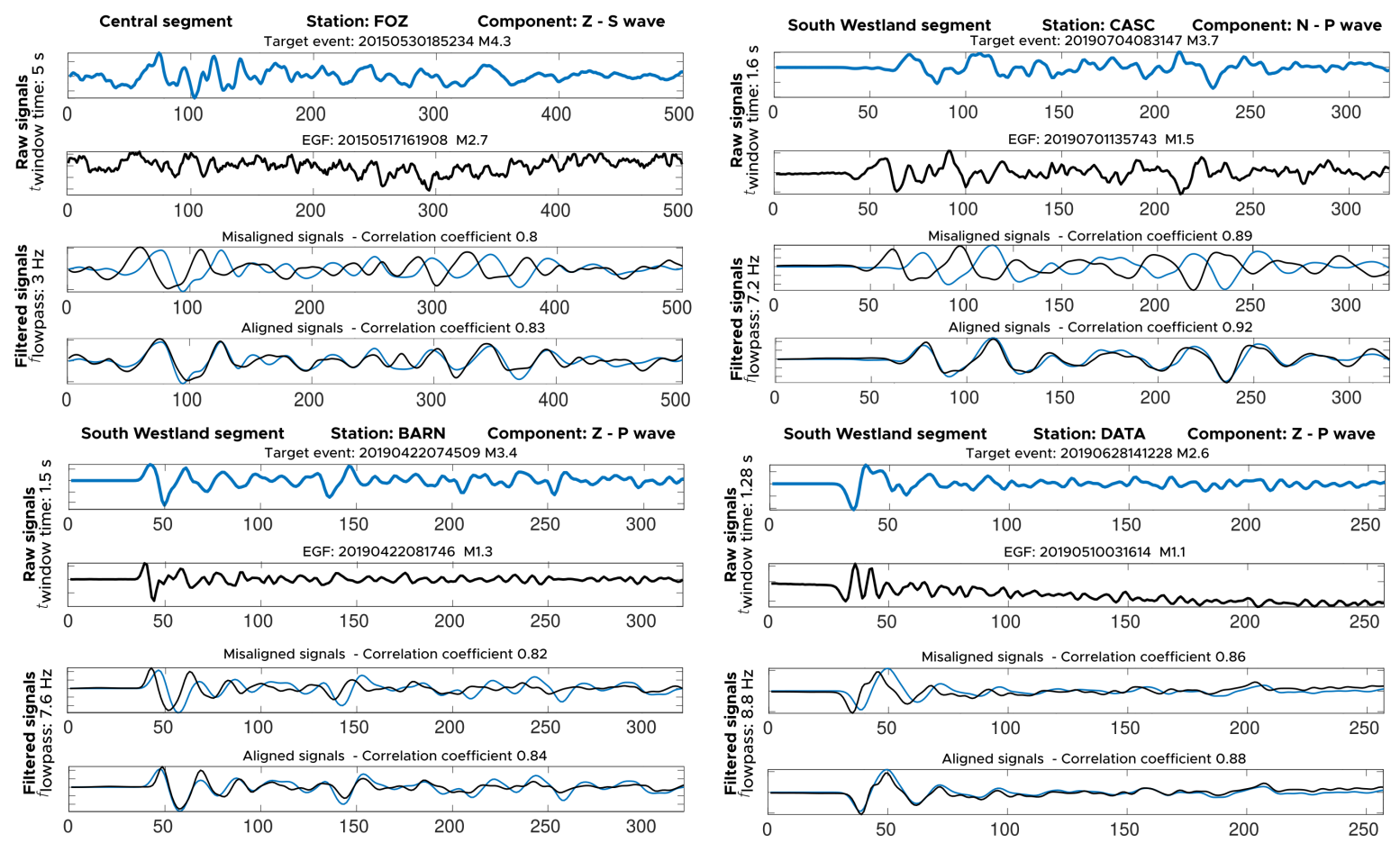

Figure 3.5: Target-EGF waveform pairs for four earthquakes. Figure shows four panels each with a different Target event. For each event, the unfiltered Target and EGF events waveforms, the filtered Target-EGF waveform pair without the time correction and the Target-EGF waveform pair with the time shifted are shown. On the left of each panel, the time window $\left(t_{\text {window }}\right)$ and low-pass filter ( $\left.f_{\text {lowpass }}\right)$ are shown. The high-pass filter is $1 \mathbf{~ H z}$ in all cases.

and noise spectra are presented for four well-recorded earthquakes of different magnitudes. Yellow and pink lines show the part of the spectra for Target and EGF event, respectively, that includes 3 (for P-waves) and 2.5 (for S-waves) times the corresponding noise spectrum. That is the only part of the spectra that is used for the calculation of the spectral ratios using the multitaper method (Prieto et al., 2009).

The multitaper approach produces the most reliable amplitude spectra by direct division in the frequency domain. It also includes complex division enabling the extraction of the relative STF (Figure 3.7) of the Target event from each ratio. Observing a clear STF pulse in both phase and amplitude confirms that the EGF assumptions are valid. Visual inspection of the STF also assists in identifying complex sources that are not well fit by the simple source models (Ruhl et al., 2017).

This multitaper spectral estimation is considered the most reliable, although Prieto et al. (2007) estimate that uncertainties in calculating the spectrum can lead to $50 \%$ uncertainty in stress drop calculation. 

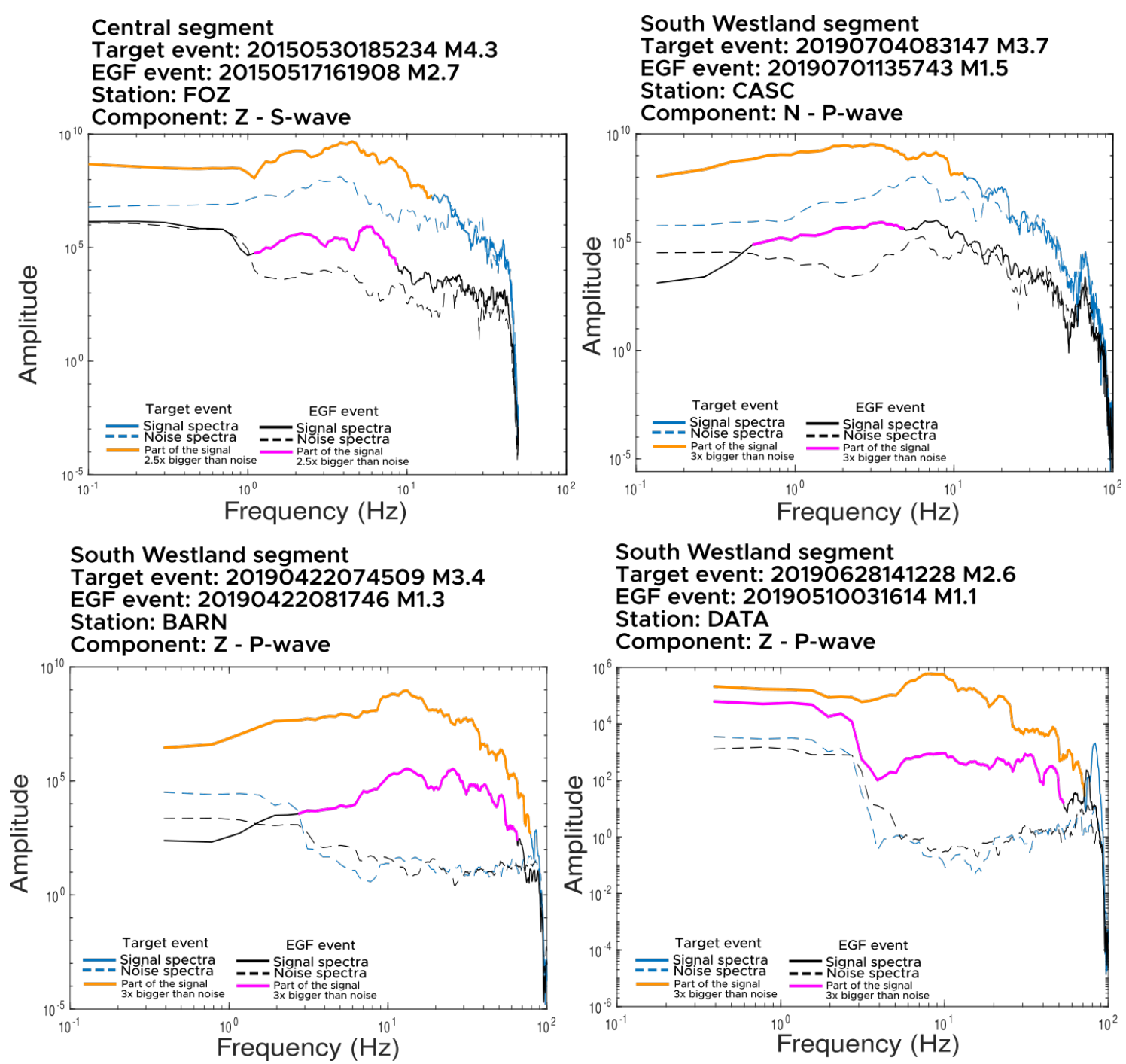

South Westland segment

Target event: 20190628141228 M2.6

EGF event: 20190510031614 M1.1

Station: DATA

Component: Z - P-wave

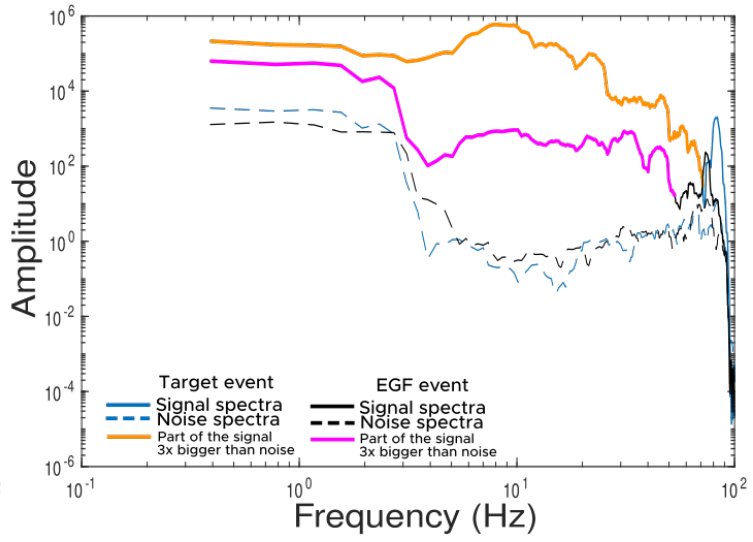

Figure 3.6: Signal and noise spectra for four well-recorded Target events. Each panel presents the signal and noise spectra for both Target and EGF event. Solid lines represent the signal spectra (blue for the Target event and black for the EGF event) and dashed lines the noise spectra (blue for the Target event and black for the EGF event). The yellow and pink thick solid lines overlaping the blue and black solid lines show the part of the signal spectra that is 3 (for $\mathrm{P}$-waves) and 2.5 (for $\mathrm{S}$-waves) times bigger than the noise spectra.

\subsection{Corner Frequency Calculation}

Once we estimate the individual spectral ratios, we use two methods to calculate the corner frequency: (1) fitting of individual ratios (Section 3.5.1) and (2) fitting of stacked ratios (Section 3.5.2). The first method fits each individual Target-EGF pair's spectral ratios for corner frequency and then calculates the average for each Target event using a weighted mean approach. The second method stacks all spectral ratios available for a particular Target event and fits the averaged spectral ratio for corner frequency (Ruhl 

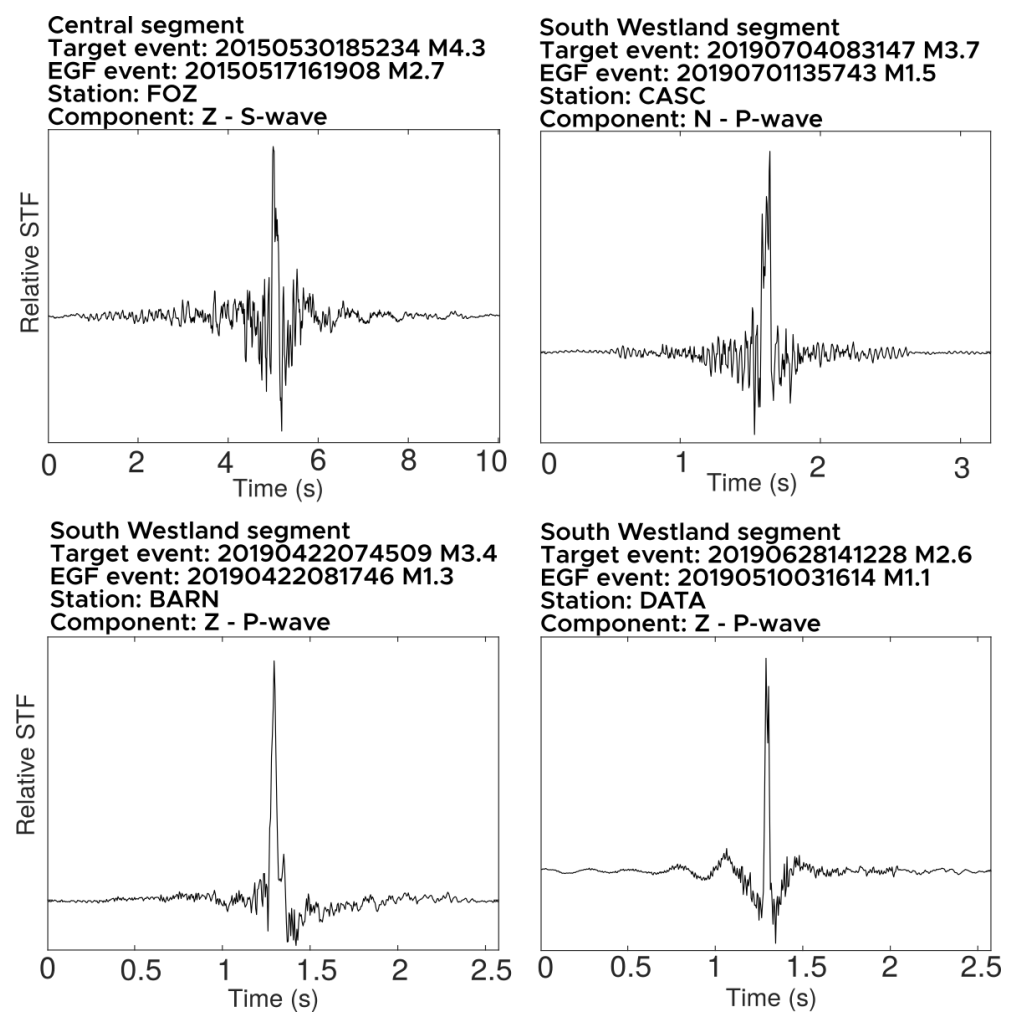

Figure 3.7: Single station Source Time Functions of four Target events of different magnitudes. The STFs observed in this figure present different duration and some complexity. In this thesis, the STFs are used to check if the EGF approach is working well and no measurements are made on them.

et al., 2017; Abercrombie et al., 2017a). In both cases we used the Brune (1970) and Boatwright (1980) spectral source models (models defined by a circular fault model) to fit the spectral ratios. Both models have the form:

$$
\frac{\dot{M}_{1}(f)}{\dot{M}_{2}(f)}=\frac{M_{01}}{M_{02}}\left(\frac{1+\left(f / f_{c 1}\right)^{\gamma n}}{1+\left(f / f_{c 2}\right)^{\gamma n}}\right)^{\frac{1}{\gamma}}
$$

where $\dot{M}_{1}(f)$ and $\dot{M}_{2}(f)$ are the amplitude spectra, $M_{01}$ and $M_{02}$ are the seismic moment of the larger (Target) and small (EGF) earthquakes, respectively; $f$ is the frequency and $f_{c 1}$ and $f_{c 2}$ are the corner frequencies of the larger (Target) and small (EGF) earthquakes, respectively. $n$ is the high-frequency fall off (we assume $n=2$ ) and $\gamma$ is a constant controlling the shape of the corner. We try both the Brune (1970) model $(\gamma=1)$ for a broader corner and the Boatwright (1980) model $(\gamma=2)$ for a sharper corner. 


\subsubsection{Fitting Individual Spectral Ratios for Corner Frequency}

We follow the approach of Abercrombie (2015) and Abercrombie et al. (2017a) and fit each individual Target-EGF spectral ratio pair using the Nelder-Meade inversion in MATLAB (2019) with Equation 3.4 to calculate corner frequencies using both Brune (1970) and Boatwright (1980) spectral source models on a station-by-station, component-by-component basis. Finally the average for each Target event is calculated using a weighted-mean approach.

We then perform a grid search around the resulting value of $f_{c 1}$ following Viegas et al. (2010) and Abercrombie et al. (2017a) and define a parabola with which the $f_{c 1}$ value is a clear minimum. According to Viegas et al. (2010), Abercrombie et al. (2017b) and Ruhl et al. (2017) a low variance $(\leq 0.005)$ at the minimum parabola value is required. Thus, we use frequencies at which the variance exceeds $5 \%$ of the minimum variance as an estimate of the individual corner frequency uncertainty bounds $f_{\text {clerr } 1}$ and $f_{c 1 e r r 2}$. The $f_{c}$ error is calculated as the frequency normalised ratio $\left(f_{c 1 e r r o r}-\right.$ $\left.f_{\text {clerror } 1}\right) / f_{c 1}$ which reflects the range of frequencies within $5 \%$ of the minimum variance. The estimations of $f_{c 2}$ (the corner frequency of the EGF event) are not used in this thesis.

Next we use the individual corner frequency measurements to calculate the weightedmean $(\hat{y})$ and standard deviation $(D)$ for each Target event using inverse-variance weighting which downweights values with larger uncertainties (e.g. Hartung et al., 2008):

$$
\begin{gathered}
\hat{y}=\frac{\sum_{i}\left(y_{i} / \sigma_{i}^{2}\right)}{\sum_{i}\left(1 / \sigma_{i}^{2}\right)} \\
D^{2}(\hat{y})=\frac{1}{\sum_{i}\left(1 / \sigma_{i}^{2}\right)}
\end{gathered}
$$

where $y_{i}$ is the $i$ th measurement and $\sigma_{i}$ is its variance. We calculate the weighted and weighted mean of the corner frequency for each event using all available stations, components and EGFs. 


\subsubsection{Fitting Stacked Spectral Ratios for Corner Frequency}

According to Abercrombie et al. (2017a), stacking large numbers of seismograms or spectra is an efficient way of increasing the signal and cancelling out azimuthal variation and variability arising from noise. Kane et al. (2013) and Abercrombie (2015) showed that stacking poorer-quality data and ratios computed with less appropriate EGFs can, however, increase the uncertainty and bias the result. For this reason we only include ratios in a stack when they cross-correlate above each threshold from 0.7 to 0.9 every 0.5 units and if they meet the signal-to-noise criteria.

We follow Abercrombie et al. (2017a) and normalize each spectral ratio before stacking using its average long-period amplitude below the expected corner frequency for the larger (Target) event. Each frequency band is required to have at least five ratios to compute the stack. We then stack the spectral ratios per station to investigate azimuthal variation and then fit the stacked ratios using the same approach as for the individual spectral ratios (Figure 3.8). STFs are also stacked by station (Figure 3.8). As mentioned in Section 3.4, STFs are used only to check which the EGF approach is working well and for source complexities; no other measurements were made on them here, although they may from the basis for future directivity analysis describe in Chapter 5.4.

\subsection{Calculation of Stress Drop}

According to Brune (1970) and Boatwright (1980) the relationship between the slip in an earthquake, its fault dimensions and its seismic moment represents the magnitude of the stress released by the earthquake or stress drop $(\Delta \sigma)$. Seismic waves can thus be used to estimate the stress change on a fault. The stress drop is proportional to the seismic moment ( $M_{o}$, explained later in this Section) and inversely proportional to the fault dimension $(L)$ (Equation 3.7), although it should be noted that since seismic moment is also dependent on fault dimension (Equation 3.11), stress drop is nearer constant. In earthquake source parameters studies it is common to assume a circular fault model with radius $r$, in which case Equation 3.7 can be rewritten as 3.8:

$$
\begin{aligned}
& \Delta \sigma=\frac{c M_{o}}{L^{3}} \\
& \Delta \sigma=\frac{c M_{o}}{r^{3}}
\end{aligned}
$$



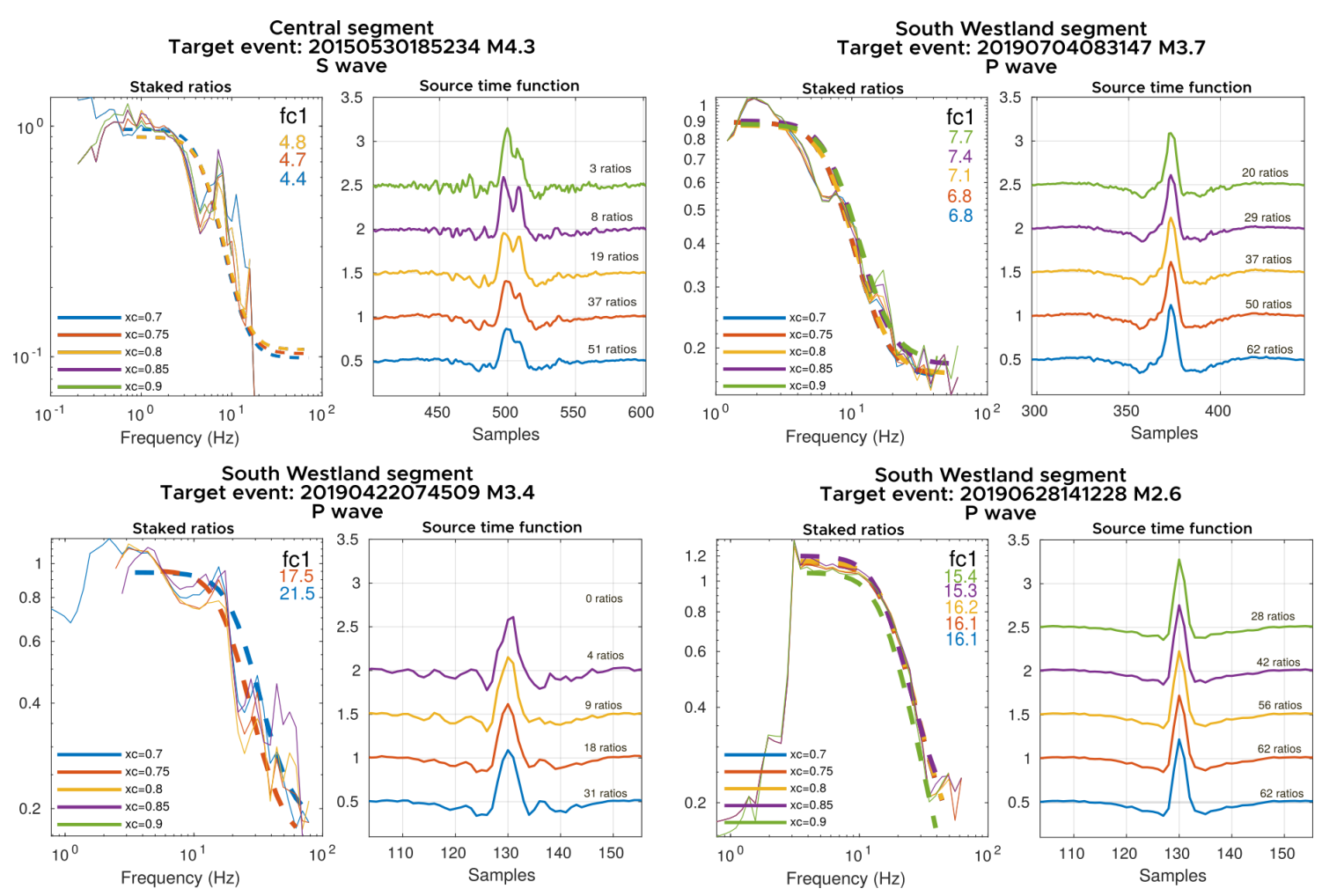

Figure 3.8: Stacked spectral ratios and source time functions for four wellrecorded Target events. There are four panels, one for each Target event. Each panel presents two figures. The first shows, the stacked spectral ratios (solid lines) with its fit (dashed lines; using the Boatwright (1980) model, in Chapter 4.3) we will explain why we choose the Boatwright (1980) source model over the Brune (1970) one), coloured by cross-correlation (xc), on the top right the corner frequency per cross-correlation is shown. The second figure shows the stacked STF also coloured by cross-correlation. On the left of each STF the number of ratios stacked is shown. The 20150530185234 Target event presents a complex STF, and several steps in the spectral ratios.

where $c$ depends on the fault shape and the rupture direction, normally $7 / 16$ is used. The fault radius $(r)$ is determined by the circular source model. In this study we follow Madariaga (1976):

$$
r=\frac{k \beta}{f_{c}}
$$

where $k$ is a constant determined by the source model, $\beta$ is the S-wave velocity and $f_{c}$ the corner frequency. We combine Equation 3.9 with Equation 3.8 to obtain a relationship (Equation 3.10) between corner frequency $\left(f_{c}\right)$ and stress drop $(\Delta \sigma)$ :

$$
\Delta \sigma=\frac{7}{16} \frac{M_{o} f_{c}^{3}}{k^{3} \beta^{3}}
$$


Table 3.1: $\beta$ values for the Alpine Fault segment. Depth values were chosen based on the observed seismicity distribution of the Target events catalogue.

\begin{tabular}{|l|c|c|}
\hline & $\beta(\mathrm{km} / \mathrm{s})$ & Depth $(\mathrm{km})$ \\
\hline \hline North Westland segment & 3.58 & 15 \\
Central segment & 3.48 & 15 \\
South Westland segment & 3.88 & 10 \\
\hline
\end{tabular}

We use appropriate values for $\beta$ from the New Zealand 3-D velocity model (EberhartPhillips et al., 2020) (Table 3.1).

The Madariaga (1976) source model used $k=0.32$ for P-waves and $k=0.21$ for S-waves and found a $f_{c} P / f_{c} S$ ratio of 1.52. Kaneko and Shearer (2015) performed dynamic modelling of simple sources and obtained $k$ values of $k=0.32$ for P-waves (same as Madariaga, 1976) and $k=0.26$ (higher than Madariaga, 1976) for S-waves using a circular model with a rupture velocity of $0.7 \beta$. For that geometry and rupture velocity, Kaneko and Shearer (2015) obtained a $f_{c P} / f_{c S}$ ratio of 1 . Abercrombie et al. (2017a) obtained a $f_{c P} / f_{C S}$ ratio of 1.23 for four earthquakes sequences in New Zealand and used the Kaneko and Shearer (2015) $k$ values. Kaneko and Shearer (2015) estimate that uncertainties arising from $k$ values can produce variations in stress drop of up to a factor of 10. For that reason, based on our $f_{c P} / f_{c S}$ results (see Figure 4.10) we opt to use the Kaneko and Shearer $(2015)$ model $\left(k_{P}=0.32 k_{S}=0.26\right)$ which is consistent with the $f_{c P} / f_{c S}$ ratio of 1.1 that we obtain for our corner frequency calculations (see Figure 4.10).

Equation 3.10 contains two main terms to be further determined in this thesis: the corner frequency $\left(f_{c}\right)$ (calculated following the methodology established in Chapter 3 and results shown in Chapter 4.3) and the scalar seismic moment $\left(M_{o}\right)$.

The seismic moment $\left(M_{o}\right)$ is a measure of the size of an earthquake based on the area of fault rupture, the average amount of slip and the rigidity $(\mu)$ of the material (Aki and Richards, 2002).

$$
M_{o}=\text { fault area } \times \text { average slip } \times \mu
$$

Directly calculating seismic moment is outside the scope of this thesis, so we use the $M_{o}-M_{w}$ relationship from Hanks and Kanamori (1979) (Equation 3.12) to obtain seismic moment $\left(M_{o}\right)$ from moment magnitude $\left(M_{w}\right)$. Kanamori (1977) introduced the concept of a moment magnitude $\left(M_{w}\right)$ based on the seismic moment $\left(M_{o}\right)$.

$$
\log M_{o}=1.5 M_{w}+9
$$


We obtain estimates of $M_{w}$ from $M_{L}$ recorded by the local networks, this conversion is discussed in more detail in Chapter 4.2

We assume that this relation applies across the range of magnitudes considered in this study, although in reality a different scaling may apply to both moderate and small $(M<2-3)$ earthquakes (Hanks and Kanamori, 1979; Hanks and Boore, 1984; Deichmann, 2017). This simplification, and the effect on our calculated stress drops, are discussed further in Chapter 5. 


\section{Chapter 4}

\section{Results}

In this chapter the results of the corner frequency (Section 4.3) and stress drop (Section 4.4) analysis are presented. We also describe the procedure use to obtain the most accurate $M_{L}-M_{w}$ conversion in order to calculate seismic moment Section (4.2), and thus stress drop.

\subsection{EGF Analysis Results}

Following selection of the moderate-magnitude Target events near and on the fault, as outlined in the previous chapter, 245 earthquakes remained. During the spectral ratio analysis, further events are rejected at each stage based on quality criteria discussed below. Table D.1 in Appendix D lists details of the initial 245 Target events, including the latitude, longitude, depth, magnitudes, number of EGFs, number of ratios, seismic moment, corner frequency and stress drop values. Some of the Target events and Target-EGF waveform pairs are later rejected for the following reasons (these are further explained in Section 4.3):

1. Fewer than five associated EGFs for a Target event.

2. Cross-correlation values lower than 0.7 between Target-EGF waveforms pairs.

3. Signal spectrum of the Target-EGF waveform pair $\leq 3$ over the noise spectrum for P-waves and $\leq 2.5$ for $\mathrm{S}$-waves.

4. Fewer than five ratios for each station and fewer than five stations for each Target event. 
5. Ratio between the higher and lower frequency amplitude of the spectral ratios lower than two.

Following this initial quality control, we estimate stress drop values along the three main segments of the Alpine Fault for 94 and 95 Target events for P-and S-waves, respectively (Table 4.1 ).

Table 4.1: Number of Target events for the Alpine Fault segments for Pand S-waves.

\begin{tabular}{||l|c|c|c||}
\hline & North Westland & Central & South Westland \\
\hline \hline P-waves & 25 & 43 & 26 \\
S-waves & 25 & 44 & 26 \\
\hline
\end{tabular}

The local magnitude distributions of the Target events are shown in Figures 4.1 and 4.2. Figure 4.1 shows that for Northern and Southern DWARFS, most of the events are between magnitudes $M_{L} 2.0-M_{L} 2.6$. This confirms the decision made in Chapter 2.3 to lower the magnitude from $M_{L} 2.5$ to $M_{L} 2.0$ for earthquakes occurring on the North Westland and South Westland segments was justified. The catalogue of Michailos et al. (2019) for the Central segment (Figure 4.2) has most of the Target events between $M_{L} 2.5-M_{L} 3.0$, although local magnitudes $\left(M_{L}\right)$ between the DWARFS catalogue and that of Michailos et al. (2019) are not directly comparable (see Section 4.2).

For this thesis we only use ratios where the cross-correlation between Target-EGF waveform pairs was at least 0.7 . All the results were calculated using threshold spectral ratio cross-correlation values of: $0.70,0.75,0.80,0.85$ and 0.90 . Figure 4.3 shows the number of ratios that meet each cross-correlation threshold. The abundance of ratios for S-waves over P-waves is evident, which is also observed by Ruhl et al. (2017) and Abercrombie et al. (2017a). Figure 4.3 is useful to decide between cross-correlation values based on the quantity of available ratios. Abercrombie (2015) suggested that a good EGF must be very highly correlated $(\geq 0.90)$ with the Target event; stress drop values decrease as cross-correlation decreases. However, using only measurements with high cross-correlation values $(\geq 0.90)$ reduces the number of ratios and the results may become unstable. Therefore a compromise must be considered.

Ruhl et al. (2017) demonstrated that for data from the 2008 Nevada swarm, the corner frequencies are stable between cross-correlation limits of 0.70 and 0.85 . Abercrombie et al. (2017a) chose to work with cross-correlation $\geq 0.80$ for four sequences of earthquakes in New Zealand. Therefore, based on the number of ratios available to produce 

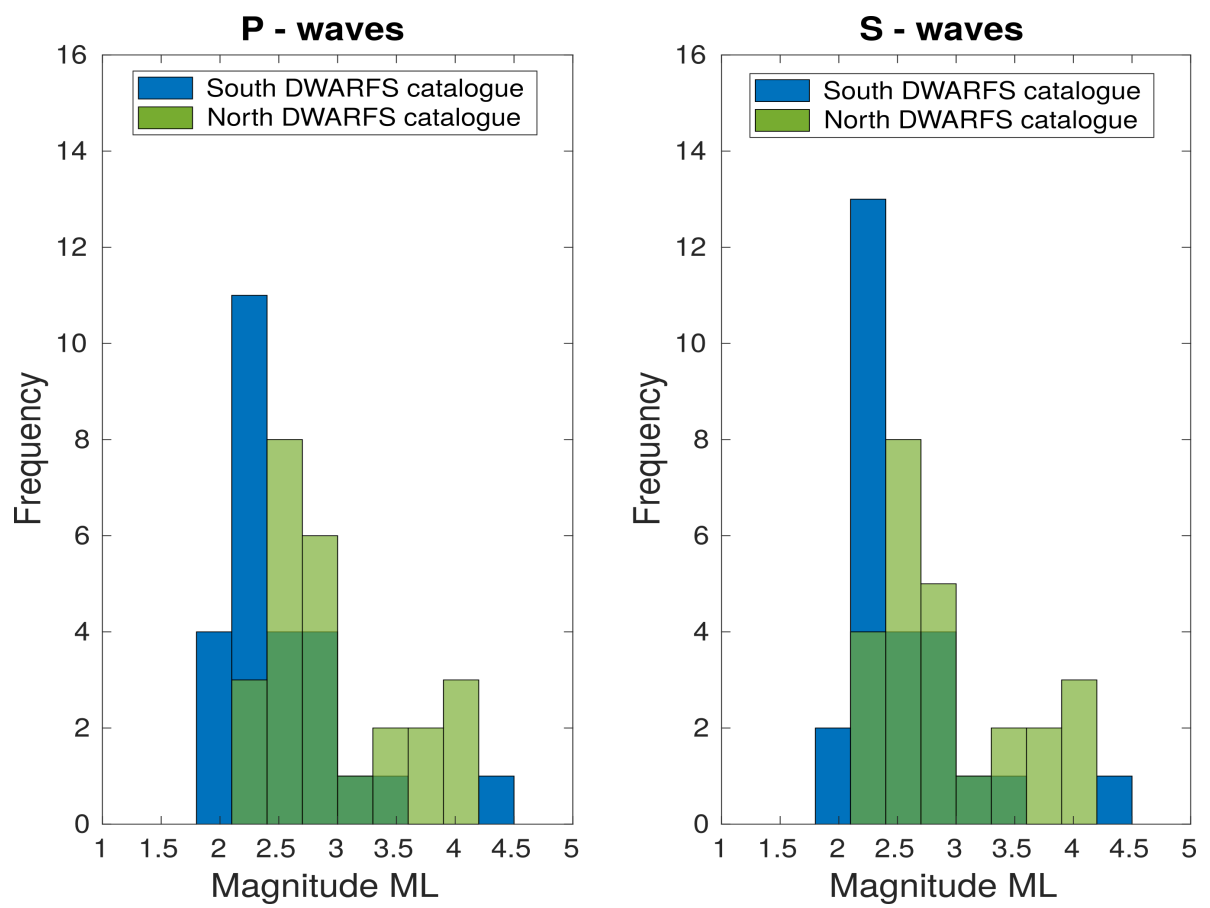

Figure 4.1: Magnitude histograms for $\mathrm{P}$ - and S-waves of final Target events from Northern and Southern DWARFS. In green, Northern DWARFS Target events. There are 25 events for $\mathrm{P}$ - and S-waves. Magnitude ranges pf $\mathrm{P}$ - and S-waves for most of the events in this segment are between 2.2-2.6. For Southern DWARFS events, in blue, the range of magnitudes of $\mathrm{P}$ - and S-waves for most of the Target events are between 2.0-2.5. There are 26 events for P- and S-waves along this segment.

stable results (Figure 4.3), the subsequent analyses are made with cross-correlation value $\geq 0.80$.

\subsection{Seismic Moment}

As mentioned in Chapter 3, we estimate the moment magnitude $\left(M_{w}\right)$ of the events from the calculated local magnitude $\left(M_{L}\right)$ in the event catalogue, and then use the $M_{o}-M_{w}$ relationship from Hanks and Kanamori (1979) in Nm, to calculate seismic moment (Equation 4.1).

$$
\log M_{o}=1.5 M_{w}+9
$$

For the North and South Westland segments (catalogues made by Dr. Emily WarrenSmith), local magnitudes were calculated and calibrated against GeoNet $M_{L}$, whereas for the Central segment catalogue made by Michailos et al. (2019) local magnitudes were calculated and calibrated against moment magnitudes that were calculated using 

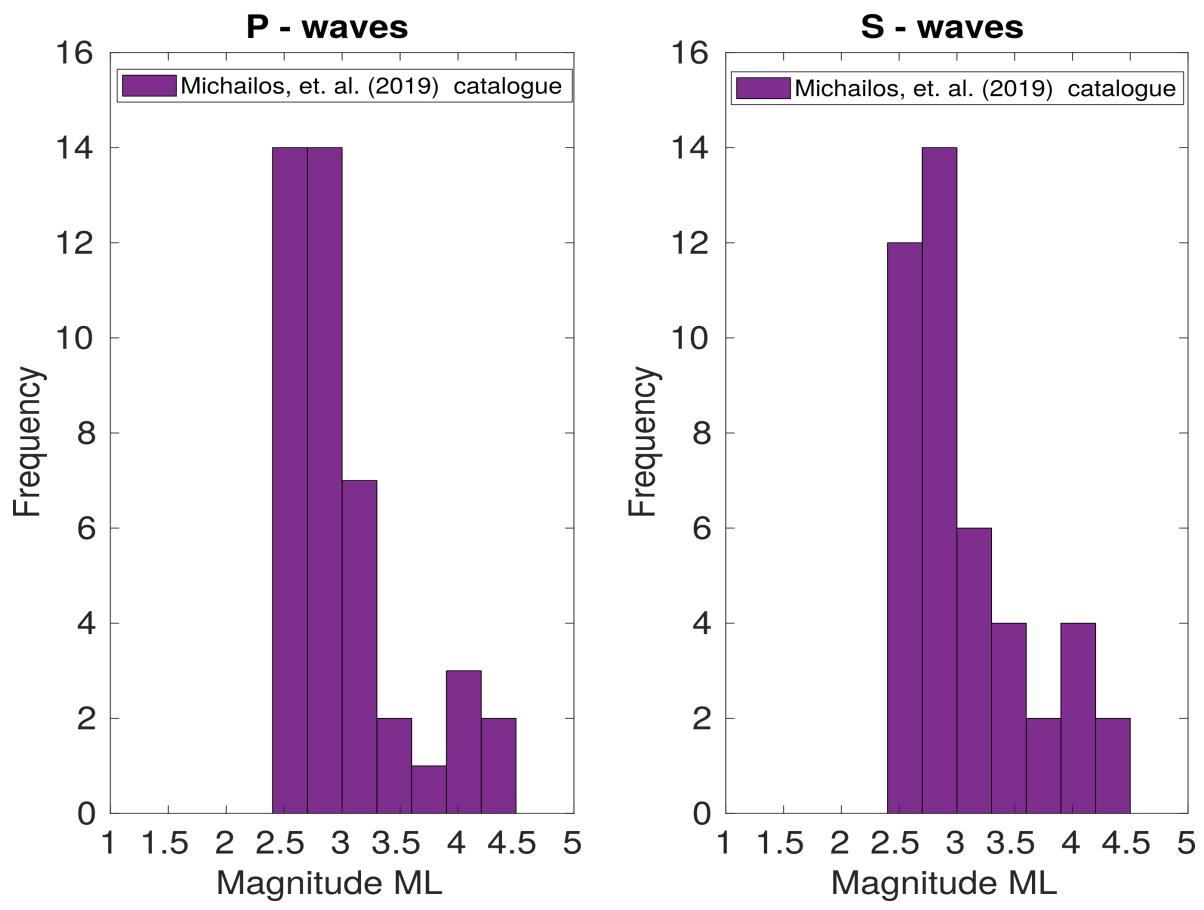

Figure 4.2: Magnitude histograms for $\mathrm{P}$ - and S-waves of final Target events from the Central segment. There are 43 events for the $P$-wave and 44 for the S-wave. For both P- and S-waves, most of the final events are between magnitudes 2.5-3.0.

methods described in Ristau (2013). Since local magnitudes $\left(M_{L}\right)$ for events along the Central segment of the Alpine Fault were calibrated against $M_{w}$, for this analysis the $M_{L}$ values of Michailos et al. (2019) will be considered as $M_{w}$ and no more magnitude analysis is required for this segment. However, in order to relate the local magnitude estimates for the North Westland and South Westland segments, we have to establish a reliable relationship between local and moment magnitudes. According to Ristau et al. (2016), the most common approach for relating $M_{L}$ to $M_{w}$ is by applying a correction to $M_{L}$, typically determined by a best-fit regression between $M_{L}$ and $M_{w}$ (e.g. Ristau, 2013; Braunmiller et al., 2002).

Ristau (2013) obtained a $M_{L}$ to $M_{w}$ relationship (Equation 4.2) for all New Zealand excluding the Fiordland region:

$$
M_{L}=0.93 M_{w}+0.54
$$

Since stress drops $(\Delta \sigma)$ are sensitive to $M_{o}$ (Equation 3.10), it is important to ensure we are using the most reliable $M_{o}$ estimation. Therefore, we examine whether using a homogeneous scale (Equation 4.2), derived for the whole country (other than Fiordland) might introduce bias into the stress drop $(\Delta \sigma)$ values we calculate. 


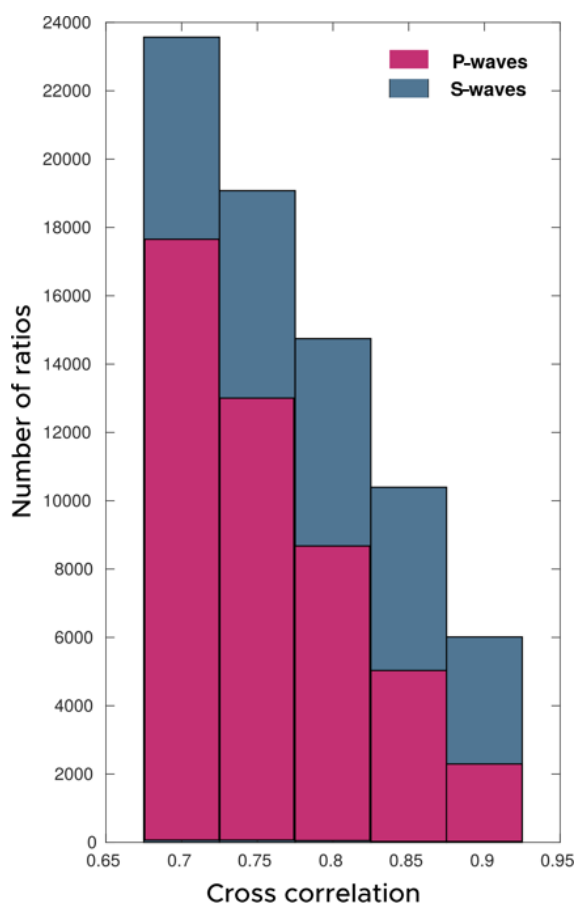

Figure 4.3: Histogram of number of ratios per cross-correlation value. Total ratios available for $\mathrm{P}$ - (pink) and S-waves (blue).

To do this, we use events reported by GeoNet located along the North and South Westland segments of the Alpine Fault that have moment tensor solutions (which represent the best estimate of magnitude for moderate earthquakes in New Zealand (Ristau, 2013)). We then determine the best-fit regression between GeoNet's local $M_{L}$ magnitude and the moment $M_{w}$ magnitude derived from moment tensor solutions to obtain a local $M_{L}$ to $M_{w}$ relationship (Figure 4.4). Since 2012, GeoNet has used the SeisComP system for its earthquake location and magnitude estimation, replacing the California Institute of Technology U.S. Geological Survey Seismic Processing (CUSP) system used previously (Rhoades et al., 2020). We therefore only consider events occurring after this change to maintain consistency in magnitude scales. In total, we calculate a regression for 101 and 81 events near the South Westland and North Westland segments, respectively (Figure 4.4).

The bottom-left panel in Figure 4.4 shows the regression fit for the North and South Westland segment together with the Ristau (2013) relationship. This way, we obtain two new $M_{L}-M_{w}$ relationships for the North (Equation 4.3) and South (Equation 4.3) Westland Alpine Fault segments:

$$
\begin{gathered}
M_{L \mathrm{NW}}=1.08 M_{w}-0.08 \\
M_{L \mathrm{SW}}=1.06 M_{w}+0.1
\end{gathered}
$$



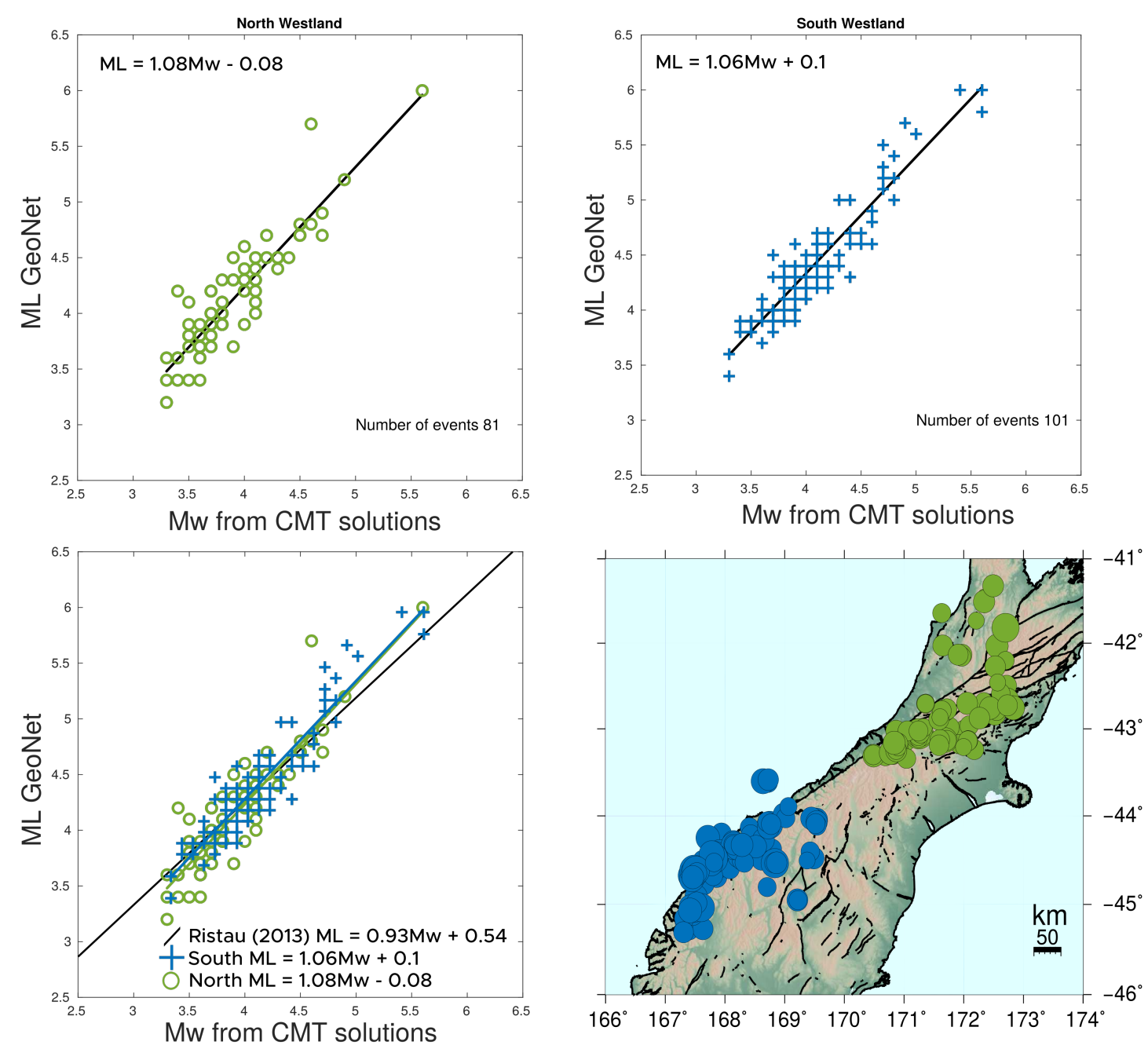

Figure 4.4: Best $M_{L}-M_{w}$ regression fit for North Westland and South Westland segments for GeoNet events since 2012. North and South Westland events in green and blue, respectively. Locations of events used in regressions are plotted on the map figure in the bottom right panel.

To investigate how different $M_{L}$ to $M_{w}$ relationships introduce bias into stress drop $(\Delta \sigma)$ values along strike, we selected events from the Target event catalogue that have local magnitude $\left(M_{L}\right)$ reported by GeoNet and calculate stress drop $(\Delta \sigma)$ with two different approaches:

1. Using GeoNet local magnitudes $\left(M_{L}\right)$ and the $M_{L}-M_{w}$ relationship (Equation 4.2) from Ristau (2013).

2. Using DWARFS local magnitudes $\left(M_{L}\right)$ and segment-specific $M_{L}-M_{w}$ relationships (Equations 4.3 and 4.4). For the Central segment, we directly use the magnitudes obtained by Michailos et al. (2019).

Using approach number one, we observe no significant differences in stress drop for 
either P- or S-waves along strike using GeoNet local magnitudes $\left(M_{L}\right)$ and the general Ristau (2013) $M_{L}-M_{w}$ relationship for New Zealand. However, there are differences observed along strike using approach number two; The North Westland segment has higher values of stress drop than the South Westland one (Figure 4.5).

In light of the analysis above, we choose to use the segment-specific $M_{L}-M_{w}$ relationship (Equations 4.3 and 4.4 ) calculated here to obtain moment magnitude $\left(M_{w}\right)$ from DWARFS local magnitude $\left(M_{L}\right)$, as it is a more accurate representation of along-strike heterogeneity in magnitude scaling. This observation highlights that care should be taken to consider accurate magnitude scaling relationships when considering spatial variations in earthquake stress drop. 

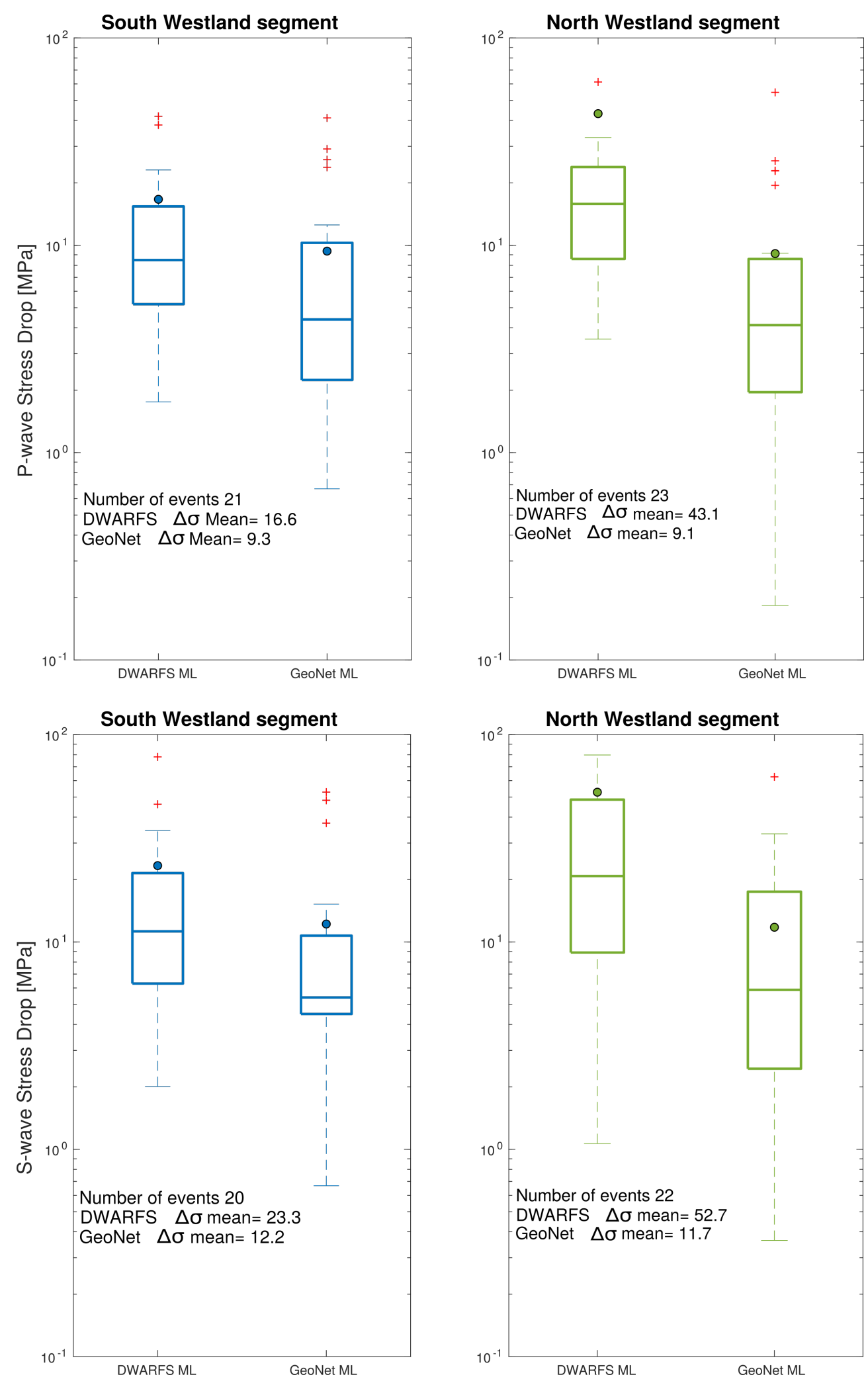

Figure 4.5: Box plots of test stress drop values for different local magnitude conversions. The box with the label "DWARFS ML" represents the stress drop calculated with approach two, while the box label "GeoNet ML" represents the stress drop calculated with approach one. Top two plots are stress drop values calculated from P-waves and bottom two with S-waves. South Westland segment in blue and North Westland segment in green. Coloured circles at each box represent the mean of the stress drop values. 

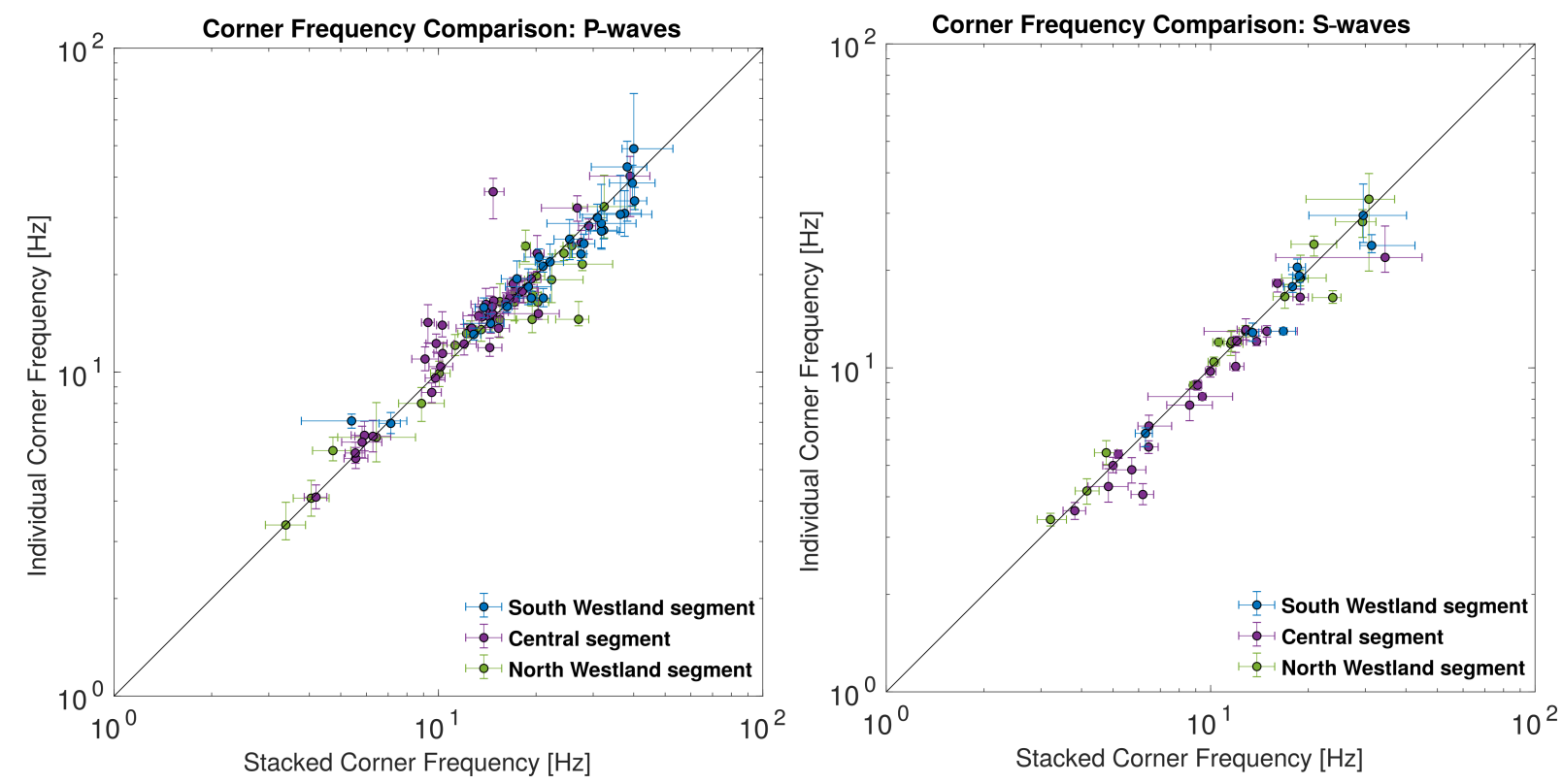

Figure 4.6: Comparison of corner frequency measurements made on both individual and stacked by station ratios for $\mathrm{P}$ - and $\mathrm{S}$-waves. These results were estimated using the Boatwright model. The Target events presented in this figure are those which pass the quality controls for both the individual and stacked approach.

\subsection{Corner Frequency}

In this section corner frequency results, using both individual and stacked ratios, are presented for cross-correlation values $\geq 0.8$. Results from using both individual and stacked ratios are not significantly different (Figure 4.6). However, the individual ratio fitting method shows more variation than the stacked approach for P-waves. The benefit of using an individual fitting is that results can be obtained for Target events with fewer than five ratios, but this leads to larger uncertainties and lower azimuthal coverage. Fitting of stacked ratios needs at least five ratios per station (Abercrombie, 2015) as this provides more reliable and stable results. For P-waves, the corner frequency results for both individual and stacked method are similar for the whole frequency range $(3-50 \mathrm{~Hz})$. For S-waves, the individual fitting method underestimates the corner frequency compared to the stacked fitting method (Figure 4.6). In view of the similar results obtained with the individual and stacking methods, we select the stacked approach over the individual one as the results shows that we have enough ratios to stack for each Target event, for both P- and S-waves.

Once the cross-correlation limit (0.80) and the preferred method of calculating (stacked ratios) corner frequencies are chosen, the next step is to compare any differences in results between the Brune (1970) and Boatwright (1980) source models. 
P-waves

Event ID $20160606021359 M_{L} 2.5$
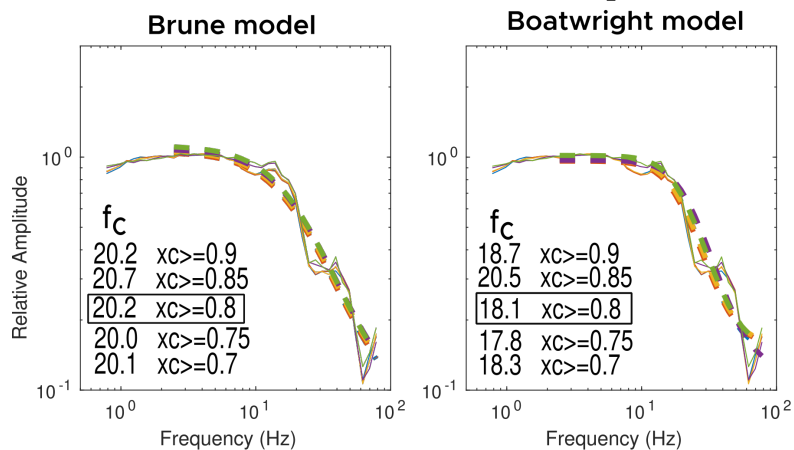

Event ID $20190511083623 M_{t} 2.8$
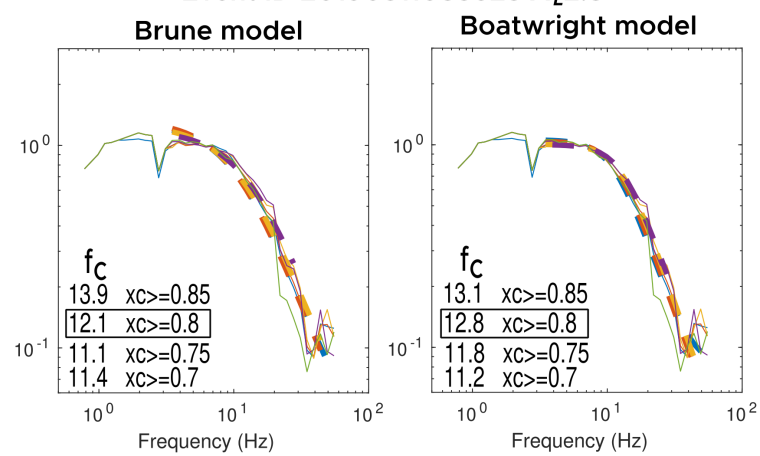

Event ID $20160830010056 M_{L} 4.0$
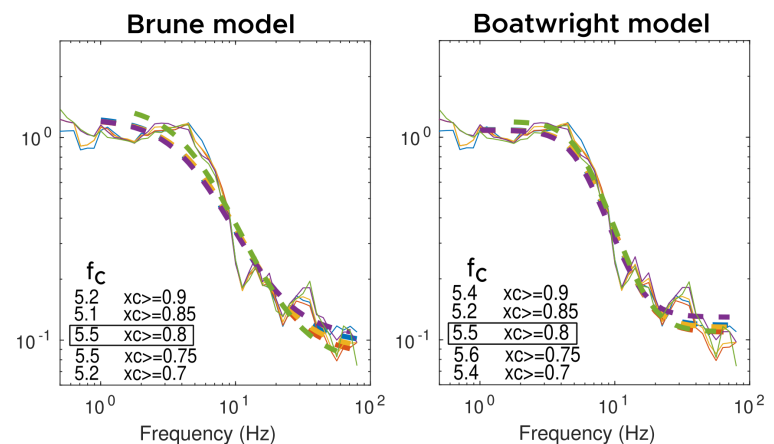

S-waves

Event ID $20190602184554 M_{L} 2.0$
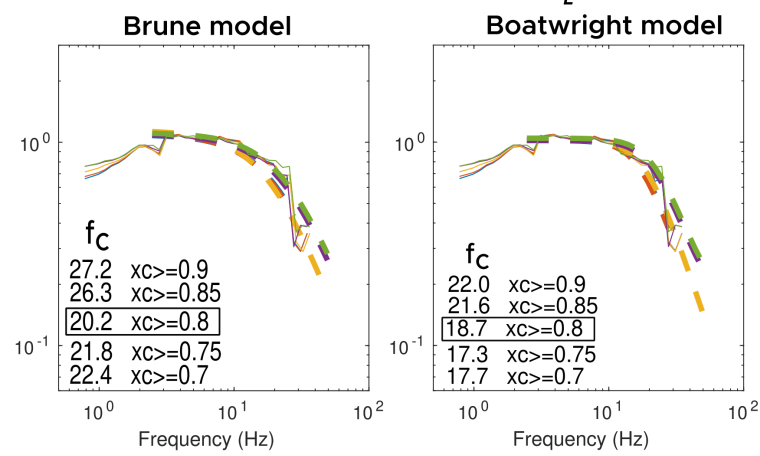

Event ID $20150612123501 M_{L} 3.0$
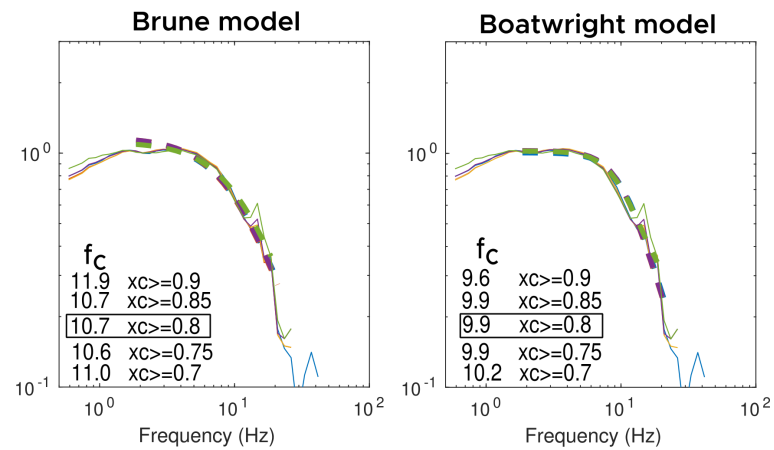

Event ID $20190925112909 M_{L} 3.4$
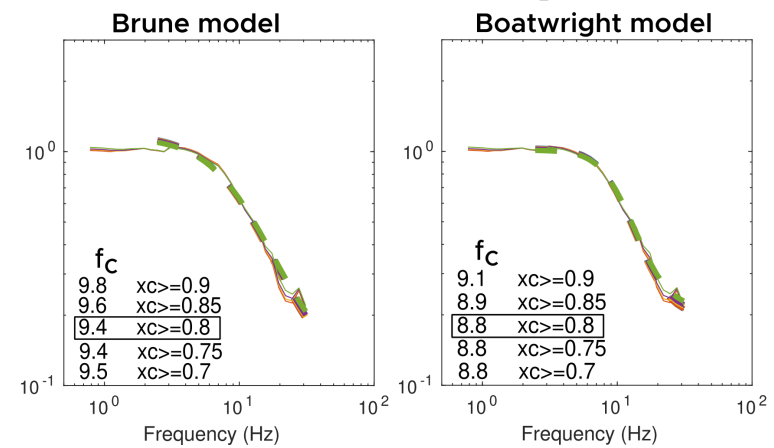

Figure 4.7: Stacked spectral ratios and fits obtained with the Brune (1970) and Boatwright (1980) source models for six well-recorded Target events. Stacks of (continuous lines) and fits to (dashed lines) ratios that have crosscorrelation $\geq 0.70$ (blue), $\geq 0.75$ (orange), $\geq 0.80$ (yellow), $\geq 0.85$ (purple) and $\geq 0.90$ (green). The numbers in the lower left corner are the bestfitting corner frequency. The 0.8 cross-correlation value is in a black box. The first two columns correspond to P-waves (column one Brune model column two Boatwright model) and the last two to the S-waves. 

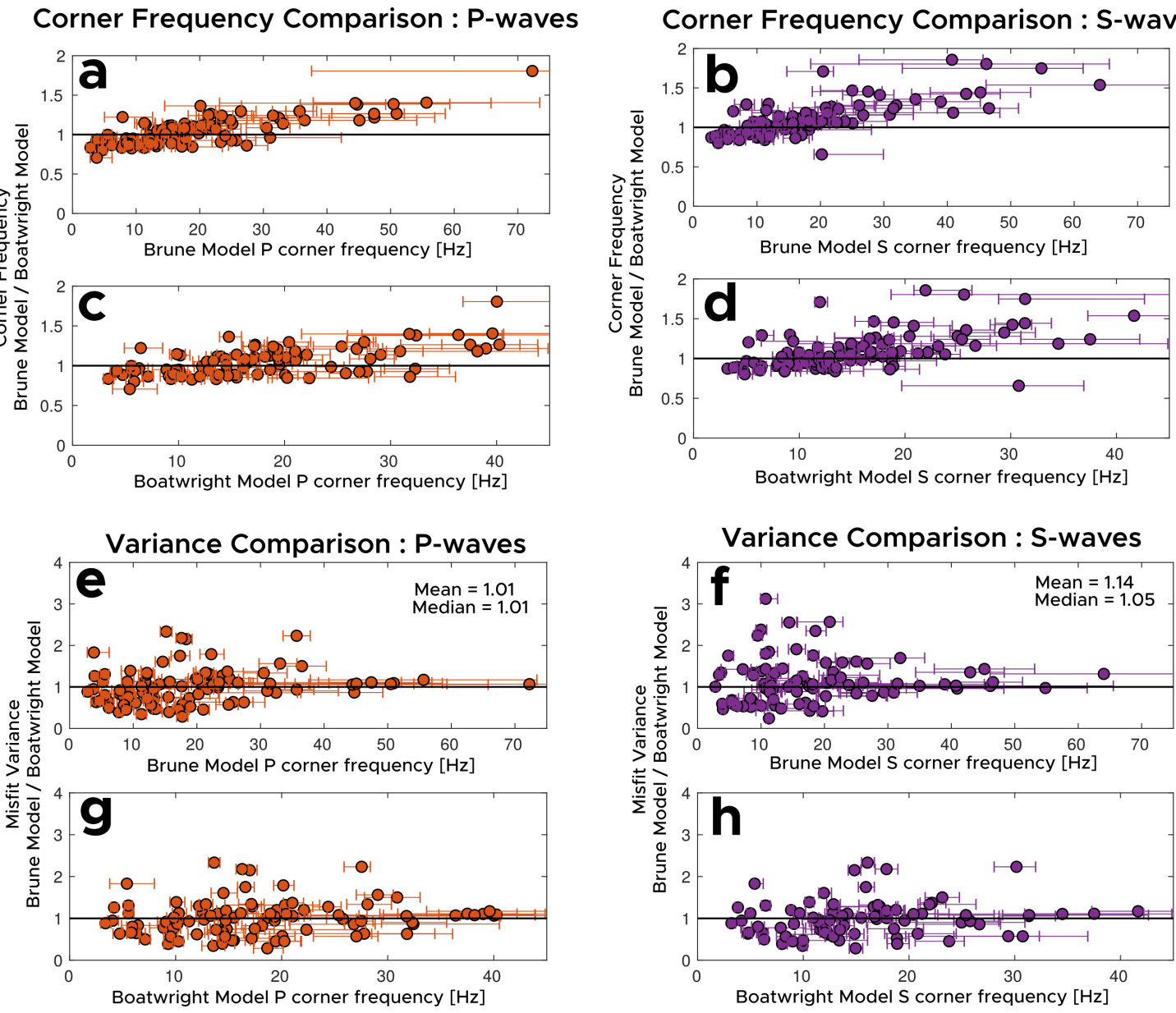

Figure 4.8: Comparison of corner frequency and the variance estimated with both the Brune and Boatwright source models. (a) and (b) show the ratio of the Brune corner frequency and the Boatwright corner frequency from the P-wave (orange circles) and S-wave (purple circles), as a function of the Brune model corner frequency value. The same for (c) and (d) but here the $x$-axis represents the Boatwright corner frequencies. (e) and (f) show the ratio of the variance between the Brune and Boatwright models for $\mathrm{P}$-waves (orange circles) and S-waves (purple circles) plotted against the Brune model corner frequencies. The same for $(\mathrm{g})$ and $(\mathrm{h})$ but plotted against the Boatwright model corner frequencies. 
Figure 4.7 shows the stacked and fitted ratios for six Target events of different magnitudes. As the magnitude of the earthquake increases, the corner frequency decreases. For the bigger earthquakes, the absolute difference in the estimated corner frequency between the cross-correlation values is not as large as for the smaller earthquakes, although the percentage change remains similar. In Figure 4.7, it is visually evident that the sharper-cornered Boatwright (1980) model provides a better fit overall for the six Target events shown. This is also observed for the majority of the stacked spectral ratios of all Target events. The corner frequency value for cross-correlations $\geq 0.80$ (highlighted in a black boxes in Figure 4.7) is similar for both the Brune and Boatwright models, a good indication that choosing this correlation limit produces stable results.

As noted above, the sharper-cornered Boatwright model fits the stacked ratios slightly better and with lower variance than the Brune model for the majority of the Target events. In panels (a), (b), (c) and (d) in Figure 4.8 it is observed that the bigger differences between the Brune and the Boatwright model are at frequencies higher than $40 \mathrm{~Hz}$, outside the bandwidth limit, where the Brune corner frequencies are higher than the Boatwright. On the contrary, for the low-frequency limit, the Boatwright corner frequencies are slightly higher than the Brune ones. The variance comparison for Pwaves and S-waves in Figure 4.8 indicates that the Brune model fits less well. The ratio of the variance between the Brune and Boatwright model indicates that the variance for the Brune model has higher values than the Boatwright model. Despite that, both mean and median values (shown in (e) and (f) in Figure 4.8) of the ratio only slightly exceed one. Consequently the Boatwright source model will be used in all subsequent analysis.

Results for P- and S-wave corner frequency measurements for different segments of the Alpine Fault are shown in Figure 4.9. Of the 245 Target events identified originally, a total of 94 for P-waves and 95 for S-waves passed the first criterion automatically applied during processing (points 1-3 at the beginning of this chapter) and the second criteria, also automatically applied (points 4-5 at the beginning of this Chapter). Visual inspection of independent P- and S-wave corner frequency measurements were made in order to determinate only the highest-quality results. To summarise, we chose the cross-correlation limit ( $\geq 0.80$ ), the fitting method (stacked ratios) and the source model (Boatwright, 1980). Then, we exclude results with fewer than five ratios in the stack and an amplitude ratio between the higher and lower frequency of the spectral ratios lower than two.

The comparison of corner frequency measurements for P- and S-waves (Figure 4.10) 

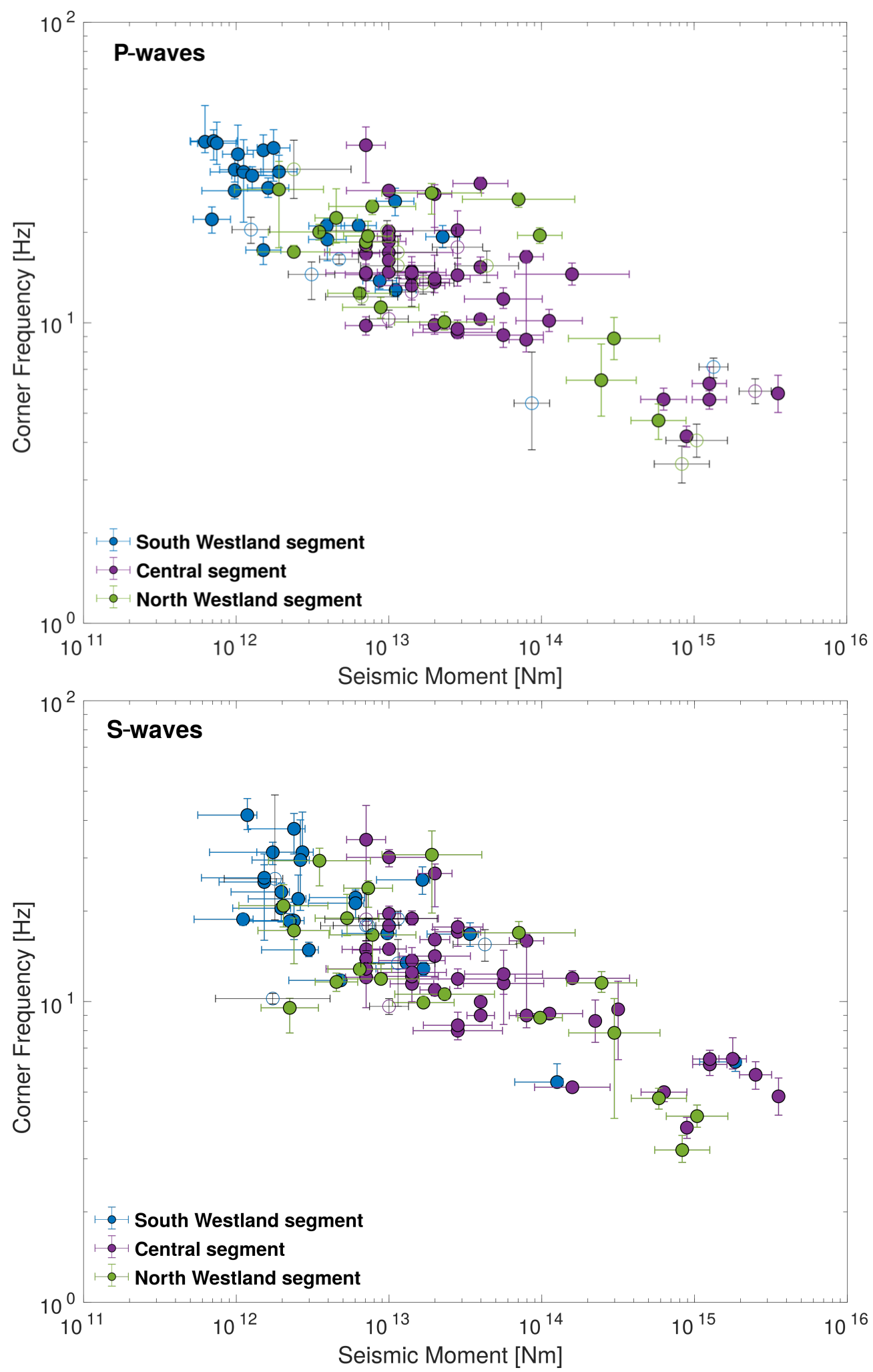

Figure 4.9: P- and S-wave corner frequency vs seismic moment. Measurements coloured by Alpine Fault segment. Green, North Westland segment. Purple, Central segment. Blue, South Westland segment. Open circles with errors bars in black are events that not meet the criteria 4 and 5 listed at the start of Section 4.1. Moment error bars show moment calculated from $M_{L}$ using $95 \% \mathrm{CI}$ on station $M_{L}$ values. Corner frequency errors represent the frequency normalized ratio $\left(f_{c 1 \text { error } 2}-f_{c 1 \text { error } 1}\right) / f_{c} 1$ which reflects the range of frequencies within $5 \%$ of the minimum variance. 


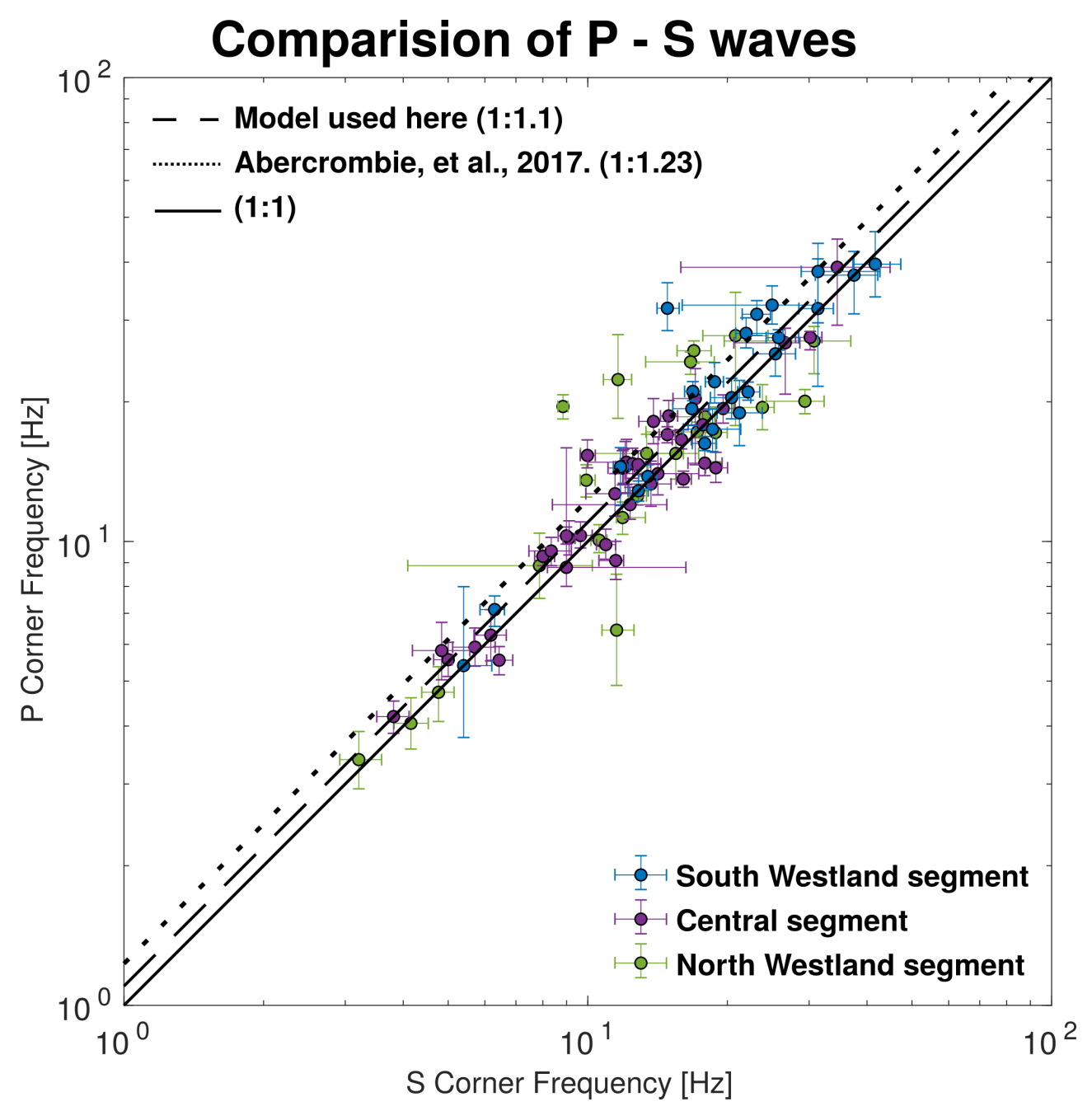

Figure 4.10: Comparison of $\mathrm{P}$ - and S-wave corner frequencies. Circles coloured by Alpine Fault segment. Green, North Westland segment. Purple, Central segment. Blue, South Westland segment. Continuous black line indicates $f_{c} P / f_{c} S$ ratios of 1 . Dashed line 1:1.1 is regression fitting the data presented here. Dotted line is 1:1.23 (Abercrombie et al. (2017a) data). 
show a high degree of consistency. As addressed in Chapter 3, the ratio between the corner frequency measurements for $\mathrm{P}$ - and S-waves enables us to choose appropriate $k$ values. We opt to use the Kaneko and Shearer (2015) $k$ values (obtained using a circular model with a rupture velocity of $0.7 \beta$ because our 1:1.1 is similar to the $1: 1$ that Kaneko and Shearer (2015) obtained. Abercrombie et al. (2017a) also used the Kaneko and Shearer (2015) $k$ values to calculate stress drops for four earthquake sequences in New Zealand despite finding a slightly higher P- to S-wave ratio (1:1.23) than those obtained here.

\subsection{Stress Drops}

Here we present stress drop results for 76 and 86 Target events for both P- and S-waves, respectively that meet the initial criteria. In total, we calculate 21 (for P-waves) and 24 (for S-waves) stress drops for the South Westland segment, 43 (for P-waves) and 44 (for S-waves) for the Central segment and 16 (for P-waves) and 20 (for S-waves) for the North Westland segment.

We obtain stress drop values in the range of 1-352 MPa for P-waves and 1-301 MPa for S-waves for all segments (Figure 4.11). There is not a big difference in stress drop values along strike of the Alpine Fault (Figure 4.14). The North Westland and Central segments have slightly higher stress drop values compared with the South Westland segment, as observed on Figure 4.14. A summary of stress drop values for each Alpine Fault segment is shown in Table 4.2 and Figure 4.14 .

We estimate the source radius (Figure 4.12) of the final Target events using Equation 3.9. The ranges found for each Alpine Fault segment are: 30-290 $\mathrm{m}$ for the North Westland segment, 26-265 $\mathrm{m}$ for the Central segment and 24-186 $\mathrm{m}$ for the South Westland segment. In Figure 4.12, the values for the South Westland segment are lower (for both P- and S-wave) than the values of the other segments. The values for the North Westland and Central segment overlap.

As shown in Figure 4.13, our results are similar to stress drop measurements found in many previous studies (using the same or different methodologies) in different tectonic settings (e.g. Abercrombie, 2014; Oth and Kaiser, 2014; Abercrombie et al., 2017a; Ruhl et al., 2017). However the North Westland and Central segment present slightly higher stress drop values for both $\mathrm{P}$ and $\mathrm{S}$ measurements than other studies, but do exhibit overlap with values calculated by Abercrombie et al. (2017b) for the Cook Strait sequence in South Island. We discuss the possible controls on, and patterns in stress 

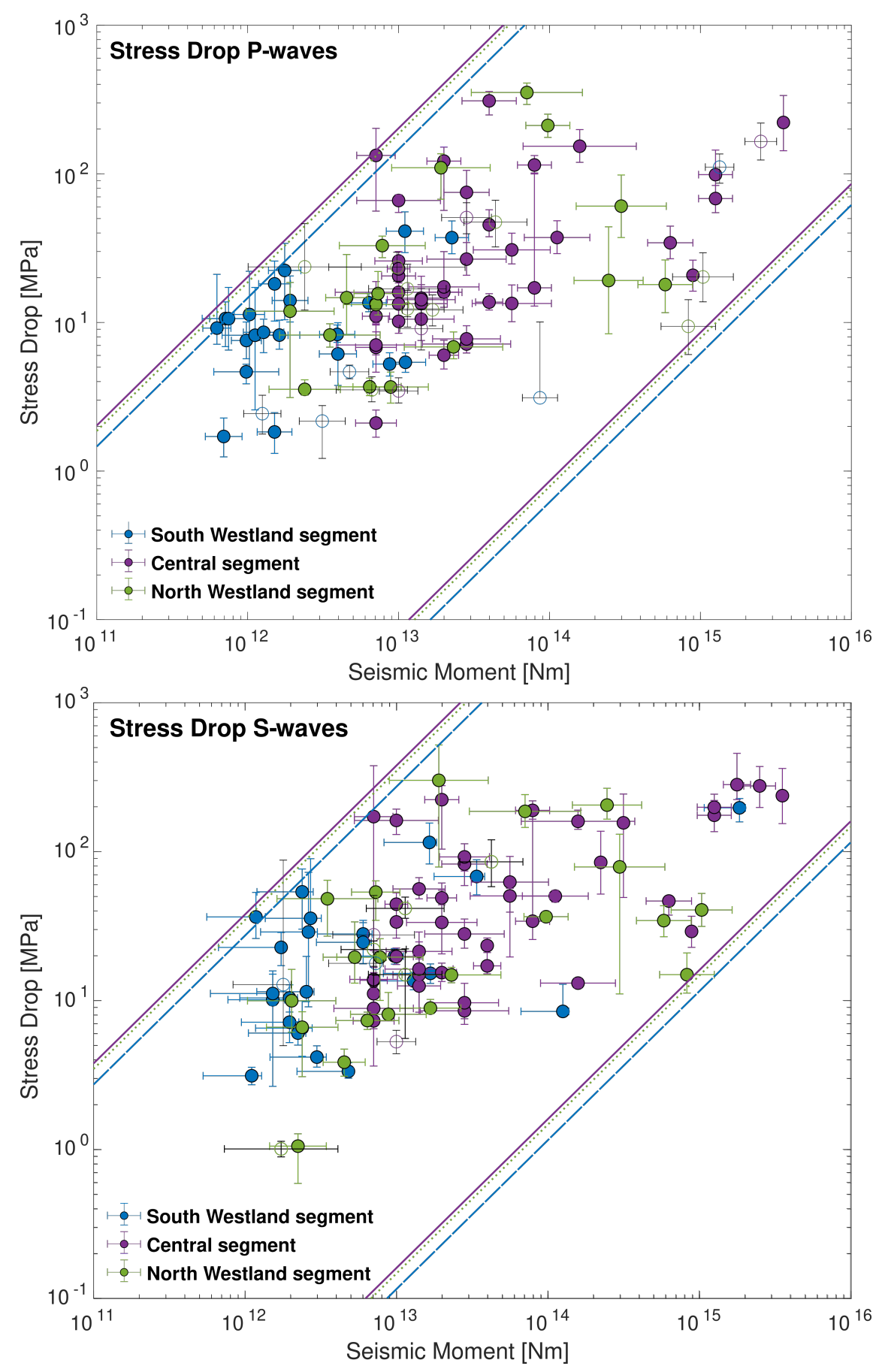

Figure 4.11: P- and S-wave stress drop vs seismic moment. Circles coloured by Alpine Fault segment. Green, North Westland segment. Purple, Central segment. Blue, South Westland segment. Open circles with error bars in black are events that do not meet criteria 4 and 5 listed at the start of the Section 4.1. Moment error bars show moment calculated from $M_{L}$ using $95 \%$ CI on station $M_{L}$ values. Stress drop uncertainties include corner frequency errors that represent the frequency normalized ratio $\left(f_{c 1 \text { error2 } 2}-f_{c 1 \text { error1 } 1}\right) / f_{c} 1$ which reflects the range of frequencies within $5 \%$ of the minimum variance. Coloured lines indicates measurement limits from the frequency bandwidth. These represent stress drop values that would be obtained using a maximum and minimum corner frequency for each segment. 

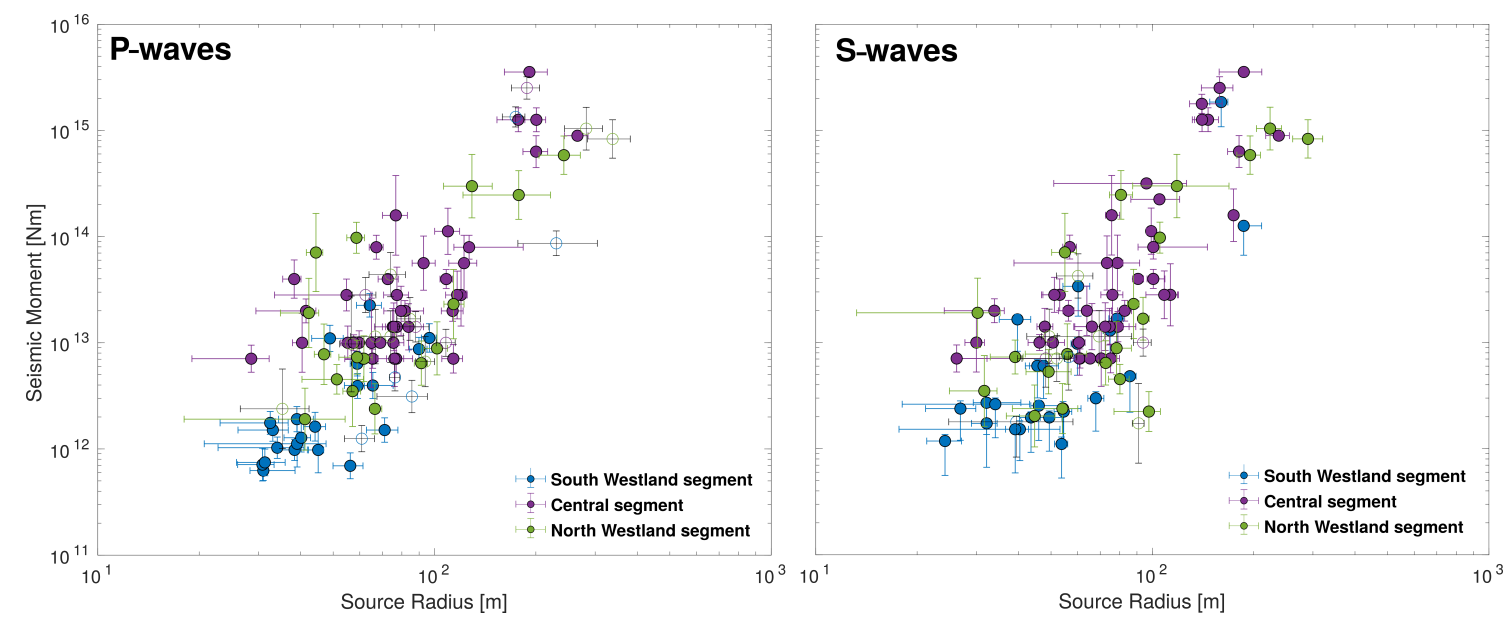

Figure 4.12: Source radius plotted vs seismic moment. Circles coloured by Alpine Fault segment. Green, North Westland segment. Purple, Central segment. Blue, South Westland segment. Open circles with errors bars in black are events that do not meet the criteria 4 and 5 listed at the start of the Section 4.1.
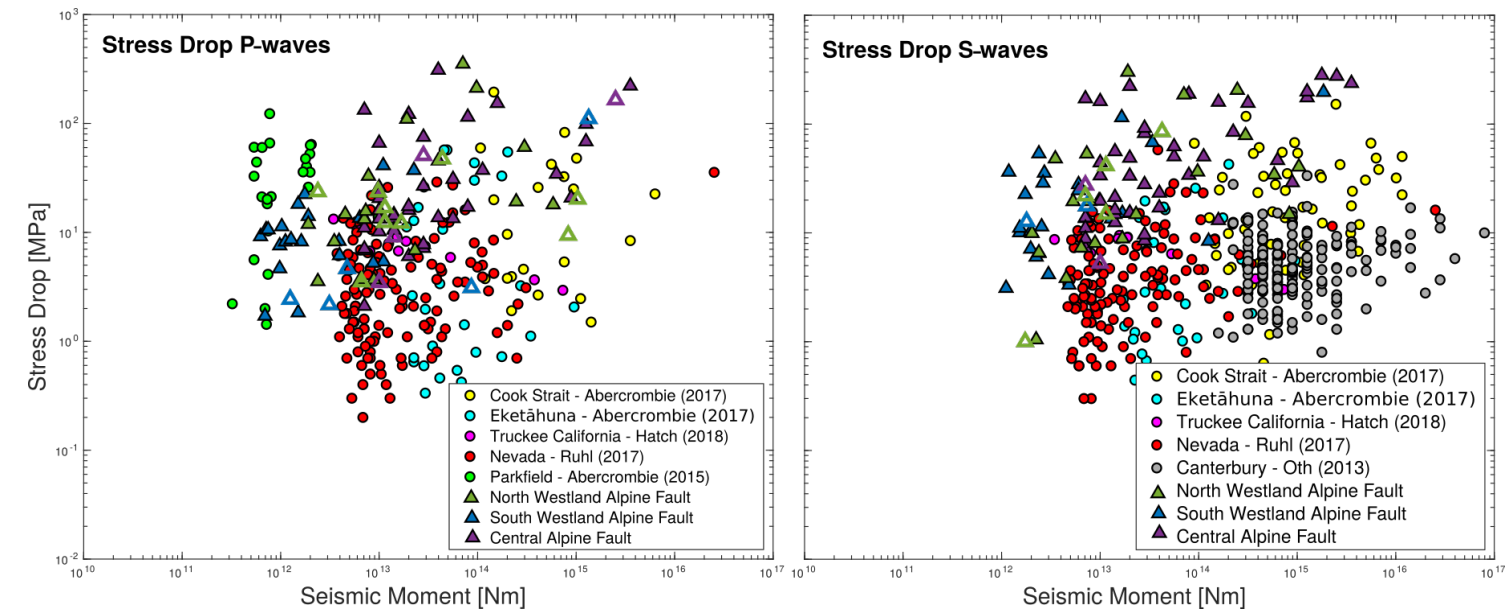

Figure 4.13: P- and S-stress drop measurements from different studies. The stress drop results obtained here are shown in triangles coloured by Alpine Fault segment. We observe that our stress drop values are, in general, higher than other studies, however the Cook Strait, New Zealand and Parkfield, U.S. (Abercrombie et al., 2017a; Abercrombie, 2015) sequences have similarly high stress drop values as well. There is also overlap between our Central Alpine fault values and the stress drop of the highest measurement of the Nevada swarm (Ruhl et al., 2017). 
Table 4.2: Minimum, mean, median and maximum stress drop values calculated for each Alpine Fault segment in this study.

\begin{tabular}{|l|c|c|c|c|c|c|}
\hline & SW P & SW S & Central P & Central S & NW P & NW S \\
\hline \hline N values & 21 & 24 & 39 & 42 & 16 & 20 \\
$\Delta \sigma$ min $(\mathrm{MPa})$ & 1 & 1 & 2 & 5 & 3 & 1 \\
$\Delta \sigma$ mean $(\mathrm{MPa})$ & 12 & 20 & 47 & 77 & 55 & 55 \\
$\Delta \sigma$ median $(\mathrm{MPa})$ & 8 & 9 & 17 & 39 & 15 & 19 \\
$\Delta \sigma$ max $(\mathrm{MPa})$ & 41 & 143 & 309 & 223 & 352 & 301 \\
\hline
\end{tabular}

drops in more detail in Chapter 5.

Some events did not meet the final two quality control criteria outlined at the start of the chapter, these are shown as open symbols in Figure 4.11. Despite their lower quality of observations, we conclude that they do not exhibit extreme low or high stress drop values. This suggests that the highest stress drop values, outside of the interquartile range, may depend more on magnitude uncertainties. Stress drop measurements are superficially simple to calculate from the corner frequency of the radiated spectrum, but its actually harder to be certain that estimates are accurate and reliable. In the next chapter we will talk about the uncertainties of stress drop coming from the corner frequency and the seismic moment. 


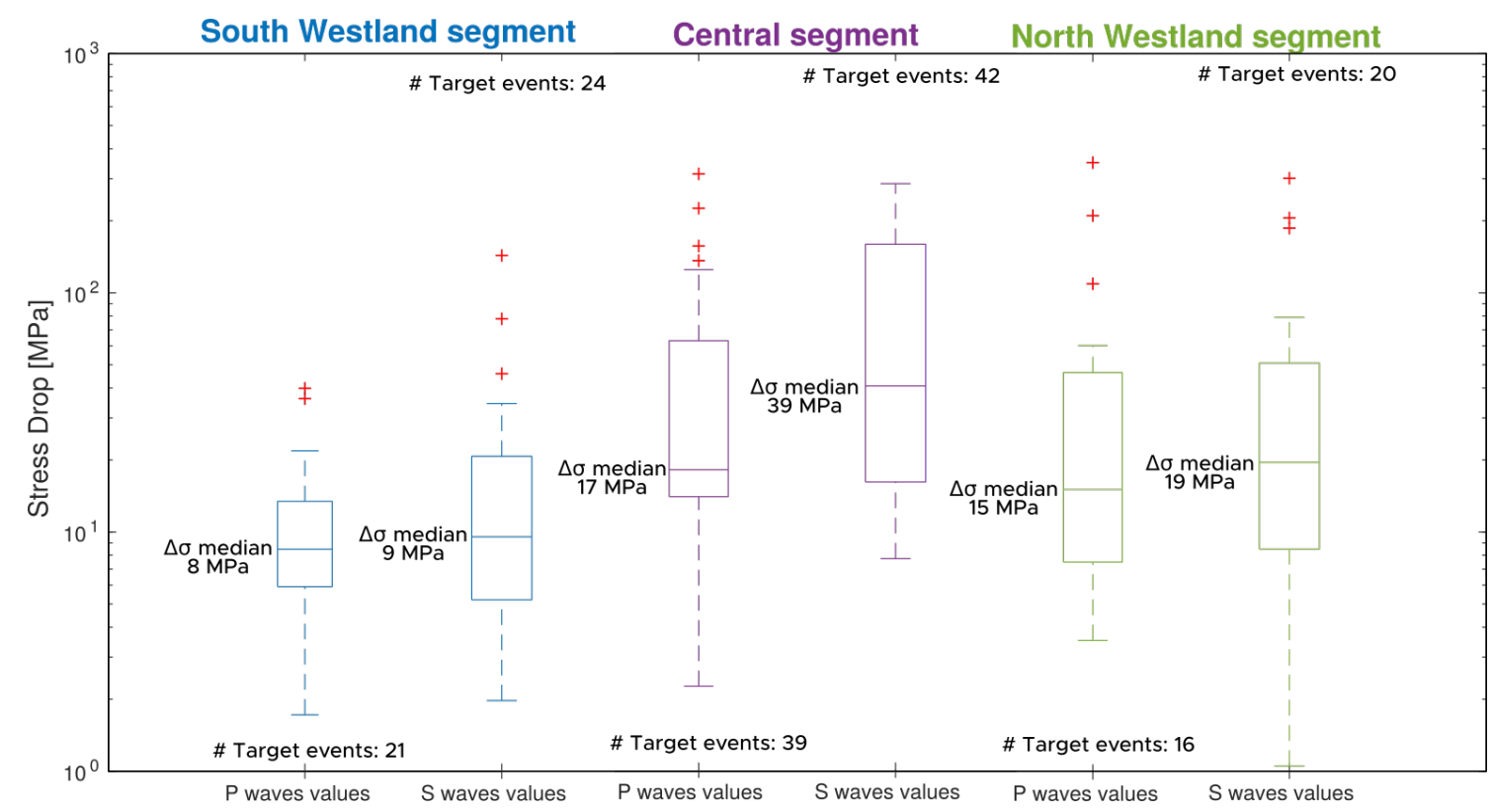

Figure 4.14: Box plots for final stress drop measurements. Box plots are coloured by Alpine Fault segment. The bottom and top of each box are the 25 th and 75 th percentiles of the stress drop values, respectively. The line in each box is the median. Red plus symbols are outliers. It is evident that the stress drops for the Central segment present the highest values (range $\sim 10 \mathrm{MPa}$ to $\sim 100 \mathrm{MPa}$ ) compared to the other segments. The lowest stress drop values correspond to the South Westland segment (range $\sim 3 \mathrm{MPa}$ to $\sim 30 \mathrm{MPa})$. The North Westland segment presents very similar average stress drop values for $\mathrm{P}$ and $\mathrm{S}$ (range $\sim 10 \mathrm{MPa}$ to $\sim 50 \mathrm{MPa}$ ). 


\section{Chapter 5}

\section{Discussion and Conclusions}

This chapter is divided into five main sections. First is a discussion of the key findings (Section 5.1) including the final stress drop estimate variations along strike and with depth. Next in Section 5.2 we discuss the factors that affect stress drop measurements. The third section (Section 5.3) discusses the implications of our observations on understanding fault strength. The fourth section (Section 5.4) presents recommendations for further research surrounding the EGF methodology, corner frequency and stress drop estimations and a more detailed source analysis, which will provide the opportunity to extend the understanding of earthquakes occurring on and close the Alpine Fault. The final section (Section 5.5) lists the main conclusions of this thesis.

For simplicity, the analysis here focuses solely on the stress drop measurements from $\mathrm{S}$-waves, unless otherwise noted. Since there is a very strong correlation between our results for P- and S-waves, the same conclusions can be drawn from either dataset.

\subsection{Key Findings}

Table 4.2 presents a summary of the final stress drop estimates from this study. The median values for the North Westland, Central and South Westland are: 19, 39 and 9 MPa, respectively. Given the logarithmic range of stress drops, outliers likely strongly bias mean averages, and so the median values are likely more representative of the averages for each segment. Regardless of the averaging method considered, the South Westland segment exhibits the lowest stress drops, while the Central segment exhibits the highest. The relative differences in stress drop values are better resolved than the absolute ones. The stress drop values estimated in this thesis are within the range of 
global estimates and of those obtained by Abercrombie et al. (2017a) for four different earthquake sequences (in different tectonic settings) in New Zealand (range $\sim 1-100$ MPa), and higher than those obtained by Oth and Kaiser (2014) for the 2010-2011 Canterbury earthquake sequence (range 1-20 MPa).

In the section below, we investigate stress drop variability in relation to different parameters, namely position along strike, depth, focal mechanism, and seismicity rate.

\subsubsection{Stress Drop Variability Along Strike and with Depth}

Given the pronounced along-strike changes in other parameters (e.g. strike, dip, seismicity rate and cut-off depths; see Table 1.1) we first examine whether there are also any distinct changes in stress drop values along strike (see Figures 5.1 and 5.2).

\section{- North Westland segment}

The North Westland segment presents a median stress drop value of $17 \mathrm{MPa}$ (averaged between $\mathrm{P}$ and $\mathrm{S}$ ). This segment has fewer Target events than the other segments, but it is also the segment exhibiting the most complex sources (which are not analysed in this thesis, but may be the topic of future work; see Section 5.4). Relatively high stress drop values are estimated for this segment (compared with others values within New Zealand), but these are not the highest that we calculate for the Alpine Fault as a whole. This segment also has the lowest strike-slip slip rate, the lowest plate boundary motion percentage (Barth et al., 2013) and the lowest seismicity rate of the three main Alpine Fault segments (Boese et al., 2012; Bourguignon et al., 2015).

Cross-section D of Figure 5.1 shows the Target events for this segment. These include a distinct cluster in the footwall and more scattered events that are closer to the fault. The footwall cluster contains 15 events with magnitudes of $M_{L} 4.1-M_{L} 2.2$ : some of the events in the cluster present complex sources and the highest stress drop estimates for this segment.

The four events that are closer to the fault plane have similar magnitudes $\left(M_{L} 2.4-\right.$ $\left.M_{L} 2.8\right)$ and similar low stress drop values $(\sim 10 \mathrm{MPa})$.

On the ternary diagram of focal mechanism type illustrated in Figure 5.2, the circles represent this segment and we do not see any systematic variation of stress drop depending on the fault mechanism. The red square in this figure shows that the footwall cluster has a predominantly thrust mechanism and that within this cluster there is high stress drop variation. 

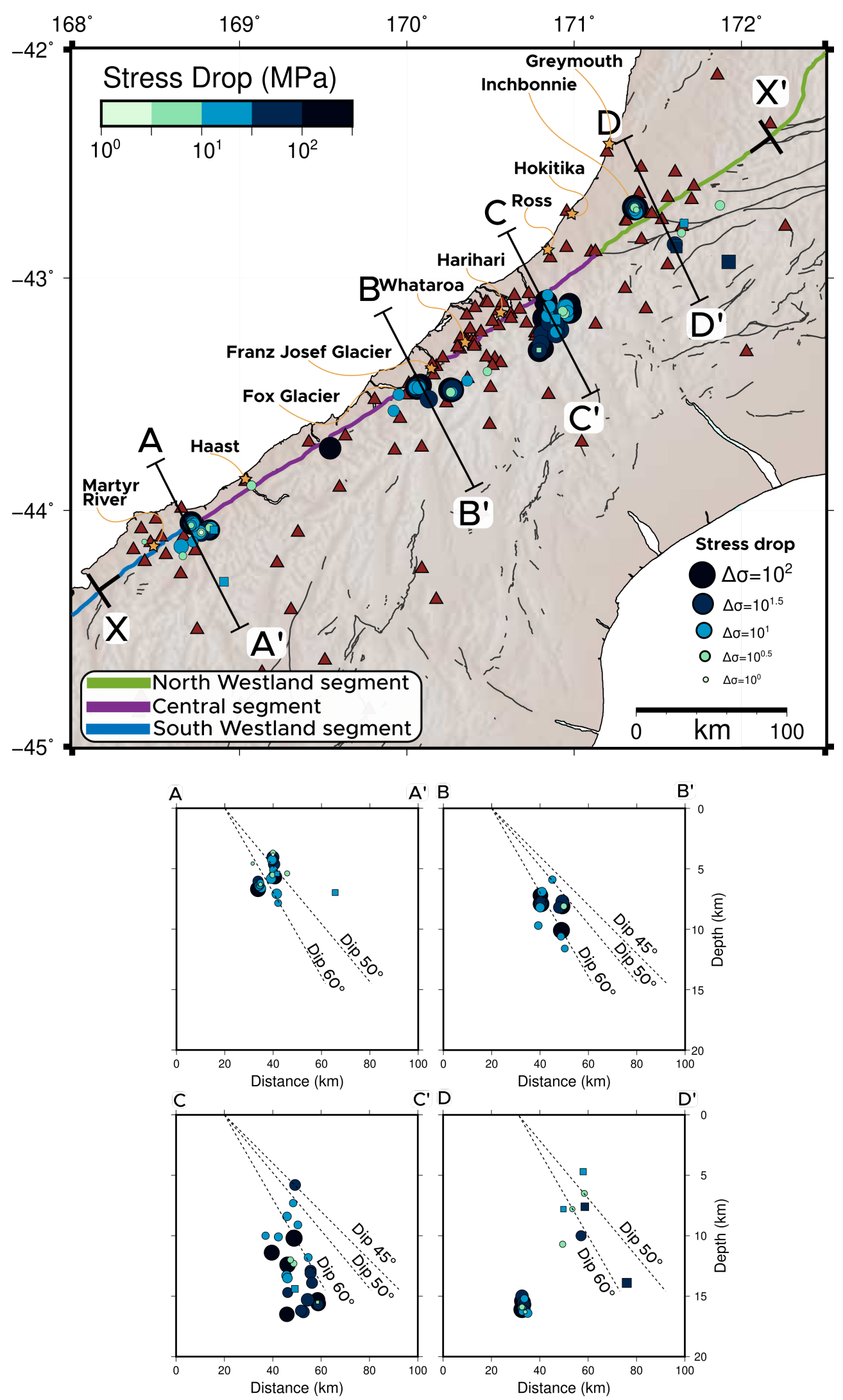

Figure 5.1: Map of stress drop variations along strike and in vertical crosssections. Circles represent Target events that meet quality criteria and squares are events that did not meet the criteria. Target events are coloured and scaled by stress drop values. Lines in cross-section A, B, C and D represent the possible dips of the Alpine Fault in that section. 


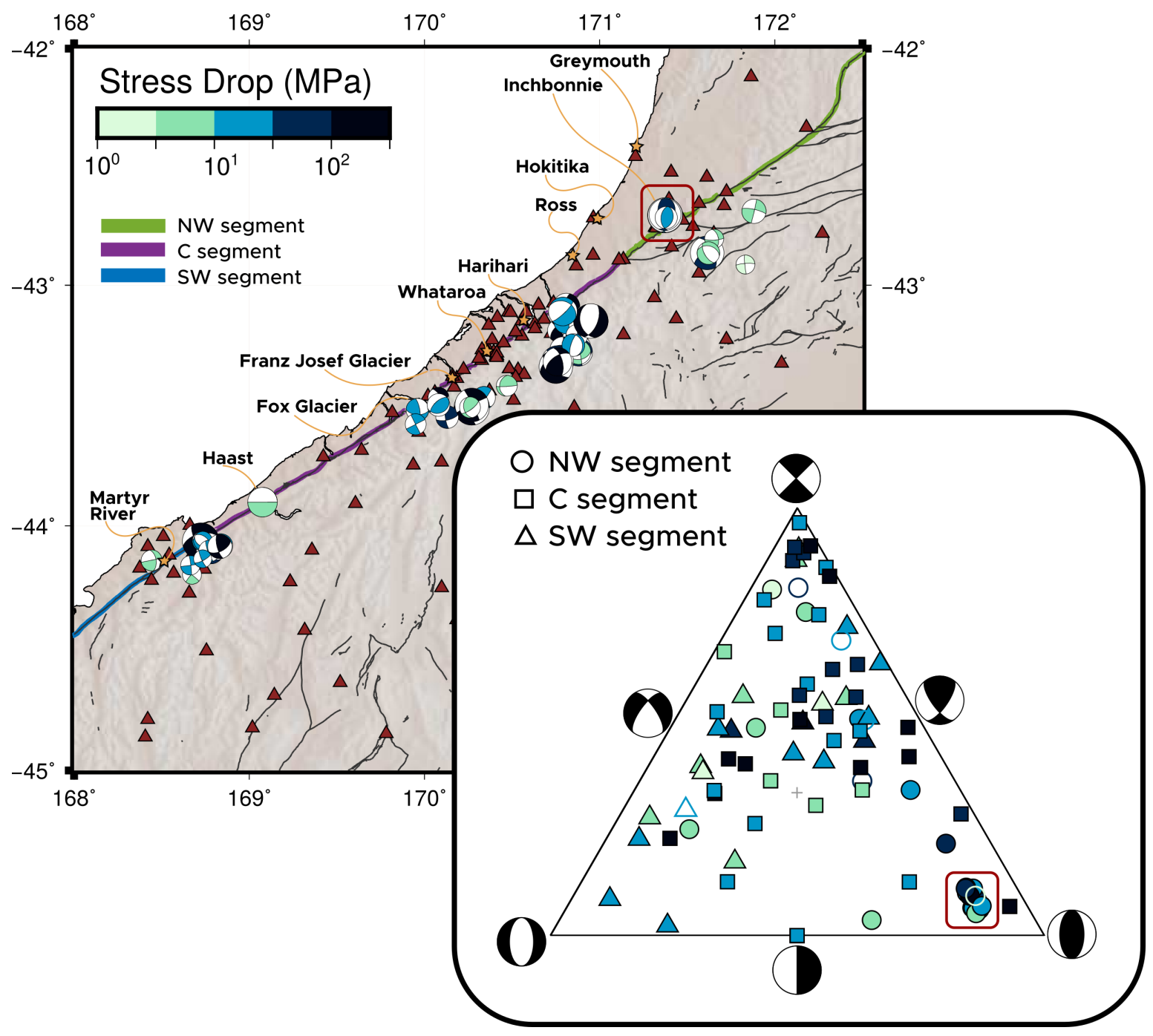

Figure 5.2: Ternary diagram of focal mechanism type and stress drop. Focal mechanism, circles, squares and triangles are coloured by stress drop. Open circles, squares and triangles are those that do not meet quality criteria. Map shows the distribution of focal mechanisms along the Alpine Fault. Ternary diagram shows the focal mechanism distribution of all Target events from all segments. The red square on both the map and ternary diagram outlines the north cluster discussed in the text. 
In summary, we do not see any systematic dependence of stress drop on depth, magnitude, or focal mechanism for the North Westland segment.

\section{- Central segment}

The Central segment exhibits the highest stress drop values along the Alpine Fault, with a median value of $28 \mathrm{MPa}$ (averaged between $\mathrm{P}$ and $\mathrm{S}$ ). This segment has more Target events than the other two and presents the highest strike-slip and dip-slip rates and the highest proportion of plate boundary motion overall Barth et al. (2013). The segment has generally low seismicity rates Boese et al. (2012); Bourguignon et al. (2015) and has been observed in the last decade to produce a range of seismic phenomena (swarms Boese et al. (2014), tremors (Wech et al., 2012, 2013) and LFEs (Chamberlain et al., 2014; Baratin et al., 2018)).

Along this segment, all Target events are located within $5 \mathrm{~km}$ of the three possible fault planes (see cross-sections B and C in Figure 5.1). Cross-section C shows the most Target events, and it is clear that most of the highest stress drop values correspond to the deepest events for that cross-section. We do not see this trend in cross-section B.

The ternary focal mechanism diagram (Figure 5.2) does not reveal any clear variation in stress drop with focal mechanism for Target events in the Central segment. We do observe, however, that the strike-slip corner of the diagram indicates predominantly high stress drop values $(\sim 30-100 \mathrm{MPa})$.

In the Central segment, there is thus no clear dependence of stress drop on magnitude, depth or fault mechanism.

\section{- South Westland segment}

The South Westland segment exhibits the lowest stress drop values on the Alpine Fault, with a median value of $8 \mathrm{MPa}$ (averaged between $\mathrm{P}$ and $\mathrm{S}$ ). This segment also has the lowest dip-slip rate, the steepest dip and the highest background seismicity rate Barth et al. (2013).

Cross-section A in Figure 5.1 shows a cluster of Target events (not on the fault plane) with distinctively different stress drop values. Also, there are several events that are close to the fault plane, but with different depths, with indistinctly varying stress drop values. The magnitudes of most of those events are very similar $\left(M_{L} 2.0-M_{L} 2.8\right)$. We do not see any difference in stress drop values between events that are on or off the fault plane. Target events along this segment are much shallower compared with the other segments.

In the ternary plot (Figure 5.2), the triangles illustrating results for this segment 


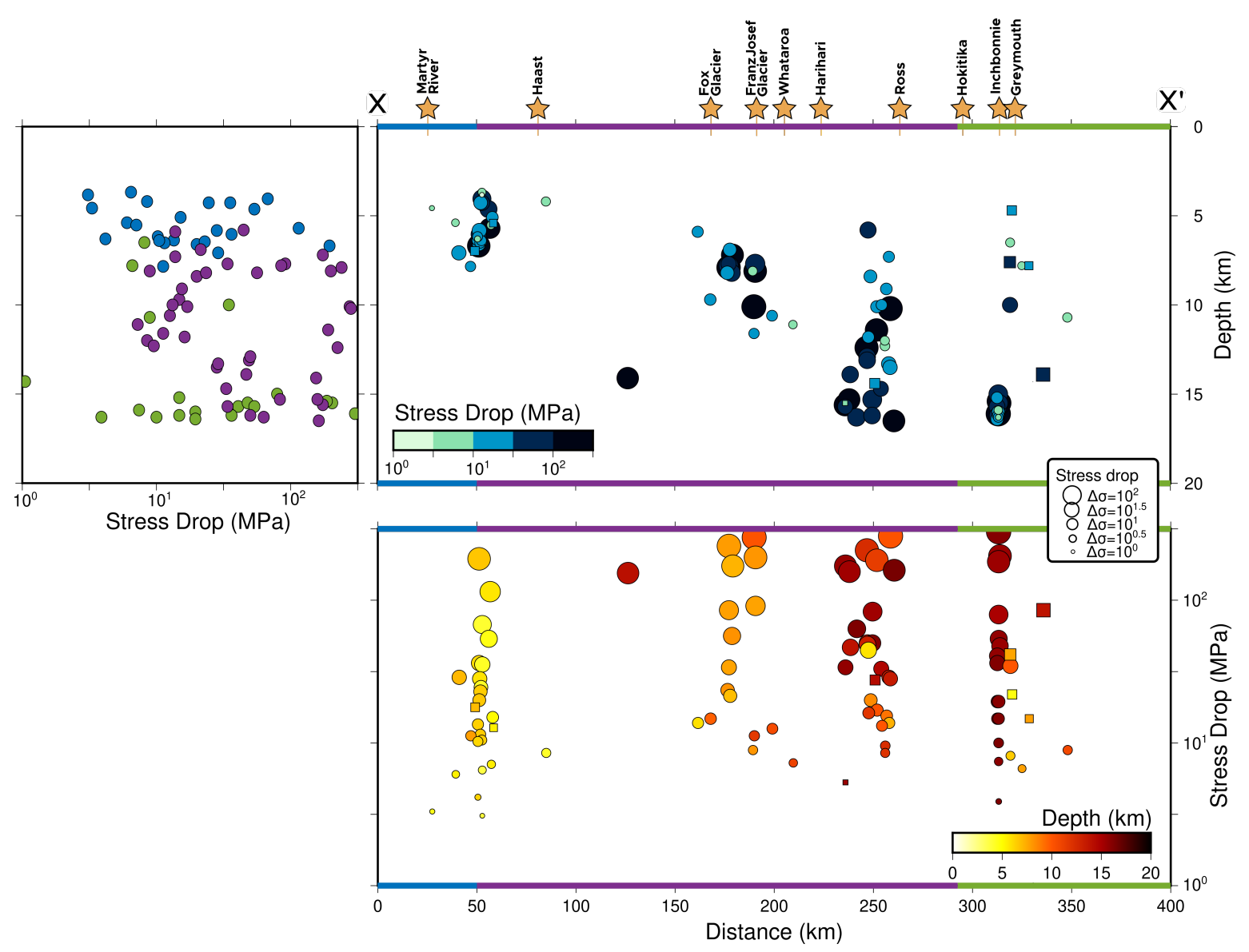

Figure 5.3: Sections along strike of the Alpine Fault. Circles represent Target events that meet quality criteria, and squares represent events that did not meet criteria. The top panel is a plot of along strike distance versus depth. Circles and squares are coloured by stress drop values. The bottom panel is a plot of along strike distance versus stress drop. Circles and squares are coloured by depth.

are mainly coloured in the light colours, indicating relatively low stress drop values $(\sim 3-30 \mathrm{MPa})$.

Like the Central segment, there is no evidence for the South Westland segment of systematic stress drop variations related to magnitude, depth or focal mechanism.

The low stress drop estimations for this segment can be bias by the bandwidth limits of the data. In Figure 4.11 we observe that this segment also has the lowest seismic moments (smallest magnitude events). The blue line (in Figure 4.11) represent the bandwidth limits for this section and at low seismic moments, high stress drops will not be well-constrained.

Figure 5.3 illustrates two cross-sections along strike of the Alpine Fault. Both show the distribution of stress drop values and depth along strike but presented in different ways. The upper left inset panel illustrates that stress drop does not appear to vary 
with depth. On the top right hand panel in Figure 5.3 we see that the depth of the Target earthquakes increases from the south (Martyr River) to the north on the Alpine Fault. Overall, however, this figure confirms that there is no depth dependence on stress drop values.

Shearer et al. (2006) obtained stress drops for earthquakes in southern California ranging from 0.2 to $20 \mathrm{MPa}$ and found a depth dependence with median stress drop of 2.2 $\mathrm{MPa}$ at $8 \mathrm{~km}$ depth and a median stress drop of $0.6 \mathrm{MPa}$ at the surface. Hardebeck and Aron (2009) also reported a depth dependence in California with a median stress drop of $\sim 5 \mathrm{MPa}$ for $1-7 \mathrm{~km}$ depth, $\sim 10 \mathrm{MPa}$ for $7--13 \mathrm{~km}$ depth, and $\sim 50 \mathrm{MPa}$ deeper than 13 km. However, Abercrombie et al. (2017a) and Oth and Kaiser (2014) observed no dependence of stress drop on depth, as observed here, for earthquakes elsewhere in New Zealand.

Moyer et al. (2018) reported limited spatial variation in stress drop along the Gofar transform fault, with stress drops ranging between 0.04 and 3.2 MPa. They observed a median 0.6 MPa stress drop in zones of high seismic coupling and a median $0.2 \mathrm{MPa}$ stress drop for zones of low seismic coupling. These differences are small considering the log normal distribution of stress drops, whereas we document relatively large variability of individual stress drop values along strike, with the values from the North Westland and Central segments overlapping but the values from the South Westland being lower by 10-20 MPa. This could be a reflection of a bigger difference in fault geometry, slip and seismicity rate between the South Westland and Central segments, compared with relatively minor along-strike changes between the Central and North Westland segments. However, it is also possible that real changes in stress drop along strike (and with depth) are masked by analytical uncertainties, which we address below.

\subsection{Factors Affecting Stress Drop Measurements}

Accurate, reliable and precise stress drop estimates are hard to obtain due to uncertainties and simplifications made in the analysis. While we have taken several commonly used and reasonable steps to minimise uncertainties in the parameters affecting our stress drop estimates, the final uncertainties are likely to still be significant.

Several factors throughout the stress drop calculation process influence uncertainties in the final value. These include, in particular: the selection of the EGF earthquakes, spectral ratio calculation, the assumed cross-correlation limit, the source assumptions (e.g. circular model), fitting of the corner frequency and uncertainties in seismic mo- 
ment calculation.

We assume a suitable EGF event will produce similar corner frequency estimates at every station. We find that limiting hypocentral separation distances between mainshock and EGF events to $\leq 1 \mathrm{~km}$ (within $\sim 1-3$ mainshock fault lengths) is an effective criterion for choosing EGFs. When EGF events within $1 \mathrm{~km}$ are not available, we suggest limiting EGF events to those with highly similar waveforms to the mainshock waveforms to ensure source similarity. It is also important to consider mis-located earthquakes, or those with large uncertainties in depth, which may be truly co-located with the Target earthquakes but are inferred to be separated by several kilometers on the basis of hypocentral uncertainties.

The selection of the appropriate EGF earthquakes is crucial as stress drop estimation depends on it directly. Abercrombie (2015) found that as the hypocentral separation between the Target and EGF events increases, the stress drop value decreased by a factor of 3. This was also observed by Kane et al. (2013) for earthquakes on the San Jacinto Fault Zone: they suggested that having a maximum hypocentral separation of $2 \mathrm{~km}$ (again within $\sim 1-3$ mainshock fault lengths) between Target and EGF events is appropriate when sufficient data are available (they used $>183,000$ seismograms). To minimise uncertainties in our Alpine Fault study, we first followed Abercrombie et al. (2017a) and used a $2 \mathrm{~km}$ maximum epicentral distance between Target and EGF events but this did not yield enough EGF events for each Target event. We therefore decided to extend the epicentral distance limit to $3 \mathrm{~km}$ and also use an absolute depth difference of $\leq 5 \mathrm{~km}$, as mentioned in Section 3.2. We observed that small variations in hypocentral location translate to very small differences in path between the Target and EGF events and conclude that the spatial criteria used were sufficient to select appropriate EGF events, especially after all non-similar seismograms had been removed at the cross-correlation thresholding stages.

In general, we identified fewer EGF earthquakes for the largest-magnitude Target events. This is in part dependent on the Gutenberg-Richter distribution of magnitudes, whereby fewer earthquakes within 1-3 magnitude units of a mainshock exist for larger earthquakes than for smaller target events. Additionally, the corner frequencies of larger earthquakes lie within the low-frequency range, while small earthquakes do not produce low frequency energy, and the uncetainty increases. The choice of crosscorrelation limit can go some way to mitigating the choice of poor EGF-Target pairs. Throughout the calculations we rejected all Target-EGF waveform pairs for which the cross-correlation was less than 0.7. As the cross-correlation limit is increased, the number of useable data decreases. We find that we had sufficient spectral ratios to 
stack using pairs with cross-correlation values bigger than 0.8, and only used those to estimate stress drop. Ruhl et al. (2017) demonstrated that for data from the 2008 Nevada swarm the corner frequencies are stable from cross-correlation limits of 0.7 and Abercrombie et al. (2017b) found stable results from cross-correlation limits of 0.8 . Importantly, we also observed that corner frequency values do not incur significant differences for different cross-correlation limits within these ranges. By using a high cross-correlation limit we make sure to eliminate EGF events with markedly different focal mechanisms.

In order to calculate corner frequency, we have to make some assumptions regarding source parameters. We assume a simplistic circular source model with a fixed rupture velocity $(0.7 \beta)$. Hence, the corner frequency and stress drop estimation for complex earthquake sources will not be well represented by this simple source. We opt to use the Boatwright (1980) (sharper-cornered) model rather than the Brune (1970) model because it gave a better quantitative fit to our data. Other studies from different tectonic settings have also tended to prefer the Boatwright (1980) model, e.g. Abercrombie et al. (2017a) for earthquakes in New Zealand, Ruhl et al. (2017) and Huang et al. (2016) for swarms in Nevada and Arkansas, respectively.

The corner frequency calculation is a significant factor affecting stress drop estimates, as stress drop is proportional to the cube of the corner frequency (Equation 3.10). Accordingly, errors in corner frequency estimation will be compounded in the stress drop estimation. To calculate corner frequency, the source assumptions and bandwidth limitation are the bigger sources of uncertainty. Earthquakes with corner frequencies in the center of the data bandwidth will be the best resolved (Abercrombie et al., 2017a). Corner frequency estimations outside the signal bandwidth are not taken into account because the spectral ratios cannot constrain corner frequency in that frequency range. The fitting of the spectral ratios can also bring uncertainty to the corner frequency estimation. In order to avoid or minimize those uncertainties as best as possible, Abercrombie (2015) suggested using at least five EGFs or five station measurements for each Target event. We only keep those corner frequency measurements that were made with both five EGFs and five stations. Using both constraints can significantly decrease the uncertainties (Abercrombie et al., 2017a). Abercrombie et al. (2017a) also found that corner frequency estimation from stacked spectra are less affected by limited frequency bandwidth than the individual ratio fitting.

Seismic moment estimations contain notable uncertainties, especially when calculating seismic moments from local magnitudes via moment magnitudes, as we do here. In Section 2.2, we briefly described the procedure used by Michailos et al. (2019) and 
Dr. Emily Warren-Smith to calculate local magnitudes from earthquake signals. They calculate magnitude uncertainties from the $95 \%$ confidence intervals of the individual station magnitudes for each earthquake. We then estimate the moment magnitude from local magnitude using new scaling relationships (Equations 4.3 and 4.4 for the North and South Westland segments, respectively; see Section 4.2). To calculate the seismic moment, we use the Kanamori (1977) relationship (Equation 3.12). We assume the relation applies across the range of magnitudes considered in this thesis, but in reality a different scaling may apply to both moderate and small $(M<2-3)$ earthquakes (Hanks and Kanamori, 1979; Hanks and Boore, 1984; Deichmann, 2017). We calculate the seismic moment uncertainty from the local magnitude uncertainty, but the underlying regression relationships used to compute seismic moment from local magnitudes are themselves imprecise and also introduce uncertainties into the seismic moment estimation. However, overall, the uncertainties calculated for the local magnitudes are bigger than would be introduced by the regression relationships used to calculate moment magnitude and seismic moment.

To calculate stress drop uncertainty fully and accurately, we have to combine corner frequency and moment uncertainties together. Presently, seismic moment uncertainties are calculated from the the $95 \%$ confidence intervals of the individual $M_{L}$ station magnitudes for each earthquake, and corner frequency uncertainties are calculated from values within $5 \%$ of the minimum variance frequency (see Section 4.3). A focus of future work should be to calculate uncertainty using consistent methodology so that we can combine them and calculate a more robust stress drop uncertainty.

\subsection{Fault Mechanics Implications}

Given our careful analysis to reduce uncertainties, and the fact that relative changes in stress drop along strike are better resolved than absolute values, we interpret our main result that the South Westland segment appears to exhibit lower stress drops than the other segments on average. Here, we discuss a possible explanation, based on our stress drop estimations, that assumes varying fault strength along strike.

Fault strength is related to the fault's friction and represents the critical point at which the fault cannot withstand more shear stress (see Figure 5.4). Boulton et al. (2018) found that the South Westland segment is not well orientated for failure and estimated that coefficients of friction for the South Westland segment are very low $(\mu=0.12-0.16$ at temperatures of $T=25-210^{\circ} \mathrm{C}$ ) compared with the Central segment's coefficient 


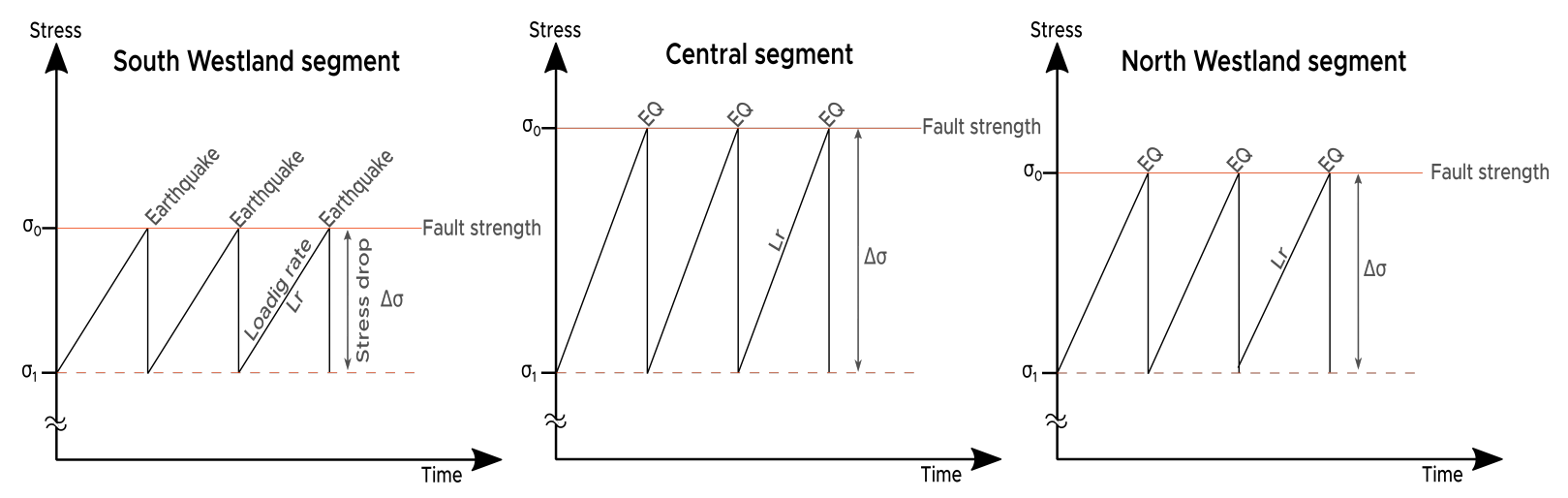

Figure 5.4: Schematic figure showing the stress drop variations along the three Alpine fault segments. $\sigma_{0}$ is the strength of the fault and $\sigma_{1}$ is the shear stress on the fault after an earthquake.

of friction $\left(\mu=0.43-0.45\right.$ at $T=20-25^{\circ} \mathrm{C}$ to $\mu=0.60-0.74$ at $\left.T=210-300^{\circ} \mathrm{C}\right)$ (Boulton et al., 2014; Niemeijer et al., 2016). At present, there are no estimates of the coefficient of friction for the North Westland segment.

As described in Section 1.5, an earthquake's stress drop is the difference between the initial shear stress $\left(\sigma_{1}\right)$ and the strength of the fault $\left(\sigma_{0}\right)$. Thus, stress drop values will be different depending on whether the fault is strong or weak (assuming constant $\left.\sigma_{1}\right)$. According to this model, a weak fault will fail at a lower resolved shear stress and produce lower stress drop values than a strong fault, which will be able to maintain higher overall stress before failing and thereby produce higher stress drop values.

For the South Westland segment, we estimate stress drop values that are lower than those of the other Alpine Fault segments by $\sim 10-20 \mathrm{MPa}$. If we assume, based on the arguments above, that this indicates that the fault here is weak, then our stress drop results are consistent with observations made by Boulton et al. (2018) that the fault exhibits a low coefficient of friction and is poorly oriented in the prevailing 3D stress field for failure. This then agrees with the model illustrated in Figure 5.4, such that if the fault strength is low, the corresponding stress drops are low too. This also agrees with the Central stress drop estimations, where the inferred fault strength is higher than the South and North Westland segments and the stress drop values are higher too. 


\subsection{Future Work}

We have estimated the stress drops of earthquakes occurring on and near the Alpine Fault to investigate the spatial variability of these source properties along the fault. This work was motivated by particular interest in whether earthquakes at the rupture segment boundaries inferred from paleoseismological observations behave differently to those in the middle of previously identified rupture segments. To address this in more detail, we suggest some possible lines of future work:

\section{- Expand the Target Event Catalogue}

We have shown for the North and South Westland segments that $M_{L} 2.0$ earthquakes perform well for calculating stress drop (in that the earthquake signal is sufficiently larger than the noise). Therefore, it would be useful to extend the Target event catalogue for the Central segment and use earthquakes of $M_{L} 2.0$ in addition to the larger ones considered here. This will increase the number of Target events from $\sim 144$ to $\sim 300$.

\section{- More Robust Uncertainty Estimates}

As discussed above in Section 5.2, the uncertainty of stress drop estimates remains significant. We would like to estimate corner frequency and seismic moment uncertainties using a more consistent methodology in order to combine both uncertainties and calculate a more robust stress drop uncertainty than is typically done in stress drop studies worldwide.

\section{- Calculate Directivity}

Earthquake directivity produces azimuthal variations in the seismic radiation Abercrombie et al. (2017b), resulting in different widths of the source time functions for different observational azimuths. Measurements of directivity can be used to infer both the orientation of the fault plane and the rupture velocity. Directivity has been observed for small to moderate-sized earthquakes in New Zealand and induced earthquakes in Brazil (Tomic et al., 2009; Abercrombie et al., 2017b). To accurately measure the directivity of small earthquakes and thus distinguish between the two nodal planes, we suggest using the stretching method to measure the duration of the STF. The stretching method, developed by Warren and Silver (2006), allows the whole waveform to be used to quantify azimuthal variability, rather than relying on often ambiguous estimates of source duration. This analysis for on- and near-fault earthquakes along the Alpine Fault may help to identify whether a preferred rupture direction (either bi- or unilat- 
eral rupture) prevails along the Alpine Fault, and will contribute to a broader understanding of rupture scenarios.

\section{- Identify and Analyse Complex Sources}

We have documented complex sources for some of the earthquakes along the North Westland segment (Figure 5.5). Complex Source Time Functions can show clear evidence of rupture complexity with the presence of multiple pulses and systematic azimuthal variations. It is important to identify complex sources when using the EGF methodology, because applying simple source models to complex earthquake sources will not only bias the resulting source parameter estimates but also hamper progress in understanding earthquake source processes more generally. In addition, it is easier to observe complex sources in larger events, and careful analysis of smaller earthquakes can illustrate this is also present at lower magnitudes.

\section{- Identify Fault Zone Guided Waves}

To help constrain variations in on-fault source properties, it is important to discriminate earthquakes occurring on, rather than simply near, the fault. The fault zone guided waves are trapped waves within the damage zone, and so they indicate earthquakes happening on the fault. Eccles et al. (2015) first identified fault zone guided waves associated with the Central Alpine Fault. Further observations of fault zone guided waves at DWARFS stations would expand the catalogue constructed by Eccles et al. (2015) to encompass the other Alpine Fault segments, and enable Target events used for stress drop estimation to be more reliably discriminated into on-fault and off-fault subsets.

\section{- Template Matching to Identify Similar Earthquakes for EGFs}

Matched-filtering is an effective method for detecting clustered seismicity such as aftershocks, using waveforms of earthquakes to look for similar waveforms. This methodology will be useful to find co-located (EGF) earthquakes and therefore expand the potential associated EGF earthquakes per Target earthquake. Having a lot of EGF earthquakes associated to one Target event will generate more robust results and may increase the azimuthal coverage.

\subsection{Conclusions}

This thesis presents the first stress drop estimation for earthquakes occurring on and near New Zealand's Alpine Fault. Here we present our key findings and conclusions 


\section{Complex STFs}
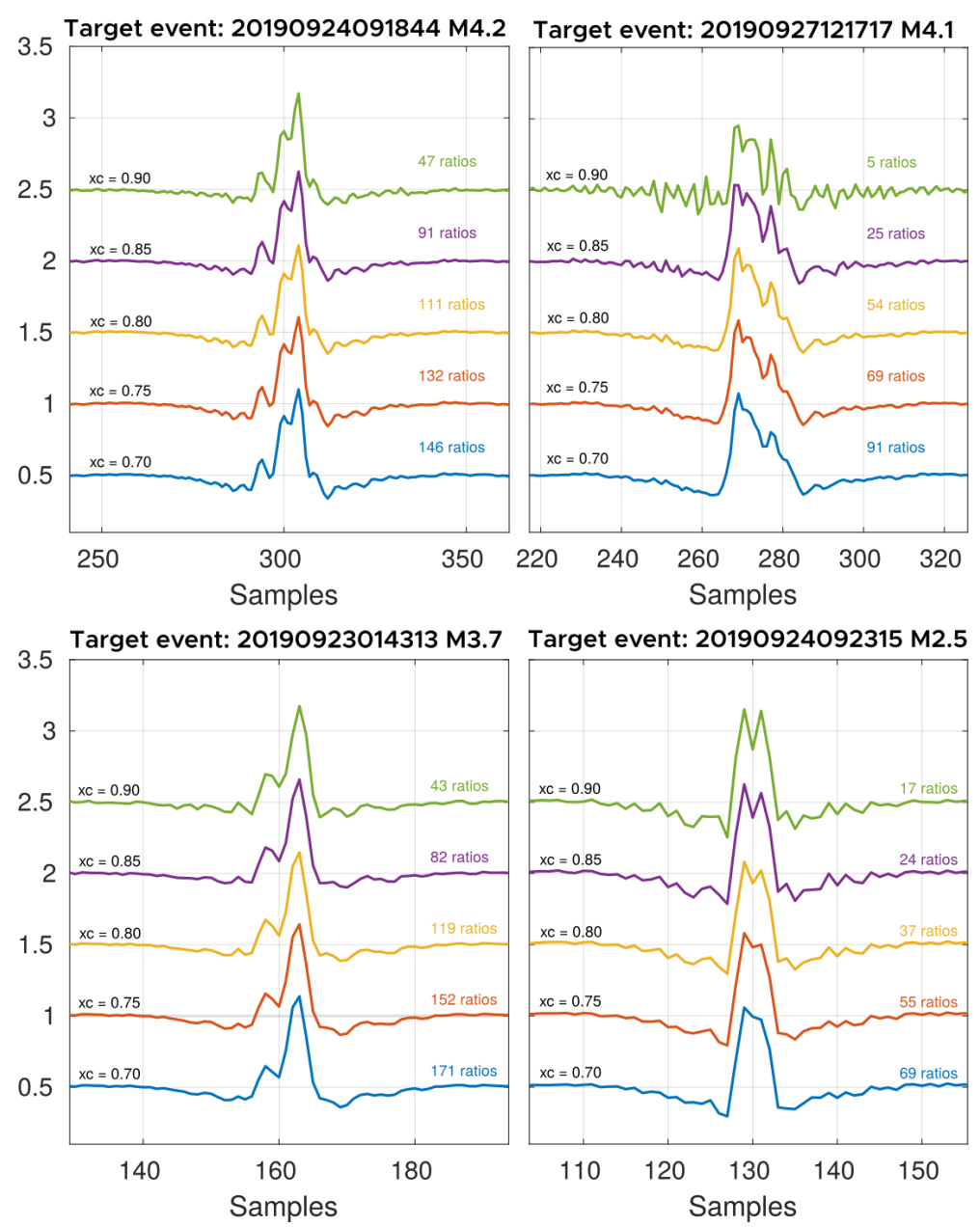

Figure 5.5: Complex STFs for four events located in a cluster along North Westland segment. Each panel presents the STFs calculated with different cross-correlation (xc) value $(\geq 0.70$ (blue), $\geq 0.75$ (orange), $\geq 0.80$ (yellow), $\geq 0.85$ (purple) and $\geq 0.90$ (green)) and the number of spectral ratios available for the calculation. 
with reference to the three main objectives established in Chapter 1:

\section{Identify moderate-magnitude earthquakes occurring on and close to the Alpine Fault}

- We use new and existing microearthquake catalogues along the Alpine Fault and identify $\sim 2500$ events of magnitudes $M_{L}-1.2$ to $M_{L} 4.3$ occurring within $5 \mathrm{~km}$ of the Alpine Fault.

- We construct a Target event catalogue of 245 earthquakes on and near the Alpine fault plane with magnitudes of $M_{L} 2.0$ to $M_{L} 4.3$.

2. Calculate stress drops for identified earthquakes on and close to the Alpine Fault

- We used an EGF approach to estimate the corner frequency and stress drop for 94 and 95 well-recorded moderate-magnitude earthquakes from P-and S-waves, respectively. These include results above a across-correlation limit of 0.8 to guarantee only the best quality results.

- The corner frequency results have been tested using two circular source models, of Brune (1970) and Boatwright (1980). We opt to use the Boatwright (1980) model as it provides a better empirical fit to our data.

- Corner frequency values range from 3 to $30 \mathrm{~Hz}$ and stress drop values range from 1 to $352 \mathrm{MPa}$.

- We derive new scaling relationships for local and moment magnitudes using events reported by GeoNet that have moment tensor solutions for the North and South Westland segments.

- Our Alpine Fault stress drop values lie within the range of global and regional (New Zealand) studies.

\section{Identify possible spatial variability in source properties along the Alpine Fault}

- We observe a stress drop variation between the three Alpine Fault segments. Stress drop median values for each Alpine Fault segment are: North Westland segment $15 \mathrm{MPa}$ (for P-wave) and $19 \mathrm{MPa}$ (for S-wave), Central segment $17 \mathrm{MPa}$ (for P-wave) and $39 \mathrm{MPa}$ (for S-wave) and South Westland segment $8 \mathrm{MPa}$ (for $\mathrm{P}$-wave) and $9 \mathrm{MPa}$ (for $\mathrm{S}$-wave) 
- Overall, the South Westland segment shows lower average stress drop values by $\sim 10-20 \mathrm{MPa}$.

- We propose an explanation for stress drop variation along the three main segments of the Alpine Fault based on fault strength. The strength of the Alpine Fault at the South Westland segment may be lower than along the Central segment, consistent with previous estimates of fault friction.

- No differences in stress drop values between events on and off the fault plane are observed. Neither do the stress drops obtained for the Alpine Fault depend systematically on depth, magnitude or focal mechanism. 


\section{Bibliography}

Abercrombie, R. E. (2014). Stress drops of repeating earthquakes on the San Andreas Fault at Parkfield. Geophysical Research Letters, 41(24):8784-8791.

Abercrombie, R. E. (2015). Investigating uncertainties in empirical green's function analysis of earthquake source parameters. Journal of Geophysical Research: Solid Earth, 120(6):4263-4277.

Abercrombie, R. E., Bannister, S., Pancha, A., Webb, T. H., and Mori, J. J. (2001). Determination of fault planes in a complex aftershock sequence using two-dimensional slip inversion. Geophysical Journal International, 146(1).

Abercrombie, R. E., Bannister, S., Ristau, J., and Doser, D. (2017a). Variability of earthquake stress drop in a subduction setting, the Hikurangi Margin, New Zealand. Geophysical Journal International, 208(1):306-320.

Abercrombie, R. E., Poli, P., and Bannister, S. (2017b). Earthquake directivity, orientation, and stress drop within the subducting plate at the Hikurangi Margin, New Zealand. Journal of Geophysical Research: Solid Earth, 122(12):176-10.

Aki, K. and Richards, P. (2002). Quantitative Seismology. Science, University Books, California, U.S.A, 2nd edition.

Allmann, B. P. and Shearer, P. M. (2009). Global variations of stress drop for moderate to large earthquakes. Journal of Geophysical Research: Solid Earth, 114(B1).

Anderson, J. and Hough, S. (1984). A model for the shape of the Fourier amplitude spectrum of acceleration at high frequencies. Bulletin of the Seismological Society of America, 75(5):1969-1993.

Arabasz, W. J. and Robinson, R. (1976). Microseismicity and geologic structure in the northern South Island, New Zealand. New Zealand Journal of Geology and Geophysics, 19(5):569-601.

Baratin, L.-M., Chamberlain, C. J., Townend, J., and Savage, M. K. (2018). Focal mechanisms and inter-event times of low-frequency earthquakes reveal quasicontinuous deformation and triggered slow slip on the deep Alpine Fault. Earth and Planetary Science Letters, 484:111-123.

Barnes, P. M. (2009). Postglacial (after $20 \mathrm{ka}$ ) dextral slip rate of the offshore Alpine fault, New Zealand. Geology, 37(1):3-6. 
Barnes, P. M., Sutherland, R., and Delteil, J. (2005). Strike-slip structure and sedimentary basins of the southern Alpine Fault, Fiordland, New Zealand. Geological Society of America Bulletin, 117(3):411.

Barth, N., Kulhanek, D., Beu, A., Murray-Wallace, C., Hayward, B., Mildenhall, D., and Lee, D. (2014). New c. 270 kyr strike-slip and uplift rates for the southern Alpine Fault and implications for the New Zealand plate boundary. Journal of Structural Geology, 64:39-52.

Barth, N. C., Boulton, C., Carpenter, B. M., Batt, G. E., and Toy, V. G. (2013). Slip localization on the southern Alpine Fault, New Zealand. Tectonics, 32(3).

Beavan, J., Denys, P., Denham, M., Hager, B., Herring, T., and Molnar, P. (2010). Distribution of present-day vertical deformation across the Southern Alps, New Zealand, from 10 years of GPS data. Geophysical Research Letters, 37(15):12-24.

Beavan, J., Moore, M., Pearson, C., Henderson, M., Parsons, B., Bourne, S., England, P., Walcott, D., Blick, G., Darby, D., and Hodgkinson, K. (1999). Crustal deformation during 1994-1998 due to oblique continental collision in the central Southern Alps, New Zealand, and implications for seismic potential of the Alpine fault. Journal of Geophysical Research: Solid Earth, 104(B11):25233-25255.

Bell, J. and Fraser, C. (1906). The geology of the Hokitika Sheet, north Westland quadrangle. New Zealand Geological Survey, pages 1-101.

Berryman, K., Beanland, S., Cooper, A. F., Cutten, H., Norris, R., and Wood, P. (1992). The Alpine Fault, New Zealand : Variation in Quaternary structural style and geomorphic expression. Annales Tectonicae, VI:126-163.

Berryman, K., Cooper, A., Norris, R., Villamor, P., Sutherland, R., Wright, T., Schermer, E., Langridge, R., and Biasi, G. (2012). Late Holocene rupture history of the Alpine Fault in South Westland, New Zealand. Bulletin of the Seismological Society of America, 102(2):620-638.

Beyreuther, M., Barsch, R., Krischer, L., Megies, T., Behr, Y., and Wassermann, J. (2010). ObsPy: A python toolbox for seismology. Seismological Research Letters, 81(3):530-533.

Boatwright, J. (1980). A spectral theory for circular seismic sources; simple estimates of source dimension, dynamic stress drop, and radiated seismic energy. Bulletin of the Seismological Society of America, 70(1):1-27.

Boese, C. (2012). Microseismicity in the Central Southern Alps, Westland, New Zealand. PhD thesis, Victoria Univeristy of Wellington.

Boese, C. M., Jacobs, K. M., Smith, E. G. C., Stern, T. A., and Townend, J. (2014). Background and delayed-triggered swarms in the central Southern Alps, South Island, New Zealand. Geochemistry, Geophysics, Geosystems, 15(4). 
Boese, C. M., Stern, T. A., Townend, J., Bourguignon, S., Sheehan, A., and Smith, E. G. (2013). Sub-crustal earthquakes within the Australia-Pacific plate boundary zone beneath the Southern Alps, New Zealand. Earth and Planetary Science Letters, $376: 212-219$.

Boese, C. M., Townend, J., Smith, E., and Stern, T. (2012). Microseismicity and stress in the vicinity of the Alpine Fault, central Southern Alps, New Zealand. Journal of Geophysical Research: Solid Earth, 117(B2).

Bormann, P., Baumbach, M., Bock, G., Grosser, G., Choy, L., and Boatwright, J. (2002). Seismic sources and source parameters. In IASPEI New Manual of Seismological Observatory Practice, volume 1, chapter 3, pages 1-94. Deutsches GeoForschungsZentrum.

Boulton, C., Barth, N. C., Moore, D. E., Lockner, D. A., Townend, J., and Faulkner, D. R. (2018). Frictional properties and 3-D stress analysis of the southern Alpine Fault, New Zealand. Journal of Structural Geology, 114.

Boulton, C., Moore, D. E., Lockner, D. A., Toy, V. G., Townend, J., and Sutherland, R. (2014). Frictional properties of exhumed fault gouges in DFDP-1 cores, Alpine Fault, New Zealand. Geophysical Research Letters, 41(2).

Bourguignon, S., Bannister, S., Henderson, C. M., Townend, J., and Zhang, H. (2015). Structural heterogeneity of the midcrust adjacent to the central Alpine Fault, New Zealand: Inferences from seismic tomography and seismicity between Harihari and Ross. Geochemistry, Geophysics, Geosystems, 16(4).

Boyd, O. S., McNamara, D. E., Hartzell, S., and Choy, G. (2017). Influence of lithostatic stress on earthquake stress drops in North America. Bulletin of the Seismological Society of America, 107(2):856-868.

Braunmiller, J., Kradolfer, U., Baer, M., and Giardini, D. (2002). Regional moment tensor determination in the European-Mediterranean area - initial results. Tectonophysics, 356(1-3):5-22.

Brune, J. N. (1970). Tectonic stress and the spectra of seismic shear waves from earthquakes. Journal of Geophysical Research, 75(26).

Calderoni, G., Rovelli, A., and Singh, S. K. (2013). Stress drop and source scaling of the 2009 April L'Aquila earthquakes. Geophysical Journal International, 192(1):260-274.

Caldwell, J. G. and Frohlich, C. (1975). Microearthquake study of the Alpine fault zone near Haast, South Island, New Zealand. Bulletin of the Seismological Society of America, 65(5):1097-1104.

Carter, R. and Norris, R. (1976). Cainozoic history of southern New Zealand: An accord between geological observations and plate-tectonic predictions. Earth and Planetary Science Letters, 31(1). 
Chamberlain, C. J. (2016). Improved earthquake detection as a probe for active fault structures in New Zealand's central Southern Alps. PhD thesis, Victoria University of Wellington, Wellington.

Chamberlain, C. J., Boese, C. M., Eccles, J. D., Savage, M. K., Baratin, L., Townend, J., Gulley, A. K., Jacobs, K. M., Benson, A., Taylor-Offord, S., Thurber, C., Guo, B., Okada, T., Takagi, R., Yoshida, K., Sutherland, R., and Toy, V. G. (2017). Real-time earthquake monitoring during the second phase of the Deep Fault Drilling Project, Alpine Fault, New Zealand. Seismological Research Letters, 88(6).

Chamberlain, C. J., Shelly, D. R., Townend, J., and Stern, T. A. (2014). Low-frequency earthquakes reveal punctuated slow slip on the deep extent of the Alpine Fault, New Zealand. Geochemistry, Geophysics, Geosystems, 15(7).

Cochran, U. A., Clark, K. J., Howarth, J. D., Biasi, G. P., Langridge, R. M., Villamor, P., Berryman, K. R., and Vandergoes, M. J. (2017). A plate boundary earthquake record from a wetland adjacent to the Alpine fault in New Zealand refines hazard estimates. Earth and Planetary Science Letters, 464:175-188.

Cooper, A. F. and Norris, R. J. (1990). Estimates for the timing of the last coseismic displacement on the Alpine Fault, northern Fiordland, New Zealand. New Zealand Journal of Geology and Geophysics, 33(2):303-307.

Cooper, R. A. (1989). Early Paleozoic terranes of New Zealand. Journal of the Royal Society of New Zealand, 19(1):73-112.

Cotton, F., Archuleta, R., and Causse, M. (2013). What is sigma of the stress drop? Seismological Research Letters, 84(1):42-48.

Cox, S. C., Stirling, M. W., Herman, F., Gerstenberger, M., and Ristau, J. (2012). Potentially active faults in the rapidly eroding landscape adjacent to the Alpine Fault, central Southern Alps, New Zealand. Tectonics, 31(2).

Cox, S. C. and Sutherland, R. (2007). Regional geological framework of South Island, New Zealand, and its significance for understanding the active plate boundary. In $A$ Continental Plate Boundary: Tectonics at South Island, New Zealand, pages 19-46. American Geophysical Union (AGU).

Cullen, L. E., Duncan, R. P., Wells, A., and Stewart, G. H. (2003). Floodplain and regional scale variation in earthquake effects on forests, Westland, New Zealand. Journal of the Royal Society of New Zealand, 33(4):693-701.

Deichmann, N. (2017). Theoretical basis for the observed break in ML/Mw scaling between small and large earthquakes. Bulletin of the Seismological Society of America, 107(2):505-520.

Dreger, D. S. (2003). 85.11 TDMT_INV: Time domain seismic moment tensor INVersion. In International Handbook of Earthquake and Engineering Seismology, page 1627. Elsevier. 
Eberhart-Phillips, D., Bannister, S., Reyners, M., and Henrys, S. (2020). New Zealand Wide model 2.2 seismic velocity and Qs and Qp models for New Zealand.

Eberhart-Phillips, D., Reyners, M., Bannister, S., Chadwick, M., and Ellis, S. (2010). Establishing a versatile 3-D seismic velocity model for New Zealand. Seismological Research Letters, 81(6):992-1000.

Eberhart-Phillips, D. (1995). Examination of seismicity in the central Alpine Fault region, South Island, New Zealand. New Zealand Journal of Geology and Geophysics, 38(4):571-578.

Eccles, J. D., Gulley, A. K., Malin, P. E., Boese, C. M., Townend, J., and Sutherland, R. (2015). Fault zone guided wave generation on the locked, late interseismic Alpine Fault, New Zealand. Geophysical Research Letters, 42(14).

Evison, F. (1971). Seismicity of the Alpine Fault, New Zealand. Bull. R. Soc. NZ, pages 161-165.

Feenstra, J., Thurber, C., Townend, J., Roecker, S., Bannister, S., Boese, C., Lord, N., Bourguignon, S., and Eberhart-Phillips, D. (2016). Microseismicity and P-wave tomography of the central Alpine Fault, New Zealand. New Zealand Journal of Geology and Geophysics, 59(4).

Fry, B. and Gerstenberger, M. C. (2011). Large apparent stresses from the Canterbury earthquakes of 2010 and 2011. Seismological Research Letters, 82(6):833-838.

Guo, B., Thurber, C., Roecker, S., Townend, J., Rawles, C., Chamberlain, C., Boese, C., Bannister, S., Feenstra, J., and Eccles, J. (2017). 3-D P- and S-wave velocity structure along the central Alpine Fault, South Island, New Zealand. Geophysical Journal International, 209(2).

Haines, A., I.M., C., and Ware, D. (1979). Crustal seismicity near Lake Pukaki, South Island. The origin of the Southern Alps. The Royal Society of New Zealand bulletin, 18:87-94.

Hanks, T. C. and Boore, D. M. (1984). Moment-magnitude relations in theory and practice. Journal of Geophysical Research: Solid Earth, 89(B7):6229-6235.

Hanks, T. C. and Kanamori, H. (1979). A moment magnitude scale. Journal of Geophysical Research, 84(B5):2348.

Hardebeck, J. L. and Aron, A. (2009). Earthquake Stress Drops and Inferred Fault Strength on the Hayward Fault, East San Francisco Bay, California. Bulletin of the Seismological Society of America, 99(3):1801-1814.

Hartung, J., Knapp, G., and Sinha, B. K. (2008). Statistical meta-analysis with applications. John Wiley \& Sons, Inc., Hoboken, NJ, USA. 
Haskell, N. A. (1964). Total energy and energy spectral density of elastic wave radiation from propagating faults. Bulletin of the Seismological Society of America, 54(6A):1811-1841.

Haskell, N. A. (1966). Total energy and energy spectral density of elastic wave radiation from propagating faults. Part II. A statistical source model. Bulletin of the Seismological Society of America, 56(1):125-140.

Hatch, R. L., Abercrombie, R. E., Ruhl, C. J., and Smith, K. D. (2018). Earthquake interaction, fault structure, and source properties of a small sequence in 2017 near Truckee, California. Bulletin of the Seismological Society of America, 108(5A).

Havskov, J. and Alguacil, G. (2016). Instrumentation in earthquake seismology. Springer International Publishing, Cham.

Herman, F., Braun, J., and Dunlap, W. J. (2007). Tectonomorphic scenarios in the Southern Alps of New Zealand. Journal of Geophysical Research: Solid Earth, 112(B4).

Herrmann, R. B. (2013). Computer programs in seismology: an evolving tool for instruction and research. Seismological Research Letters, 84(6):1081-1088.

Howarth, J. D., Barth, N. C., Fitzsimons, S. J., Richards-Dinger, K., Clark, K. J., Biasi, G. P., Cochran, U. A., Langridge, R. M., Berryman, K. R., and Sutherland, R. (2021). Spatiotemporal clustering of great earthquakes on a transform fault controlled by geometry. Nature Geoscience, 14(5).

Howarth, J. D., Cochran, U. A., Langridge, R. M., Clark, K., Fitzsimons, S. J., Berryman, K., Villamor, P., and Strong, D. T. (2018). Past large earthquakes on the Alpine Fault: paleoseismological progress and future directions. New Zealand Journal of Geology and Geophysics, 61(3):309-328.

Howarth, J. D., Fitzsimons, S. J., Norris, R. J., Langridge, R., and Vandergoes, M. J. (2016). A 2000 yr rupture history for the Alpine fault derived from Lake Ellery, South Island, New Zealand. Geological Society of America Bulletin, 128(3-4):627-643.

Huang, Y., Beroza, G. C., and Ellsworth, W. L. (2016). Stress drop estimates of potentially induced earthquakes in the Guy-Greenbrier sequence. Journal of Geophysical Research: Solid Earth, 121(9):6597-6607.

Huang, Y., Ellsworth, W. L., and Beroza, G. C. (2017). Stress drops of induced and tectonic earthquakes in the central United States are indistinguishable. Science Advances, 3(8):e1700772.

Hull, A. and Berryman, K. (1986). Holocene tectonism in the region of the Alpine Fault at Lake McKerrow, Fiordland, New Zealand. Recent crustal movements of the Pacific Region. Royal Society of New Zealand Bullentin, 24:317-331. 
Ide, S., Beroza, G. C., Prejean, S. G., and Ellsworth, W. L. (2003). Apparent break in earthquake scaling due to path and site effects on deep borehole recordings. Journal of Geophysical Research: Solid Earth, 108(B5).

Imanishi, K. and Ellsworth, W. L. (2006). Source scaling relationships of microearthquakes at Parkfield, CA, determined using the SAFOD pilot hole seismic array. In Earthquakes: Radiated Energy and the Physics of Faulting, pages 81-90. American Geophysical Union (AGU).

Kame, N., Rice, J. R., and Dmowska, R. (2003). Effects of prestress state and rupture velocity on dynamic fault branching. Journal of Geophysical Research: Solid Earth, 108(B5).

Kanamori, H. (1977). The energy release in great earthquakes. Journal of Geophysical Research, 82(20):2981-2987.

Kanamori, H. (1994). Mechanics of Earthquakes. Annual Review of Earth and Planetary Sciences, 22(1):207-237.

Kanamori, H. and Brodsky, E. E. (2001). The physics of earthquakes. Physics Today, $54(6): 34-40$.

Kane, D. L., Kilb, D. L., and Vernon, F. L. (2013). Selecting Empirical Green's Functions in regions of Fault complexity: A study of data from the San Jacinto Fault Zone, Southern California. Bulletin of the Seismological Society of America, 103(2A).

Kaneko, Y. and Shearer, P. M. (2015). Variability of seismic source spectra, estimated stress drop, and radiated energy, derived from cohesive-zone models of symmetrical and asymmetrical circular and elliptical ruptures. Journal of Geophysical Research: Solid Earth, 120(2).

Ko, Y.-T., Kuo, B.-Y., and Hung, S.-H. (2012). Robust determination of earthquake source parameters and mantle attenuation. Journal of Geophysical Research: Solid Earth, 117(B4).

Kohler, M. D. (2003). Intermediate-depth warthquakes in a region of continental convergence: South Island, New Zealand. Bulletin of the Seismological Society of America, 93(1):85-93.

Koons, P. O. (1990). Two-sided orogen: Collision and erosion from the sandbox to the Southern Alps, New Zealand. Geology, 18(8):679.

Koons, P. O., Norris, R. J., Craw, D., and Cooper, A. F. (2003). Influence of exhumation on the structural evolution of transpressional plate boundaries: An example from the Southern Alps, New Zealand. Geology, 31(1):3.

Landis, C. and Coombs, D. (1967). Metamorphic belts and orogenesis in southern New Zealand. Tectonophysics, 4(4-6). 
Langridge, R., Villamor, P., Basili, R., Almond, P., Martinez-Diaz, J., and Canora, C. (2010). Revised slip rates for the Alpine fault at Inchbonnie: Implications for plate boundary kinematics of South Island, New Zealand. Lithosphere, 2(3):139-152.

Langridge, R. M., Basili, R., Basher, L., and Wells, A. P. (2012). Late Holocene landscape change history related to the Alpine Fault determined from drowned forests in Lake Poerua, Westland, New Zealand. Natural Hazards and Earth System Sciences, 12(6):2051-2064.

Langridge, R. M., Ries, W. F., Dolan, J. F., Schermer, E. R., and Siddoway, C. (2017). Slip rate estimates and slip gradient for the Alpine Fault at Calf Paddock, Maruia River, New Zealand. New Zealand Journal of Geology and Geophysics, 60(2):73-88.

Leitner, B., Eberhart-Phillips, D., Anderson, H., and Nabelek, J. L. (2001). A focused look at the Alpine fault, New Zealand: Seismicity, focal mechanisms, and stress observations. Journal of Geophysical Research: Solid Earth, 106(B2).

Little, T. A. and Jones, A. (1998). Seven million years of strike-slip and related off-fault deformation, northeastern Marlborough fault system, South Island, New Zealand. Tectonics, 17(2):285-302.

Lomax, A., Michelini, A., and Curtis, A. (2009). Earthquake location, direct, globalsearch Methods. In Encyclopedia of Complexity and Systems Science, pages 24492473. Springer New York, New York, NY.

Lozos, J. C., Oglesby, D. D., Brune, J. N., and Olsen, K. B. (2012). Small intermediate fault segments can either aid or hinder rupture propagation at stepovers. Geophysical Research Letters, 39(18).

Mackinnon, T. (1983). Origin of the Torlesse terrane and coeval rocks, South Island, New Zealand. Geological Society of America Bulletin, 94(8):967.

Madariaga, R. (1976). Dynamics of an expanding circular fault. Bulletin of the Seismological Society of America, 66(3):639-666.

MATLAB (2019). 9.7.0.1190202 (R2019b). The MathWorks Inc., Natick, Massachusetts.

McNamara, D. E. (2004). Ambient noise levels in the continental United States. Bulletin of the Seismological Society of America, 94(4).

Michailos, K. (2019). Microseismicity, tectonic stress, and exhumation rates near the central Alpine Fault, New Zealand. PhD thesis, Victoria University of Wellington, Wellington.

Michailos, K., Smith, E. G., Chamberlain, C. J., Savage, M. K., and Townend, J. (2019). Variations in seismogenic thickness along the central Alpine Fault, New Zealand, revealed by a decade's relocated microseismicity. Geochemistry, Geophysics, Geosystems, 20(1):470-486. 
Michailos, K., Warren-Smith, E., Savage, M. K., and Townend, J. (2020). Detailed spatiotemporal analysis of the tectonic stress regime near the central Alpine Fault, New Zealand. Tectonophysics, 775.

Mori, J. and Frankel, A. (1990). Source parameters for small events associated with the 1986 North Palm Springs, California, earthquake determined using empirical Green functions. Bulletin of the Seismological Society of America, 80(2):278-295.

Mortimer, N. (1994). Origin of the Torlesse Terrane and Coeval Rocks, North Island, New Zealand. International Geology Review, 36(10):891-910.

Mortimer, N. (2004). New Zealand's geological foundations. Gondwana Research, 7(1).

Mortimer, N. and Campbell, H. (2014). Zealandia: Our Continent Revealed. Penguin.

Moyer, P. A., Boettcher, M. S., McGuire, J. J., and Collins, J. A. (2018). Spatial and temporal variations in earthquake stress drop on Gofar Transform Fault, East Pacific Rise: implications for fault strength. Journal of Geophysical Research: Solid Earth, 123(9):7722-7740.

Nathan, S. (1976). Geochemistry of the Greenland Group (early Ordovician), New Zealand. New Zealand Journal of Geology and Geophysics, 19(5):683-706.

Niemeijer, A. R., Boulton, C., Toy, V. G., Townend, J., and Sutherland, R. (2016). Large-displacement, hydrothermal frictional properties of DFDP-1 fault rocks, Alpine Fault, New Zealand: Implications for deep rupture propagation. Journal of Geophysical Research: Solid Earth, 121(2).

Norris, R. J. and Cooper, A. F. (1997). Erosional control on the structural evolution of a transpressional thrust complex on the Alpine fault, New Zealand. Journal of Structural Geology, 19(10):1323-1342.

Norris, R. J. and Cooper, A. F. (2001). Late Quaternary slip rates and slip partitioning on the Alpine Fault, New Zealand. Journal of Structural Geology, 23(2-3):507-520.

Norris, R. J. and Toy, V. G. (2014). Continental transforms: A view from the Alpine Fault. Journal of Structural Geology, 64:3-31.

O'Keefe, B. (2008). Microseismicity of the central Alpine Fault region, New Zealand. $\mathrm{PhD}$ thesis, Victoria University of Wellington.

Oth, A., Bindi, D., Parolai, S., and Di Giacomo, D. (2011). Spectral analysis of K-NET and kiK-net data in Japan, part II: On attenuation characteristics, source spectra, and site response of borehole and surface stations. Bulletin of the Seismological Society of America, 101(2).

Oth, A. and Kaiser, A. E. (2014). Stress release and source scaling of the 2010-2011 Canterbury, New Zealand earthquake sequence from spectral inversion of ground motion data. Pure and Applied Geophysics, 171(10). 
Pacor, F., Spallarossa, D., Oth, A., Luzi, L., Puglia, R., Cantore, L., Mercuri, A., D'Amico, M., and Bindi, D. (2016). Spectral models for ground motion prediction in the L'Aquila region (central Italy): evidence for stress-drop dependence on magnitude and depth. Geophysical Journal International, 204(2).

Peterson, J. R. and Survey, U. S. G. (1993). Observations and modeling of seismic background noise. Technical report, U.S. Geological Survey.

Prieto, G. A., Parker, R. L., and Vernon III, F. L. (2009). A Fortran 90 library for multitaper spectrum analysis. Computers $\&$ Geosciences, 35(8):1701 - 1710.

Prieto, G. A., Thomson, D. J., Vernon, F. L., Shearer, P. M., and Parker, R. L. (2007). Confidence intervals for earthquake source parameters. Geophysical Journal International, 168(3):1227-1234.

Reed, J. J. (1964). Mylonites, cataclasites, and associated rocks along the Alpine Fault, South Island, New Zealand. New Zealand Journal of Geology and Geophysics, $7(4): 645-684$.

Reyners, M. (1988). Reservoir-induced seismicity at Lake Pukaki, New Zealand. Geophysical Journal International, 93(1):127-135.

Reyners, M., Eberhart-Phillips, D., Upton, P., and Gubbins, D. (2017). Threedimensional imaging of impact of a large igneous province with a subduction zone. Earth and Planetary Science Letters, 460:143-151.

Rhoades, D. A., Christophersen, A., Bourguignon, S., Ristau, J., and Salichon, J. (2020). A depth-dependent local magnitude scale for New Zealand earthquakes consistent with moment magnitude. Bulletin of the Seismological Society of America.

Ristau, J. (2013). Update of regional moment tensor analysis for earthquakes in New Zealand and adjacent offshore regions. Bulletin of the Seismological Society of America, 103(4):2520-2533.

Ristau, J., Harte, D., and Salichon, J. (2016). A revised local magnitude (ML) scale for New Zealand earthquakes. Bulletin of the Seismological Society of America, 106(2):398-407.

Ruhl, C. J., Abercrombie, R. E., and Smith, K. D. (2017). Spatiotemporal variation of stress drop during the 2008 Mogul, Nevada, earthquake swarm. Journal of Geophysical Research: Solid Earth, 122(10).

Rynn, J. M. W. and Scholz, C. H. (1978). Seismotectonics of the Arthur's Pass region, South Island, New Zealand. Geological Society of America Bulletin, 89(9).

Scholz, C. H., Rynn, J. M. W., Weed, R. W., and Frohlich, C. (1973). Detailed seismicity of the Alpine Fault Zone and Fiordland Region, New Zealand. Geological Society of America Bulletin, 84(10). 
Shearer, P. M., Abercrombie, R. E., Trugman, D. T., and Wang, W. (2019). Comparing EGF methods for estimating corner frequency and stress drop from P save spectra. Journal of Geophysical Research: Solid Earth, 124(4):3966-3986.

Shearer, P. M., Prieto, G. A., and Hauksson, E. (2006). Comprehensive analysis of earthquake source spectra in southern California. Journal of Geophysical Research: Solid Earth, 111(B6).

Stein, S. and Wysession, M. (2003). Introduction to Seismology, Earthquakes, and Earth Structure. Blackwell Publishing Ltd.

Stirling, M., McVerry, G., Gerstenberger, M., Litchfield, N., Van Dissen, R., Berryman, K., Barnes, P., Wallace, L., Villamor, P., Langridge, R., Lamarche, G., Nodder, S., Reyners, M., Bradley, B., Rhoades, D., Smith, W., Nicol, A., Pettinga, J., Clark, K., and Jacobs, K. (2012). National seismic hazard model for New Zealand: 2010 update. Bulletin of the Seismological Society of America, 102(4):1514-1542.

Sutherland, R., Davey, F., and Beavan, J. (2000). Plate boundary deformation in South Island, New Zealand, is related to inherited lithospheric structure. Earth and Planetary Science Letters, 177(3-4):141-151.

Sutherland, R., Eberhart-Phillips, D., Harris, R. A., Stern, T., Beavan, J., Ellis, S., Henrys, S., Cox, S., Norris, R. J., Berryman, K. R., Townend, J., Bannister, S., Pettinga, J., Leitner, B., Wallace, L., Little, T. A., Cooper, A. F., Yetton, M., and Stirling, M. (2007). Do great earthquakes occur on the alpine fault in central South Island, New Zealand? In Geophysical Monograph Series, volume 175, pages 235-251. Blackwell Publishing Ltd.

Sutherland, R., Townend, J., Toy, V., Upton, P., Coussens, J., Allen, M., Baratin, L.-M., Barth, N., Becroft, L., Boese, C., Boles, A., Boulton, C., Broderick, N. G. R., Janku-Capova, L., Carpenter, B. M., Célérier, B., Chamberlain, C., Cooper, A., Coutts, A., Cox, S., Craw, L., Doan, M.-L., Eccles, J., Faulkner, D., Grieve, J., Grochowski, J., Gulley, A., Hartog, A., Howarth, J., Jacobs, K., Jeppson, T., Kato, N., Keys, S., Kirilova, M., Kometani, Y., Langridge, R., Lin, W., Little, T., Lukacs, A., Mallyon, D., Mariani, E., Massiot, C., Mathewson, L., Melosh, B., Menzies, C., Moore, J., Morales, L., Morgan, C., Mori, H., Niemeijer, A., Nishikawa, O., Prior, D., Sauer, K., Savage, M., Schleicher, A., Schmitt, D. R., Shigematsu, N., TaylorOfford, S., Teagle, D., Tobin, H., Valdez, R., Weaver, K., Wiersberg, T., Williams, J., Woodman, N., and Zimmer, M. (2017). Extreme hydrothermal conditions at an active plate-bounding fault. Nature, 546(7656):137-140.

Sutherland, R., Townend, J., and Toy, V. G. (2013). Deep Fault Drilling Project, DFDP-1 and DFDP-2, Alpine Fault, New Zealand. In AGU Fall Meeting Abstracts, volume 2013, pages T23E-2630.

Tomic, J., Abercrombie, R. E., and do Nascimento, A. F. (2009). Source parameters and rupture velocity of small M 2.1 reservoir induced earthquakes. Geophysical Journal International, 179(2):1013-1023. 
Townend, J., Sutherland, R., and Toy, V. (2009). Deep Fault Drilling Project-Alpine fault, New Zealand. Scientific Drilling.

Trugman, D. T. and Shearer, P. M. (2017). Application of an improved spectral decomposition method to examine earthquake source scaling in Southern California. Journal of Geophysical Research: Solid Earth, 122(4):2890-2910.

Uchida, N., Matsuzawa, T., Ellsworth, W. L., Imanishi, K., Shimamura, K., and Hasegawa, A. (2012). Source parameters of microearthquakes on an interplate asperity off Kamaishi, NE Japan over two earthquake cycles. Geophysical Journal International, 189(2).

Viegas, G., Abercrombie, R. E., and Kim, W.-Y. (2010). The 2002 M5 Au Sable Forks, NY, earthquake sequence: Source scaling relationships and energy budget. Journal of Geophysical Research, 115(B7).

Waldhauser, F. (2001). hypoDD-A Program to compute double-difference hypocenter locations. Technical report, Earthquake Science Center.

Wallace, L. M., Beavan, J., McCaffrey, R., Berryman, K., and Denys, P. (2007). Balancing the plate motion budget in the South Island, New Zealand using GPS, geological and seismological data. Geophysical Journal International, 168(1):332-352.

Walsh, D., Arnold, R., and Townend, J. (2009). A Bayesian approach to determining and parametrizing earthquake focal mechanisms. Geophysical Journal International, $176(1)$.

Warren, L. M. and Silver, P. G. (2006). Measurement of differential rupture durations as constraints on the source finiteness of deep-focus earthquakes. Journal of Geophysical Research: Solid Earth, 111(B6).

Warren-Smith, E., Lamb, S., and Stern, T. A. (2017a). Stress field and kinematics for diffuse microseismicity in a zone of continental transpression, South Island, New Zealand. Journal of Geophysical Research: Solid Earth, 122(4).

Warren-Smith, E., Lamb, S., Stern, T. A., and Smith, E. (2017b). Microseismicity in Southern South Island, New Zealand: Implications for the mechanism of crustal deformation adjacent to a major continental transform. Journal of Geophysical Research: Solid Earth, 122(11).

Wech, A. G., Boese, C. M., Stern, T. A., and Townend, J. (2012). Tectonic tremor and deep slow slip on the Alpine Fault. Geophysical Research Letters, 39(10).

Wech, A. G., Sheehan, A. F., Boese, C. M., Townend, J., Stern, T. A., and Collins, J. A. (2013). Tectonic tremor recorded by ocean bottom seismometers. Seismological Research Letters, 84(5).

Wellman, H. and Willet, R. (1942). The Geology of the West Coast from Abut Head to Milford Sound-Part 1. Transactions and Proceedings of the Royal Society of New Zealand, 71:282-301. 
Wells, A., Duncan, R. P., and Stewart, G. H. (2001). Forest dynamics in Westland, New Zealand: the importance of large, infrequent earthquake-induced disturbance. Journal of Ecology, 89(6):1006-1018.

Wells, A., Stewart, G. H., and Duncan, R. P. (1998). Evidence of widespread, synchronous, disturbance-initiated forest establishment in Westland, New Zealand. Journal of the Royal Society of New Zealand, 28(2):333-345.

Wells, A., Yetton, M. D., Duncan, R. P., and Stewart, G. H. (1999). Prehistoric dates of the most recent Alpine fault earthquakes, New Zealand. Geology, 27(11):995.

Yetton, M. and Wells, A. (2010). Earthquake rupture history of the Alpine fault over the last 500 years. In Geologically Active: Proceedings of 11th International Association for Engineering Geology and the Environment Congress, Auckland, pages 881-891. CRC Press/Balkema - Taylor \& Francis Group.

Zachariasen, J., Berryman, K., Langridge, R., Prentice, C., Rymer, M., Stirling, M., and Villamor, P. (2006). Timing of late Holocene surface rupture of the Wairau Fault, Marlborough, New Zealand. New Zealand Journal of Geology and Geophysics, 49(1):159-174.

Zeitler, P. K., Meltzer, A. S., Koons, P. O., Craw, D., Hallet, B., Chamberlain, C. P., Kidd, W. S., Park, S. K., Seeber, L., Bishop, M., and Shroder, J. (2001). Erosion, Himalayan Geodynamics, and the Geomorphology of Metamorphism. GSA Today, 11(1):4. 


\section{Appendix A}

\section{DWARFS: Dense Westland Arrays Researching Fault Segmentation appendix}

In this Appendix, the methods for event detection, picking, location, magnitude and focal mechanism calculations undertaken by Dr Emily Warren-Smith are outlined. These methods outline work not included in this thesis, but provide the context for the unpublished DWARFS catalogues used for further analysis in this thesis. Earthquake catalogues for both Northern and Southern DWARFS regions are constructed using the same methodologies, based on previous microearthquake studies along the Alpine Fault (e.g. Boese et al., 2012; Michailos et al., 2019).

\section{A.1 Event Detection and Phase Picking}

In addition to the 19 DWARFS broadband stations, GeoNet strong motion and broadband stations are utilised (JCZ, NSBS, MSZ, HDWS for DWARFS South and INZ, LTZ, OXZ, WVZ, APPS and ARPS for DWARFS North). For DWARFS South, four SAMBA sites (MTBA, LARB, SOLU, COVA) and COSA sites were also used for the larger events. Event detection is initially undertaken manually, by applying a $2-10 \mathrm{~Hz}$ bandpass filter to vertical channels of hour-long waveforms and identifying by eye events occurring on at least 2 stations. This enabled easy separation of local events from falsely detected regional waveforms, which were difficult to remove from amplitude-based STA/LTA detections approaches, particularly with productive 
Appendix A. DWARFS: Dense Westland Arrays Researching Fault Segmentation appendix

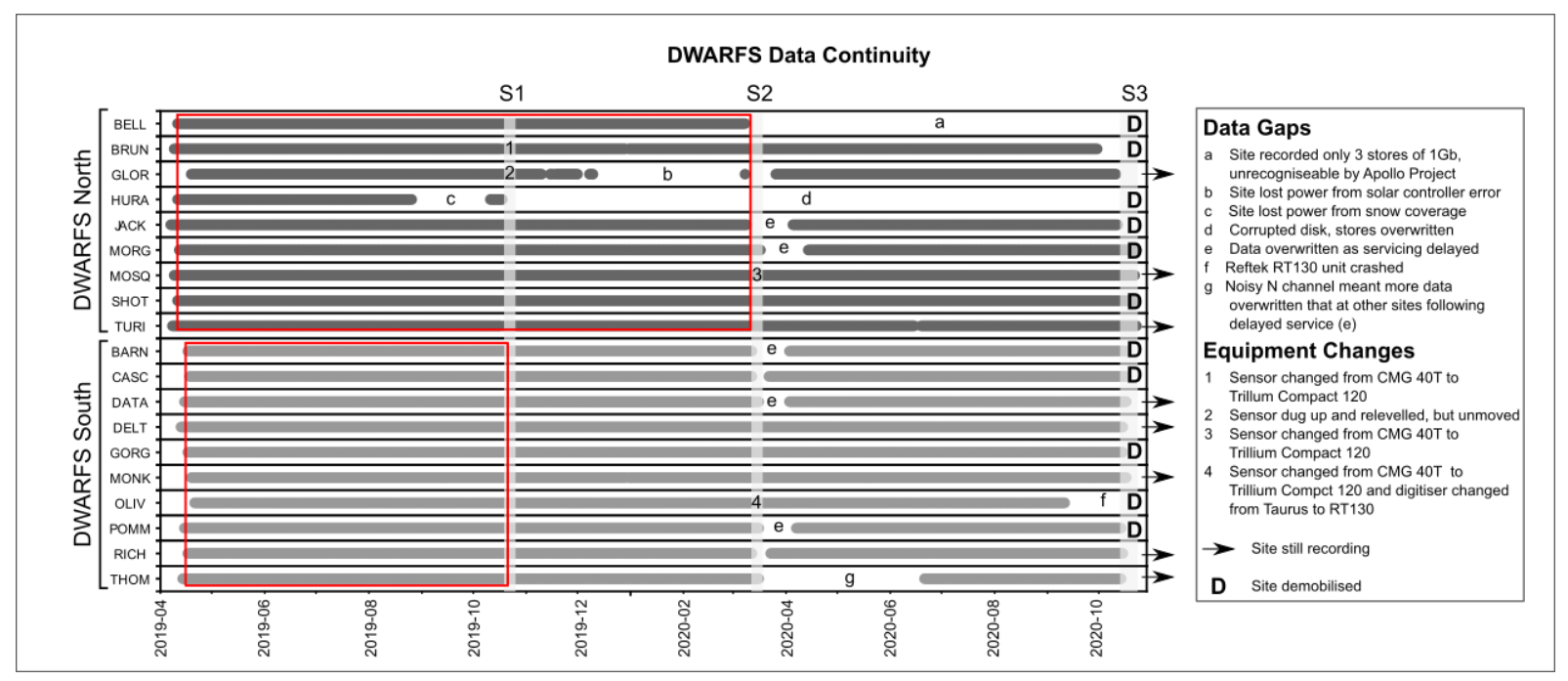

\section{Figure A.1: DWARFS data continuity}

19 DWARFS stations were installed during April 2019 and only 11 were removed during October 2020. Eighth stations continue recording. The continuity of the data during the 18 month DWARFS was good overall, only two stations (BELL and HURA, northern DWARFS) stopped working due to climatic conditions and instruments failures.

Fiordland sequences located close to DWARFS South. P-phases were then manually picked, polarities recorded where possible and the event registered. Following this, the horizontal channels are added into the hour long-waveforms containing detections and S-phases are picked where possible on the horizontal channels. This enabled some events with only $2 \mathrm{P}$-phases to then be locatable as S-phases could be added onto a third or fourth station with no clear P-arrival.

\section{A.2 Event Location}

Resulting registered events are then located using a linear location algorithm (HYPOCENTRE) in SEISAN using a 1D velocity model unique to each network and extracted from Eberhart-Phillips et al. (2010) to produce origin times. All events are then relocated using a non-linear location algorithm (NonLinLoc, Lomax et al. (2009)) and a 3D velocity model from Eberhart-Phillips et al. (2010). A final round of double difference relative relocation is performed using HypoDD 3D (Waldhauser, 2001), where starting locations are determined by NonLinLoc locations (or SEISAN if NonLinLoc locations unavailable). Both catalogue and cross-correlation data were used and clustering was enabled across 35 iterations with increasing weight on cross-correlation data from the 15th iteration onwards to help resolve fine-scale structures. For events which were not 
able to be relocated, the origin calculated using NonLinLoc is assigned.

\section{A.3 Magnitudes}

Peak displacement amplitudes (half peak to trough, in $\mathrm{mm}$ ) are picked on pre-filtered $(2-20 \mathrm{~Hz})$ vertical channel waveforms following instrument response removal. Local magnitudes $\left(M_{L v}\right)$ are calculated for events with at least 2 amplitude picks using a least squares inversion method to solve for attenuation geometrical spreading and station correction terms and develop a localised magnitude scale for each study region independently (following Boese et al. (2012); Warren-Smith et al. (2017b); Michailos et al. (2019)). We calibrate our scale against $\left(M_{L v}\right)$ estimates of earthquakes from GeoNet as insufficient moment magnitude $\left(M_{w}\right)$ estimates exist during our study period to invert for a more accurate moment scale as preferred by Michailos et al. (2019).

\section{A.4 Focal Mechanisms}

Direct P-phase arrival polarities were picked on unfiltered waveforms where unambiguous and events with at least 5 polarities were selected for focal mechanism calculation using the Bayesian approach of Walsh et al. (2009). This approach includes the effect location uncertainties on take off angles, by incorporating the PDF scatter of hypocentres calculated using NonLinLoc (Lomax et al., 2009). For events that were not relocatable with HypoDD and where the NonLinLoc location was the best estimate, the PDF scatter calculated for that location was used. For events relocated with HypoDD, the PDF uncertainty was forward modelled with the HypoDD location as fixed using the Time2EQ programme in NonLinLoc. 
Appendix A. DWARFS: Dense Westland Arrays Researching Fault Segmentation appendix 


\section{Appendix B}

\section{DWARFS: Ambient Noise Characteristics}

This appendix summarises the performance of DWARFS stations, though analysis of frequency dependent noise characteristics.

\section{B.1 Spectral Noise Plots}

Ambient noise signals recorded at seismographs provide information pertaining to the site quality. Ambient noise is characterised using the power spectral density, $P(\omega)$, which is the Fourier transform of the auto-correlation function of the noise, $p(\tau)$, according to (Bormann et al., 2002):

$$
P(\omega)=\int_{\infty}^{-\infty} p(\tau) \exp (i \omega \tau) d \tau
$$

where $\omega$ is the angular frequency, and $\tau$ a time interval. Ambient noise sources include water bodies (i.e. rivers, lakes, ocean waves), which dominate in the microseismic frequency band 0.05-0.5 Hz, wind and cultural noise (e.g. traffic and machinery), which dominate at higher frequencies ( $>2-4 \mathrm{~Hz}$ ) (Havskov and Alguacil, 2016).

Plots presented in Figures B.1-B.19 characterise response corrected noise energy over the frequency range $0-100 \mathrm{~Hz}$ (to the Nyquist frequency of the sampling rate of $200 \mathrm{~Hz}$ ), calculated for a one month period (July 2019) on all three-components. Plots are generated using the Python Obspy package, PPSD (probabilistic power spectral density), based on the routine of McNamara (2004). Gray lines represent the high and 
low noise levels from Peterson and Survey (1993).

All stations show a similar general pattern; a peak in noise is observed at $0.2 \mathrm{~Hz}$, and two lows at $0.09 \mathrm{~Hz}$ and $2 \mathrm{~Hz}$. 

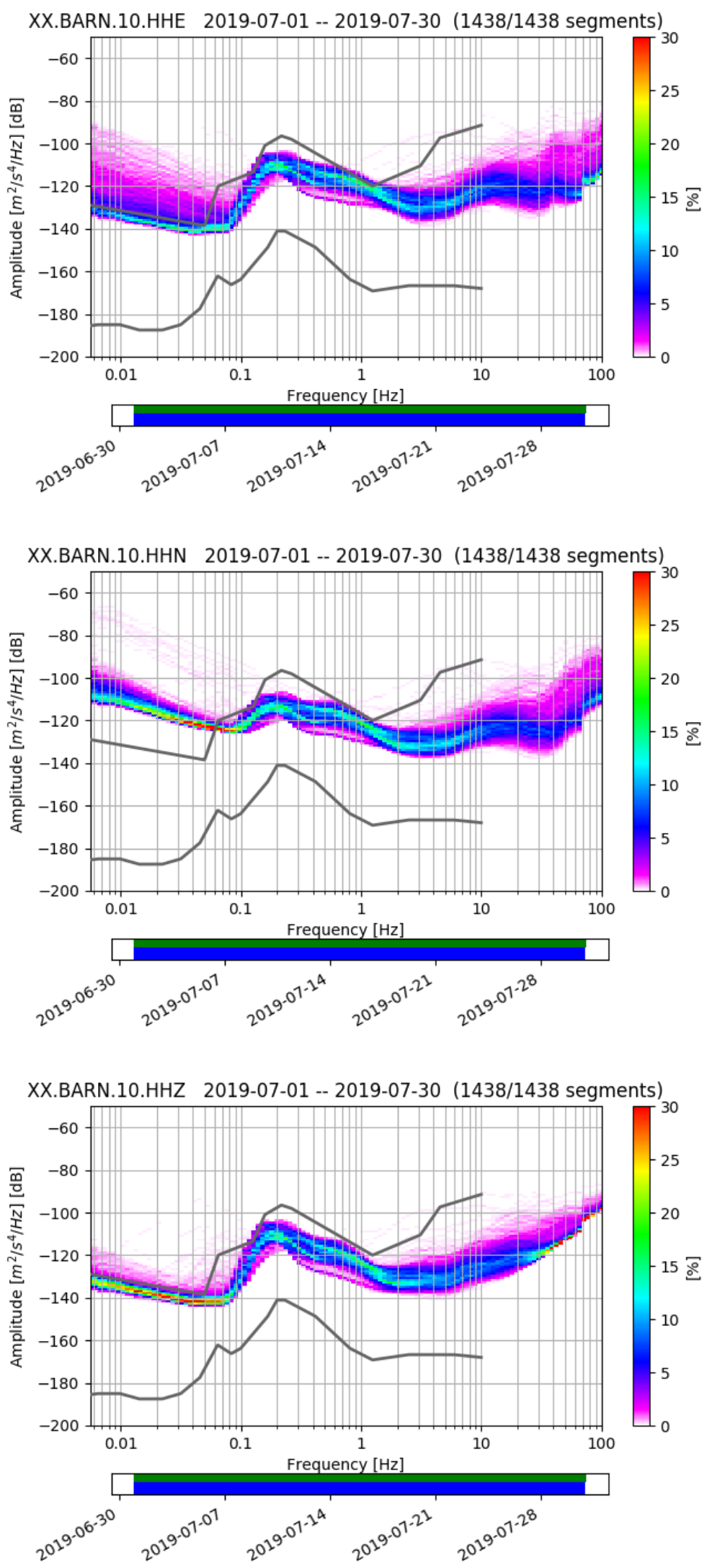

Figure B.1: Spectral energy plots for vertical (HHZ) and horizontal (HHE, HHN) channels for Southern DWARFS station BARN. 

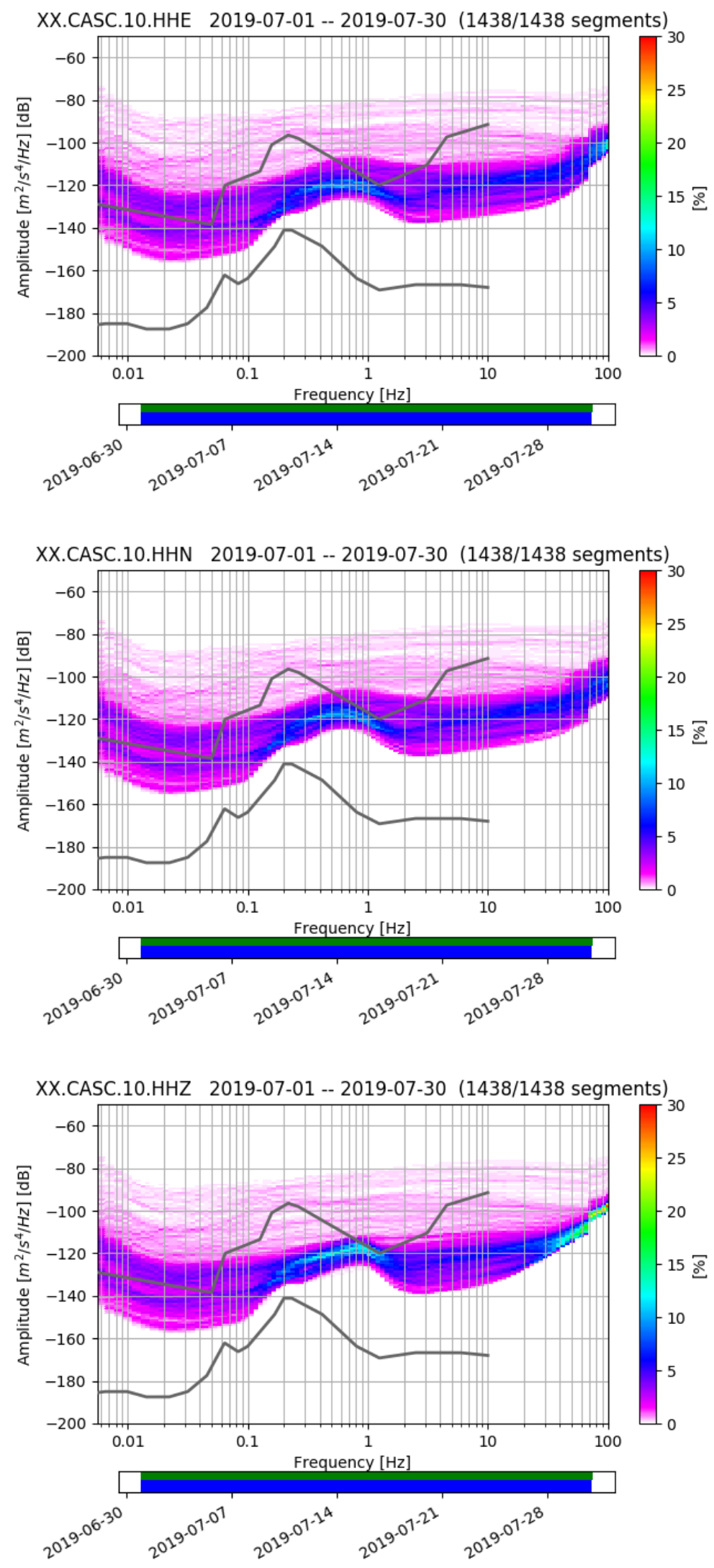

Figure B.2: Spectral energy plots for vertical (HHZ) and horizontal (HHE, HHN) channels for Southern DWARFS station CASC. 

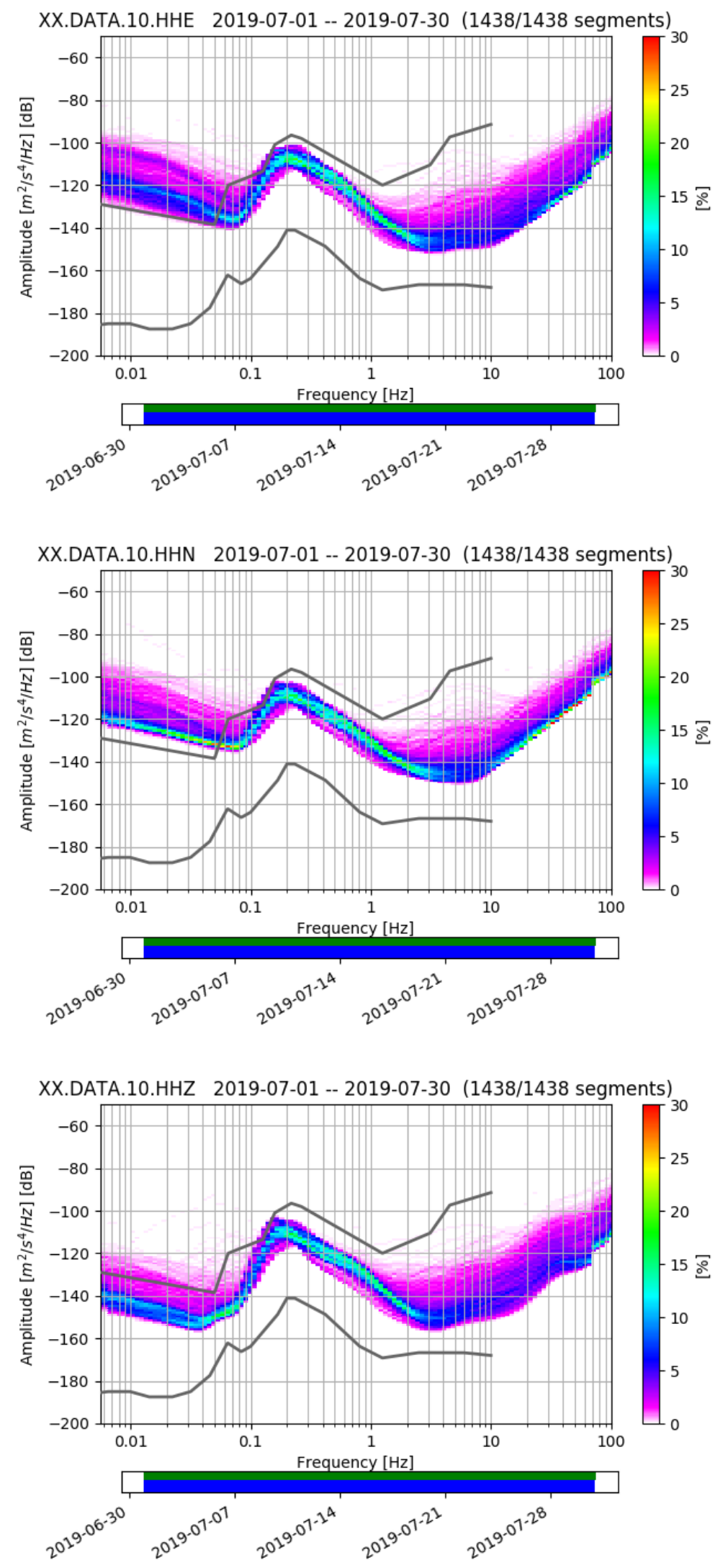

Figure B.3: Spectral energy plots for vertical (HHZ) and horizontal (HHE, HHN) channels for Southern DWARFS station DATA. 

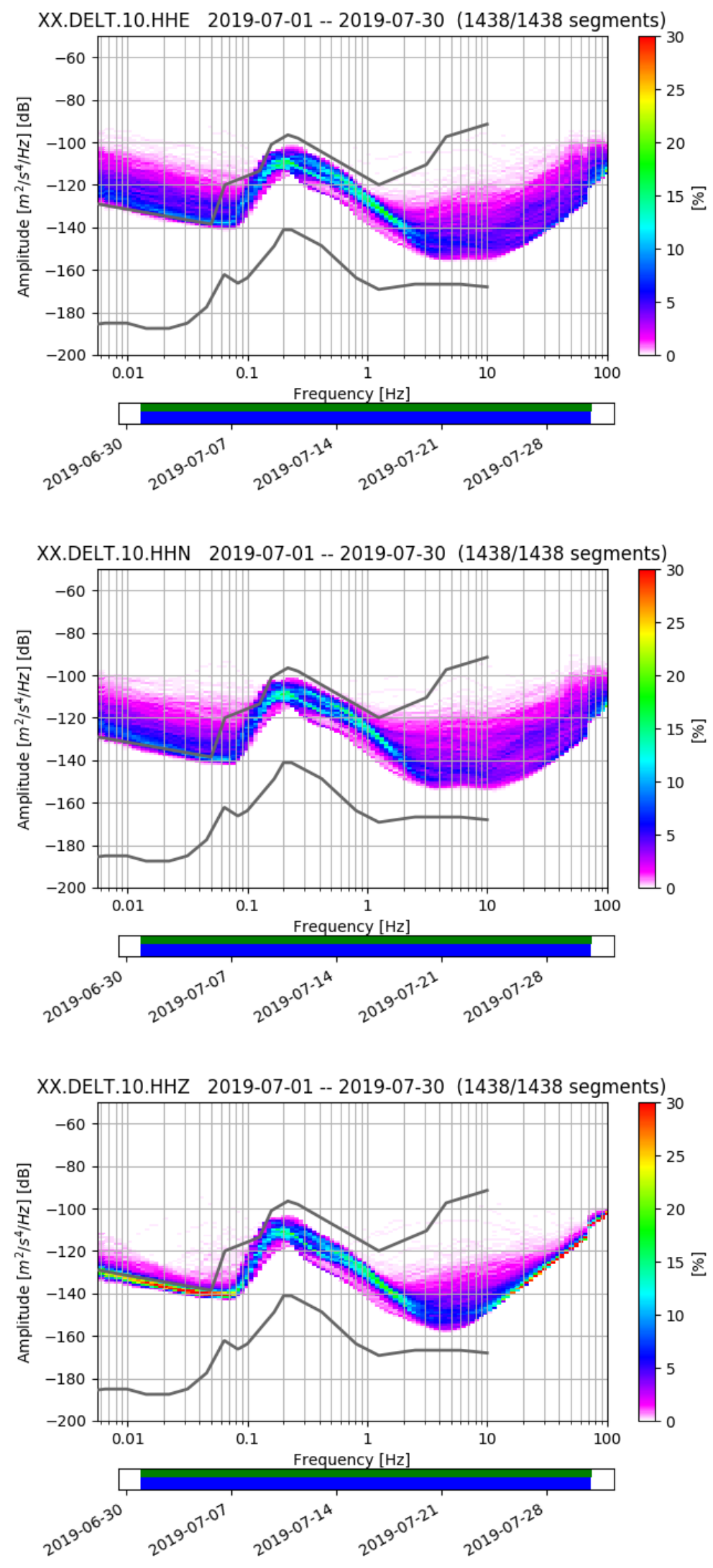

Figure B.4: Spectral energy plots for vertical (HHZ) and horizontal (HHE, HHN) channels for Southern DWARFS station DELT. 

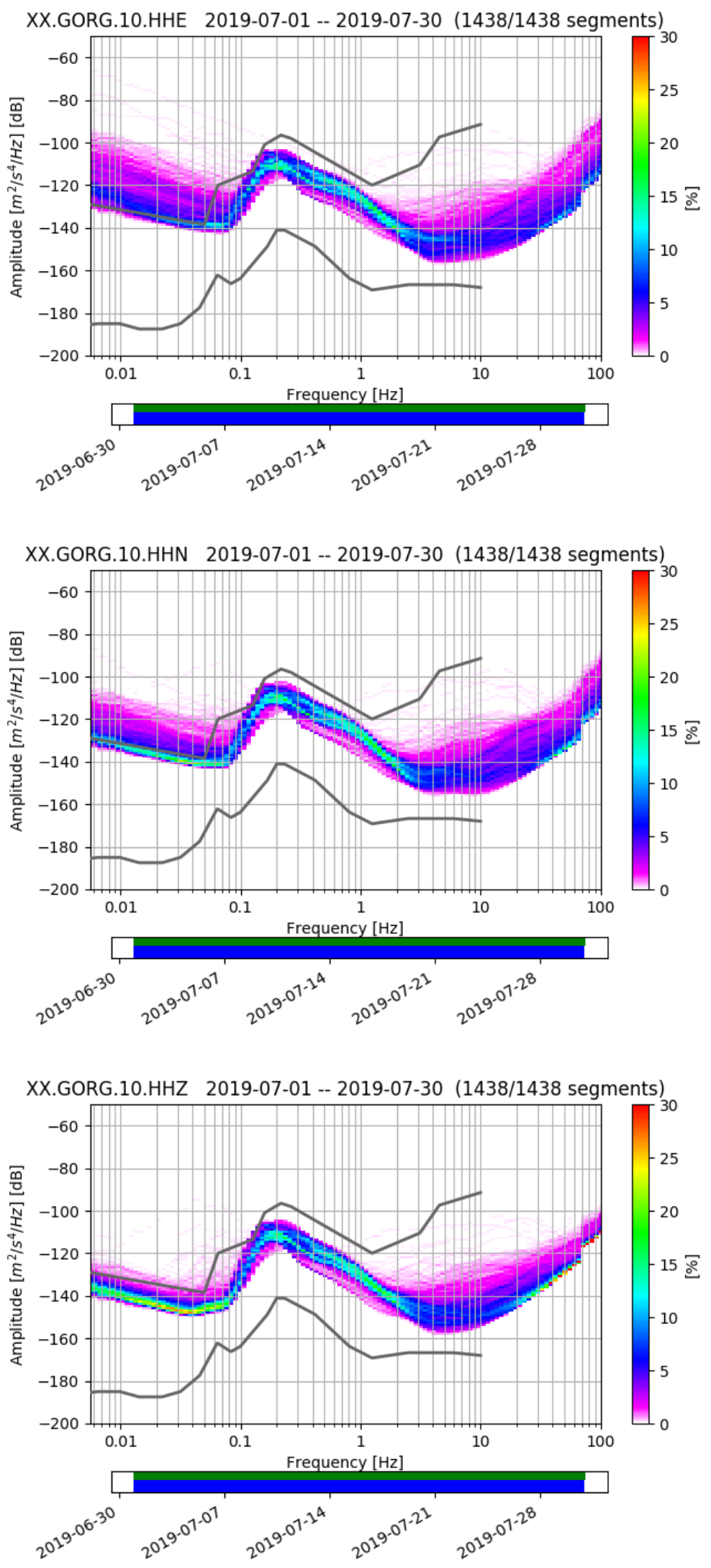

Figure B.5: Spectral energy plots for vertical (HHZ) and horizontal (HHE, HHN) channels for Southern DWARFS station GORG. 

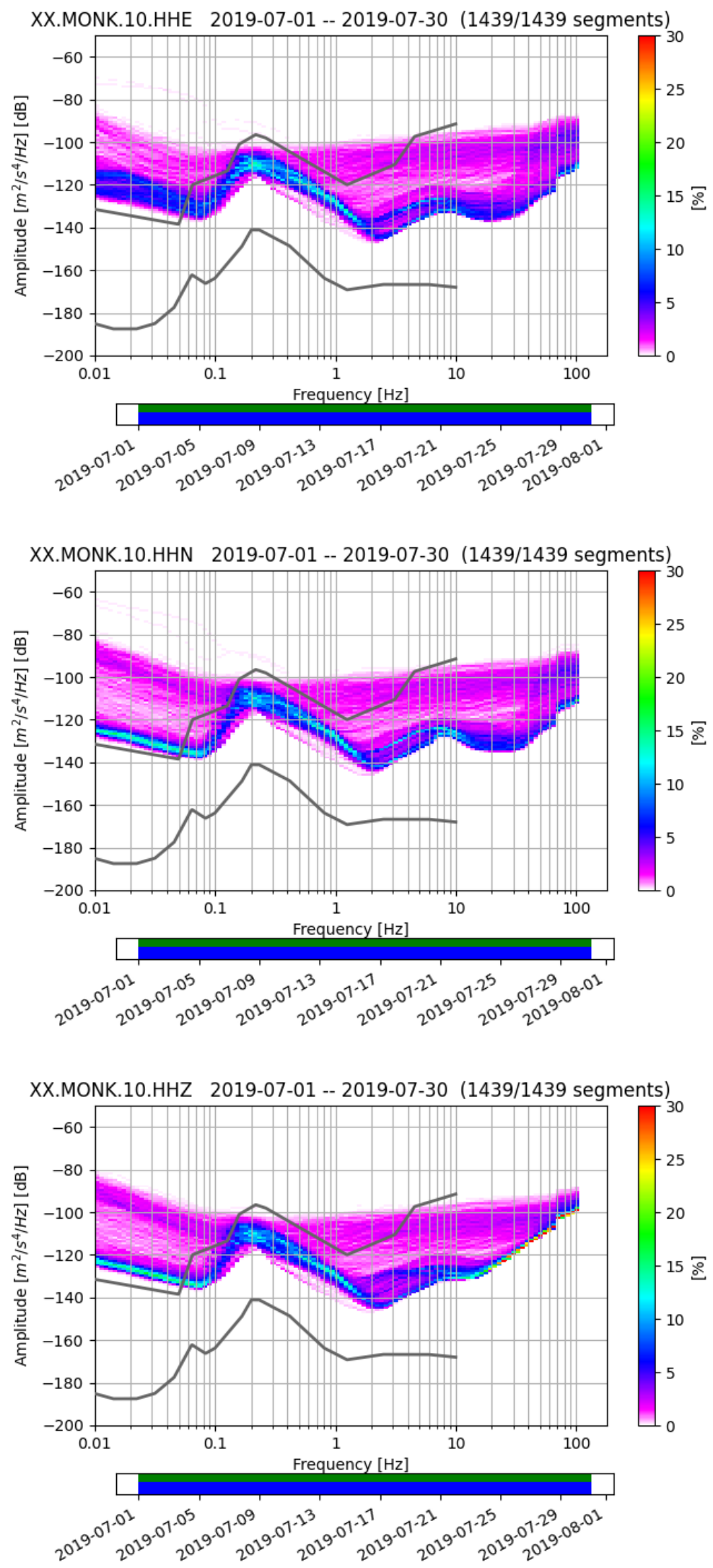

Figure B.6: Spectral energy plots for vertical (HHZ) and horizontal (HHE, HHN) channels for Southern DWARFS station MONK. 

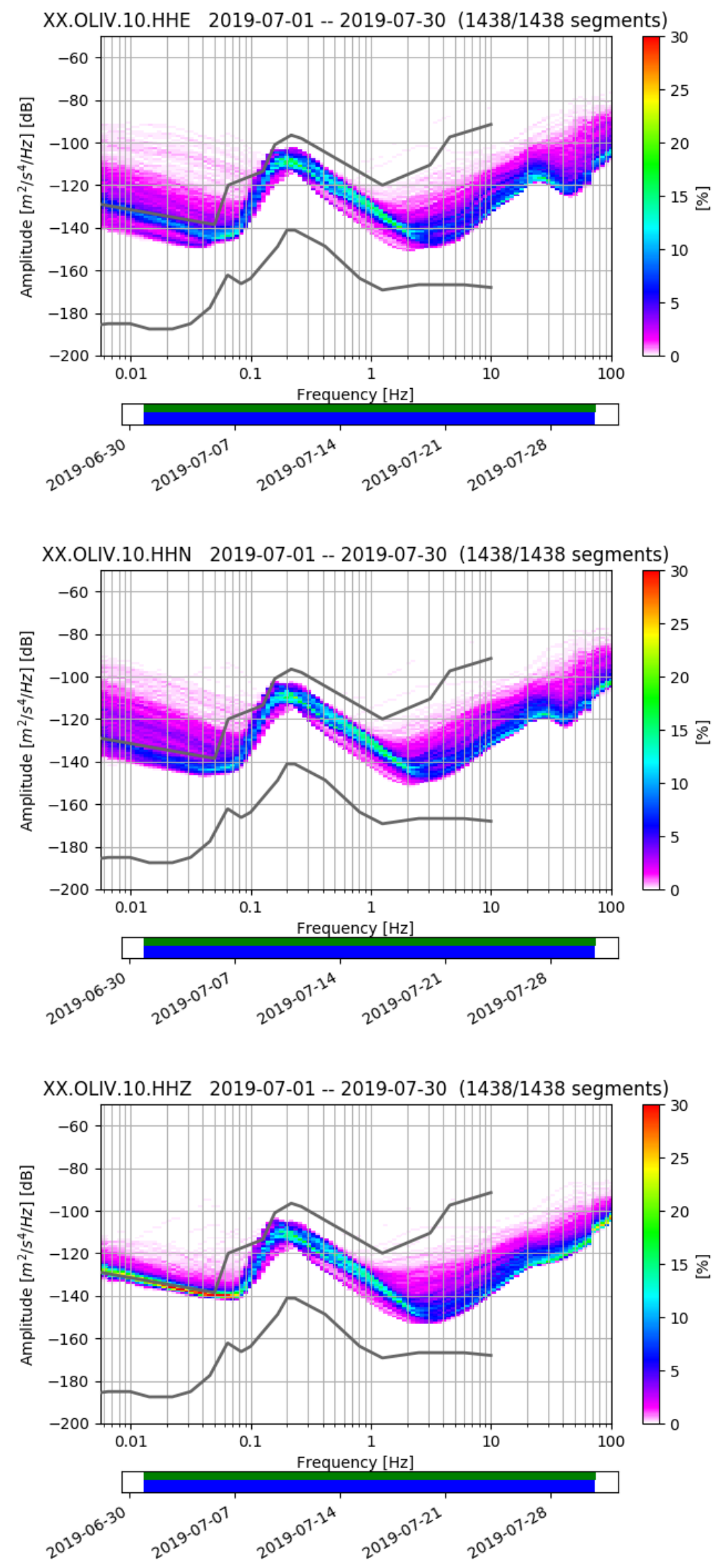

Figure B.7: Spectral energy plots for vertical (HHZ) and horizontal (HHE, HHN) channels for Southern DWARFS station OLIV. 

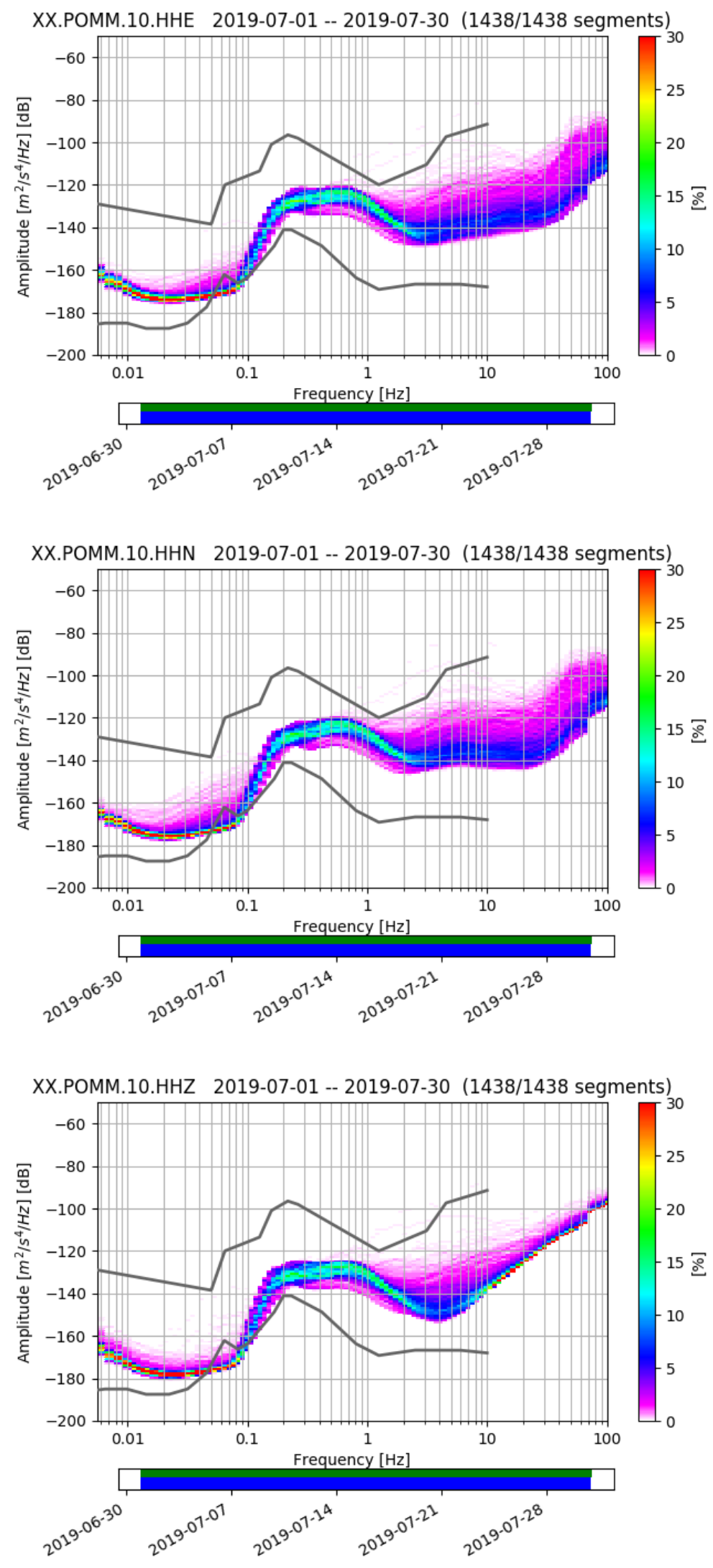

Figure B.8: Spectral energy plots for vertical (HHZ) and horizontal (HHE, HHN) channels for Southern DWARFS station POMM. 

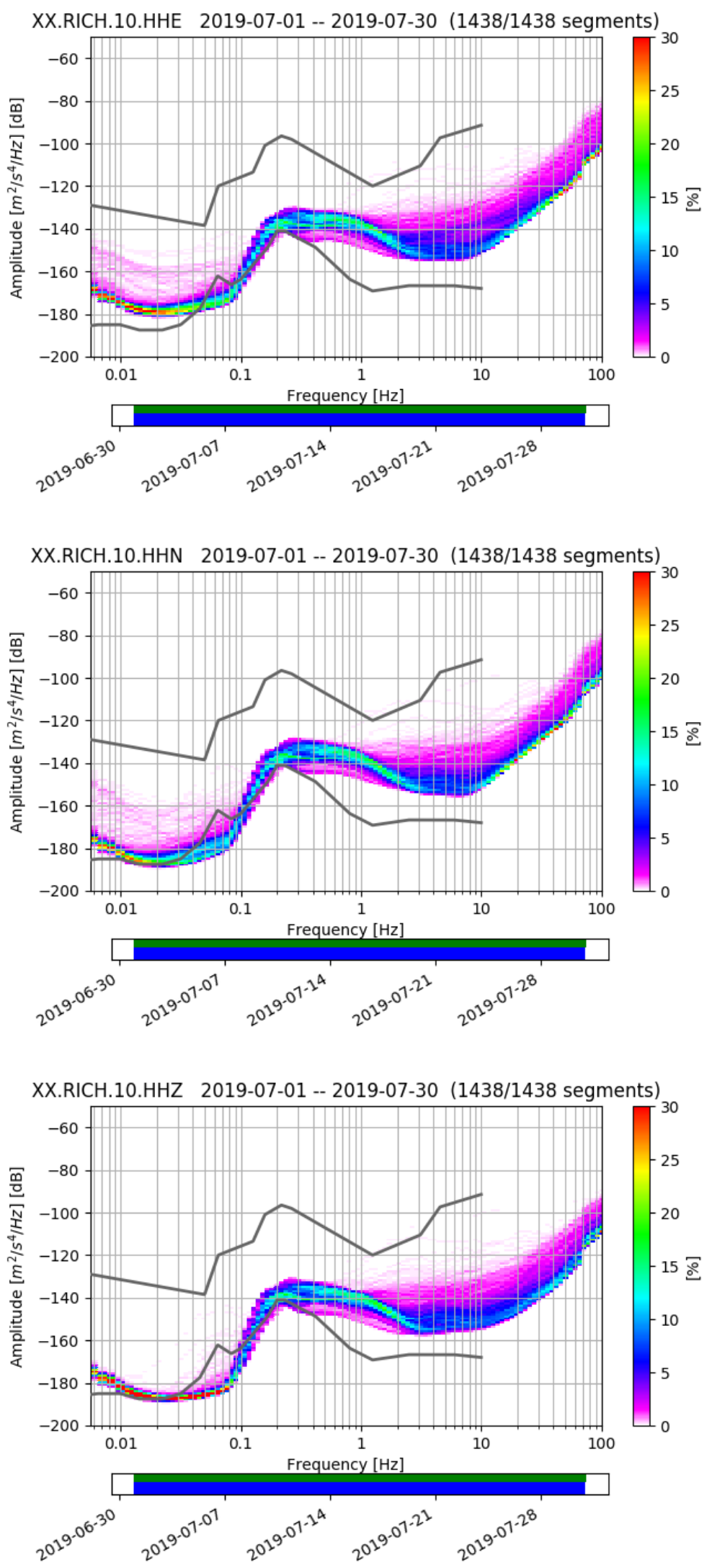

Figure B.9: Spectral energy plots for vertical (HHZ) and horizontal (HHE, HHN) channels for Southern DWARFS station RICH. 

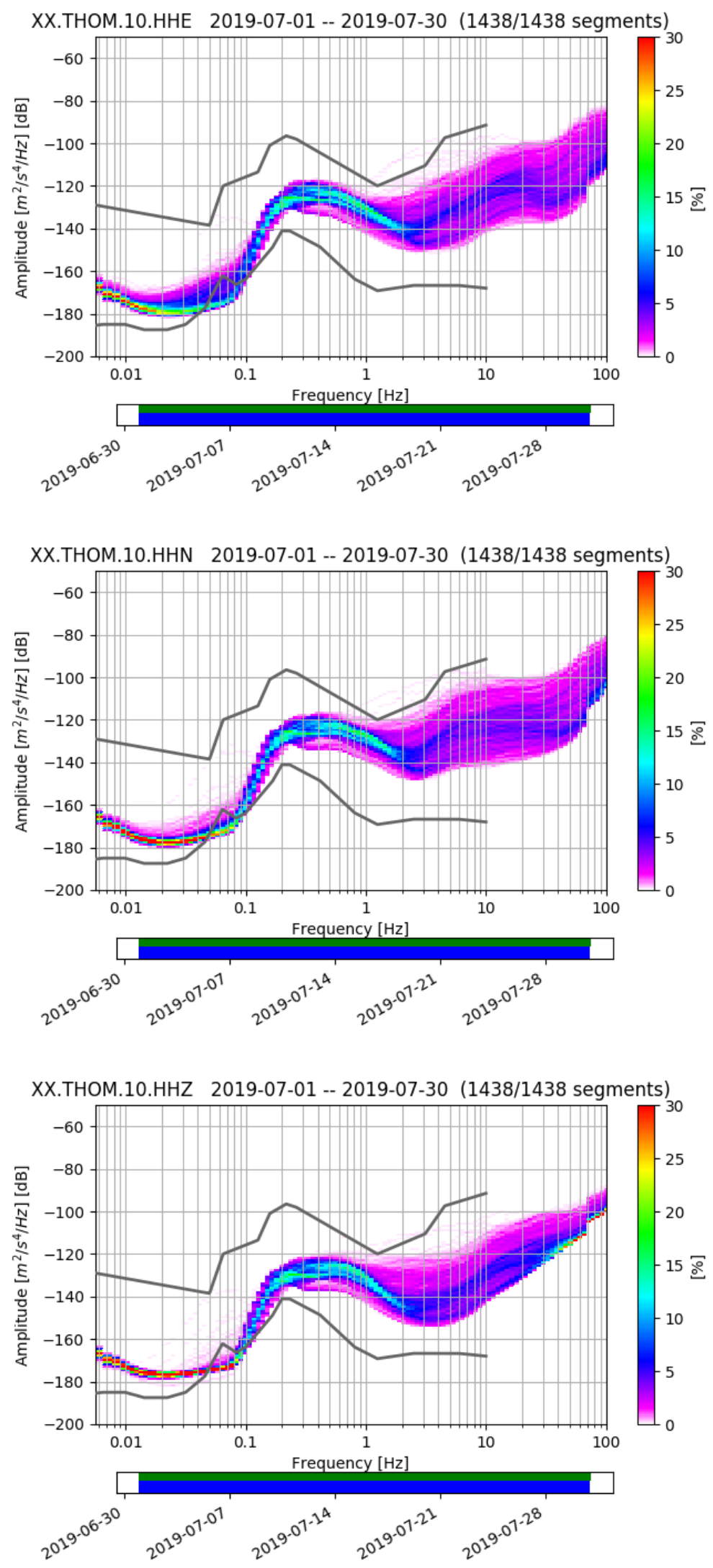

Figure B.10: Spectral energy plots for vertical (HHZ) and horizontal (HHE, HHN) channels for Southern DWARFS station THOM. 

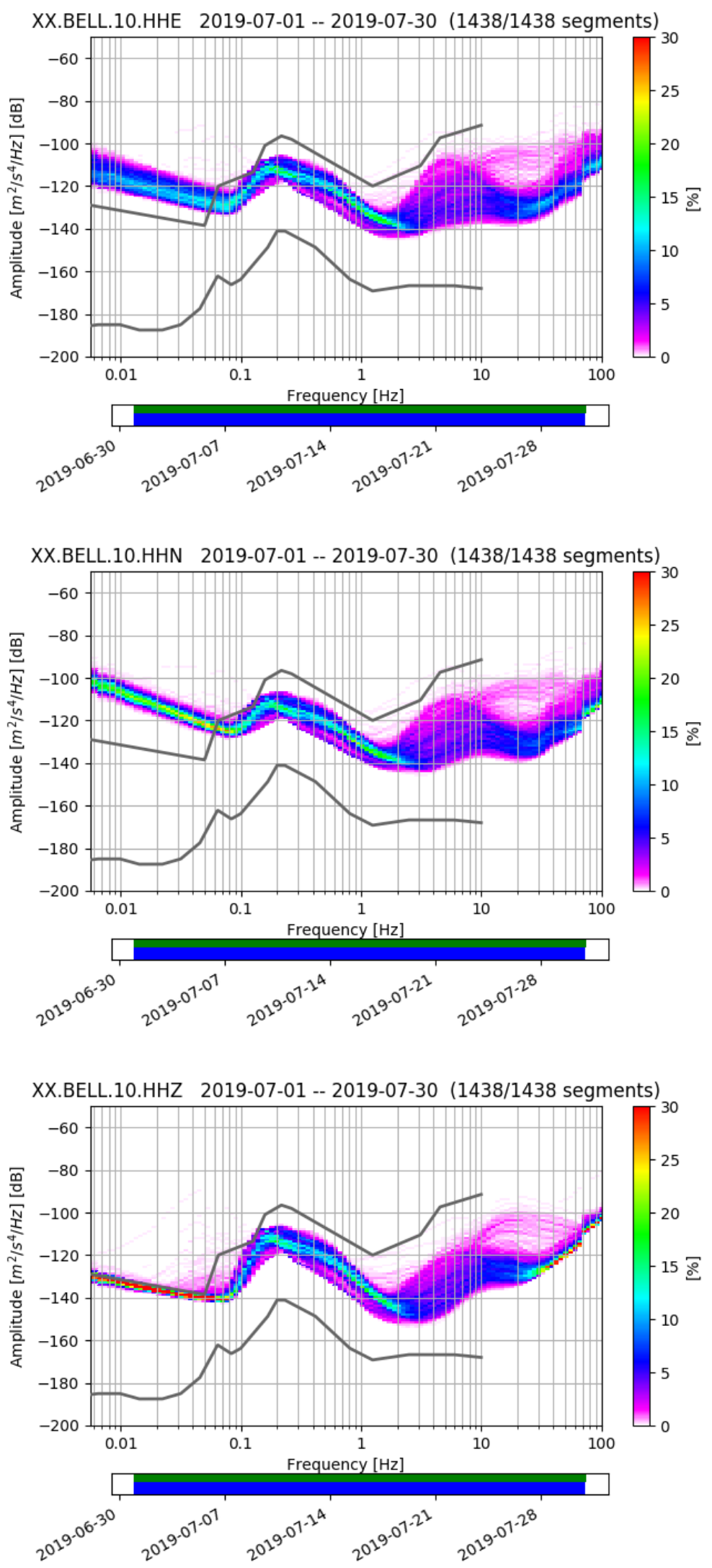

Figure B.11: Spectral energy plots for vertical (HHZ) and horizontal (HHE, HHN) channels for Northern DWARFS station BELL. 

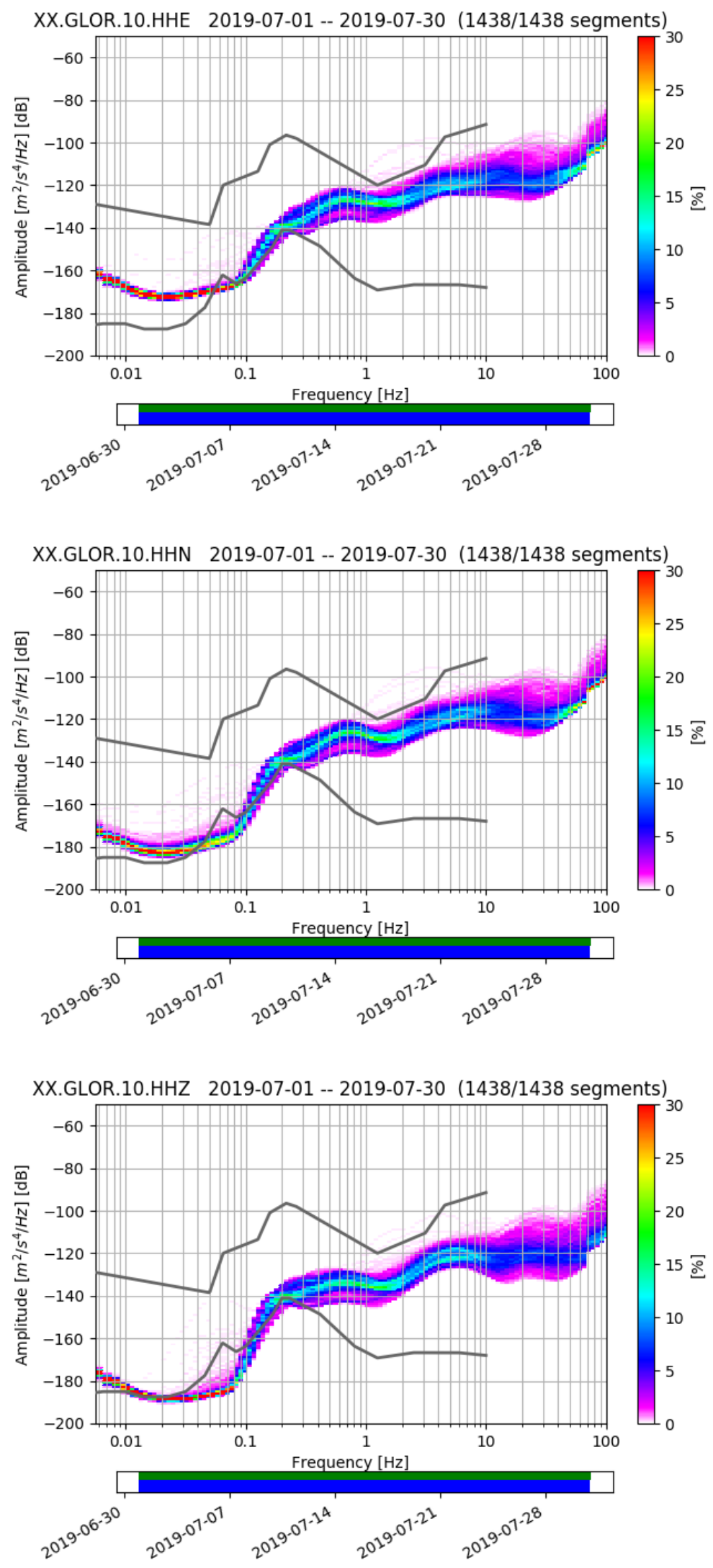

Figure B.12: Spectral energy plots for vertical (HHZ) and horizontal (HHE, HHN) channels for Northern DWARFS station GLOR. 

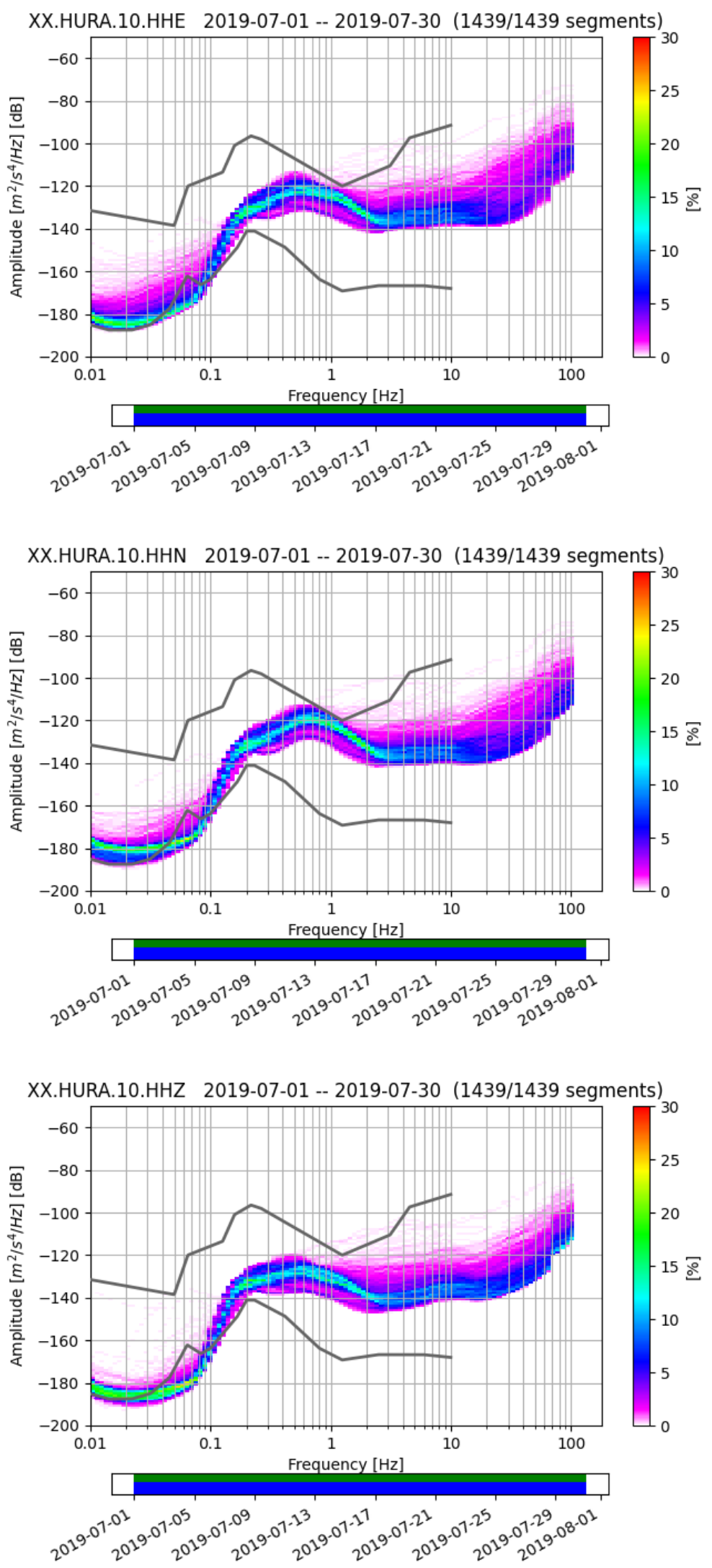

Figure B.13: Spectral energy plots for vertical (HHZ) and horizontal (HHE, HHN) channels for Northern DWARFS station HURA. 

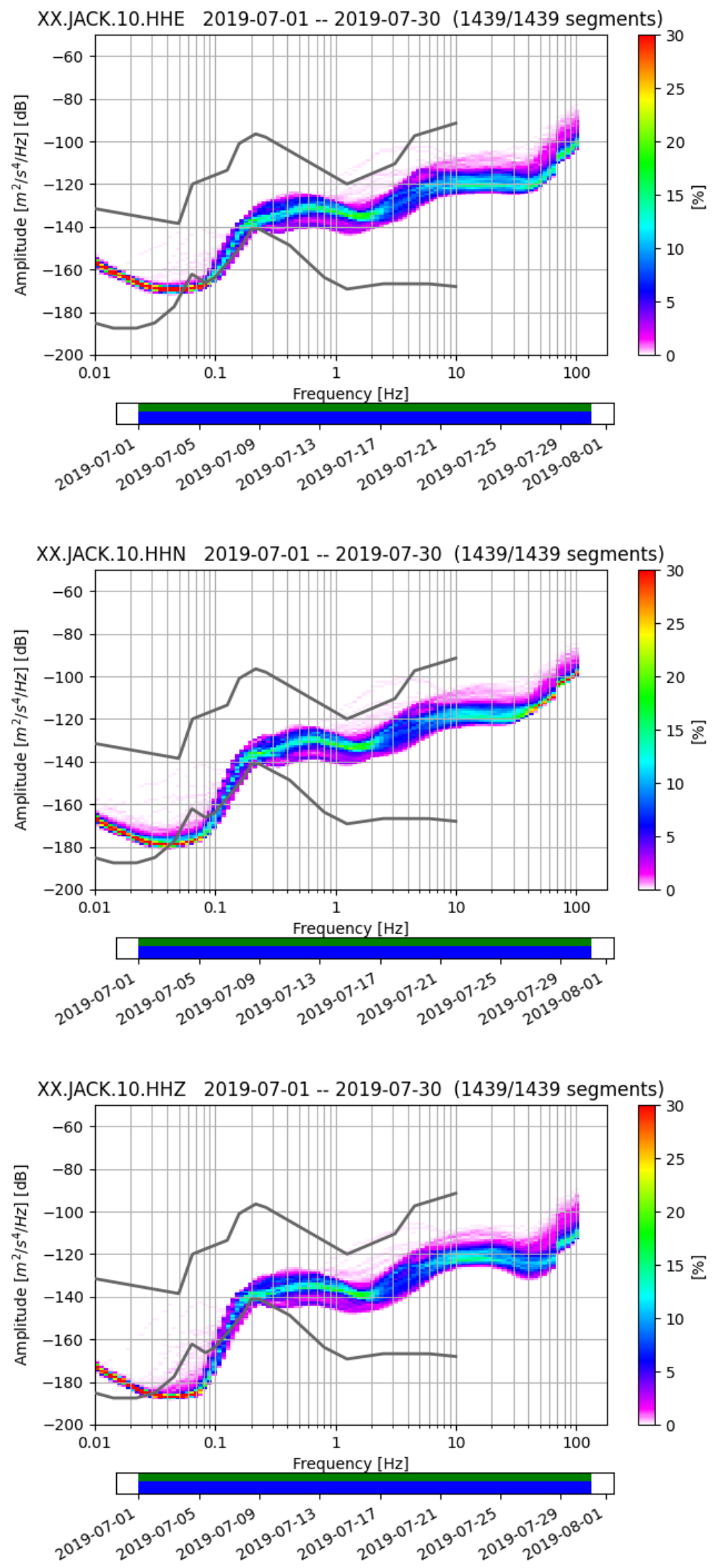

Figure B.14: Spectral energy plots for vertical (HHZ) and horizontal (HHE, HHN) channels for Northern DWARFS station JACK. 

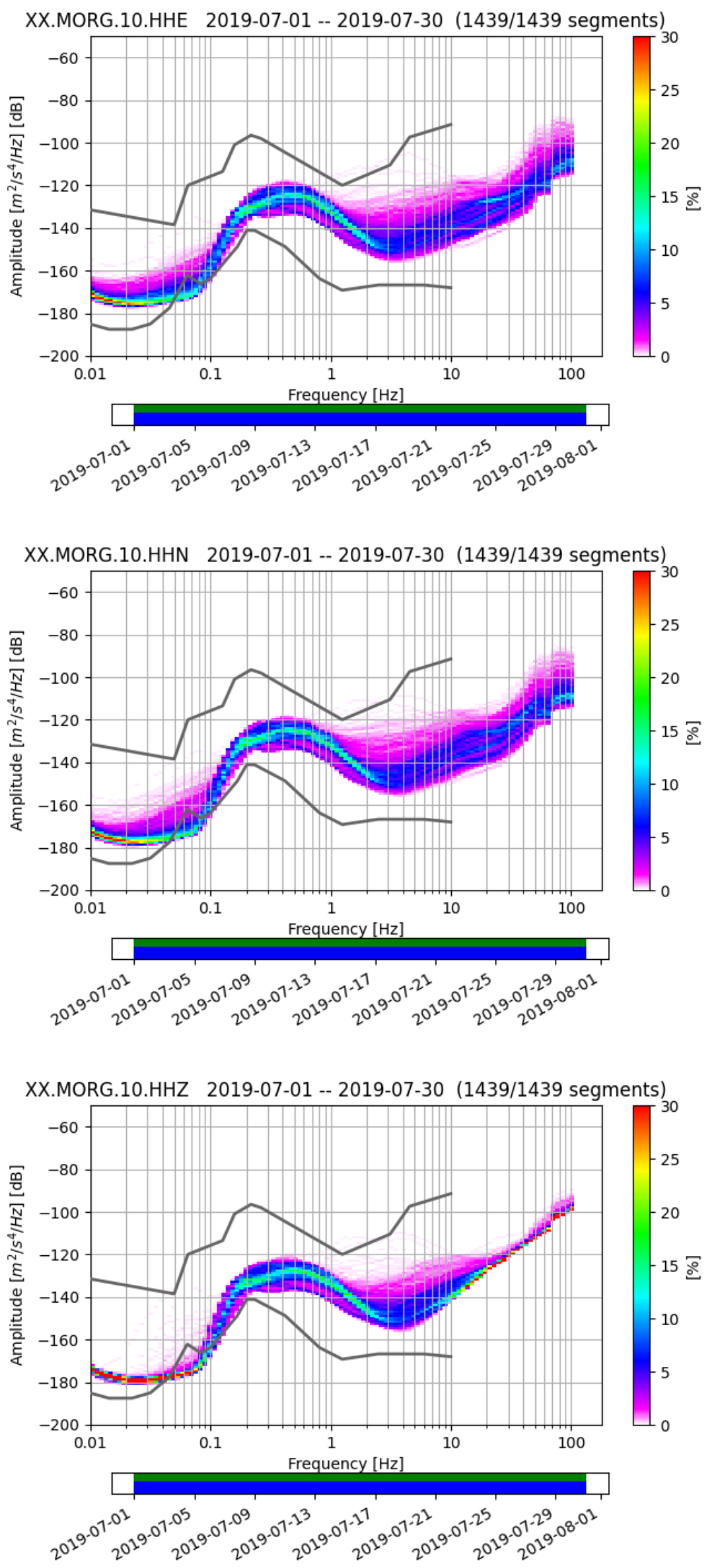

Figure B.15: Spectral energy plots for vertical (HHZ) and horizontal (HHE, HHN) channels for Northern DWARFS station MORG. 

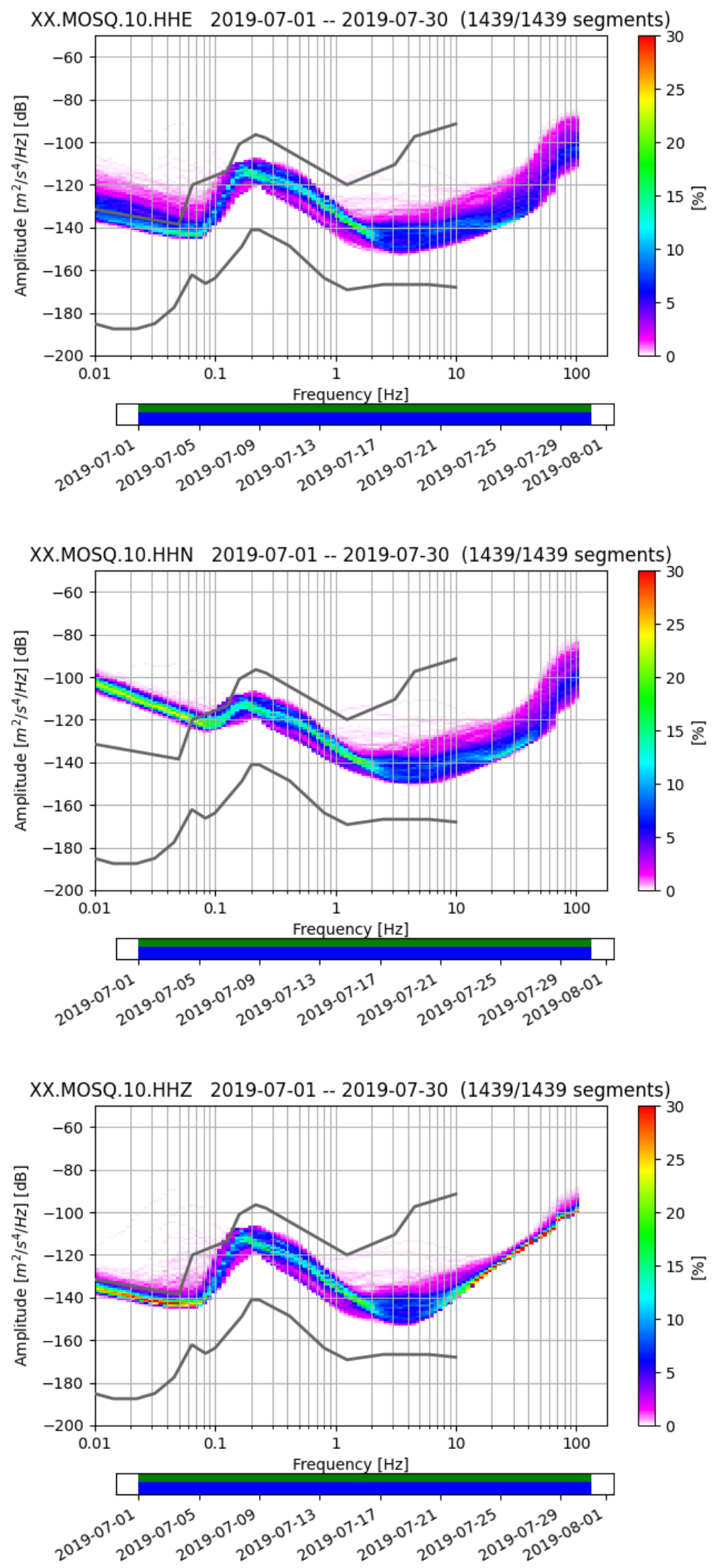

Figure B.16: Spectral energy plots for vertical (HHZ) and horizontal (HHE, HHN) channels for Northern DWARFS station MOSQ. 

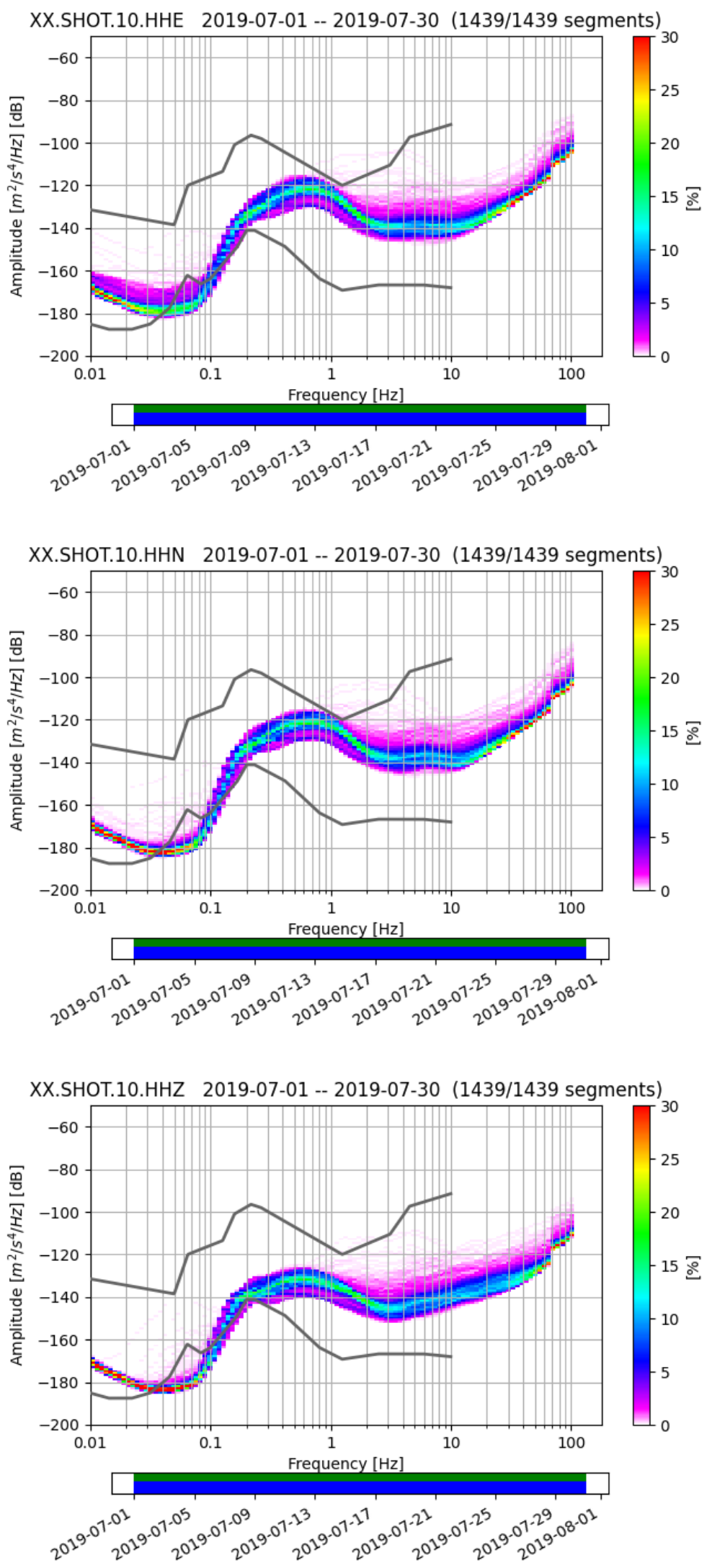

Figure B.17: Spectral energy plots for vertical (HHZ) and horizontal (HHE, HHN) channels for Northern DWARFS station SHOT. 

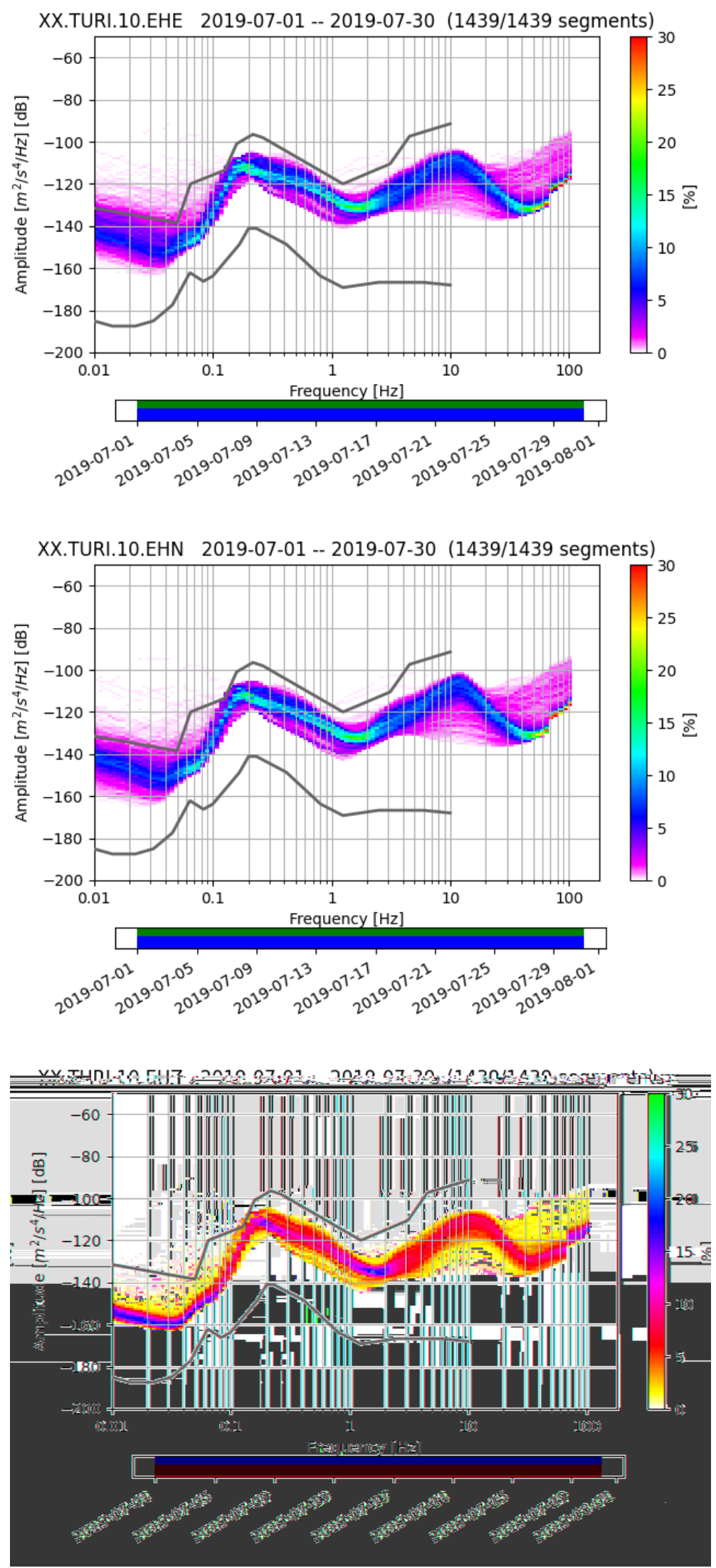

Figure B.18: Spectral energy plots for vertical (HHZ) and horizontal (HHE, HHN) channels for Northern DWARFS station TURI. 


\section{Appendix C}

\section{MATLAB Scripts Workflow}

This appendix includes a detailed description of the scripts used to estimate corner frequency and stress drop. All scripts of the EGF methodology are run using MATLAB (2019).

The first MATLAB script (make_egf_clusters.m) reads the information of earthquakes from a file called eqinfo.mat. This file includes location, time, depth and magnitude of the earthquakes from the Target events catalogue (see Chapter 2).

To select potential EGF events (step 1 in Figure C.1, we used a script called make_egf_ clusters.m. This script reads in a summary file (eqinfo.mat) containing event origin information and groups all the events together based on location, timing and magnitude, and then calculates which ones are potential EGFs for the Target events. Once the EGF events are identified, it is time to calculate the time window for each Target event, perform the cross-correlation and then the deconvolution (steps 2-4 in Figure C.1) of each Target-EGF waveform. This is done by the script named EGF_decon.m.

Steps 5 and 6 of the methodology (see Figure C.1) are performed using three scripts: (1) get_spec4stack.m calculates the signal and noise spectra of each Target-EGF waveform pair. (2) stack_spec1.m calculates the spectral ratios and (3) stack_spec2.m performs the fit of the individual and stacked spectral ratios and calculate the corner frequency.

The final script named get_stress_drop.m estimates the stress drop of each Target event.

All codes can be found at Geogarfias-GitHub 


\section{Empirical Green's Function Methodology}

\section{STEPS}

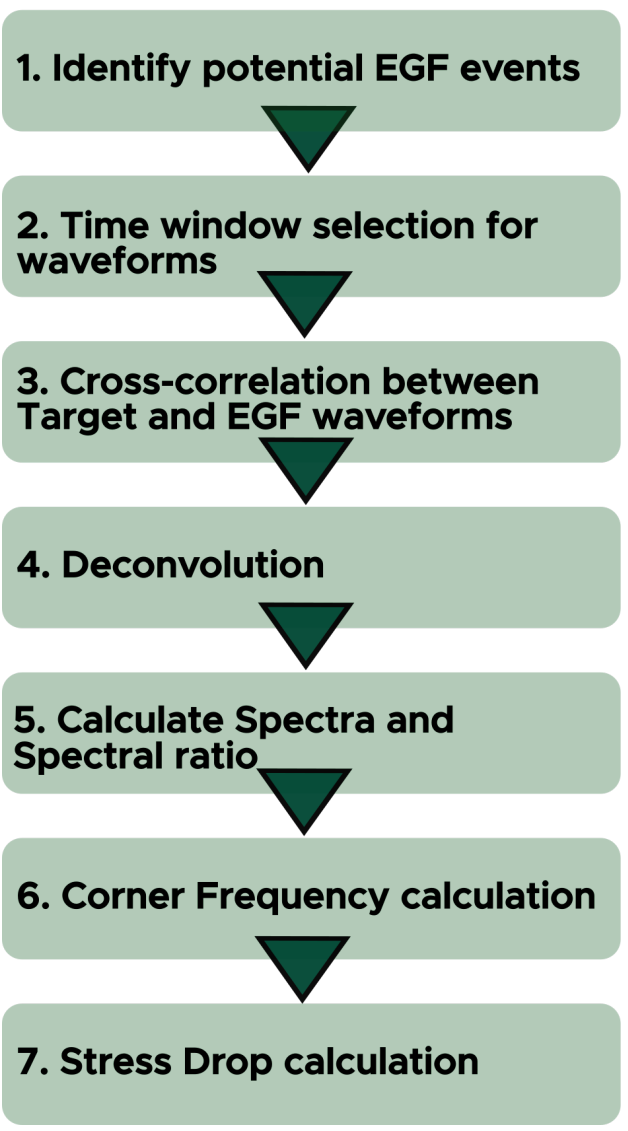

\section{CHAPTER 3 SECTIONS}

Section 3.2

Section 3.3

Section 3.4

Section 3.5

Section 3.6

\section{SCRIPT NAMES}

Script: make_egf_cluster.m

Script: egf_decon.m

Script: get_spec4stack.m

Calculate the signal and noise spectra

Script: stack_spec1_.m

Calculate the spectral ratios

Script: stack_spec2_m

Fits the individual and stacked spectral ratios and calculate corner frequency

Script: get_stress_drop.m

Figure C.1: Extended workflow of the EGF methodology. Includes the script names used at each step of the methodology. 


\section{Appendix D}

\section{Target Events Catalogue}

This appendix includes hypocentral and source properties information for the Target events used in this thesis. Events are divided by Alpine Fault segment. 
Table D.1: Table of Target events

\begin{tabular}{|c|c|c|c|c|c|c|c|c|c|c|c|c|}
\hline Event name & $\begin{array}{c}\text { Latitude } \\
\left({ }^{\circ}\right)\end{array}$ & $\begin{array}{c}\text { Longitude } \\
\left({ }^{\circ}\right) \\
\end{array}$ & $\begin{array}{c}\text { Depth } \\
(\mathrm{km})\end{array}$ & $\begin{array}{c}\text { Local } \\
\text { Magnitude }\end{array}$ & $\begin{array}{c}\text { Seismic } \\
\text { moment }(\mathrm{Nm})\end{array}$ & $\begin{array}{l}\text { No. } \\
\text { EGF }\end{array}$ & $\begin{array}{l}\text { No. } \mathrm{P} \\
\text { ratios }\end{array}$ & $\begin{array}{l}\text { No. S } \\
\text { ratios }\end{array}$ & $\begin{array}{c}\text { P Corner } \\
\text { frequency }(\mathrm{Hz})\end{array}$ & $\begin{array}{c}\text { S Corner } \\
\text { frequency }(\mathrm{Hz})\end{array}$ & $\begin{array}{c}\text { P stress } \\
\text { drop (Mpa) }\end{array}$ & $\begin{array}{c}\text { S stress } \\
\text { drop (Mpa) }\end{array}$ \\
\hline \multicolumn{13}{|c|}{ North Westland segment events } \\
\hline 20190514185637 & -42.838 & 171.809 & 10.6 & 2.3 & & 10 & 7 & 4 & & & & \\
\hline 20190520071324 & -42.913 & 171.832 & 14.3 & 2.3 & $2.24 \mathrm{E}+12$ & 15 & 13 & 25 & & 9.5 & & 1.0 \\
\hline 20190525212841 & -42.884 & 171.796 & 12.4 & 2.3 & & 10 & 8 & 5 & & & & \\
\hline 20190603234707 & -42.962 & 171.434 & 9.3 & 2.3 & & 7 & & 2 & & & & \\
\hline 20190731152024 & -42.864 & 171.614 & 10.0 & 4.0 & $5.84 \mathrm{E}+14$ & 14 & 20 & 43 & 4.7 & 4.8 & 18.0 & 34.7 \\
\hline 20190805213540 & -42.805 & 171.654 & 7.8 & 2.3 & $2.39 \mathrm{E}+12$ & 45 & 16 & 41 & 17.2 & 17.2 & 3.5 & 6.6 \\
\hline 20190813121129 & -42.865 & 171.621 & 6.5 & 2.6 & $8.86 \mathrm{E}+12$ & 77 & 40 & 163 & 11.3 & 11.9 & 3.7 & 8.1 \\
\hline 20190814053750 & -42.863 & 171.626 & 4.7 & 2.6 & $7.08 \mathrm{E}+12$ & 59 & 34 & 113 & 18.6 & 17.9 & 13.2 & 22.0 \\
\hline 20190916095727 & -42.943 & 171.571 & 8.9 & 2.3 & & 9 & & 8 & & & & \\
\hline 20190921183142 & -42.950 & 171.894 & 13.2 & 2.0 & & 2 & 1 & & & & & \\
\hline 20190923014313 & $\begin{array}{l}-42.703 \\
\end{array}$ & 171.377 & 15.5 & 3.7 & $2.46 \mathrm{E}+14$ & 35 & 119 & 311 & 6.4 & 11.5 & 19.2 & 204.2 \\
\hline 20190923024033 & -42.688 & 171.373 & 15.5 & 2.2 & $1.73 \mathrm{E}+12$ & 23 & & 62 & & 10.2 & & 1.0 \\
\hline 20190924091844 & -42.706 & 171.374 & 15.7 & 4.2 & $1.04 \mathrm{E}+15$ & 20 & 111 & 214 & 4.1 & 4.2 & 20.2 & 40.7 \\
\hline 20190924092315 & -42.706 & 171.376 & 16.3 & 2.5 & $4.52 \mathrm{E}+12$ & 29 & 37 & 167 & 22.3 & 11.6 & 14.7 & 3.9 \\
\hline 20190924154235 & -42.703 & 171.381 & 15.5 & 2.4 & $3.50 \mathrm{E}+12$ & 26 & 35 & 131 & 20.1 & 29.4 & 8.2 & 47.9 \\
\hline 20190924161012 & -42.704 & 171.373 & 16.2 & 3.0 & $2.31 \mathrm{E}+13$ & 35 & 74 & 194 & 10.1 & 10.6 & 6.8 & 14.8 \\
\hline 20190924203940 & -42.703 & 171.374 & 16.3 & 2.2 & $1.91 \mathrm{E}+12$ & 23 & 19 & 123 & 27.8 & 20.8 & 11.9 & 10.0 \\
\hline 20190924204345 & -42.703 & 171.373 & 16.0 & 2.5 & $5.31 \mathrm{E}+12$ & 30 & 25 & 184 & 0.0 & 18.9 & & 19.5 \\
\hline 20190925112909 & -42.707 & 171.373 & 16.2 & 3.5 & $9.75 \mathrm{E}+13$ & 34 & 134 & 207 & 19.5 & 8.8 & 211.6 & 36.3 \\
\hline 20190927121717 & -42.705 & 171.374 & 15.2 & 4.1 & $8.31 \mathrm{E}+14$ & 23 & 54 & 150 & 3.4 & 3.2 & 9.4 & 14.8 \\
\hline 20190927163023 & -42.701 & 171.372 & 16.1 & 2.9 & $1.91 \mathrm{E}+13$ & 34 & 40 & 178 & 27.0 & 30.8 & 109.9 & 302.0 \\
\hline 20190928230745 & -42.701 & 171.372 & 15.4 & 3.3 & $7.08 \mathrm{E}+13$ & 35 & 119 & 234 & 25.8 & 16.9 & 352.6 & 186.2 \\
\hline 20190929140740 & -42.701 & 171.374 & 15.9 & 2.6 & $6.43 \mathrm{E}+12$ & 31 & 33 & 152 & 12.5 & 12.8 & 3.7 & 7.4 \\
\hline 20191005053418 & -42.710 & 171.380 & 15.7 & 2.6 & $7.31 \mathrm{E}+12$ & 30 & 30 & 86 & 19.5 & 23.8 & 15.7 & 53.7 \\
\hline 20191017104924 & -42.703 & 171.373 & 15.0 & 3.8 & $2.99 \mathrm{E}+14$ & 36 & 129 & 184 & 8.9 & 7.9 & 60.6 & 79.4 \\
\hline 20191020005117 & -42.938 & 171.960 & 14.5 & 2.2 & & 1 & & & & & & \\
\hline 20191104071030 & -42.716 & 171.380 & 16.4 & 2.6 & $7.79 \mathrm{E}+12$ & 26 & 47 & 122 & 24.4 & 16.7 & 32.9 & 19.5 \\
\hline 20191123001556 & -42.631 & 171.944 & 14.6 & 2.7 & $9.75 \mathrm{E}+12$ & 17 & 10 & 17 & 20.3 & & 23.6 & \\
\hline 20191127032748 & -42.645 & 171.960 & 12.3 & 2.3 & $2.39 \mathrm{E}+12$ & 18 & 7 & 18 & 32.4 & & 23.7 & \\
\hline
\end{tabular}


Table D.1 continued from previous page

\begin{tabular}{|c|c|c|c|c|c|c|c|c|c|c|c|c|}
\hline 20191129040810 & -42.689 & 171.881 & 10.7 & 2.9 & $1.68 \mathrm{E}+13$ & 58 & 11 & 16 & 13.6 & 9.9 & 12.2 & 8.9 \\
\hline 20191205210122 & -42.754 & 171.736 & 9.2 & 2.1 & & 62 & 3 & 10 & & & & \\
\hline 20191207133544 & -42.946 & 171.414 & 6.0 & 2.5 & & 8 & & & & & & \\
\hline 20191208134937 & -42.765 & 171.753 & 7.2 & 2.3 & & 54 & 4 & 17 & & & & \\
\hline 20191212223555 & -42.506 & 171.600 & 15.3 & 2.1 & & 1 & & & & & & \\
\hline 20191215121458 & -42.508 & 171.601 & 15.8 & 2.4 & & 1 & & & & & & \\
\hline 20191224142518 & -42.987 & 171.757 & 9.0 & 2.1 & & 3 & 1 & 2 & & & & \\
\hline 20191226191316 & -42.517 & 171.995 & 0.0 & 2.1 & & 2 & & & & & & \\
\hline 20200111135645 & -42.936 & 171.932 & 13.9 & 3.2 & $4.38 \mathrm{E}+13$ & 9 & 54 & & 15.5 & 15.5 & 47.3 & 85.4 \\
\hline 20200126070145 & -42.989 & 171.864 & 10.1 & 2.3 & & 2 & & & & & & \\
\hline 20200209021806 & -42.768 & 171.665 & 7.8 & 2.8 & $1.14 \mathrm{E}+13$ & 76 & 40 & 53 & 15.5 & 13.4 & 12.3 & 14.9 \\
\hline 20200216233719 & -42.903 & 171.602 & 8.8 & 2.1 & & 13 & 5 & 20 & & & & \\
\hline 20200302064402 & -42.872 & 171.620 & 7.6 & 2.7 & $1.14 \mathrm{E}+13$ & 83 & 45 & 163 & 17.2 & 18.9 & 16.8 & 41.6 \\
\hline 20200305162006 & -42.807 & 171.659 & 7.3 & 2.6 & $6.64 \mathrm{E}+12$ & 45 & 27 & 34 & 12.2 & & 3.5 & \\
\hline \multicolumn{13}{|c|}{ Central segment events } \\
\hline 20081202164901 & -43.100 & 171.067 & 9.5 & 3.1 & & 16 & 7 & 6 & & & & \\
\hline 20081208173421 & -43.447 & 170.374 & 10.6 & 2.7 & $1.41 \mathrm{E}+13$ & 73 & 54 & 64 & 12.7 & 11.4 & 9.1 & 12.6 \\
\hline 20090114164326 & -43.149 & 171.091 & 15.2 & 2.7 & & 16 & 8 & 9 & & & & \\
\hline 20090208060744 & -43.172 & 170.852 & 8.4 & 2.6 & $1.00 \mathrm{E}+13$ & 62 & 43 & 42 & 18.6 & 14.9 & 20.6 & 20.0 \\
\hline 20090225214217 & -43.471 & 170.324 & 7.8 & 2.6 & & 233 & 5 & 5 & & & & \\
\hline 20090324135649 & -43.182 & 170.825 & 12.4 & 2.8 & $2.00 \mathrm{E}+13$ & 30 & 26 & 29 & 26.8 & 26.7 & 121.8 & 223.9 \\
\hline 20090403123714 & -43.145 & 170.747 & 11.2 & 2.9 & & 16 & 6 & 5 & & & & \\
\hline 20090417085600 & -43.689 & 169.655 & 12.5 & 2.8 & & 23 & 12 & 8 & & & & \\
\hline 20090422101936 & -43.126 & 170.955 & 13.5 & 2.9 & $2.82 \mathrm{E}+13$ & 34 & 31 & 30 & 14.4 & 11.9 & 26.7 & 28.2 \\
\hline 20090427184333 & -43.205 & 170.897 & 16.2 & 3.1 & $5.62 \mathrm{E}+13$ & 21 & 18 & 19 & 9.1 & 11.5 & 13.4 & 50.1 \\
\hline 20090503052658 & -43.123 & 170.976 & 16.5 & 2.6 & $1.00 \mathrm{E}+13$ & 29 & 27 & 26 & 27.5 & 30.2 & 66.2 & 162.2 \\
\hline 20090507172004 & -43.248 & 170.817 & 16.3 & 3.1 & $5.62 \mathrm{E}+13$ & 25 & 19 & 18 & 12.0 & 12.3 & 30.8 & 63.1 \\
\hline 20090508003438 & -43.128 & 170.949 & 13.3 & 3.9 & $8.91 \mathrm{E}+14$ & 16 & 12 & 13 & 4.2 & 3.8 & 20.8 & 28.8 \\
\hline 20090525014213 & -42.948 & 171.386 & 16.8 & 2.6 & & 16 & 1 & 1 & & & & \\
\hline 20090526192530 & -43.224 & 170.853 & 13.7 & 2.7 & & 17 & 14 & 15 & & & & \\
\hline 20090530155821 & -43.443 & 170.305 & 10.0 & 2.8 & & 39 & 5 & 6 & & & & \\
\hline 20090708072513 & -43.153 & 170.938 & 12.0 & 2.9 & $2.82 \mathrm{E}+13$ & 41 & 35 & 36 & 9.3 & 8.0 & 7.2 & 8.5 \\
\hline 20090710103032 & -43.236 & 170.912 & 12.4 & 3.0 & & 49 & 32 & 39 & & & & \\
\hline
\end{tabular}


Table D.1 continued from previous page

\begin{tabular}{|c|c|c|c|c|c|c|c|c|c|c|c|c|}
\hline 20090818103443 & & & & & & & & & & & & \\
\hline & 40.220 & 110.010 & 10.0 & & & 29 & $2 \pm$ & 21 & 20.0 & 17.1 & 10.0 & 00.4 \\
\hline 20090907223334 & -43.246 & 170.899 & 13.2 & 2.5 & $7.08 \mathrm{E}+12$ & 42 & 39 & 40 & 9.8 & & 2.1 & \\
\hline 20090908192047 & -43.248 & 170.902 & 13.0 & 2.6 & $1.00 \mathrm{E}+13$ & 48 & 47 & 47 & 17.1 & & 16.0 & \\
\hline 20090925201228 & -43.25 & 170.898 & 13.1 & 2.8 & $2.00 \mathrm{E}+13$ & 49 & 47 & 48 & 13.6 & 16.1 & 16.0 & 49.0 \\
\hline 20091002025242 & -43.248 & 170.902 & 12.9 & 3.3 & $1.12 \mathrm{E}+14$ & 48 & 45 & 45 & 10.2 & 9.1 & 37.3 & 50.1 \\
\hline 20091010180638 & -43.189 & 170.82 & 12.2 & 2.6 & & 27 & 21 & 24 & & & & \\
\hline 20091112011703 & -43.252 & 170.845 & 10.3 & 2.6 & & 27 & 20 & 20 & & & & \\
\hline 20091214160525 & -43.245 & 170.985 & 16.2 & 2.6 & & 16 & 5 & 4 & & & & \\
\hline 20091229063342 & -43.157 & 170.95 & 12.3 & 2.9 & $2.82 \mathrm{E}+13$ & 34 & 28 & 25 & 9.5 & 8.3 & 7.8 & 9.5 \\
\hline 20100217072856 & -43.155 & 171.005 & 9.0 & 2.8 & & 16 & 10 & 8 & & & & \\
\hline 20100618051308 & -43.151 & 171.018 & 17.8 & 2.9 & & 16 & 8 & 8 & & & & \\
\hline 20100625191016 & -43.706 & 169.629 & 13.8 & 2.9 & & 23 & 17 & 17 & & & & \\
\hline 20100625194408 & -43.713 & 169.618 & 8.3 & 3.0 & & 20 & 12 & 14 & & & & \\
\hline 20100703112927 & -43.473 & 170.121 & 11.5 & 2.8 & & 49 & 45 & 47 & & & & \\
\hline 20100706192456 & -43.157 & 170.663 & 9.9 & 2.7 & & 16 & 3 & 3 & & & & \\
\hline 20100713163904 & -43.231 & 170.868 & 12.9 & 2.9 & & 46 & 36 & 36 & & & & \\
\hline 20100819204309 & -43.701 & 169.588 & 17.0 & 2.5 & & 16 & 2 & 2 & & & & \\
\hline 20100904141748 & -43.673 & 169.713 & 13.3 & 2.8 & & 16 & 2 & 4 & & & & \\
\hline 20110211120039 & -43.293 & 170.808 & 13.9 & 3.8 & $6.31 \mathrm{E}+14$ & 61 & 60 & 60 & 5.6 & 5.0 & 34.4 & 46.8 \\
\hline 20110211230723 & -43.288 & 170.821 & 15.7 & 2.7 & & 37 & 32 & 36 & & & & \\
\hline 20110226173347 & -43.418 & 170.303 & 5.2 & 2.5 & & 16 & 1 & 1 & & & & \\
\hline 20110322011549 & -43.505 & 169.962 & 9.7 & 2.7 & $1.41 \mathrm{E}+13$ & 19 & 13 & 18 & 14.8 & 12.1 & 14.6 & 14.8 \\
\hline 20110525144351 & -43.316 & 170.801 & 15.7 & 3.2 & $7.94 \mathrm{E}+13$ & 55 & 20 & 20 & 8.8 & 9.0 & 17.1 & 33.9 \\
\hline 20110525150212 & -43.318 & 170.798 & 15.5 & 2.6 & $1.00 \mathrm{E}+13$ & 32 & 7 & 7 & 10.3 & 9.6 & 3.5 & 5.3 \\
\hline 20110526045423 & -43.317 & 170.807 & 15.2 & 2.5 & & 34 & 3 & 3 & & & & \\
\hline 20110526045558 & -43.315 & 170.803 & 15.6 & 4.0 & $1.26 \mathrm{E}+15$ & 43 & 39 & 40 & 6.3 & 6.2 & 98.8 & 173.8 \\
\hline 20110629074345 & -43.493 & 170.269 & 10.1 & 4.2 & $2.51 \mathrm{E}+15$ & 29 & 24 & 27 & 5.9 & 5.7 & 165.1 & 275.4 \\
\hline 20110805165515 & -43.344 & 170.646 & 14.3 & 2.8 & & 16 & 3 & 3 & & & & \\
\hline 20110808083302 & -43.73 & 169.649 & 14.0 & 2.7 & & 16 & 2 & 3 & & & & \\
\hline 20110809050531 & -43.41 & 170.486 & 11.1 & 2.5 & $7.08 \mathrm{E}+12$ & 33 & 31 & 32 & 14.5 & 12.0 & 6.8 & 7.2 \\
\hline 20110925101658 & -43.485 & 170.283 & 7.7 & 2.9 & $2.82 \mathrm{E}+13$ & 320 & 36 & 37 & 17.8 & 17.7 & 50.8 & 91.2 \\
\hline 20111002130810 & -43.154 & 170.895 & 12.5 & 2.5 & & 29 & 22 & 23 & & & & \\
\hline 20111212010058 & -43.319 & 170.81 & 15.9 & 2.5 & & 30 & 3 & 3 & & & & \\
\hline
\end{tabular}


Table D.1 continued from previous page

\begin{tabular}{|c|c|c|c|c|c|c|c|c|c|c|c|c|}
\hline 20111228164124 & -43.169 & 170.839 & 14.8 & 3.4 & & 19 & 15 & 14 & & & & \\
\hline 20120114045420 & -43.218 & 170.87 & 10.8 & 3.0 & $3.98 \mathrm{E}+13$ & 41 & 33 & 36 & 29.1 & & 309.8 & \\
\hline 20120227015352 & -43.085 & 171.127 & 10.0 & 3.3 & & 16 & 3 & 3 & & & & \\
\hline 20120406111701 & -43.578 & 169.935 & 9.5 & 3.4 & & 22 & 15 & 20 & & & & \\
\hline 20120427005807 & -43.125 & 170.886 & 10.1 & 4.0 & & 16 & 8 & 9 & & & & \\
\hline 20120427131020 & -43.134 & 170.862 & 10.1 & 2.8 & $3.98 \mathrm{E}+13$ & 20 & 15 & 16 & 10.3 & 9.0 & 13.7 & 17.0 \\
\hline 20120510162115 & -43.47 & 170.088 & 7.2 & 2.5 & $7.08 \mathrm{E}+12$ & 102 & 60 & 97 & 39.0 & 34.5 & 133.0 & 173.8 \\
\hline 20120516070424 & -43.476 & 170.079 & 8.5 & 2.6 & $1.00 \mathrm{E}+13$ & 116 & 90 & 112 & 20.2 & & 25.9 & \\
\hline 20120525175630 & -43.17 & 170.972 & 9.1 & 2.8 & $2.00 \mathrm{E}+13$ & 22 & 21 & 20 & 9.8 & 10.9 & 6.0 & 15.5 \\
\hline 20120612215855 & -43.113 & 170.844 & 11.4 & 3.2 & $7.94 \mathrm{E}+13$ & 16 & 12 & 14 & 16.6 & 15.9 & 114.7 & 190.5 \\
\hline 20120919111159 & -43.199 & 170.861 & 5.8 & 2.6 & $1.00 \mathrm{E}+13$ & 36 & 35 & 34 & 19.3 & 19.6 & 23.0 & 44.7 \\
\hline 20121019184839 & -43.118 & 171.111 & 15.0 & 2.8 & & 16 & 2 & 3 & & & & \\
\hline 20121022051701 & -43.147 & 170.966 & 7.3 & 2.5 & $7.08 \mathrm{E}+12$ & 28 & 22 & 23 & 17.0 & 14.8 & 11.0 & 13.8 \\
\hline 20130319133743 & -43.149 & 170.975 & 10.2 & 4.1 & $1.78 \mathrm{E}+15$ & 16 & 11 & 10 & & 6.5 & & 281.8 \\
\hline 20130730211311 & -43.582 & 169.927 & 5.9 & 2.5 & $7.08 \mathrm{E}+12$ & 31 & 13 & 24 & & 14.9 & & 13.8 \\
\hline 20130731072151 & -43.578 & 169.933 & 7.3 & 3.0 & & 36 & 23 & 30 & & & & \\
\hline 20130815205218 & -43.592 & 169.824 & 7.2 & 2.6 & & 53 & 41 & 41 & & & & \\
\hline 20130827061505 & -43.435 & 170.168 & 5.7 & 2.7 & & 33 & 17 & 28 & & & & \\
\hline 20140405154912 & -43.155 & 170.814 & 15.8 & 2.8 & & 16 & 5 & 5 & & & & \\
\hline 20140413215745 & -43.122 & 170.77 & 8.8 & 2.5 & & 27 & 15 & 19 & & & & \\
\hline 20140512094501 & -43.572 & 169.932 & 8.2 & 2.6 & & 45 & 35 & 38 & & & & \\
\hline 20140519085921 & -43.202 & 170.906 & 14.0 & 2.6 & & 28 & 14 & 8 & & & & \\
\hline 20140522182538 & -43.456 & 170.319 & 6.8 & 2.5 & & 131 & 2 & 2 & & & & \\
\hline 20140818155530 & -43.185 & 170.897 & 14.4 & 2.5 & $7.08 \mathrm{E}+12$ & 33 & 24 & 24 & & 18.8 & & 27.6 \\
\hline 20140908021454 & -43.165 & 170.821 & 3.0 & 3.0 & & 16 & 13 & 12 & & & & \\
\hline 20140908122828 & -43.109 & 170.927 & 16.8 & 4.4 & & 16 & 5 & 5 & & & & \\
\hline 20140908123113 & -43.145 & 170.909 & 14.7 & 2.8 & $2.00 \mathrm{E}+13$ & 34 & 23 & 15 & 14.0 & 14.2 & 17.3 & 33.1 \\
\hline 20141018170328 & -43.114 & 170.91 & 17.9 & 2.7 & & 16 & 5 & 1 & & & & \\
\hline 20141231010938 & -43.67 & 169.708 & 14.0 & 2.5 & & 16 & 4 & 4 & & & & \\
\hline 20150105180759 & -43.14 & 171.234 & 17.0 & 3.5 & & 16 & 2 & 3 & & & & \\
\hline 20150105221324 & -43.113 & 171.251 & 16.4 & 3.6 & & 16 & 2 & 2 & & & & \\
\hline 20150106230001 & -43.094 & 171.225 & 16.7 & 2.5 & & 16 & 1 & 1 & & & & \\
\hline 20150107151353 & -43.159 & 170.977 & 9.9 & 2.7 & & 17 & 11 & 6 & & & & \\
\hline
\end{tabular}


Table D.1 continued from previous page

\begin{tabular}{|c|c|c|c|c|c|c|c|c|c|c|c|c|}
\hline 20150108122542 & -43.133 & 171.173 & 19.2 & 2.7 & & 16 & 1 & 1 & & & & \\
\hline 20150127202232 & -43.094 & 171.238 & 16.5 & 3.3 & & 16 & 1 & 1 & & & & \\
\hline 20150130014738 & -43.116 & 171.234 & 18.6 & 2.7 & & 16 & 1 & 1 & & & & \\
\hline 20150203145813 & -43.1 & 171.204 & 19.7 & 3.4 & & 16 & 6 & 6 & & & & \\
\hline 20150216203848 & -43.525 & 170.138 & 8.2 & 2.7 & $1.41 \mathrm{E}+13$ & 96 & 94 & 93 & 14.4 & 18.9 & 13.4 & 56.2 \\
\hline 20150310211225 & -43.86 & 169.384 & 10.1 & 3.8 & & 16 & 2 & 3 & & & & \\
\hline 20150315041508 & -43.096 & 171.227 & 16.2 & 2.8 & & 16 & 2 & 2 & & & & \\
\hline 20150517161908 & -43.48 & 170.077 & 6.9 & 2.7 & $1.41 \mathrm{E}+13$ & 119 & 86 & 114 & 13.3 & 13.7 & 10.5 & 21.4 \\
\hline 20150530185234 & -43.482 & 170.065 & 7.9 & 4.3 & $3.55 \mathrm{E}+15$ & 16 & 15 & 15 & 5.8 & 4.8 & 221.6 & 239.9 \\
\hline 20150530185611 & -43.482 & 170.068 & 7.8 & 3.5 & $2.24 \mathrm{E}+14$ & 55 & 18 & 54 & & 8.6 & & 85.1 \\
\hline 20150602085829 & -43.482 & 170.065 & 7.7 & 2.6 & $1.00 \mathrm{E}+13$ & 114 & 87 & 111 & 14.8 & 17.9 & 10.2 & 33.9 \\
\hline 20150602184317 & -43.487 & 170.061 & 7.3 & 2.6 & $1.00 \mathrm{E}+13$ & 115 & 83 & 112 & 16.1 & & 13.3 & \\
\hline 20150612023807 & -43.236 & 170.895 & 11.8 & 2.7 & $1.41 \mathrm{E}+13$ & 57 & 43 & 49 & 14.7 & 12.5 & 14.2 & 16.2 \\
\hline 20150612123501 & -43.481 & 170.056 & 8.2 & 3.0 & $3.98 \mathrm{E}+13$ & 100 & 85 & 87 & 15.3 & 10.0 & 45.4 & 23.4 \\
\hline 20150622080626 & -43.052 & 171.27 & 18.0 & 3.8 & & 16 & 1 & 1 & & & & \\
\hline 20150828050121 & -43.081 & 170.964 & 18.7 & 2.6 & & 16 & 2 & 2 & & & & \\
\hline 20151204210541 & -43.231 & 170.881 & 17.5 & 4.1 & & 17 & 16 & 16 & & & & \\
\hline 20160215135838 & -43.121 & 170.894 & 19.3 & 2.5 & & 16 & 1 & 3 & & & & \\
\hline 20160220213200 & -43.532 & 169.936 & 11.6 & 4.1 & & 16 & 1 & 1 & & & & \\
\hline 20160221084509 & -43.537 & 169.936 & 11.1 & 3.5 & & 17 & 5 & 15 & & & & \\
\hline 20160419014928 & -43.175 & 170.943 & 15.9 & 2.8 & & 16 & 10 & 10 & & & & \\
\hline 20160422232958 & -43.757 & 169.551 & 9.9 & 2.6 & & 16 & 6 & 7 & & & & \\
\hline 20160528230343 & -43.744 & 169.545 & 14.1 & 3.6 & $3.16 \mathrm{E}+14$ & 16 & 8 & 14 & & 9.4 & & 154.9 \\
\hline 20160606021359 & -43.498 & 170.281 & 11.6 & 2.5 & $7.08 \mathrm{E}+12$ & 80 & 75 & 70 & 18.1 & 13.9 & 13.4 & 11.2 \\
\hline 20160809222648 & -43.253 & 170.794 & 19.2 & 2.6 & & 16 & 4 & 4 & & & & \\
\hline 20160830010056 & -43.492 & 170.279 & 8.1 & 4.0 & $1.26 \mathrm{E}+15$ & 55 & 53 & 53 & 5.5 & 6.4 & 68.2 & 199.5 \\
\hline 20161005232050 & -43.393 & 170.474 & 7.8 & 3.4 & & 18 & 15 & 17 & & & & \\
\hline 20161007234558 & -43.076 & 170.849 & 10.0 & 3.4 & $1.58 \mathrm{E}+14$ & 23 & 14 & 16 & & 5.2 & & 13.2 \\
\hline 20161007234908 & -43.091 & 170.858 & 0.0 & 2.5 & & 16 & 7 & 8 & & & & \\
\hline 20161129031535 & -43.1 & 171.003 & 15.4 & 2.6 & & 16 & 6 & 3 & & & & \\
\hline 20161205173704 & -43.139 & 170.979 & 19.8 & 3.2 & & 16 & 4 & 3 & & & & \\
\hline 20161209200912 & -43.305 & 170.823 & 15.3 & 3.4 & $1.58 \mathrm{E}+14$ & 66 & 61 & 61 & 14.5 & 11.9 & 153.4 & 158.5 \\
\hline 20170111192850 & -43.496 & 170.271 & 8.1 & 2.5 & $7.08 \mathrm{E}+12$ & 316 & 298 & 299 & 14.7 & 12.8 & 7.1 & 8.9 \\
\hline
\end{tabular}


Table D.1 continued from previous page

\begin{tabular}{|c|c|c|c|c|c|c|c|c|c|c|c|c|}
\hline 20170114033216 & -43.437 & 170.339 & 8.6 & 3.3 & & 49 & 8 & 18 & & & & \\
\hline \multicolumn{13}{|c|}{ South Westland segment events } \\
\hline 20190422074509 & -44.207 & 168.447 & 7.2 & 3.5 & & 6 & 9 & 9 & & & & \\
\hline 20190423204701 & -44.210 & 168.425 & 6.2 & 2.0 & & 61 & & & & & & \\
\hline 20190424053250 & -44.090 & 168.856 & 5.4 & 2.2 & $1.79 \mathrm{E}+12$ & 14 & 20 & 6 & & 25.6 & & 8.2 \\
\hline 20190501033509 & -44.269 & 168.937 & 7.0 & 3.1 & & 1 & & & & & & \\
\hline 20190511061111 & -44.085 & 168.855 & 5.6 & 2.3 & & 14 & 15 & 18 & & & & \\
\hline 20190511083623 & -44.083 & 168.837 & 5.1 & 2.9 & $1.11 \mathrm{E}+13$ & 12 & 13 & 6 & 12.9 & 12.9 & 5.4 & 10.1 \\
\hline 20190517180151 & -44.051 & 168.854 & 4.4 & 2.9 & & 2 & & & & & & \\
\hline 20190523114632 & -44.148 & 168.520 & 5.7 & 2.3 & & 19 & & 4 & & & & \\
\hline 20190602184554 & -44.100 & 168.781 & 3.8 & 2.0 & $6.94 \mathrm{E}+11$ & 115 & 68 & 196 & 22.1 & 18.8 & 1.7 & 2.0 \\
\hline 20190613012055 & -44.065 & 168.725 & 6.6 & 2.7 & $6.35 \mathrm{E}+12$ & 169 & 726 & 362 & 21.1 & 16.8 & 13.6 & 13.1 \\
\hline 20190615033108 & -44.066 & 168.722 & 6.2 & 2.1 & $9.80 \mathrm{E}+11$ & 329 & 462 & 626 & 32.3 & 25.0 & 7.6 & 6.4 \\
\hline 20190623063412 & -44.242 & 168.683 & 5.9 & 2.8 & & 3 & 2 & 3 & & & & \\
\hline 20190623105709 & -44.067 & 168.721 & 6.2 & 2.0 & $6.25 \mathrm{E}+11$ & 338 & 323 & 687 & 40.0 & & 9.2 & \\
\hline 20190624061848 & -44.063 & 168.721 & 6.2 & 2.0 & $7.12 \mathrm{E}+11$ & 322 & 303 & 392 & 40.3 & & 10.6 & \\
\hline 20190626001117 & -44.103 & 168.780 & 4.0 & 3.1 & $2.25 \mathrm{E}+13$ & 24 & 139 & 158 & 19.3 & 16.8 & 37.2 & 45.9 \\
\hline 20190627160744 & -44.154 & 168.793 & 6.6 & 2.0 & & 22 & 11 & 13 & & & & \\
\hline 20190628141228 & -44.310 & 168.916 & 7.0 & 2.6 & $4.73 \mathrm{E}+12$ & 6 & 56 & 60 & 16.3 & 17.9 & 4.7 & 11.6 \\
\hline 20190629195520 & -43.741 & 168.375 & 25.2 & 2.5 & & 1 & & & & & & \\
\hline 20190701135743 & -44.068 & 168.720 & 6.3 & 2.3 & $1.91 \mathrm{E}+12$ & 302 & 365 & 442 & 31.8 & 14.8 & 14.1 & 2.7 \\
\hline 20190701184632 & -44.067 & 168.724 & 6.4 & 2.8 & $8.72 \mathrm{E}+12$ & 134 & 279 & 523 & 13.8 & 13.5 & 5.2 & 9.0 \\
\hline 20190702031545 & -44.063 & 168.722 & 6.0 & 2.1 & $7.47 \mathrm{E}+11$ & 331 & 254 & 288 & 39.6 & 41.7 & 10.6 & 23.0 \\
\hline 20190702213329 & -44.064 & 168.728 & 6.5 & 2.2 & $1.12 \mathrm{E}+12$ & 318 & 145 & 585 & 31.8 & 31.3 & 8.2 & 14.5 \\
\hline 20190704083147 & -44.064 & 168.723 & 6.7 & 4.4 & $1.34 \mathrm{E}+15$ & 6 & 37 & 92 & 7.1 & 6.3 & 111.0 & 143.2 \\
\hline 20190704162416 & -44.088 & 168.821 & 4.6 & 2.3 & $1.51 \mathrm{E}+12$ & 36 & 21 & 17 & 37.5 & 37.5 & 18.2 & 34.4 \\
\hline 20190705185504 & -44.142 & 168.442 & 4.6 & 2.5 & $3.12 \mathrm{E}+12$ & 31 & 9 & 75 & 14.5 & 11.8 & 2.2 & 2.2 \\
\hline 20190710082627 & -44.100 & 168.760 & 5.8 & 2.6 & $3.92 \mathrm{E}+12$ & 61 & 37 & 76 & 21.0 & 22.2 & 8.3 & 18.3 \\
\hline 20190711220419 & -44.063 & 168.730 & 6.5 & 2.3 & $1.62 \mathrm{E}+12$ & 312 & 367 & 439 & 28.1 & 21.9 & 8.2 & 7.4 \\
\hline 20190712042406 & -44.149 & 168.478 & 6.3 & 2.2 & & 58 & & 7 & & & & \\
\hline 20190717104304 & -43.993 & 168.901 & 5.5 & 2.4 & & 3 & 3 & 1 & & & & \\
\hline 20190719094538 & -44.062 & 168.735 & 6.4 & 2.2 & $1.27 \mathrm{E}+12$ & 312 & 141 & 450 & 30.9 & 23.1 & 8.6 & 6.6 \\
\hline 20190720043854 & -44.102 & 168.780 & 3.7 & 2.3 & $1.51 \mathrm{E}+12$ & 109 & 138 & 152 & 17.5 & 18.6 & 1.8 & 4.2 \\
\hline
\end{tabular}


Table D.1 continued from previous page

\begin{tabular}{|c|c|c|c|c|c|c|c|c|c|c|c|c|}
\hline 20190721070054 & -44.236 & 168.612 & 4.9 & 2.0 & & 19 & & 5 & & & & \\
\hline 20190722112829 & -44.237 & 168.516 & 7.3 & 3.3 & & 4 & & 5 & & & 11.3 & \\
\hline 20190723200202 & -44.064 & 168.716 & 6.2 & 2.2 & $1.03 \mathrm{E}+12$ & 327 & 134 & 504 & 36.4 & & & \\
\hline 20190725022031 & -44.024 & 169.033 & 7.0 & 2.1 & & 1 & & & & & & \\
\hline 20190727100233 & -44.306 & 168.397 & 7.0 & 2.2 & & 7 & & 2 & & & & \\
\hline 20190728134305 & -44.364 & 168.929 & 9.2 & 2.4 & & 1 & & & & & & \\
\hline 20190801233312 & -44.093 & 168.845 & 5.0 & 2.4 & & 19 & 22 & 27 & & & & \\
\hline 20190805091419 & -43.891 & 169.067 & 5.4 & 2.3 & & 1 & & & & & & \\
\hline 20190807084714 & -43.902 & 169.076 & 4.2 & 3.5 & $8.64 \mathrm{E}+13$ & 6 & 18 & 42 & 5.4 & 5.4 & 3.1 & 5.8 \\
\hline 20190811151647 & -43.908 & 169.072 & 3.9 & 2.3 & & 1 & & & & & & \\
\hline 20190824234411 & -43.898 & 169.074 & 5.3 & 2.2 & & 1 & & & & & & \\
\hline 20190825045650 & -44.201 & 168.673 & 5.4 & 2.3 & $2.24 \mathrm{E}+12$ & 124 & 6 & 50 & & 18.5 & & 3.9 \\
\hline 20190829121738 & -44.201 & 168.670 & 5.7 & 2.0 & & 134 & 9 & 25 & & & & \\
\hline 20190830022535 & -44.102 & 168.779 & 4.3 & 2.3 & $1.76 \mathrm{E}+12$ & 105 & 128 & 263 & 38.2 & 31.4 & 22.4 & 22.9 \\
\hline 20190901132954 & -44.163 & 168.664 & 7.1 & 2.3 & $2.63 \mathrm{E}+12$ & 65 & 4 & 20 & & 29.5 & & 18.5 \\
\hline 20190905185335 & -44.395 & 168.334 & 5.2 & 3.0 & & 7 & 3 & 10 & & & & \\
\hline 20190906110550 & -43.944 & 169.056 & 6.8 & 2.0 & & 1 & & & & & & \\
\hline 20190910044226 & -44.104 & 168.773 & 4.3 & 2.6 & $3.96 \mathrm{E}+12$ & 66 & 109 & 185 & 18.9 & 21.2 & 6.1 & 16.1 \\
\hline 20190914073102 & -44.389 & 168.365 & 5.9 & 2.1 & & 17 & & & & & & \\
\hline 20190915072620 & -43.894 & 169.067 & 6.8 & 2.2 & & 1 & & & & & & \\
\hline 20190926223153 & -44.382 & 168.359 & 3.9 & 3.2 & & 11 & & 2 & & & & \\
\hline 20190927041331 & -44.136 & 168.734 & 7.8 & 2.1 & $9.78 \mathrm{E}+11$ & 43 & 15 & 29 & 27.5 & 25.8 & 4.7 & 7.1 \\
\hline 20190929184504 & -44.384 & 168.359 & 4.3 & 2.3 & & 21 & & & & & & \\
\hline 20191004070443 & -44.084 & 168.834 & 5.5 & 2.2 & $1.25 \mathrm{E}+12$ & 22 & 12 & 1 & 20.4 & 20.4 & 2.4 & 4.6 \\
\hline 20191005182525 & -44.085 & 168.832 & 5.7 & 2.9 & $1.10 \mathrm{E}+13$ & 18 & 19 & 3 & 25.4 & 25.4 & 41.1 & 77.9 \\
\hline 20191007171900 & -44.139 & 168.699 & 3.6 & 2.5 & & 48 & 8 & 43 & & & & \\
\hline
\end{tabular}

